Florida International University

FIU Digital Commons

5-16-2019

\title{
Towards Trigonal Prismatic Hexanuclear Copper Complexes For Catalytic Water Oxidation
}

David I. Kreiger

Florida International University, dkrei003@fiu.edu

Follow this and additional works at: https://digitalcommons.fiu.edu/etd

Part of the Inorganic Chemistry Commons

\section{Recommended Citation}

Kreiger, David I., "Towards Trigonal Prismatic Hexanuclear Copper Complexes For Catalytic Water Oxidation" (2019). FIU Electronic Theses and Dissertations. 4206.

https://digitalcommons.fiu.edu/etd/4206

This work is brought to you for free and open access by the University Graduate School at FIU Digital Commons. It has been accepted for inclusion in FIU Electronic Theses and Dissertations by an authorized administrator of FIU Digital Commons. For more information, please contact dcc@fiu.edu. 


\section{FLORIDA INTERNATIONAL UNIVERSITY}

Miami, Florida

\section{TOWARDS TRIGONAL PRISMATIC HEXANUCLEAR COPPER COMPLEXES FOR CATALYTIC WATER OXIDATION}

A dissertation submitted in partial fulfillment of the

requirements for the degree of

DOCTOR OF PHILOSOPHY

in

CHEMISTRY

by

David lan James Kreiger

2019 
To: Dean Michael R. Heithaus

College of Arts, Sciences and Education

This dissertation, written by David lan James Kreiger, and entitled Towards Trigonal Prismatic Hexanuclear Copper Complexes for Catalytic Water Oxidation having been approved in respect to style and intellectual content, is referred to you for judgment.

We have read this dissertation and recommend that it be approved.

Kathleen Rein

Wenzhi Li

Xiaotang Wang

Konstantinos Kavallieratos

Raphael G. Raptis, Major Professor

Date of Defense: May 16, 2019

The dissertation of David lan James Kreiger is approved.

Dean Michael R. Heithaus
College of Arts, Sciences and Education

College of Arts, Sciences and Education

Vice President for Research and Economic Development and Dean of the University Graduate School

Florida International University, 2019 


\section{Copyright Page}

Permission granted to reproduce figure 5 was given by the Royal Chemical Society, from Metallomics 2012, 4 (1), 37-47.32

Permission granted to reproduce figure 6 by Elsevier, from Coord. Chem. Rev. 2013, 257 (2), 445-458.38

Chapter 3, was reproduced in most part, from CrystEngComm. DOI: 10.1039/C9CE00421A 120 Copyright permission not needed for Royal Chemical Society, as per their guidelines. 


\section{ACKNOWLEDGMENTS}

Firstly, I would like to thank my committee for being supportive of my studies and being accommodating with my scheduling. I will be ever grateful to Dr. Raptis for the support and guidance he has given me, and all the coffee. And I want to thank the Raptis' group for asking difficult questions in group meeting, giving me ideas to follow when I hit a dead-end in my research, and helping to prepare me for presentations, especially Dr. Logesh for all his help and his work that I built my research on (and the coffee). I love to thank my wife, Vanessa Barcelo for her patience and understanding and my family for encouraging me to persevere through the most difficult times. I also am deeply grateful to Dr. Daniel Belisario for the computational calculations and for his friendship, that without, I would not have been able to endure the first 4 years of my life in Miami. Now to thank those who made this work possible, Zim and Luisa my undergraduates that helped with the synthesis of these samples and Ya-Li Hsu for help with the various data collections and the urgency he put on my work. He was always able to fit in my research needs within a week or two. Furthermore, I thank NSF, NRC and FIU for funding, and the ToposPro team for topology determination.

I want to acknowledge my fluffy family for their understanding.

Finally, I want to thank God for giving me the strength and ability to complete this endeavor. 
ABSTRACT OF THE DISSERTATION

TOWARDS TRIGONAL PRISMATIC HEXANUCLEAR COPPER COMPLEXES

FOR CATALYTIC WATER OXIDATION

\author{
by \\ David lan James Kreiger \\ Florida International University, 2019 \\ Miami, Florida \\ Professor Raphael G. Raptis, Major Professor
}

Our planet is running out of energy resources and traditional renewables are not easily transported nor will be sufficient to cover the void left by fossil fuels. Therefore, a new energy storage system needs to be adopted. The medium with highest energy density that is readily available is hydrogen from water. However, to access hydrogen, water needs to be oxidized and water oxidation catalysts (WOCs) will be required for widespread adoption. In pursuit of WOCs, several hexauclear copper complexes were synthesized and characterized, including the isolation and characterization of a mixed-valent $\mathrm{Cu}_{6}$ (formally, $\mathrm{Cu}_{5}{ }_{5} \mathrm{Cu}{ }^{\prime \prime \prime}$ ) complex. Furthermore, early in the research, several novel coordination polymers (CPs) were serendipitously synthesized.

This dissertation is divided into three major parts:

(i) A series of trigonal prismatic $\mathrm{Cu}_{6}$-pyrazolato complexes $\left(\mathrm{Cu}_{6}\right)$ form a unique arrangement of two $\mathrm{O}^{2-}$ ions in a favorable position to form an $\mathrm{O}-\mathrm{O}$ bond without much external influence. The $\mathrm{Cu}_{6}$ complexes undergo two reversible one-electron oxidations and a structurally characterized one-electron oxidized mixed-valent 
complex displays an $\mathrm{O} \cdots \mathrm{O}$ distance $\sim 0.3 \AA$ closer than the homovalent compound, which highlights the propensity of the system towards O-O bond formation. Spectroscopic findings and DFT calculations on the electronic structure of the mixed-valent $\mathrm{Cu}_{6}$-complex are reported. The results support the hypothesis that a variation of a $\mathrm{Cu}_{6}$ motif could function as a water oxidation catalyst.

(ii) Three new coordination polymers containing trinuclear $\mathrm{Cu}(\mathrm{II})-4$-formyl pyrazolato units connected by formyl group coordination were prepared and the crystal structures are reported: a 1D polymer formed by linking secondary building units (SBUs) and two 3D polymers with novel topologies consist of 14-nodal $3^{8} 4^{2}, 5^{4}-\mathrm{c}$ and 3-nodal 3,3,4-c nets, respectively.

(iii) Two new motifs of $\mathrm{Cu}_{6}$-pyrazolato complexes were prepared. One motif has two pyrazolato bridges between the trinuclear copper subunits with a $\mu_{4}-\mathrm{Cl}$ situated inside the open cage, and the other has the subunits bridged by a single pyrazolato ligand. Variable low-temperature NMR and magnetic studies were conducted. And for the first time, far-infrared spectroscopy studies were used to determine the characteristic absorptions of various coordination bonds in copper pyrazolate complexes. 


\section{TABLE OF CONTENTS}

CHAPTER

PAGE

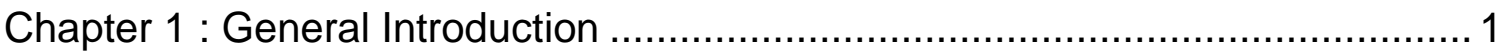

1.1. Importance and Overview of Water Oxidation Catalysts ............................ 1

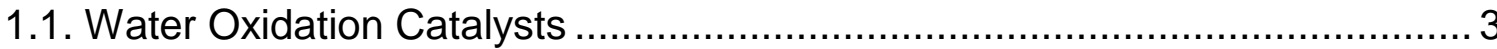

1.2. Polynuclear Copper Centers in Nature - Oxygen Reduction Enzymes in Comparison to Trigonal Copper Complexes ..................................................... 7

1.3. Classification of Mixed-Valence Complexes ............................................. 10

1.4. Cofacial Porphyrins and Pacman Complexes........................................ 11

1.5. Coordination Polymer Overview .......................................................... 13

1.6. Brief Overview of Pyrazolate Coordination Chemistry ............................... 14

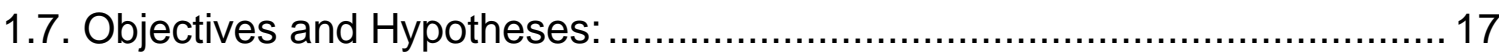

Chapter 2 : Mixed-Valent Cu6-Pyrazolato Complex as a Candidate for Water

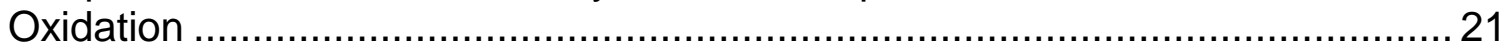

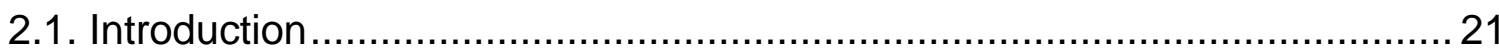

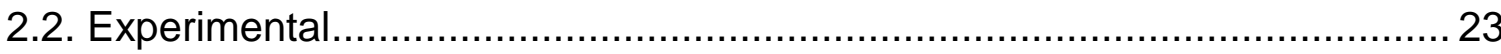

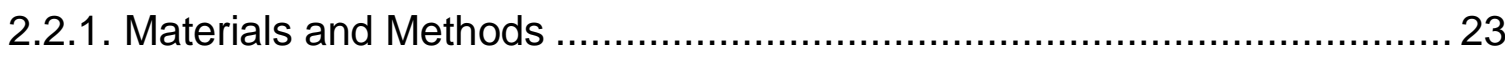

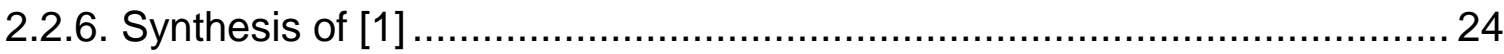

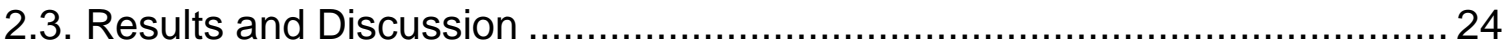

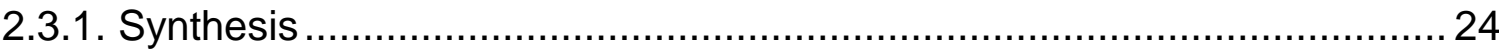

2.3.2. UV-vis-NIR absorption Spectroscopy and UV-vis-NIR

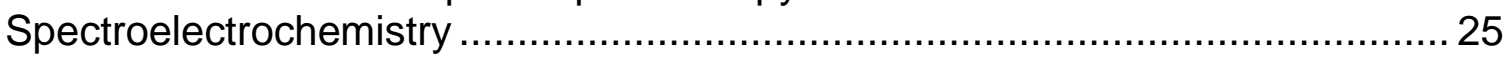

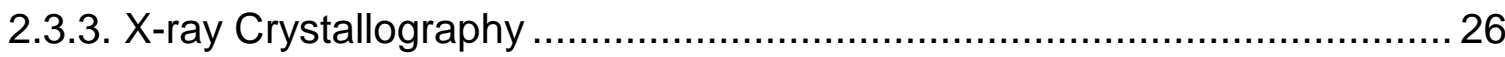

2.3.4. Cu K-edge X-ray absorption spectroscopy …...................................... 29

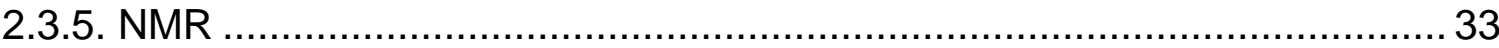




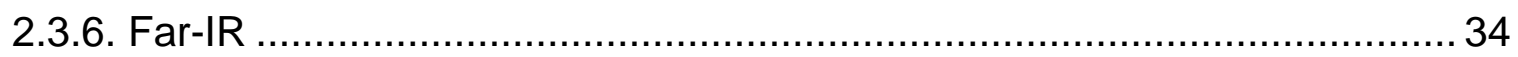

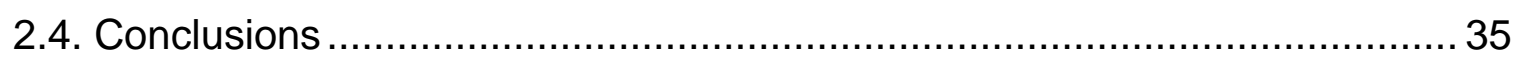

Chapter 3 : Coordination polymers based on pyrazole-4-carboxaldehydecontaining $\mathrm{Cu}_{3} \mathrm{~N}_{6}$ metallacycles as building units. ${ }^{118}$

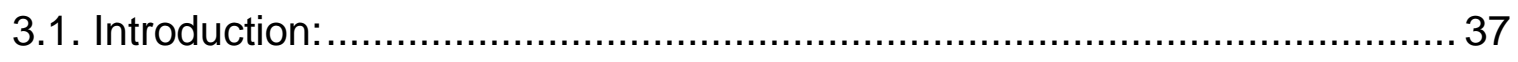

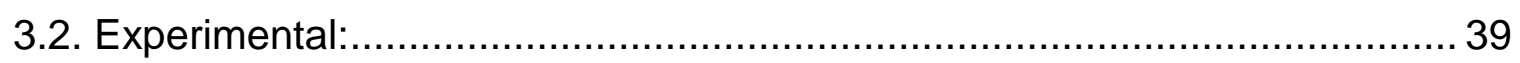

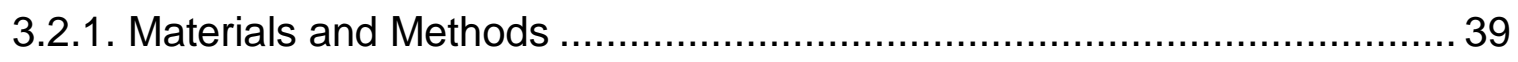

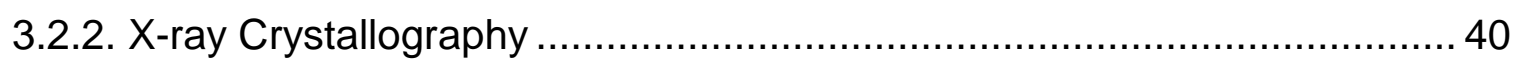

3.2.3. X-ray Powder Diffraction .................................................................... 40

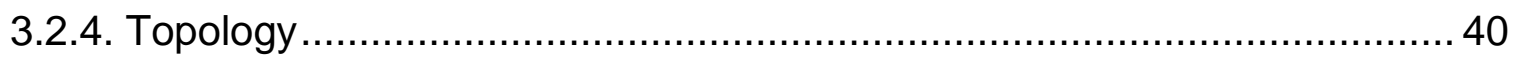

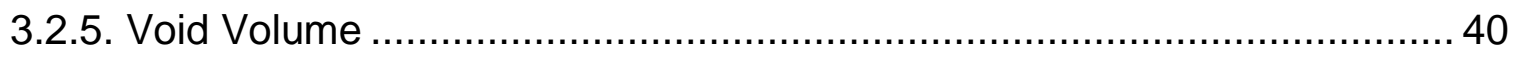

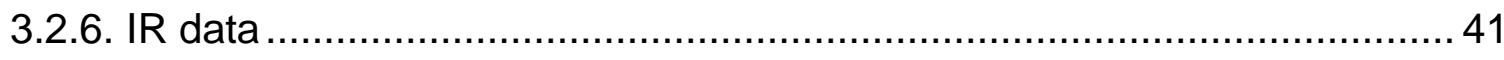

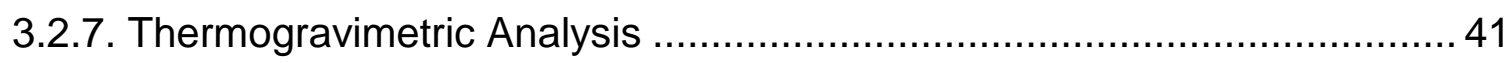

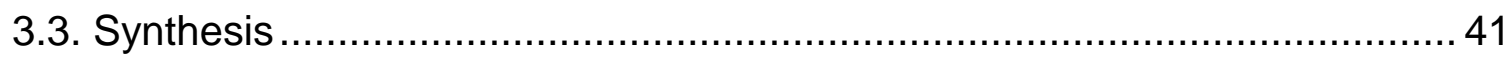

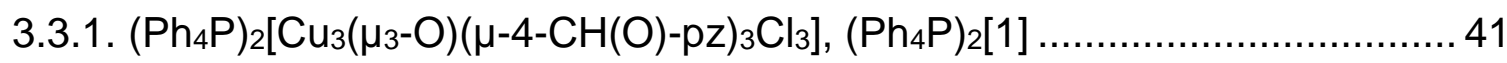

3.3.2. $\left[\mathrm{Cu}_{3}\left(\mu_{3}-\mathrm{OH}\right)(\mu-4-\mathrm{CH}(\mathrm{O})-\mathrm{pz})_{3}(\mu-1,2-\mathrm{bpe})_{2}(1,2-\mathrm{bpe})_{2}\left(\mathrm{H}_{2} \mathrm{O}\right)\right]\left(\mathrm{CF}_{3} \mathrm{SO}_{3}\right)_{2}$

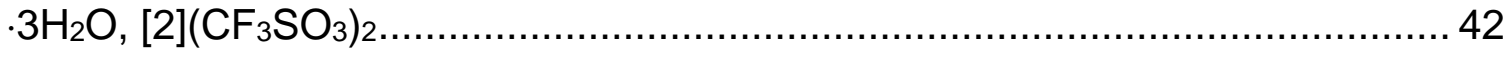

3.3.3. $\left\{\left[\mathrm{Cu}_{3}\left(\mu \mu_{3}-\mathrm{OH}\right)(\mu-4-\mathrm{CH}(\mathrm{O})-\mathrm{pz})_{3}\left(\mathrm{H}_{2} \mathrm{O}\right)_{3}\right]\left(\mathrm{CF}_{3} \mathrm{SO}_{3}\right)_{2}\right\}_{n},[3]\left(\mathrm{CF}_{3} \mathrm{SO}_{3}\right)_{2} \ldots \ldots \ldots \ldots . . . . .42$

3.3.4. $\left\{\left[\mathrm{Cu}_{3}\left(\mu_{3}-\mathrm{OH}\right)(\mu-4-\mathrm{CH}(\mathrm{O})-\mathrm{pz})_{3}\left(\mathrm{py}_{3}\right]\left(\mathrm{CF}_{3} \mathrm{SO}_{3}\right)_{2}\right\}_{n},[4]\left(\mathrm{CF}_{3} \mathrm{SO}_{3}\right)_{2} \ldots \ldots \ldots \ldots \ldots . . . . . . .42\right.$

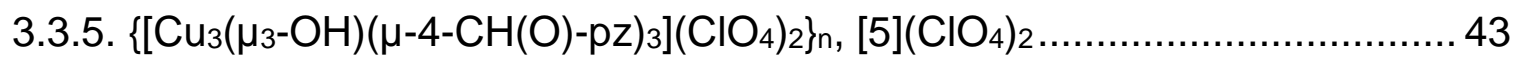

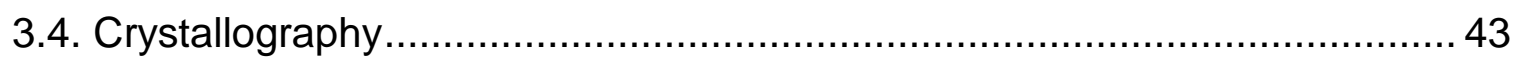

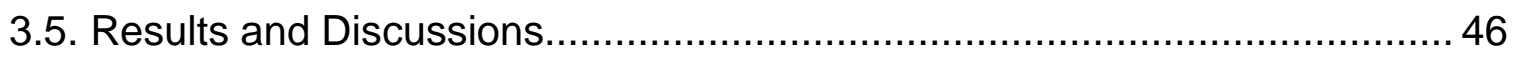

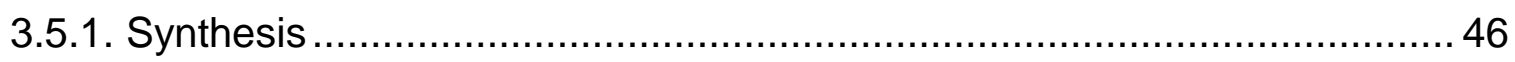

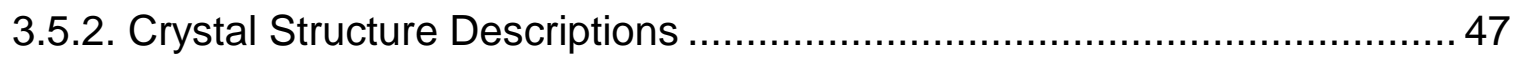

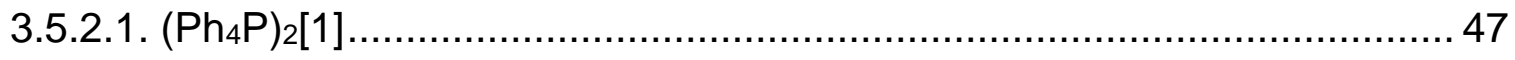




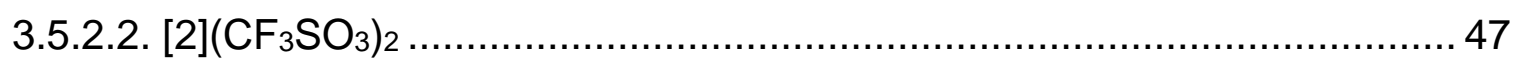

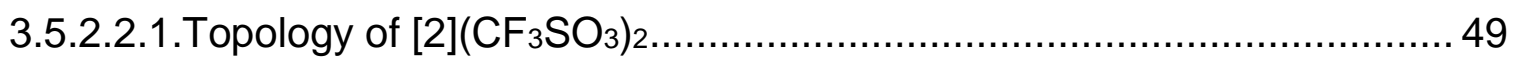

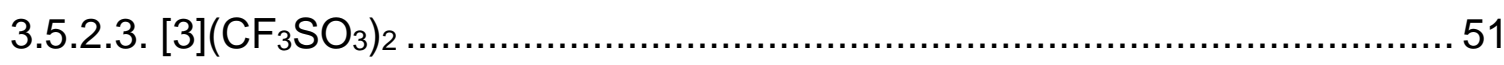

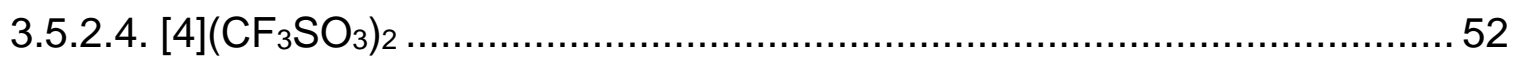

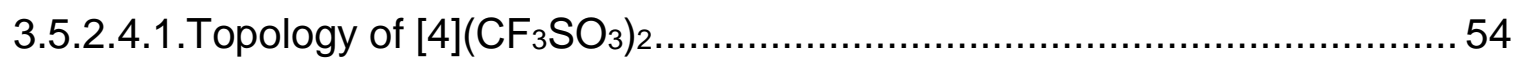

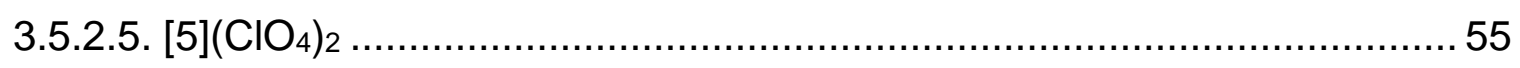

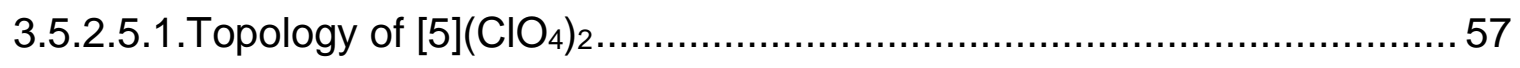

3.5.3. Powder X-Ray Diffraction Patterns ....................................................... 58

3.5.4. Thermogravimetric Analysis ............................................................. 60

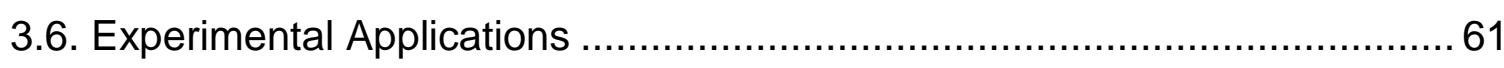

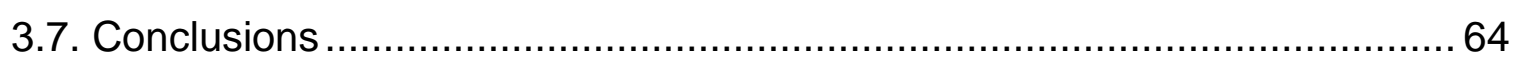

Chapter 4 : Synthesis and Characterization of Hexanuclear Interacting Prismatic Pyrazolato Open-Cage Complexes (HIPPOs); Structural, VT-NMR,

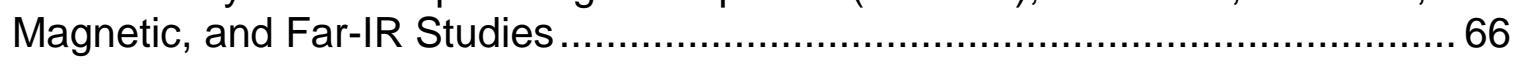

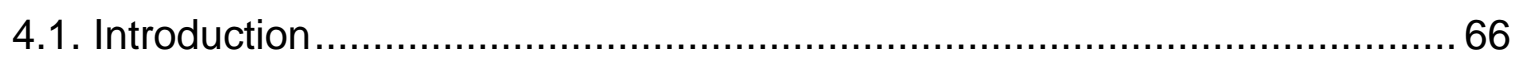

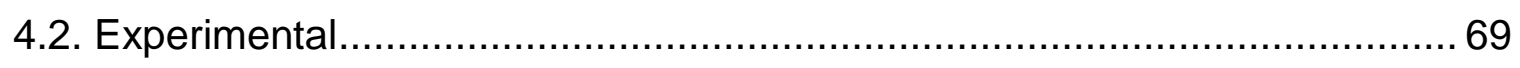

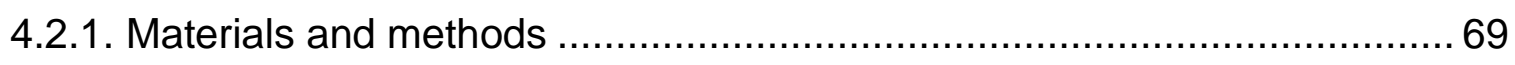

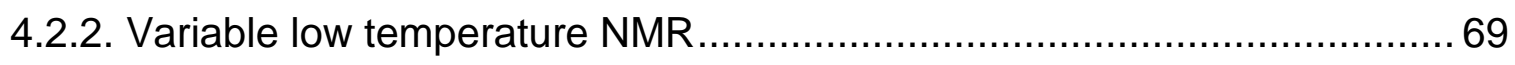

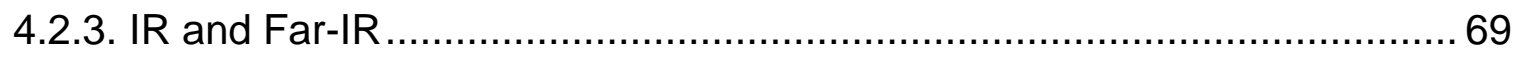

4.2.5. Magnetic Data Acquisition .................................................................. 70

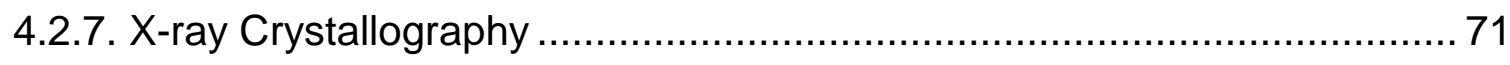

4.3. Synthetic procedures ........................................................................... 72

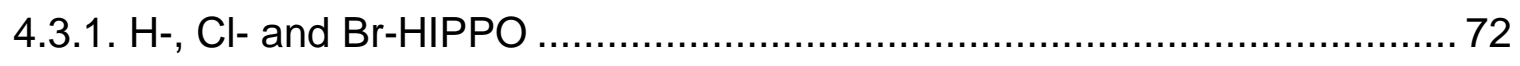

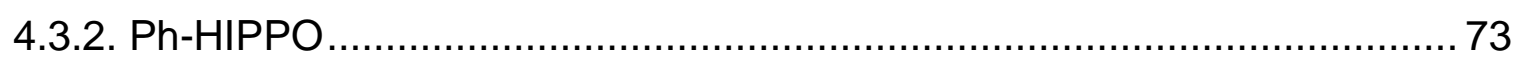

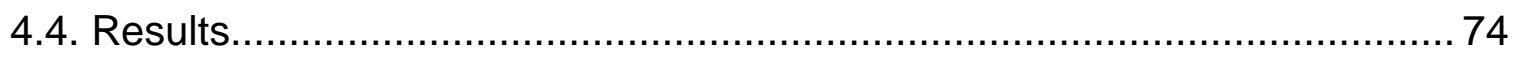




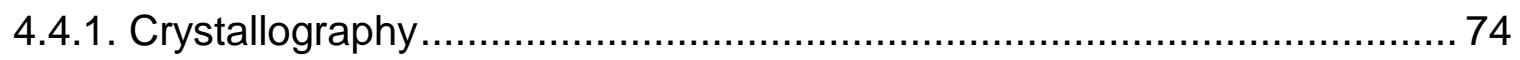

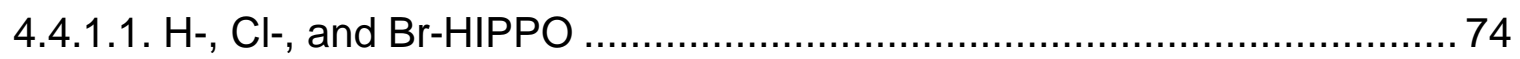

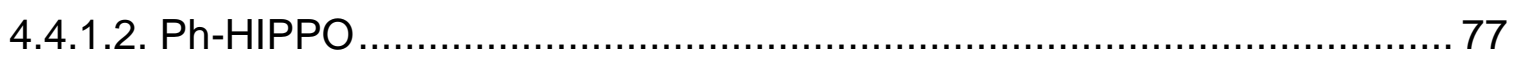

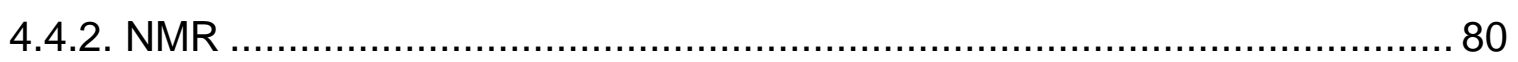

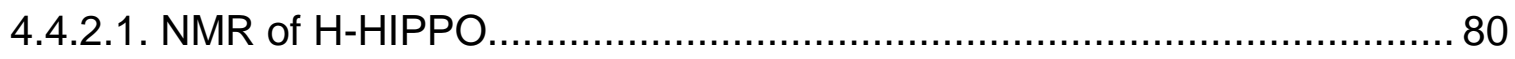

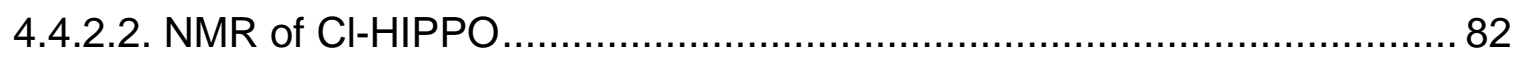

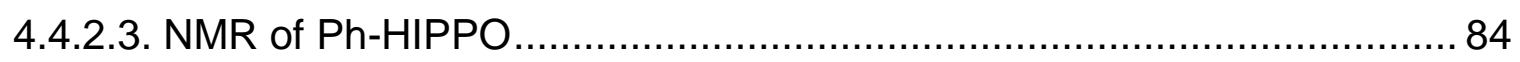

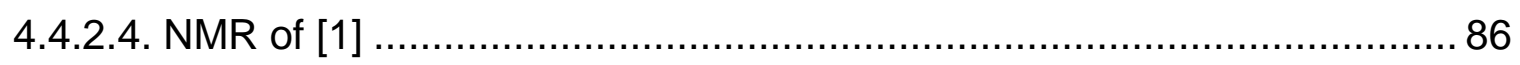

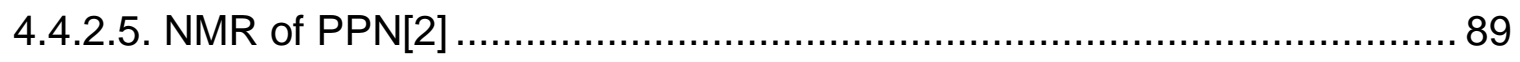

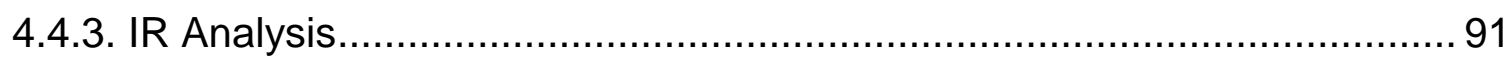

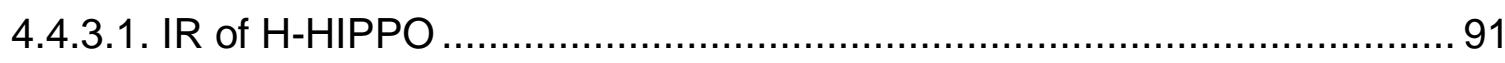

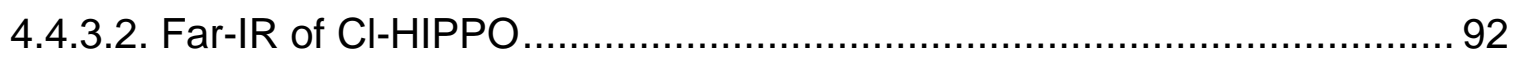

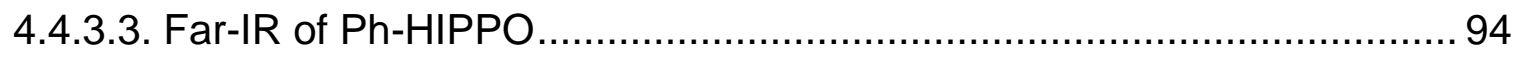

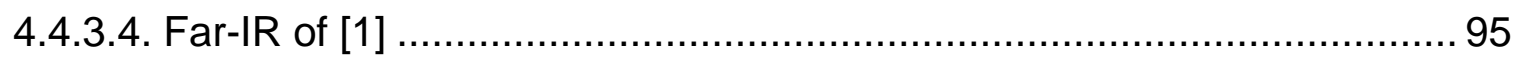

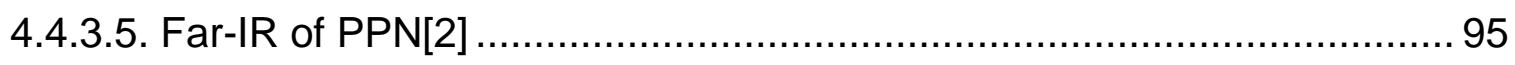

4.4.3.6. IR Compared to Literature Values ..................................................... 96

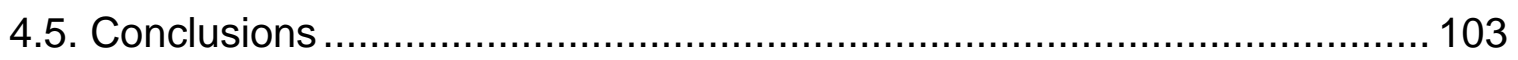

5. Summary and Future Work ............................................................ 104

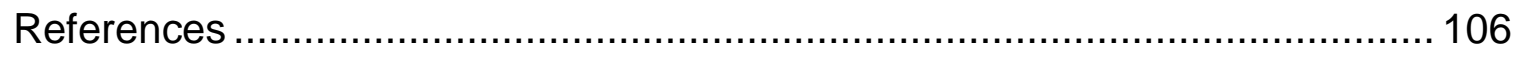

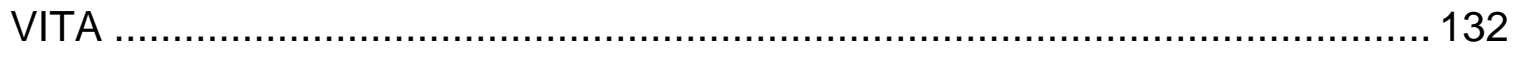




\section{LIST OF TABLES}

TABLE

PAGE

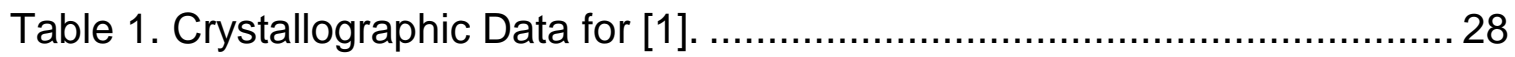

Table 2. Structural parameters between PPN[1'] and mixed-valent [1]. ............ 29

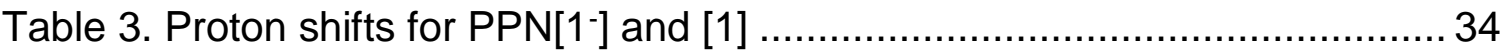

Table 4. Crystallographic data parameters for compounds in Chapter 2........... 44

Table 5. Selected bond lengths and angles for complexes 1-5 in chapter 2...... 45

Table 6. Crystal parameters for chapter 4 …….......................................... 78

Table 7. Selected interatomic lengths $(\AA)$ and angles $\left(^{\circ}\right)$ for chapter $4 \ldots \ldots \ldots \ldots \ldots . . .79$

Table 8. NMR shifts (ppm) of H-HIPPO, with $\mathrm{T}_{2}$ times, shifts, and slope............81 81

Table 9. NMR shifts (ppm) of Cl-HIPPO, with T2 times, shifts, and slope........... 83

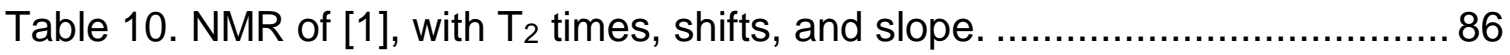

Table 11. NMR of PPN[2], with $T_{2}$ times, shifts, and slope.............................90

Table 12. Comparison of calculated absorptions and observed absorptions.

* indicates coupling with $\mathrm{pz}^{-}$deformation. 97 


\section{LIST OF FIGURES}

FIGURE

PAGE

Figure 1. The $\mathrm{Mn}_{4} \mathrm{O}_{5} \mathrm{Ca}$ active center of PSII. ${ }^{10} \mathrm{Mn}$, purple; $\mathrm{Ca}$, yellow; O, red. .. 4

Figure 2. The "Blue Dimer". ${ }^{13}$ 5

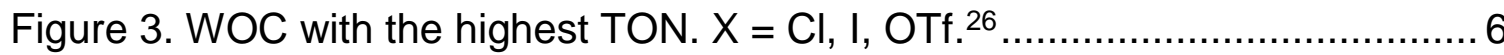

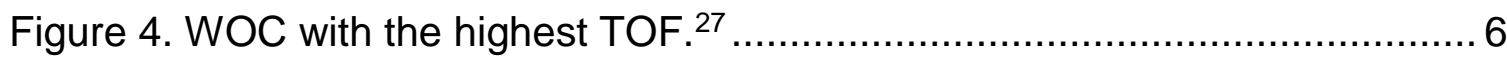

Figure 5. Multicopper enzymes with a trinuclear active site. A: McoC, PDB:3ZX1; B: CueO, PDB:1N68; C: CotA laccase, PDB:1W6L. ${ }^{32} \mathrm{Cu}$ atoms are orange spheres. Note the trinuclear $\mathrm{Cu}$ active site in all three enzymes.

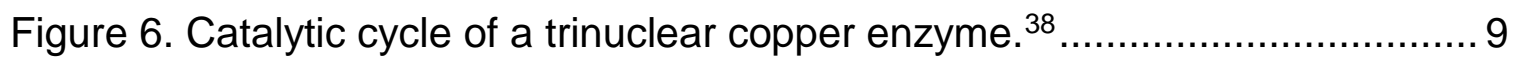

Figure 7. Left: Crystallographically determined Cu distances in the natural intermediate of CueO (a multicopper oxidase); ${ }^{42}$ right: Crystallographically determined distances for Сuз-pyrazolate. ${ }^{46}$

Figure 8. A, example of a cofacial porphyrin complex; ${ }^{81} \mathrm{~B}$, example of a Schiff-base calixpyrrole complex. ${ }^{66}$

Figure 9. Crystal structure of $\mathrm{Cu}_{6}$ with trinuclear subunits connected by bispyrazoles. ${ }^{84}$ Black, C; Blue, N; Cyan, Cu. Hydrogens omitted for clarity........ 13

Figure 10 Archetypal hexanuclear copper pyrazolate. ${ }^{49}$ Black, C; whie, $\mathrm{H}$; red, O; blue, N; cyan, $\mathrm{Cu}$. Anions are omitted for clarity.

Figure 11. NIR region of the UV-vis-NIR spectra [1] (left) and [1+] (right) .......... 26

Figure 12. Crystal structure of [1]. Black, C; white, $\mathrm{H}$; blue, N; red, O;

cyan, $\mathrm{Cu}$.

Figure 13. (Top) Cu K-edge X-ray absorption spectrum of [1-] (black) and [1] (red) and the second derivate of the spectra (bottom). 
Figure 14. L-edges of $\mathrm{Cu}_{3}{ }^{2-}$ (orange) and $\mathrm{Cu}_{3}^{-}$(blue). ${ }^{117}$ 32

Figure 15. L-edges of PPN[1-] (orange) and [1] (blue).................................. 32

Figure 16. Close-up of shift in L-edges of PPN[1-] (orange) and [1] (blue).......... 32

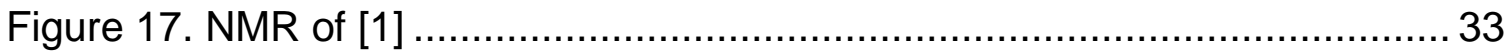

Figure 18. IR and Far IR of PPN[1] (black) and [1] (red)............................... 35

Figure 19. Qualitative map of spin density on [1] ....................................... 36

Figure 20. Ball-and-stick diagram of $1^{2-}$, counter cation omitted for clarity. Color coding: Blue, $\mathrm{Cu}$; green, $\mathrm{Cl}$; red, O; light blue, N, black, $\mathrm{C}$ and pink, $\mathrm{H}$. ... 47

Figure 21. Diagram of three-fold interpenetration of $2^{2+}$ viewed along the crystallographic $\mathrm{c}$-axis. $\mathrm{H}$-atoms and counter anions are not shown for clarity. . 49

Figure 22. Standard representation of $2^{2+}$ : a) The net obtained after primary simplification; b) The 3,4,5-c underlying net of 3,4,5T174 topological type obtained after secondary simplification procedure.

Figure 23. Underlying net of $2^{2+}$ obtained by the cluster representation procedure at 6-rings: a) Dissection of the structure by means of the cluster simplification procedure as implemented in ToposPro; b) The 4-c underlying net of dia topological type obtained.

Figure 24. Molecular structures of one of the chains of $3^{2+}$ (top); Packing diagram showing the wave-like arrangement parallel to the crystallographic a-axis (bottom). $\mathrm{CF}_{3} \mathrm{SO}_{3}$ anions are not shown. Color coding: Blue, $\mathrm{Cu}$; red, O; light blue, N, black, $\mathrm{C}$ and pink, $\mathrm{H}$

Figure 25. Molecular packing diagram for $4^{2+}$ viewed along the crystallographic a-axis. Color coding: Blue, $\mathrm{Cu}$; red, $\mathrm{O}$; light blue, $\mathrm{N}$ and black, $\mathrm{C}$. $\mathrm{H}$-atoms and counter anions are not shown for clarity. 53

Figure 26. Standard representation of $4^{2+}$ : a) The 14-nodal $3^{8}, 4^{2}, 5^{4}-\mathrm{c}$ net obtained after primary simplification. Red spheres correspond to copper atoms, purple spheres represent hydroxyl anions, grey spheres - 4- $\mathrm{CH}(\mathrm{O})-\mathrm{pz}$ 
ligands and violet spheres - pyridine molecule; b) The underlying net of new topological type obtained after secondary simplification procedure....

Figure 27. Underlying net of $4^{2+}$ obtained by the cluster representation procedure at 6-rings: a) Dissection of the structure to clusters by ToposPro; b) The 6-c underlying net of the sol topological type obtained after secondary simplification procedure.

Figure 28. Molecular packing diagram of $5^{2+}$ viewed along the crystallographic [111] plane. Counter anions and $\mathrm{H}$-atoms are not shown for clarity. Color coding: Blue, $\mathrm{Cu}$; red, O; light blue, $\mathrm{N}$, and black, $\mathrm{C}$.

Figure 29. Standard representation of $5^{2+}$ : the 3,3,4-c underlying net of unknown topological type obtained after secondary simplification procedure. ...57

Figure 30. Underlying net of $5^{2+}$ obtained by the cluster representation procedure at 5-rings: a) Dissection of the structure to clusters by ToposPro; b) The 6-c underlying net of the bcs topological type obtained after secondary simplification procedure.

Figure 31. Powder diffraction of [2] $\left(\mathrm{CF}_{3} \mathrm{SO}_{3}\right)_{2}$. Red, experimental; black, simulated

Figure 32. Powder diffraction of [3] $\left(\mathrm{CF}_{3} \mathrm{SO}_{3}\right)_{2}$. Experimental, purple; simulated pattern of [3] $\left(\mathrm{CF}_{3} \mathrm{SO}_{3}\right)_{2}$, green; simulated pattern of [4] $\left(\mathrm{CF}_{3} \mathrm{SO}_{3}\right)_{2}$, blue. 59

Figure 33. Powder pattern (red) of $[5]\left(\mathrm{ClO}_{4}\right)_{2}$ compared to the simulate (green).60

Figure 34. TGA of [2] $\left(\mathrm{CF}_{3} \mathrm{SO}_{3}\right)_{2}$ (blue), [3] $\left(\mathrm{CF}_{3} \mathrm{SO}_{3}\right)_{2}$ (black) and [5] $\left(\mathrm{ClO}_{4}\right)_{2}$ (red).

Figure 35. IR of [3] $\left(\mathrm{CF}_{3} \mathrm{SO}_{3}\right)_{2}$ before (blue) and after (orange) adding acetonitrile.

Figure 36. IR of [5] $\left(\mathrm{ClO}_{4}\right)_{2}$ before (blue) and after (red) adding acetonitrile....... 63

Figure 37. IR of [2] $\left(\mathrm{CF}_{3} \mathrm{SO}_{3}\right)_{2}$ before (blue) and after (orange) adding acetonitrile. 
Figure 38. ${ }^{1} \mathrm{H}$ NMR of $[5]\left(\mathrm{ClO}_{4}\right)_{2}$ in acetonitrile- $d^{3}$. 64

Figure 39. H-HIPPO - front view. Color code: Black, C; Grey, H; Red, O; Blue, N; Cyan, $\mathrm{Cu}$; Green, $\mathrm{Cl}$. Counter anions omitted for clarity. 75

Figure 40. Cl-HIPPO - side view. Color code: Black, C; Grey, H; Red, O; Blue, N; Cyan, Cu; Green, Cl. Counter anions omitted for clarity. 75

Figure 41. Br-HIPPO - front view. Color code: Black, C; Grey, H; Red, O; Blue, N; Cyan, Cu; Green, Cl. Counter anions omitted for clarity. 76

Figure 42. Counter ion placement in H-HIPPO 76

Figure 43. Ph-HIPPO - front view. Color code: Black, C; Grey, H; Red, O; Blue, N; Cyan, Cu; Green, Cl.

Figure 44. Variable Low-Temperature NMR plot of H-HIPPO. Red, RT; green, $-5^{\circ} \mathrm{C}$; blue, $-15^{\circ} \mathrm{C}$, purple $-25^{\circ} \mathrm{C}$. 81

Figure 45. Variable Low-Temperature NMR plot of Cl-HIPPO. Red, RT; green, $-5^{\circ} \mathrm{C}$; blue, $-15^{\circ} \mathrm{C}$, purple $-23^{\circ} \mathrm{C}$. 84

Figure 46. Variable Low-Temperature NMR plot (downfield) of Ph-HIPPO. Red, RT; green, $-5^{\circ} \mathrm{C}$; blue, $-15^{\circ} \mathrm{C}$, purple $-25^{\circ} \mathrm{C}$. 85

Figure 47. Variable Low-Temperature NMR plot (upfield) of Ph-HIPPO. Red, RT; green, $-5^{\circ} \mathrm{C}$; blue, $-15^{\circ} \mathrm{C}$, purple $-25^{\circ} \mathrm{C}$.

Figure 48. Variable Low-Temperature NMR plot (upfield) of [1]. Red, RT; green, $-5{ }^{\circ} \mathrm{C}$; blue, $-15^{\circ} \mathrm{C}$, purple $-25^{\circ} \mathrm{C}$.

Figure 49. Variable Low-Temperature NMR plot (downfield) of compound 5. Red, RT; green, $-5^{\circ} \mathrm{C}$; blue, $-15^{\circ} \mathrm{C}$, purple $-25^{\circ} \mathrm{C}$. 88

Figure 50. Variable Low-Temperature NMR plot (upfield) of PPN[2]. Red, RT; green, $-5^{\circ} \mathrm{C}$; blue, $-15^{\circ} \mathrm{C}$, purple $-25^{\circ} \mathrm{C}$.

Figure 51. Variable Low-Temperature NMR plot (downfield) of PPN[2].

Red, RT; green, $-5^{\circ} \mathrm{C}$; blue, $-15^{\circ} \mathrm{C}$, purple $-25^{\circ} \mathrm{C}$. 
Figure 52. Far-IR of H-HIPPO.

Figure 53. IR Cu-O stretching bands for ${ }^{16} \mathrm{O}$ - and ${ }^{18} \mathrm{O}-\mathrm{H}-\mathrm{HIPPO} \ldots \ldots \ldots \ldots \ldots \ldots \ldots . . . . . . . . . . . .2$

Figure 54. Far-IR of Cl-HIPPO

Figure 55. Simulated spectra of CI-HIPPO determined by DFT. ....................... 94

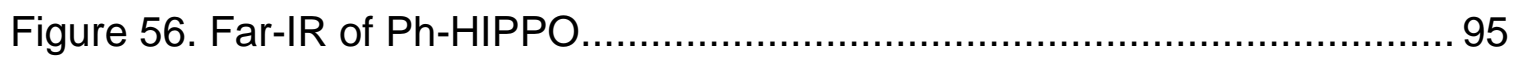

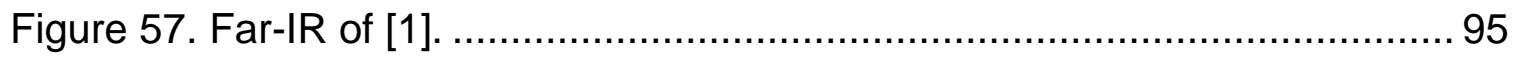

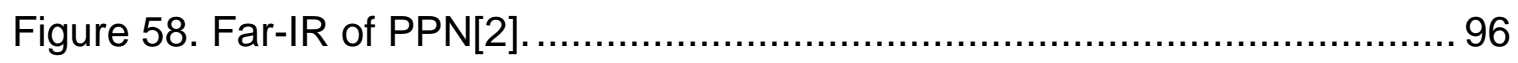

Figure 59. Magnetic properties of compounds 2 and 4. Each plot shows the temperature dependence of the effective magnetic moment and in the inset, the isothermal magnetizations measured at $T=2,5$ and $10 \mathrm{~K}$ are given. Experimental data - empty symbols, full red lines - calculated data with spin Hamiltonian in eq. 1 and parameters in the text. 100

Figure 60. The magneto-structural correlation between the angle $\mathrm{Cu}-\mathrm{O}-\mathrm{Cu}$ in $\mathrm{Cu}_{3}\left(\mu_{3}-\mathrm{OH}\right)$ triangles of $\mathrm{Cl}-\mathrm{HIPPO}$ and Ph-HIPPO extracted from X-ray structures and magnetic coupling parameters $J$ calculated by DFT using B3LYP functional. 


\section{LIST OF SCHEMES}

SCHEME

PAGE

Scheme 1. Lattimer diagram for $\mathrm{H}_{2} \mathrm{O}$

Scheme 2. Direct coupling (top); Acid-base coupling (bottom). ${ }^{17}$ 7

Scheme 3. The three classes of mixed-valence compounds according to Robin-Day classification system. A: class I, fully localized; B: class II, partially delocalized; C: class III, fully delocalized. ${ }^{56}$ 11

Scheme 4. Different coordination modes of pyrazoles and pyrazolates. ${ }^{90}$ 16

Scheme 5. Qualitative molecular orbital diagram if the O- $p_{z}$ orbital overlaps and oxidation was centered on the $\mu_{3}-\mathrm{O}$ ligands.

Scheme 6. Qualitative example of the rotation flexible ligands would facilitate. . 19

Scheme 7. Qualitative example of $\mathrm{O}_{2}{ }^{2-}$ release from an open cage. Charges only account for $\mathrm{Cu}$ and $\mathrm{O}$ atoms 20

Scheme 8. Stepwise oxidation of PPN[1-]

Scheme 9. Proton labels for PPN[1-] and [1]

Scheme 10. Proposed trimer with terminal pyridine and an overall charge of $1^{+}$......

Scheme 11. Reaction pathway determined in the study. 65

Scheme 12. Representations of the various motifs of $\mathrm{Cu}_{6}$ present in literature.. 67

Scheme 13. Proton labels for H-HIPPO. 82

Scheme 14. Proton labels for Cl-HIPPO. 83

Scheme 15. Proton labels for compound [1]. 88 
Scheme 16. Proton labels for PPN[2]. 


\section{ABBREVIATIONS AND ACRONYMS}

$\mathrm{AB}$

Acid-Base Mechanism

ATR-IR

Attenuated Total Reflectance Infrared

Bpe bispyridylethylene

$\mathrm{B} / \mathrm{R}$ Below Range

$\mathrm{CP}$ .Coordination Polymer

DC Direct Coupling

DCM Dichloromethane

DFT Density Functional Theory EPR Electron Paramagnetic Resonance Eq. Equivalents Exptl Experimental FTIR Fourier Transform Infrared GOF Goodness of Fit HIPPO ..........Hexanuclear Interacting Prismatic Pyrazolato Open-Cage Complex HV homovalent $\mathrm{IR}$ Infrared IVCT Intervalent Charge Transfer L. Ligand $\mathrm{MeCN}$ Acetonitrile MV Mixed-Valent $\mathrm{N} / \mathrm{A}$ Not Applicable NMR Nuclear Magnetic Resonance PDB Protein Data Bank

PPN Bis(triphenylphosphine)iminium PSII Photosystem II Py. Pyridine 
$\mathrm{Pz}$

Pyrazolate/pyrazolato

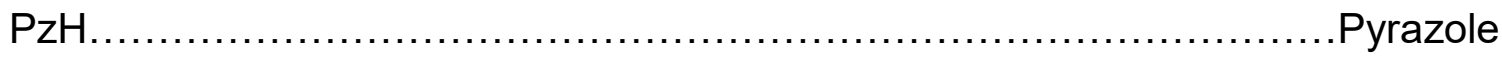

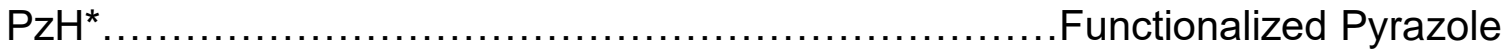

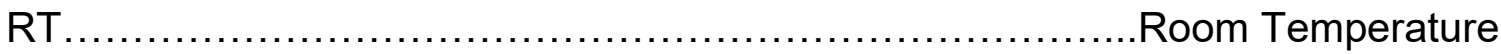

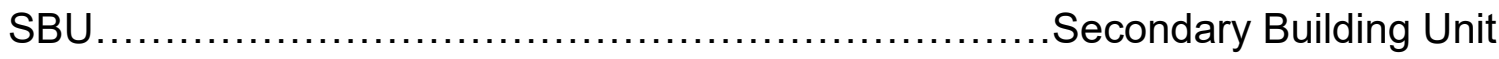

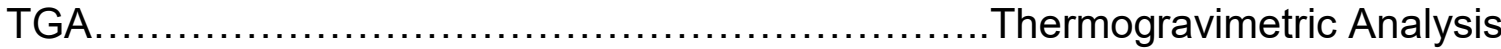

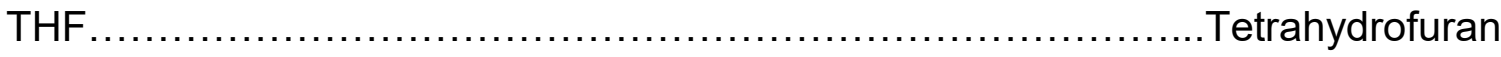

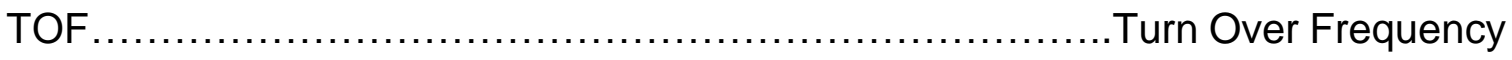

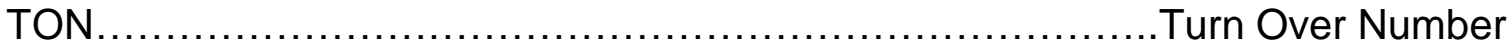

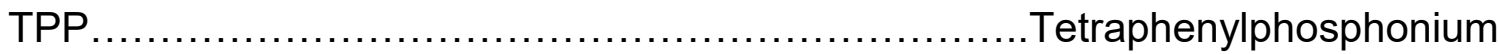

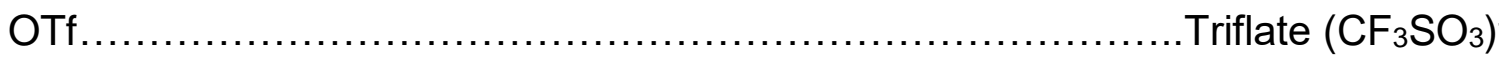

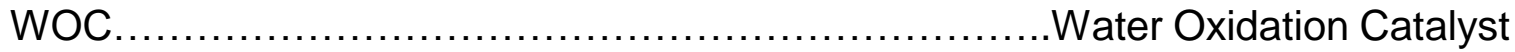

XAS ................................................... Aay Absorption Spectroscopy 


\section{Chapter 1 : General Introduction}

\subsection{Importance and Overview of Water Oxidation Catalysts}

There are many challenges for humanity to overcome in the coming decades. The most important of these challenges is, arguably, energy security. The world's oil supply is dwindling and is projected to be depleted within 150 years at the current consumption rate. With the growing population of the planet and the increased economic development of India and China, it may be depleted much sooner. ${ }^{1}$ Beyond the impending collapse of current living standards if an alternative energy source is not identified, there is the moral question of using our oil reserves for something as paltry and insignificant as moving metal boxes around and turning on light bulbs. The hydrocarbons in the oil reserves are of vital importance in the pharmaceutical and material science industries.

It has been suggested that a shift to other fossil fuels could compensate for this, however, while there is enough natural gas to last 200-600 years and enough coal to power the earth for another 1000-2000 years, the carbon emissions could lead to a runaway greenhouse effect. ${ }^{1}$

The runaway greenhouse effect leaves us with renewable energy resources for our energy needs. These too, have their problems, although they can be overcome. The main issue with renewable resources is distribution. Winds and rivers are not uniformly distributed across the planet, and therefore a way to distribute the energy is needed. Solar energy, on the other hand, is available 
almost everywhere, although typically for only half the day. Thus, a system for storage and transportation must be devised.

Currently, batteries are used for energy storage and transportation. But with an energy density of only $0.5-3.0 \mathrm{MJ} \cdot \mathrm{kg}^{-1}$, batteries cannot store enough power to make renewable resources viable. ${ }^{2,3}$ The energy storage medium should be a gas or a liquid as they have a high energy density and can easily be transported. Nuclear power would be ideal for stationary energy (or on massive vehicles like aircraft carriers), unfortunately the world is afraid of nuclear energy. Traditional liquid fuels have an energy density of $\sim 50 \mathrm{MJ} \cdot \mathrm{kg}^{-1}$, which is the benchmark for useful energy storage. Of the many potential targets, hydrogen gas would be the most desirable as its only combustion product is water and it has an energy density of $140 \mathrm{MJ} \cdot \mathrm{kg}$ at $700 \mathrm{~atm} \cdot{ }^{3}$ Molecular hydrogen effectively does not exist in nature and must be created from other hydrogen containing sources. The best option would be the electrolysis of cheap and plentiful water, according to equation 1 .

$$
\begin{aligned}
& 2 \mathrm{H}_{2} \mathrm{O} \rightarrow 2 \mathrm{H}_{2} \\
& \text { Equation } 1^{4}
\end{aligned}+\mathrm{O}_{2} \quad 113 \mathrm{kcal} \cdot \mathrm{mol}^{-1}
$$

This is a redox reaction with two half-reactions (Equations 2 and 3).

$$
\begin{aligned}
& 2 \mathrm{H}_{2} \mathrm{O} \rightarrow \mathrm{O}_{2}+4 \mathrm{H}^{+}+4 \mathrm{e}^{-} \quad \text { Oxidation } \mathrm{E}^{0}=1.23 \text { vs. } \mathrm{NHE} \\
& \text { Equation } 2
\end{aligned}
$$

$4 \mathrm{H}^{+}+4 \mathrm{e}^{-} \rightarrow 2 \mathrm{H}_{2} \quad$ Reduction $\mathrm{E}^{0}=0$ vs. $\mathrm{NHE}$ Equation 3 
Of these two reactions the formation of oxygen is the limiting step, as it requires four oxidative equivalents and a potential over $1.23 \mathrm{~V}$ as seen in Scheme 1

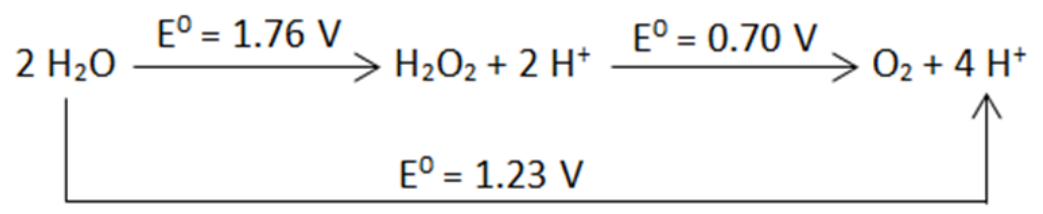

Scheme 1. Lattimer diagram for $\mathrm{H}_{2} \mathrm{O}$

While the energy requirement for water oxidation is acceptable for laboratory purposes, it is too large to be implemented on the scale needed to support the renewable energy transition. That is why it is imperative that a catalyst be developed to lower the activation energy, increasing the rate of formation. Ideally, the activation energy should be low enough to be in the range of photocatalysts.

\subsection{Water Oxidation Catalysts}

The first known water oxidation catalyst (WOC) is photosystem II (PSII), which reduces the oxidation potential by $300 \mathrm{mV} .{ }^{5}$ The active site of photosystem II was developed by Nature 2.5-3.5 billion years ago and most likely formed from the precipitation of manganese oxides that were common in the ocean at that time. ${ }^{6-8}$ The active site of PSII is a distorted chair-shape with the chemical formula $\mathrm{Mn}_{4} \mathrm{O}_{5} \mathrm{Ca}$ (Figure 1). ${ }^{9,10}$ 


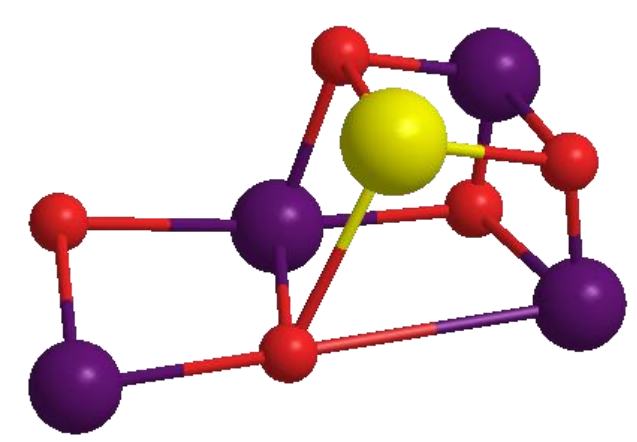

Figure 1. The $\mathrm{Mn}_{4} \mathrm{O}_{5} \mathrm{Ca}$ active center of PSII. ${ }^{10} \mathrm{Mn}$, purple; $\mathrm{Ca}$, yellow; $\mathrm{O}$, red.

Photosystem II is the active center in the chlorophyll of plants that generate most of the molecular oxygen on Earth and is essential to life as we know it. It is a very efficient catalyst with a turnover number (TON) in excess of 180,000 and a turnover frequency (TOF) of $400 \mathrm{~s}^{-1} .11,12$ In efforts to match the efficiency of Nature's catalyst, many of the catalysts being developed are multinuclear like the PSII active center. The first synthetic WOC, the "blue dimer" (Figure 2) was synthesized in 1982 by Meyer et al. and had a TON of just 13.2, using cerium ammonium nitrate as a sacrificial oxidant. ${ }^{13}$ Although the blue dimer had a poor TON, it nevertheless caused an explosion of interest in synthetic WOCs. Since then, there has been rapid growth and development in the area of WOCs. 


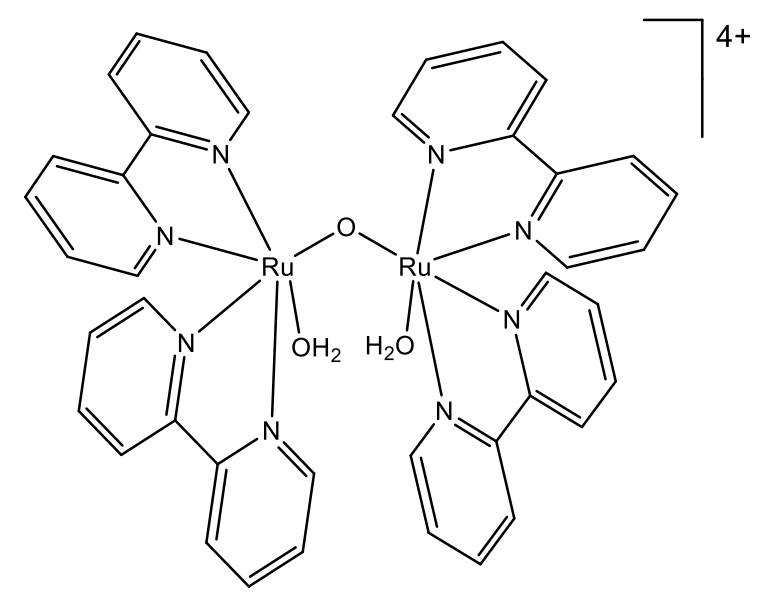

Figure 2. The "Blue Dimer". ${ }^{13}$

In the 30 some years since the first WOC was reported many schemes and metals have been tested. There is little consensus on the best metal or the number of metal centers required for an efficient WOC and it is impossible to empirically compare them because of differences in the conditions for the catalytic testing, such as $\mathrm{pH}$, oxidant, and stirring speed. ${ }^{13,15}$ Some $\mathrm{Ti}, \mathrm{Mn}, \mathrm{Fe}, \mathrm{Ni}, \mathrm{Cu}, \mathrm{Ru}$, Ir and Os complexes and their oxides can catalyze the water oxidation reaction; ${ }^{13,16-19}$ and a fully organic WOC has also been reported. ${ }^{20}$ It appears that electron releasing ligands as well as their rigidity and accessibility of their reaction site will increase the reactivity of WOCs. ${ }^{13,16,21,22}$ Although the most efficient synthetic WOCs are mononuclear, effective WOCs tend to be complexes that have antiferromagnetically coupled high-spin metal centers. ${ }^{16,22-26}$ The most efficient catalyst under mild conditions to date is an iridium half-sandwich complex with a TON near 400,000 although it has a low TOF of less than $0.2 \mathrm{~s}^{-1}$ (Figure 3). ${ }^{26}$ Ruthenium catalysts show a much higher TOF, up to an astounding TOF of 50,000 $\mathrm{s}^{-1}$, which far surpasses PSII, but require a high $\mathrm{pH}$ and an over- potential of 0.7 
V. (Figure 4) ${ }^{27}$ However, both metals are rare and expensive and will not serve for the large scale water oxidation catalysts needed to support a global economy.

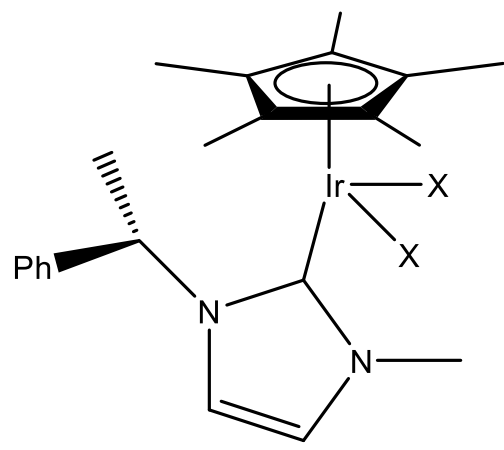

Figure 3. WOC with the highest TON. X $=\mathrm{Cl}$, I, OTf. ${ }^{26}$

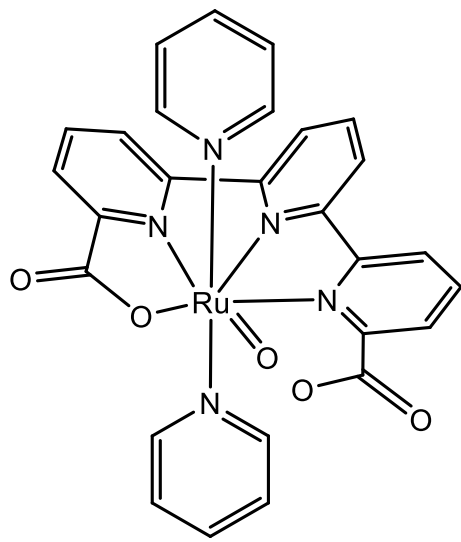

Figure 4. WOC with the highest TOF. ${ }^{27}$

As mentioned above, even the best WOCs fall far short of PSII or require harsh conditions. That is because the mechanisms for the oxidation of water by PSII and synthetic WOCs are different. ${ }^{17,22}$ Photosystem II has been extensively studied for decades and the reaction pathway is confirmed to proceed through the coupling of one oxygen radical to a bridging oxygen atom within the active center cluster. ${ }^{17,23,28}$ The pathway is significantly different from the reaction mechanism of synthetic 
WOCs, which either proceed through a nucleophilic attack by water or hydroxide to a coordinated oxygen, called the acid-base mechanism (AB), or the coupling of two oxygen radicals on adjacent metal sites, known as direct coupling (DC) (Scheme 2). ${ }^{5,16,17,22}$ Because of the involvement of highly oxidized metal centers and oxygen radicals, synthetic WOCs suffer from ligand degradation and dissociation, and thus, catalyst deactivation. ${ }^{16,22}$ Catalyst deactivation is the limiting factor that keeps WOCs from being practical. Although PSII is also degraded through the generated radicals, Nature is constantly repairing the protein. ${ }^{17,22,23} \mathrm{~A}$ common feature of PSII and synthetic catalysts alike is that all involve two or more oxo ligands in proximity, allowing the formation of an O-O bond. Although, to our knowledge, there are no discreet molecular synthetic WOCs that are known to proceed through the reaction pathway of PSII.
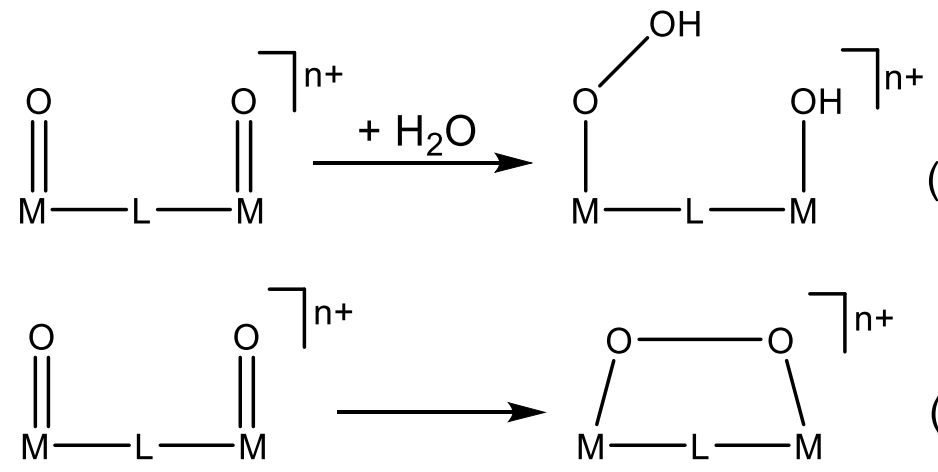

Scheme 2. Direct coupling (top); Acid-base coupling (bottom). ${ }^{17}$

\subsection{Polynuclear Copper Centers in Nature - Oxygen Reduction Enzymes in Comparison to Trigonal Copper Complexes}

Multicopper oxidases, such as tree and fungal laccases, ascorbate oxidase, ceruloplasmin, Fet3p, CueO, and $\mathrm{CotA}$ will facilitate the $4 e^{-}$reduction of $\mathrm{O}_{2}$ to 
water; three examples are shown in Figure 5. ${ }^{29-39}$ The cycle for dioxygen reduction is shown in Figure 6, and according to the principle of microscopic reversibility, multicopper enzymes should also function as catalysts for the reverse reaction, water oxidation. Several of the enzymes have a triangular $\mathrm{Cu}$ arrangement in their active site, and in the native-intermediate form, possess a $\mu_{3}-\mathrm{O}$ bridging the three $\mathrm{Cu}$ atoms, which are positioned on average about $3.30 \AA$ apart, according to calculations, ${ }^{29,32-41}$ while the crystal structure co CueO places the copper atoms $3.39 \AA$, $3.67 \AA$, and $3.82 \AA$ apart, ${ }^{42}$ the distances are shown in Figure 7 along with a Cu-pyrazolate for comparison. Furthermore, it has been determined, using DFT and magnetic susceptibility, that the copper atoms in the enzymes and the $\mathrm{Cu}_{3}-$ pyrazolato complexes are antiferromagnetically coupled with an overall ground state spin of $\mathrm{S}=1 / 2 .{ }^{29,33,36,37,43-48}$ The copper oxidases cycle between [Cu" ${ }_{2} \mathrm{Cu}^{\prime \prime \prime}$ ] and $\left[\mathrm{Cu}{ }_{2} \mathrm{Cu}^{\prime}\right]$ active centers, and involves two redox processes, which is required to facilitate the reduction of $\mathrm{O}_{2}$ to water. ${ }^{32,34,36,41}$ The active center, having two redox processes is similar to the hexanuclear copper complexes from Raptis' group in that regard. ${ }^{44-55}$ 

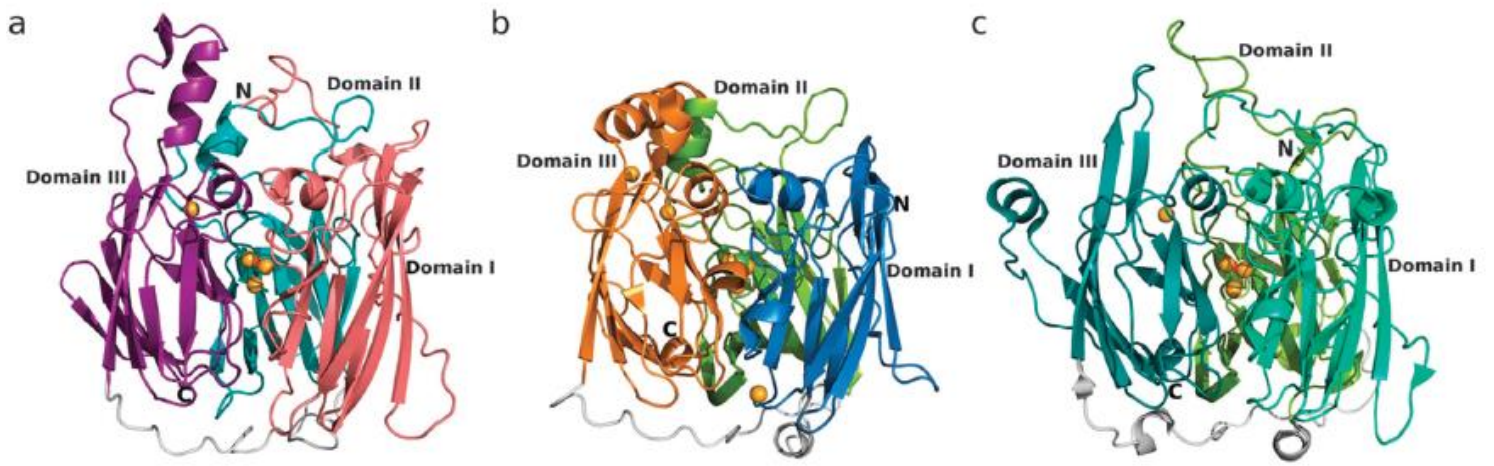

Figure 5. Multicopper enzymes with a trinuclear active site. A: McoC, PDB:3ZX1; B: CueO, PDB:1N68; C: CotA laccase, PDB:1W6L. ${ }^{32} \mathrm{Cu}$ atoms are orange spheres. Note the trinuclear $\mathrm{Cu}$ active site in all three enzymes.

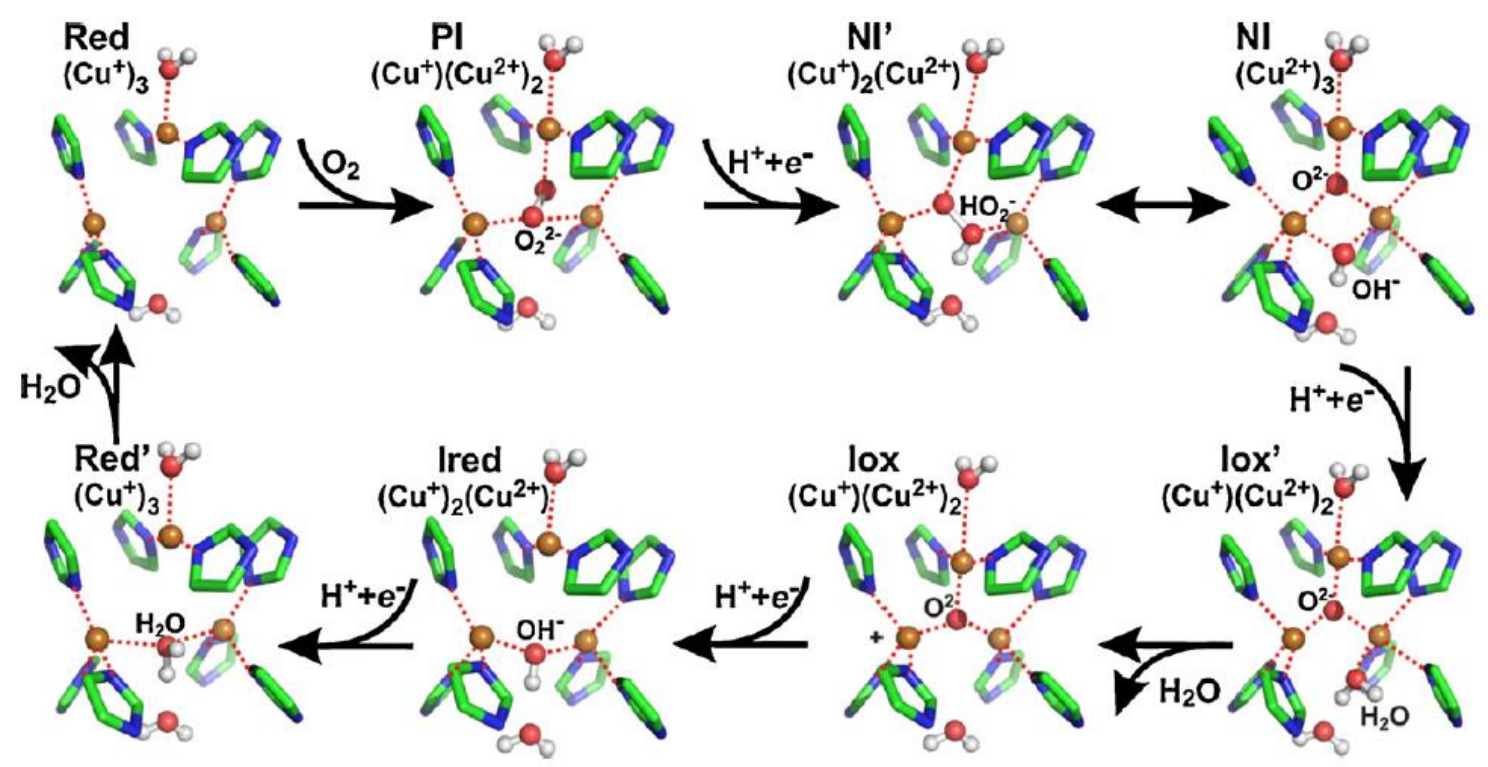

Figure 6. Catalytic cycle of a trinuclear copper enzyme. ${ }^{38}$ 


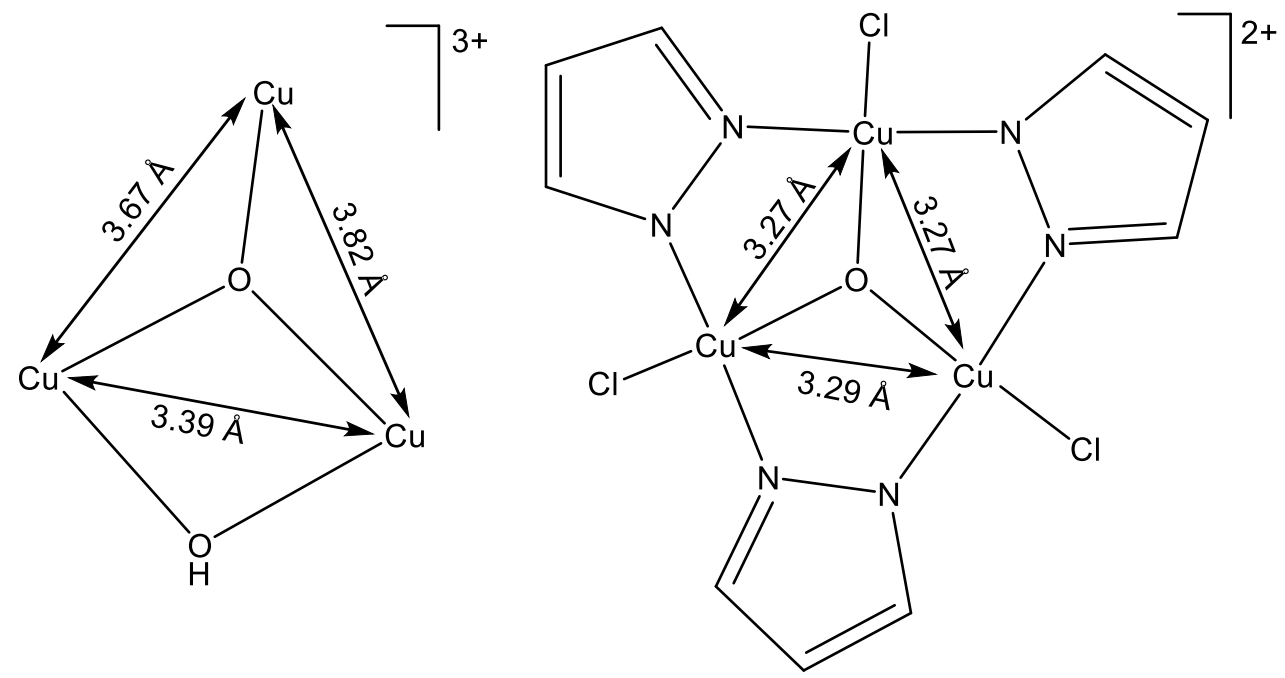

Figure 7. Left: Crystallographically determined $\mathrm{Cu}$ distances in the natural intermediate of CueO (a multicopper oxidase);42 right: Crystallographically determined distances for $\mathrm{Cu}_{3}$-pyrazolate. ${ }^{46}$

\subsection{Classification of Mixed-Valence Complexes}

As mentioned, the multicopper enzymes require a mixed-valent system to facilitate the reduction of oxygen, therefore it is important to understand the various classes of mixed-valence and how that relates to our target compounds. Like the multicopper enzymes, the trinuclear copper-pyrazolato complexes, when oxidized, are formally $\mathrm{Cu}_{2}{ }_{2} \mathrm{Cu}^{\prime \prime \prime}$, although the copper complexes are more accurately described in most cases as $\mathrm{Cu}^{2.33+}{ }_{3}, 47,49,50$ due to charge delocalization at most time scales and temperatures. The delocalization helps stabilize the high-valent Cu center in the oxidized state. According to the Robin-Day three-class system for electron delocalization (Scheme 3), ${ }^{56}$ these Cu-pyrazolate compounds fall into the Robin-Day class II, or partial delocalization, with class I being fully localized and class III being fully delocalized. The degree of electron delocalization is dependent 
on various things, such as the nature of metals and bridging ligands and the topology of the assembly. The extent of delocalization can be determined by analysis of the inter-valence charge transfer (IVCT) band in the near infrared (NIR) region of their absorption spectra, generally between $5000-10000 \mathrm{~cm}^{-1} .57,58$

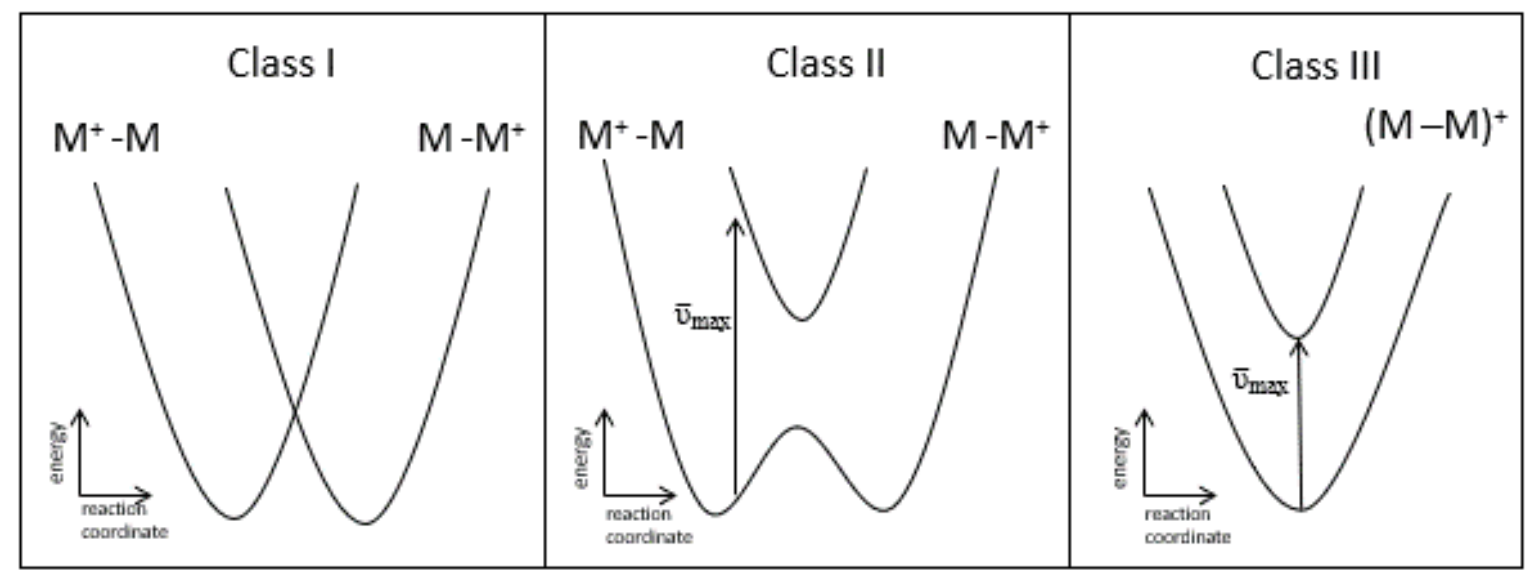

Scheme 3. The three classes of mixed-valence compounds according to RobinDay classification system. A: class I, fully localized; B: class II, partially delocalized; C: class III, fully delocalized. ${ }^{56}$

\subsection{Cofacial Porphyrins and Pacman Complexes}

There has been much interest in porphyrin dimer complexes (Figure 8a) and subsequently Schiff-base calixpyrrole complexes (Figure 8b), collectively called Pacman complexes, since the late 1970's when a cobalt porphyrin dimer was shown to catalyze oxygen reduction to water. ${ }^{59,60}$ Since then, various oxygen reduction and water oxidation catalysts were developed using Pacman-type motifs. ${ }^{61-67}$ Pacman complexes show a penchant for catalysis because of their ability to allow substrates to bind to both metal centers inside the cleft, which helps facilitate multielectron processes while inhibiting side reactions. ${ }^{62,64,67,68}$ Various 
alterations to complexes of cofacial porphyrins and calixpyrroles have emerged since that time, such as mixed metal complexes, ${ }^{69-75}$ two different porphyrins, ${ }^{71,76,77}$, multiple pillared bisporphyrins, ${ }^{78-81}$ and multinuclear variations..$^{74,82,83}$ When the porphyrins are bridged by long flexible linkers, there is a great degree of conformational freedom. Another complex of note, a hexanuclear copper complex that is reminiscent of multipillared cofacial porphyrin complexes (Figure 9), was reported by the Raptis' group and consists of a two trinuclear $\mathrm{Cu}(\mathrm{I})$ pyrazolate subunits connected by organic chains in three posisitions. ${ }^{84}$ However, bispyrazoles, like those used in the hexanuclear $\mathrm{Cu}(\mathrm{I})$ complex reported by Raptis, can easily lead to coordination polymers under various reaction conditions.

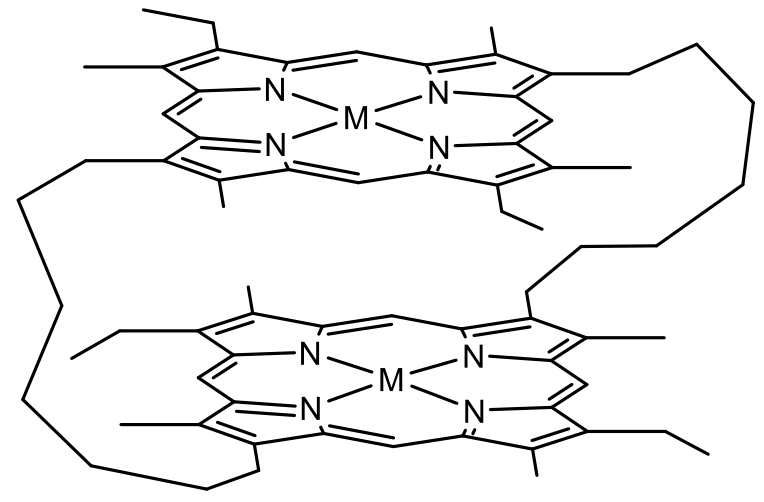

A

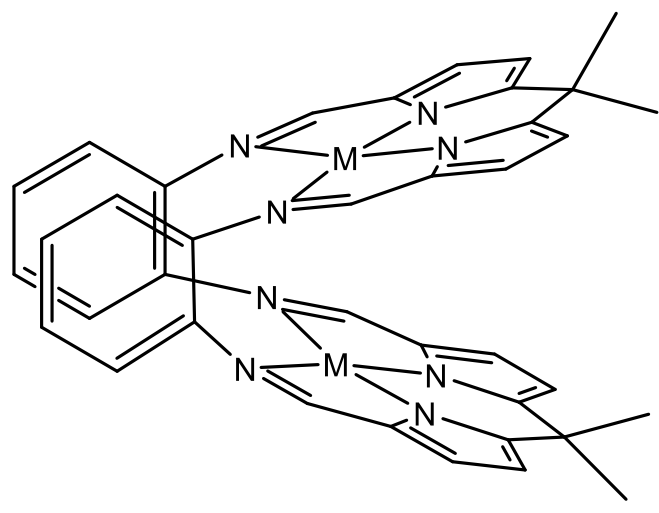

B

Figure 8. A, example of a cofacial porphyrin complex; ${ }^{81} \mathrm{~B}$, example of a Schiffbase calixpyrrole complex. ${ }^{66}$ 


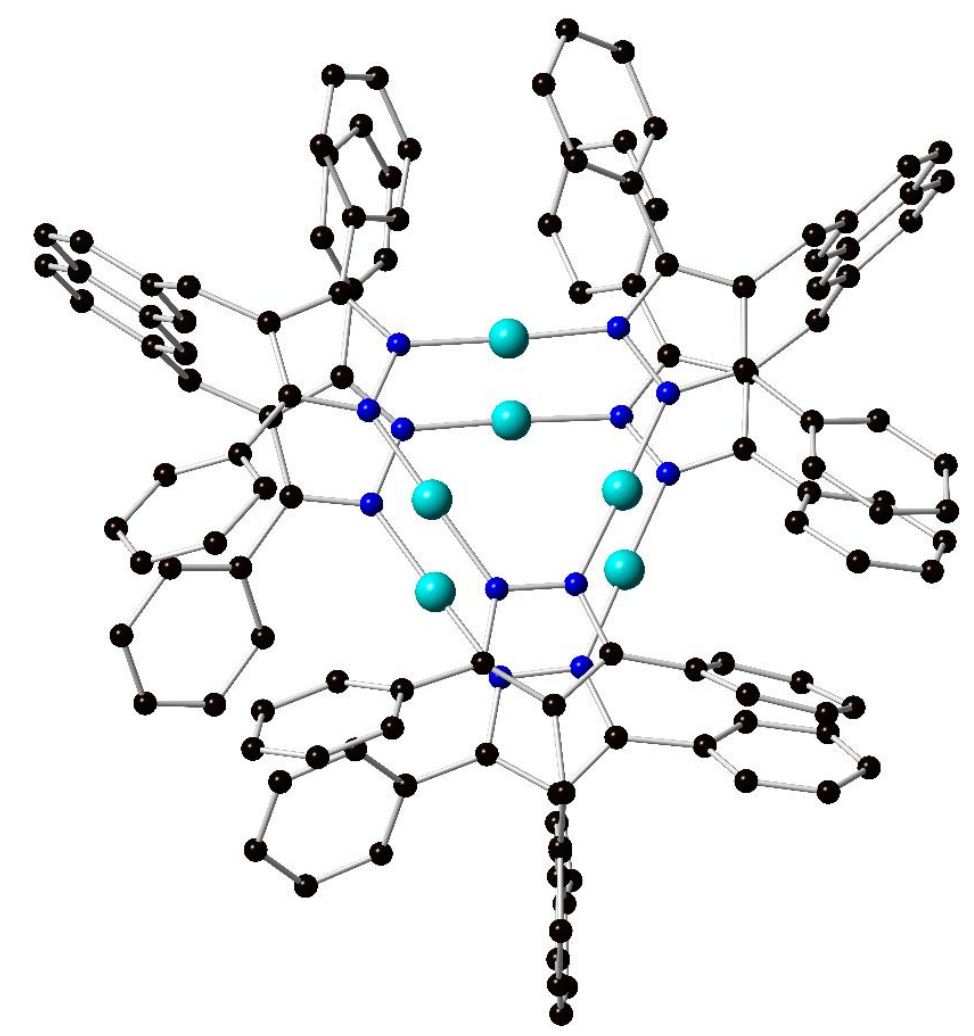

Figure 9. Crystal structure of $\mathrm{Cu}_{6}$ with trinuclear subunits connected by bispyrazoles. ${ }^{84}$ Black, C; Blue, N; Cyan, Cu. Hydrogens omitted for clarity.

\subsection{Coordination Polymer Overview}

First developed in the late 1990 's, ${ }^{85}$ permanently porous coordination polymers (CPs) have attracted a lot of attention for their potential use in various applications.

Coordination polymers generally involve repeating metal centers or clusters held together by organic bridging ligands, although there is no requirement for the compound to have metals or organic linkers. ${ }^{86-88}$ Often coordination polymers will have secondary building units (SBUs) that consist of metal clusters held together with charged bridging ligands to form a well-defined structure. The SBUs are then 
connected by neutral or charged ligands forming a 1D, 2D, or 3D topology. Coordination polymers can theoretically maintain their porosity when guest molecules are removed, making them attractive for gas sorption applications. The stability makes CPs comparable to zeolites. ${ }^{89}$

The SBUs made of metals with well understood chemistry are generally preferred as the pore size can be adjusted by using linkers that are topologically similar, but of varying lengths to form isoreticular CPs. However, the coordination and overall topology of a coordination polymer may be affected by the conditions under which the synthesis was performed, including temperature, solvent, and concentrations. ${ }^{89}$

Specifically, trinuclear copper SBU based CPs have been shown to be effective catalysts (e.g., for waste water treatment), ${ }^{90-92}$ magnetic materials, ${ }^{91,92}$ semiconductors, ${ }^{90,92}$ cathode/anode materials for rechargeable batteries, and be useful for selective gas sorption. ${ }^{90,93}$

\subsection{Brief Overview of Pyrazolate Coordination Chemistry}

Pyrazoles $(\mathrm{pzH})$ and pyrazolates $\left(\mathrm{pz}^{-}\right)$have rich coordination chemistry. Pyrazoles are monodentate while pyrazolates have a wide variety of coordination modes available (Scheme 4), ${ }^{94}$ although only a few are commonly found (e.g., $\mathrm{K}^{1}, \mathrm{~K}^{2}$, $\left.\mathrm{K}^{1}: \mathrm{K}^{1}-\mu\right)$ with the other coordination modes are restricted to more exotic reaction conditions. In copper chemistry, the $\mathrm{K}^{1}: \mathrm{K}^{1}-\mu$ coordination mode features prominently in many compounds. The $\mathrm{K}^{1}: \mathrm{K}^{1}-\mu$ coordination mode allows for the 
formation of triangular complexes as the bite angle between the two nitrogen atoms is $60^{\circ}$. The angle is similar to carboxylate ligands, but pyrazolates are less labile than carboxylates, allowing for reversible redox processes. There are also fewer atoms between the metal centers with pyrazolate ligands $(\mathrm{N}-\mathrm{N})$ compared with carboxylates (O-C-O), which allows for greater electronic and magnetic communication between the metal centers. Pyrazoles can also be functionalized at the 3,4 , and 5 positions, allowing control of electronic and steric properties, in turn enabling metal pyrazolate complexes to be modified in such a way as to preferentially favor particular geometries, nuclearities, and electrochemical properties. ${ }^{94-96}$ 

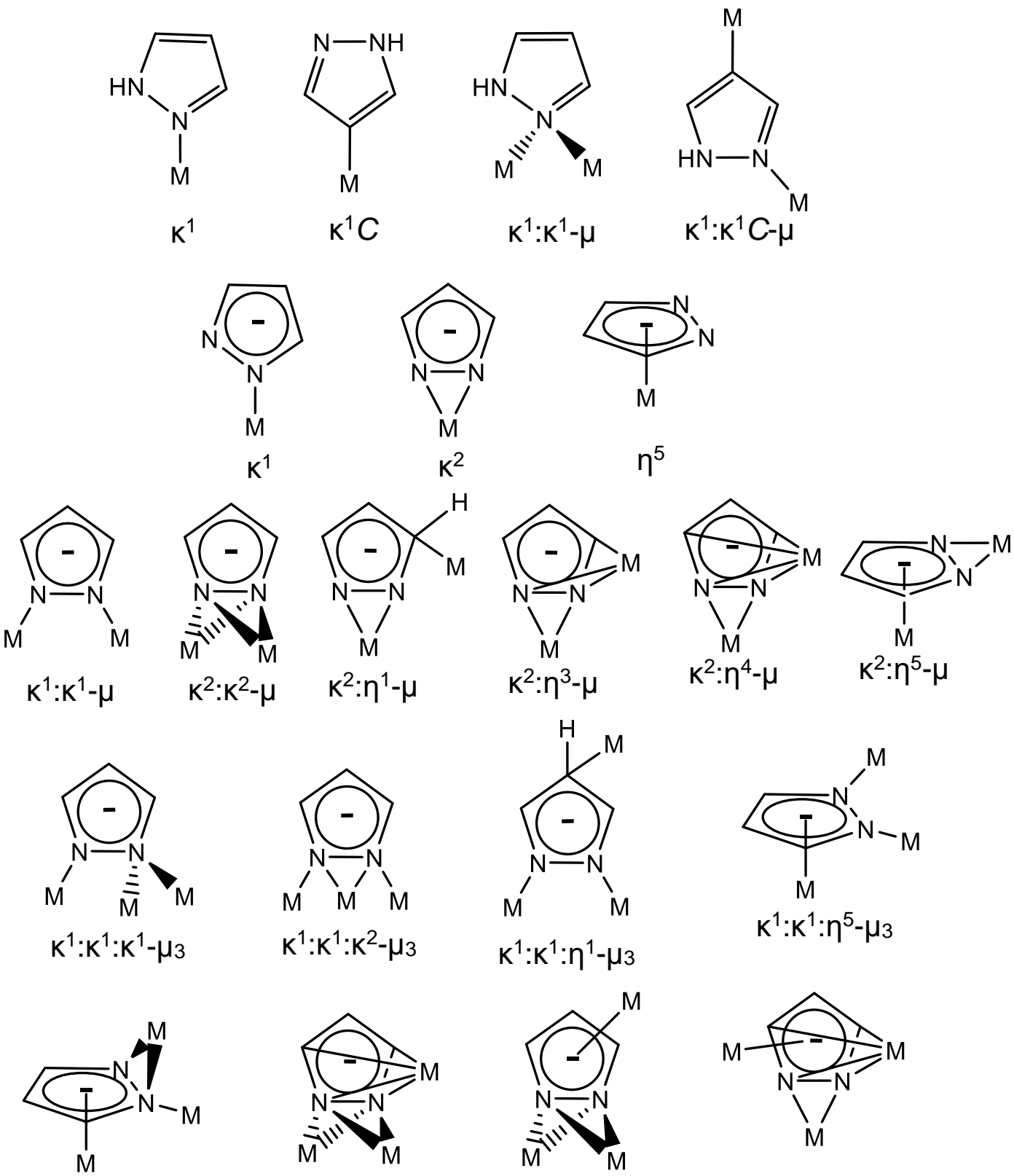

$$
\mathrm{K}^{1}: \mathrm{k}^{2}: \eta^{5}-\mu_{3}
$$$$
\kappa^{2}: k^{2}: \eta^{4}-\mu_{3}
$$$$
k^{2}: k^{2}: \eta^{5}-\mu_{3}
$$$$
\kappa^{2}: \eta^{4}: \eta^{5}-\mu_{3}
$$

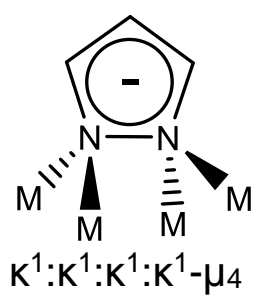

Scheme 4. Different coordination modes of pyrazoles and pyrazolates. ${ }^{90}$ 


\subsection{Objectives and Hypotheses:}

The conversion of water to dioxygen is a four-electron process that requires two oxygens being brought into close proximity. Hexanuclear copper pyrazolato complexes consist of two triangular subunits assembled from three copper atoms and three pyrazolates with a central $\mu_{3}-\mathrm{O}^{2-}$ ligand (Figure 10). The subunits are held together by three bridging pyrazolates that place the $\mu_{3}-\mathrm{O}$ atoms $\sim 3.5 \AA$ apart with little coercion. If these atoms were brought closer and the O-pzorbitals start to overlap, upon oxidation, it may be possible to form a formal bond (Scheme 5). Once this two-electron process is complete, the $\mu 6$-dioxygen ligand would have to be released, at which point the $\mathrm{O}_{2}{ }^{2-}$ would easily lose two more electrons to the surrounding environment to yield an $\mathrm{O}_{2}$ molecule, or disproportionate into $\mathrm{O}_{2}$ and $2 \mathrm{O}^{2-}$.

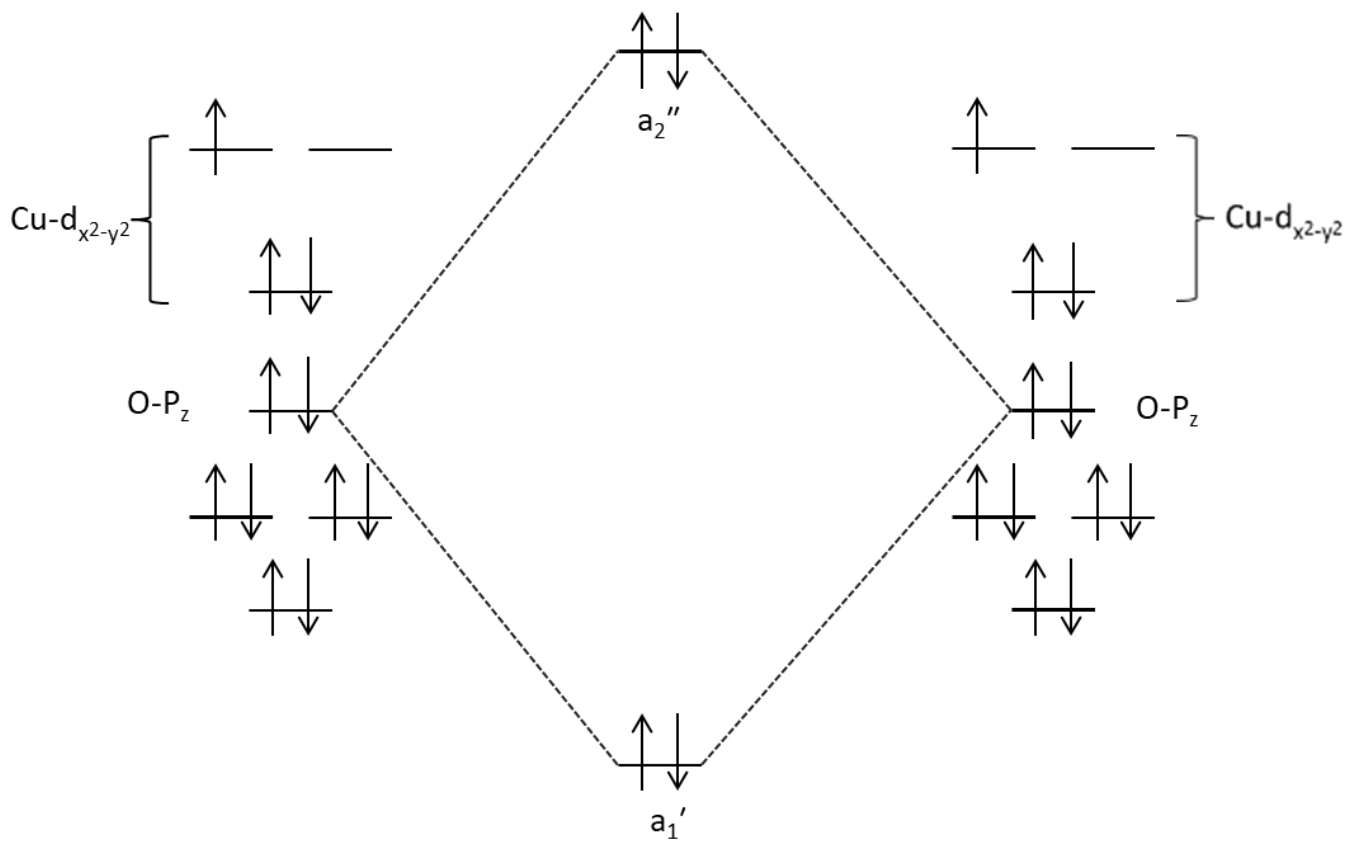

Scheme 5. Qualitative molecular orbital diagram if the O- $p_{z}$ orbital overlaps and oxidation was centered on the $\mu_{3}-\mathrm{O}$ ligands. 


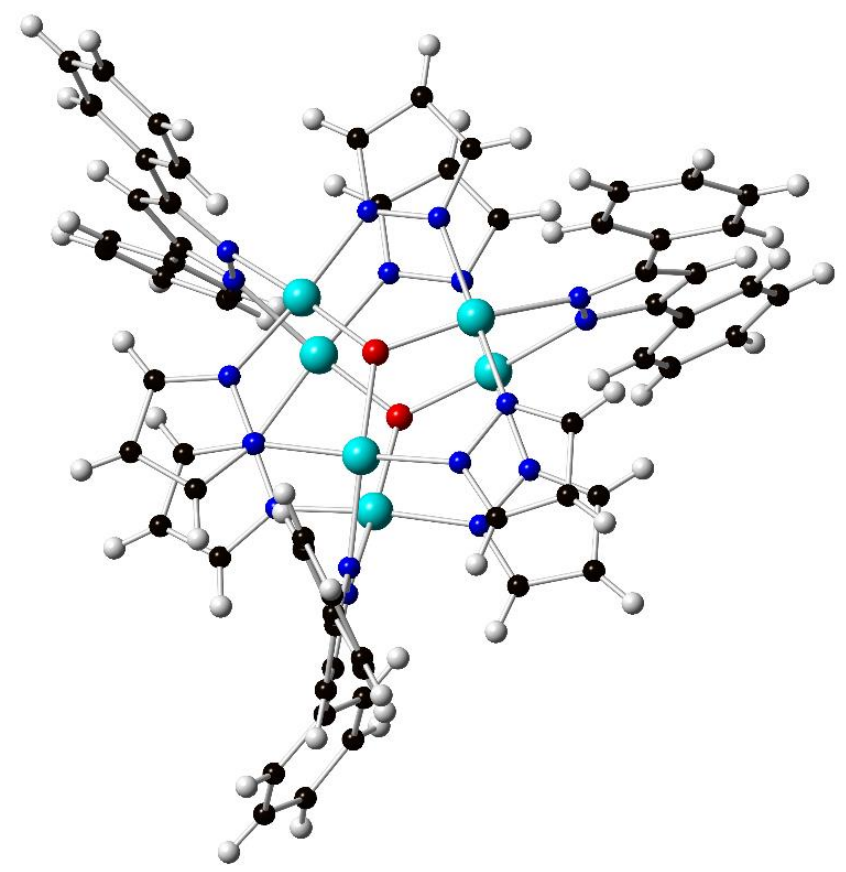

Figure 10 Archetypal hexanuclear copper pyrazolate. ${ }^{49}$ Black, C; whie, $\mathrm{H}$; red, O; blue, N; cyan, Cu. Anions are omitted for clarity.

With the goal to enable $\mathrm{Cu}_{6}$ motifs to function as catalysts, several aspects of these compounds must be explored or modified:

1) Obtain evidence that the oxidation processes of the $\mathrm{Cu}_{6}$ motif could be $\mu_{3}-\mathrm{O}$ centered.

Currently, it is known that the Cu6-pyrazolato complex has two redox processes, which have been shown to lead to an IVCT band, meaning that the electrons are delocalized over the $\mathrm{Cu}$ atoms. However, if these processes remain Cu-centered even if the $\mu_{3}-\mathrm{O}$ ligands were brought close enough together to facilitate the O-pz orbital overlap (Scheme 5), no bond will form if the electrons are lost preferentially from the $\mathrm{Cu}$ centers. That is 
why it is of utmost importance to isolate the oxidized $\mathrm{Cu}_{6}$ and characterize it by single-crystal X-ray diffraction, magnetic susceptibility, K- and L-edge absorption, and NMR to determine if there is any indication that an $\mathrm{O}-\mathrm{O}$ bond could form.

2) Bring the $\mu_{3}-O$ ligands closer together to facilitate $O-p_{z}$ overlap which will allow for a formal O-O bond to form upon oxidation.

Overlap of the $\mathrm{O}-\mathrm{p}_{z}$ orbitals can be accomplished by allowing the $\mathrm{Cu}_{3}$ subunits to rotate into a staggered position. Currently, the Cu6 motifs in the literature are held together by rigid linkers that keep the $\mathrm{Cu}$ atoms in an eclipsed position. As the $\mathrm{Cu}$ atoms are larger than the central $\mu_{3}-\mathrm{O}$ ligand, they prevent sufficient overlap of the O- $\mathrm{p}_{z}$ orbitals to make a formal bond upon oxidation. Thus, it is necessary to employ flexible ligands (Scheme 6) to allow for the $\mathrm{Cu}$ atoms to rotate into a staggered position, thereby bringing the $\mathrm{O}$ atoms closer and facilitating the $\mathrm{O}-\mathrm{p}_{z}$ overlap, which is similar to a compound Raptis has already reported. ${ }^{84}$
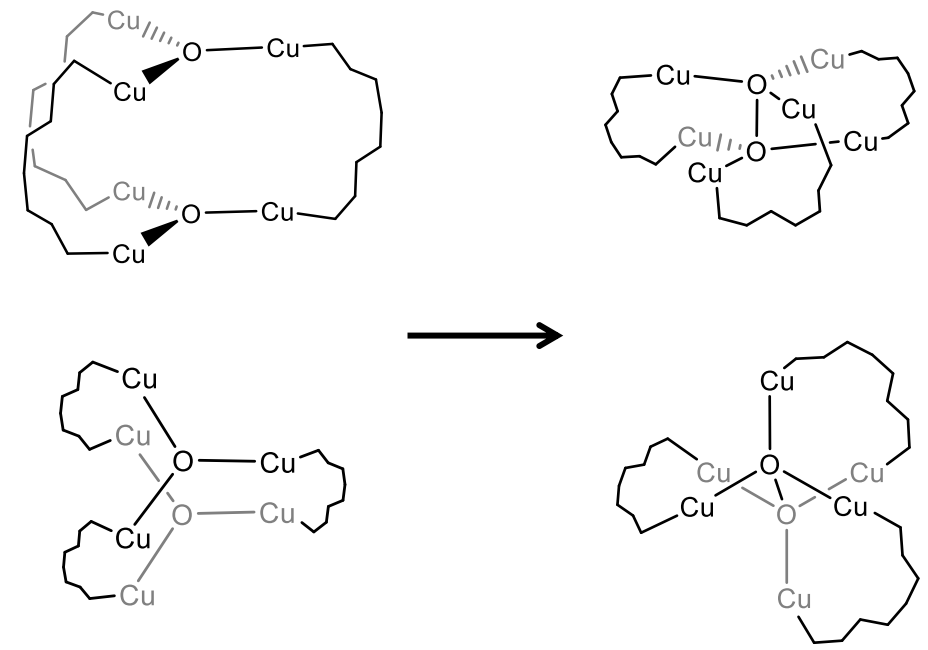

Scheme 6. Qualitative example of the rotation flexible ligands would facilitate. 
While this particular goal eluded this study, three new coordination polymers were synthesized, two with unique topologies, so it was decided to pursue studies on them.

3) Synthesize "open-cage" Cu6 Motifs.

In the literature, all $\mathrm{Cu}_{6}$ motifs are fully enclosed with three bridging ligands.

If a formal O-O could be achieved, the $\mathrm{O}_{2}{ }^{2-}$ ion would have to be released from the $\mathrm{Cu}_{6}$ motif. To facilitate this, an open cage would present an easy route for the $\mathrm{O}_{2}{ }^{2-}$ ion to be released (Scheme 7). Furthermore, this open cage motif would be structurally similar to the Pacman complexes which have been shown to catalytically facilitate $\mathrm{O}_{2}$ reduction.

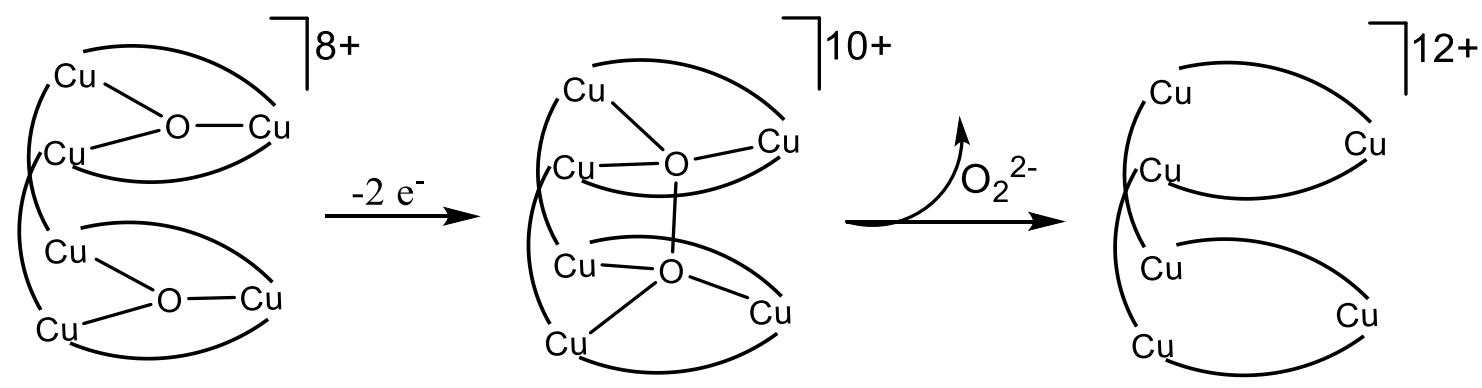

Scheme 7. Qualitative example of $\mathrm{O}_{2}{ }^{2-}$ release from an open cage. Charges only account for $\mathrm{Cu}$ and $\mathrm{O}$ atoms 


\section{Chapter 2 : Mixed-Valent $\mathrm{Cu}_{6}$-Pyrazolato Complex as a Candidate for Water Oxidation}

\subsection{Introduction}

One of the major challenges facing humanity in recent years the identification of candidate compounds that can convert water to hydrogen and oxygen for use as an energy source. Existing technology is either energetically or economically unfeasible. ${ }^{1}$ For example, fuel cells can execute water oxidation, but they require an exorbitant amount of energy to do so. There are plenty of water oxidation catalysts containing precious elements, such as ruthenium or iridium, but their practical applicability is limited by their cost. Scientists have been searching for an ideal compound for water oxidation, preferably using first row transition metals, such as cobalt, manganese or iron, and to lesser extent, copper, nickel, and titanium. ${ }^{11,19,97,98}$ Whereas, there are various examples of water oxidation catalysts in the literature, there is room for improvement: With the highest TON of 15,000 , for Mn based catalyst, ${ }^{99}$ and highest TOF of $1400 \mathrm{~s}^{-1}$, for a cobalt complex, ${ }^{100}$ both requiring an overpotential too great for mass commercial adoption or become easily poisoned.

We turned to copper as the metal of choice for water oxidation because of the following reasons: its versatile coordination geometry, tunable redox-potential defined by its coordination environment and above all, the ease with which one can obtain copper. Copper is virtually everywhere, and if we can repurpose copper from wires into a water oxidation catalyst, it is going to be a great achievement. 
Copper(II) is also present in the active sites of many enzymes that catalyze energy intensive reactions, such as methane oxidation to methanol in multicopper oxidases, some examples of these enzymes are tyrosinase and ascorbate oxidase..$^{29,30,33,35} \mathrm{~A}$ common feature in several of the Cu-containing enzymes is the presence of a multicopper center carrying out the electron transfer process in an efficient manner.

In addition to the literature examples of polynuclear $\mathrm{Cu}$ complexes with reversible redox processes, ${ }^{14,101-109}$ we have had a hand at a series of trinuclear $\mathrm{Cu}$ pyrazolato complexes that undergo a reversible one-electron oxidation process..$^{48,50}$ The redox processes are achieved at a relatively low potential and can be modified by the substitution of the pyrazolate ligands. ${ }^{50}$ Additionally, we have reported the synthesis, electronic structure, magnetic properties, and redox processes of several hexanuclear trigonal prismatic $\mathrm{Cu}_{6}$-pyrazolato complexes earlier. ${ }^{48,49}$ The Cu6-pyrazolato complexes display two step-wise, one-electron redox processes. ${ }^{48}$ It was also envisaged that, upon oxidation, depending on the substitution on the pyrazolato groups, it may be possible to transfer the oxidation from $\mathrm{Cu}$-centers to the oxygen atoms to promote the formation of a favorable $\mathrm{O} \cdots \mathrm{O}$ interaction. In this paper, we present for the first time, structural and spectroscopic characterization of a mixed-valent (MV) hexanuclear complex where the oxidation has been predominantly centered on the Cu-centers. However, there is also some shortening of $\mathrm{O} \cdots \mathrm{O}$ distance compared to its homovalent $(\mathrm{HV})$ analog and 
increased spin density on the $\mu_{3}-\mathrm{O}$ atoms. $\mathrm{Cu}$ K-edge X-ray absorption spectroscopy provides support for Cu-based oxidation.

\subsection{Experimental}

\subsubsection{Materials and Methods}

All commercially available reagents were used as received. Solvents were purified by standard purification procedures. PPN[1] was synthesized by following the previously reported procedure. ${ }^{49}$

\subsubsection{UV-vis-NIR}

The UV-vis-NIR spectra were recorded on an Agilent 5000 spectrophotometer in a quartz cuvette and dichloromethane solution.

\subsubsection{Infrared Spectroscopy}

The IR spectra were recorded on Agilent Technologies Cary 600 Series FTIR spectrometer. The sample was mixed with Csl at an approximately 1:10 ratio ground into a powder and pressed into a pellet.

\subsubsection{Single-Crystal X-ray Diffractometry}

Single crystals of the compounds were mounted on a Mitegen ${ }^{\circledR}$ Cryoloop ${ }^{\text {TM }}$ using Parabar $^{\mathrm{TM}}$ oil and diffraction data were collected on a Bruker D8 Quest diffractometer equipped with a Photon 100 CMOS using Mo-Ka radiation. Data were collected using APEX 3; structure solution was obtained using intrinsic phasing with SHELXT. ${ }^{110}$ Data were refined by least-square methods available within SHELXL ${ }^{111}$ using the Olex2 interface. ${ }^{112}$ 


\subsubsection{X-ray Absorption Spectroscopy}

The Cu K-edge X-ray absorption spectroscopy experiments were performed on beamline 6-2 at and Cu L-edge absorption spectroscopy on beamline 8-2 at Stanford Synchrotron Radiation Lightsource in Stanford, CA. The beamline was equipped with $\mathrm{Si}(111)$ double crystal monochromator. The sample data were internally calibrated using a Cu foil edge with the first inflection point assigned to $8980.3 \mathrm{eV}$.

\subsubsection{Synthesis of [1]}

To synthesize [1], PPN[1-] $(0.025 \mathrm{mmol}, 25 \mathrm{mg})$ and benzoyl peroxide $(0.0125$ mmol, $7 \mathrm{mg}$ ) were mixed in $5 \mathrm{~mL} \mathrm{CH}_{2} \mathrm{Cl}_{2}$ at room temperature for 3 hours. The reaction mixture was filtered through celite and condensed to dryness. The resulting solid was washed with cold methanol to remove excess benzoyl peroxide and the PPN-benzoate salt that was generated during the reaction. X-ray quality single crystals of [1] were obtained after one week by slow evaporation from an NMR tube. Crystalline yield $29.5 \%$.

\subsection{Results and Discussion}

\subsubsection{Synthesis}

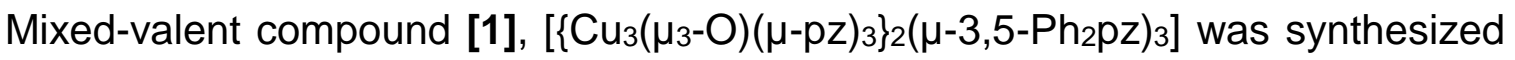
from reacting the previously reported $^{49}$ PPN[1-], where PPN = bis(triphenylphosphoranilydinium), $\left[\mathrm{Ph}{ }_{3} \mathrm{P}=\mathrm{N}=\mathrm{PPh}_{3}\right]^{+}$and $\mathrm{pz}$ is pyrazolato anion $\left(\mathrm{C}_{3} \mathrm{H}_{3} \mathrm{~N}_{2}\right)^{-}$. The oxidation was effectively performed by oxidative equivalents of $(\mathrm{NH} 4)_{2}\left[\mathrm{Ce}\left(\mathrm{NO}_{3}\right)_{6}\right], \mathrm{H}_{2} \mathrm{O}_{2}, \mathrm{PhIO}$ or benzoyl peroxide. X-ray quality single crystals 
were obtained from the reaction of PPN[1-] and 0.7 eq. benzoyl peroxide in $\mathrm{CH}_{2} \mathrm{Cl}_{2}$. [1] is relatively stable at room temperature but decomposes slowly to the parent [1] or to various $\mathrm{Cu}_{3}$ compounds. When more than 2 eq. of oxidizing reagent is used, [1] decomposes.

\subsubsection{UV-vis-NIR absorption Spectroscopy and UV-vis-NIR Spectroelectrochemistry}

The UV-vis-NIR spectroelectrochemistry helped confirm that complexes are indeed mixed-valent as [1] and [1+] showed IVCT bands (Figure 11, 9700 and $10100 \mathrm{~cm}^{-1}$ for [1] and [1+], respectively) $\sim 400 \mathrm{~cm}^{-1}$ away from each other. The presence of IVCT bands indicates that a valence-trapped situation in [1] or [1] ${ }^{+}$ does not exist in the electronic spectroscopy time-scale $\left(10^{-15} s\right)$. A $\Gamma$ value of $\sim 0.45$ for both [1] and [1+] (determined by equation 4) suggests that the system at hand is a weakly coupled delocalized system, pertaining to Robin-Day Class II $(0<\Gamma<0.5) .{ }^{56} H_{a b}$ value for [1] was calculated to be $4600 \mathrm{~cm}^{-1}$ using (equation 5) with the $r_{\mathrm{ab}}$ of $3.315 \AA$, average intra-trimer $\mathrm{Cu} \cdots \mathrm{Cu}$ distance from the crystal structure of [1].

$$
\Gamma=1-\left(\frac{\Delta v}{\Delta v_{1 / 2}^{0}}\right)
$$

Equation 4

Where $\Delta v$ is the energy of the band maximum and $\Delta v_{1 / 2}^{0}$ is the full width-at-halfheight of the band. 
$H_{a b}=\frac{\mu_{12} \Delta v}{e R}$

Equation 5

Where $H_{a b}$ is the electronic coupling parameter, $\mu_{12}$ is the transition dipole moment of the IVCT band, $\Delta v$ is the energy if the band maximum, $e$ is the electric charge, and $\mathrm{R}$ is the distance $(\AA)$ between the redox centers involved in electron transfer.
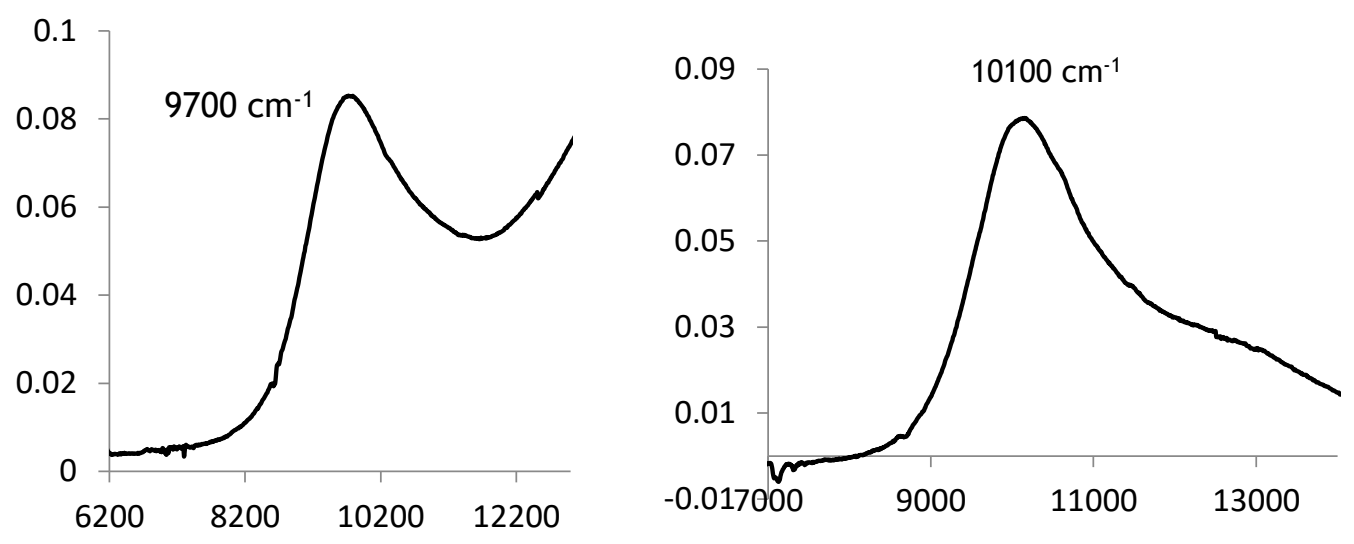

Figure 11. NIR region of the UV-vis-NIR spectra [1] (left) and [1+] (right)

\subsubsection{X-ray Crystallography}

The electrochemical reversibility from their voltammetric study tells us that there is minimal structural alteration upon oxidation of the parent $\mathrm{Cu}_{6}{ }_{6}$ species. Therefore, we attempted to prepare the one- and two-electron oxidized analogues in bulk, chemically, and isolate them. Using 0.7 equivalents of benzoyl peroxide reagent, [1] was generated in solution, as indicated by UV-vis-NIR spectrum. After 3 hours, the reaction mixture was filtered through celite and condensed to dryness. The resulting solid was washed with cold methanol to remove excess benzoyl peroxide 
and PPN-benzoate that was generated during the reaction. X-ray quality single crystals of [1] were obtained by slow evaporation in an NMR tube.

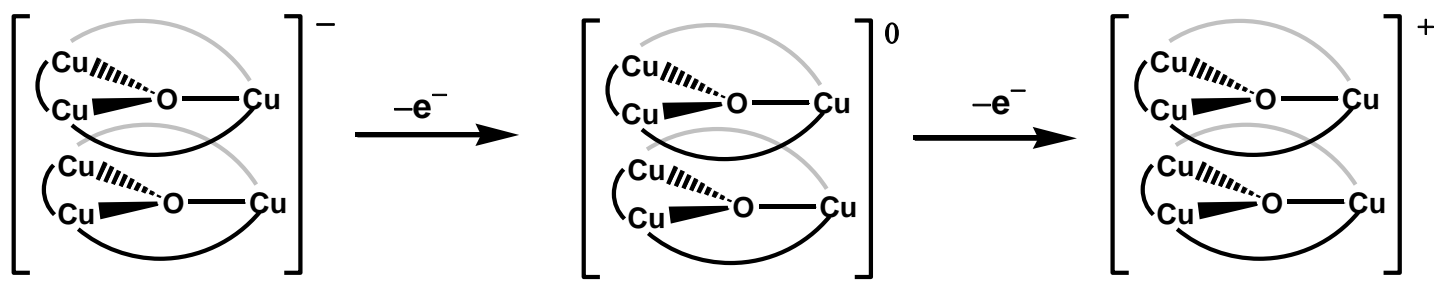

Scheme 8. Stepwise oxidation of PPN[1]

Complex [1] crystallizes in the hexagonal space group $P 6_{3} m$ and the crystallographic data are collected in Table 1 and selected angles and distances in Table 2. The standout difference between the two structures is the $0 \cdots 0$ distance: 3.467(4) $\AA$ in [1-] and 3.17(1) $\AA$ in [1]. The neutral compound has 3-fold symmetry and is reflected in the crystallographic hexagonal symmetry. One sixth of [1] is present in the asymmetric unit. The symmetry is preserved in solution, which is clear from the NMR spectrum (Figure 17). The two $\mathrm{Cu}_{3}$-pyrazolate triangles are arranged in a trigonal prismatic manner by 3,5-diphenylpyrazolato

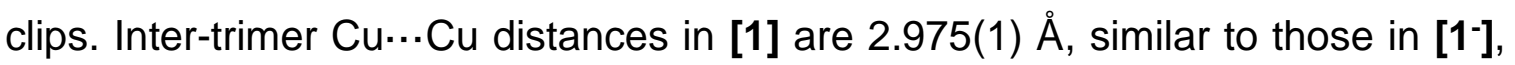
which are $2.975(3)-3.020(3) \AA$. Cu...Cu distances within trimers are slightly longer in [1-]. 
Table 1. Crystallographic Data for [1].

\begin{tabular}{|c|c|}
\hline Identification code & [1] \\
\hline Empirical formula & $\mathrm{C}_{126} \mathrm{H}_{90} \mathrm{Cu}_{12} \mathrm{~N}_{36} \mathrm{O}_{8}$ \\
\hline Formula weight & 2998.93 \\
\hline Temperature/K & 273.15 \\
\hline Crystal size $/ \mathrm{mm}^{3}$ & $0.08 \times 0.037 \times 0.027$ \\
\hline Crystal system & hexagonal \\
\hline Space group & $P 6_{3} / \mathrm{m}$ \\
\hline $\mathrm{a}(\AA)$ & $13.617(2)$ \\
\hline $\mathrm{b}(\AA)$ & $13.617(2)$ \\
\hline$c(\AA)$ & $21.124(4)$ \\
\hline$\alpha\left(^{\circ}\right)$ & 90 \\
\hline$\beta\left(^{\circ}\right)$ & 90 \\
\hline $\mathrm{Y}\left({ }^{\circ}\right)$ & 120 \\
\hline $\mathrm{V}\left(\AA^{3}\right)$ & $3392.1(1)$ \\
\hline Z & 1 \\
\hline$\rho_{\text {calc }}\left(\mathrm{g} / \mathrm{cm}^{3}\right)$ & 1.468 \\
\hline$\mu / \mathrm{mm}^{-1}$ & 1.905 \\
\hline Total data & 63945 \\
\hline Unique Data (Rint) & $2387\left(R_{\text {int }}=0.1340\right)$ \\
\hline $2 \Theta$ range $\left({ }^{\circ}\right)$ & 5.984 to 52.818 \\
\hline Goodness of fit (GOF) & 1.051 \\
\hline $\mathrm{R}_{1} / \mathrm{wR}_{2}(I>2 \sigma(I))$ & $0.0538 / 0.1241$ \\
\hline $\mathrm{R}_{1} / \mathrm{wR}_{2}$ (all data) & $0.0993 / 0.1390$ \\
\hline
\end{tabular}

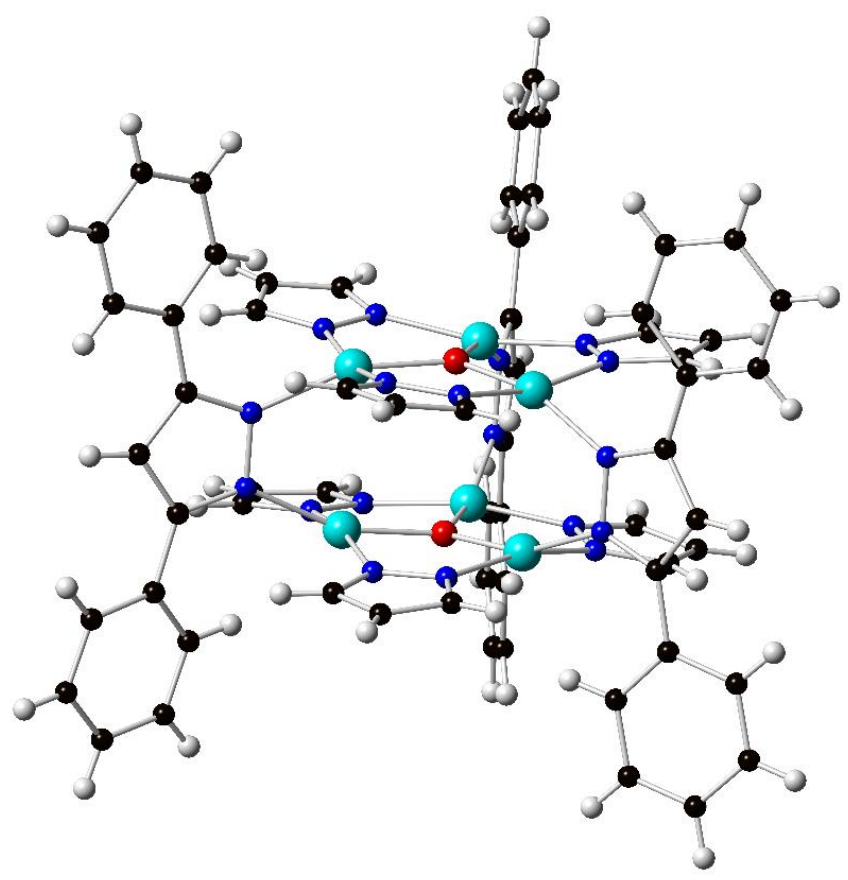

Figure 12. Crystal structure of [1]. Black, C; white, H; blue, N; red, O; cyan, Cu. 
Table 2. Structural parameters between PPN[1] and mixed-valent [1].

\begin{tabular}{|c|c|c|}
\hline & {$[1]\left[\left(\left[\mathrm{Cu}_{6} \mathrm{O}_{2}\right]^{12+}\right), \AA\right.$} & {$[1]\left(\left[\mathrm{Cu}_{6} \mathrm{O}_{2}\right]^{13+}\right), \AA$} \\
\hline $\mathrm{Cu}-\mathrm{O}$ & $1.883(5), 1.894(5), 1.886(5)$, & $1.9001(2)$ \\
\hline & $1.890(5), 1.886(5), 1.883(5)$ & \\
$\mathrm{Cu}-\mathrm{N}_{p z}$ & $\begin{array}{l}1.957(7), 1.964(6), 1.934(6), \\
1.942(6), 1.946(7), 1.949(7),\end{array}$ & $1.9319(2)$ \\
& $\begin{array}{l}1.940(6), 1.943(6), 1.943(6), \\
1.953(6), 1.946(6), 1.949(6)\end{array}$ & \\
\hline $\mathrm{Cu}-\mathrm{N}_{\text {Ph2pz }}$ & $2.020(6), 2.043(7), 2.050(6)$, & $2.0072(2)$ \\
\hline $\mathrm{Cu} \cdots \mathrm{Cu}$ (inter-trimer) & $2.051(6), 2.007(6), 2.026(6)$ & $2.9738(2)$ \\
\hline $\mathrm{Cu} \cdots \mathrm{Cu}$ (intra-trimer) & $3.206(3), 3.263(3), 3.253(3)$, & $3.2868(4)$ \\
\hline $\mathrm{O} \cdots \mathrm{O}$ & $3.213(3), 3.279(3), 3.239(3)$ & $3.1681(6)$ \\
\hline $\mathrm{Cu}-\mathrm{O}-\mathrm{Cu}\left({ }^{\circ}\right)$ & $118.5(3), 116.6(2), 120.3(3)$, & $119.745(9)$ \\
\hline
\end{tabular}

\subsubsection{Cu K-edge X-ray absorption spectroscopy (XAS)}

The K-edge XAS is instrumental in finding the oxidation state of a metal in a complex. Only rarely has the K-edge technique been used to describe highvalency in a multinuclear system. ${ }^{113,114}$ And when it comes to $\mathrm{Cu}$ (III) complexes, only a limited number of examples are available in the literature, ${ }^{113-116}$ where the $\mathrm{K}$-edge spectrum of a mononuclear $\mathrm{Cu}(\mathrm{II})$ complex originally was compared with that of its $\mathrm{Cu}(\mathrm{III})$ congener to determine the characteristic pre-edge energies. ${ }^{113,114}$ The pre-edge energies for the $\mathrm{Cu}(\mathrm{II})$ is at $8979.2 \mathrm{eV}$ whereas that for the $\mathrm{Cu}(\mathrm{III})$ complex is at $8980.2 \mathrm{eV}$. The intensity difference of the pre-edge features shows increased symmetry for $\mathrm{Cu}(\mathrm{III})$ - higher intensity in $\mathrm{Cu}(\mathrm{II})$ results from a greater distortion from the square planar geometry. The K-edge data generated from mixing two dinuclear $\mathrm{Cu}^{\prime \prime} / \mathrm{Cu}^{\prime \prime \prime}$ complexes reproduce that of a mixed-valent dinuclear $\mathrm{Cu}^{\prime \prime} / \mathrm{Cu}^{\text {III }}$ complex well. Isolated $\mathrm{Cu}^{\prime \prime} / \mathrm{Cu}^{\text {III }}$ complexes are distinguished easily by the energy shifts of the pre-edge peaks. ${ }^{113}$ However, the mixed-valent 
complex and the stoichiometric mixture do not show two peaks at 8979 and 8981 eV. Rather, they show a slight shoulder in the pre-edge region. ${ }^{113}$ The second derivatives of the spectra show that the $1 s \rightarrow 4 p+$ shakedown transition is split indicating the $\mathrm{Cu}^{\mathrm{II}}$ and $\mathrm{Cu}^{\mathrm{III}}$ energies at 8985 and $8987 \mathrm{eV}$, respectively.

Unlike previous systems, the ones studied herein comprise the homovalent and the mixed-valent analogue of the $\left[\left\{\mathrm{Cu}_{3}\left(\mu_{3}-\mathrm{O}\right)\right\}_{2}\right]-$ complex. Based on these findings, the K-edge spectra of PPN[1-] (all-Cul) and [1] (formally, $\mathrm{Cu}_{5}{ }_{5} \mathrm{Cu}^{\text {III }}$ or $\mathrm{Cu}_{6}{ }^{13+}$ ) were analyzed. The spectra were recorded on powdered samples at $10-15 \mathrm{~K}$ mounted on an aluminum slit at the Stanford Synchrotron Radiation Laboratory (see Experimental Section). Maintaining the samples at low temperatures prevents photoreduction of the samples in high energy X-rays. The homovalent complex [1-] showed a typical K-edge spectrum with a pre-edge absorption at $8977.5 \mathrm{eV}$ and a peak in the rising edge at $8982 \mathrm{eV}$ (Figure 13). The pre-edge absorption shifts slightly in the mixed-valent complex to $8978.0 \mathrm{eV}$, while the rising edge shifts to 8982.5 . The pre-edge peaks at $8977.5 \mathrm{eV}(\mathrm{HV})$ and $8978.0 \mathrm{eV}(\mathrm{MV})$ can be assigned to $1 \mathrm{~s} \rightarrow 3 \mathrm{~d}$ electronic transition in $\mathrm{Cu} .{ }^{113,114,116}$ The shifts to higher energy for the pre-edge and rising edge absorptions are, presumably, consistent with the higher nuclear charge of the mixed-valent complex. The shifts are only fractional $\left(0.5 \mathrm{eV}, \sim 4000 \mathrm{~cm}^{-1}\right)$, as expected for $\mathrm{a}+0.165$ overall charge difference per $\mathrm{Cu}$ center between the two complexes, which is similar to what is found in the $\left[\mathrm{Cu}_{3}(\mathrm{O})\right]$ system (Figure 14), ${ }^{117}$ and indicates that the charge is localized on one of the two trimers. A trinuclear $\mathrm{Cu}^{\mathrm{III}} \mathrm{Cu}_{2}$ 2 system was analyzed using $\mathrm{K}$-edge XAS and a shift 
of $0.5 \mathrm{eV}$ to higher energy indicates the presence of an additional +0.33 charge on each copper. ${ }^{114}$
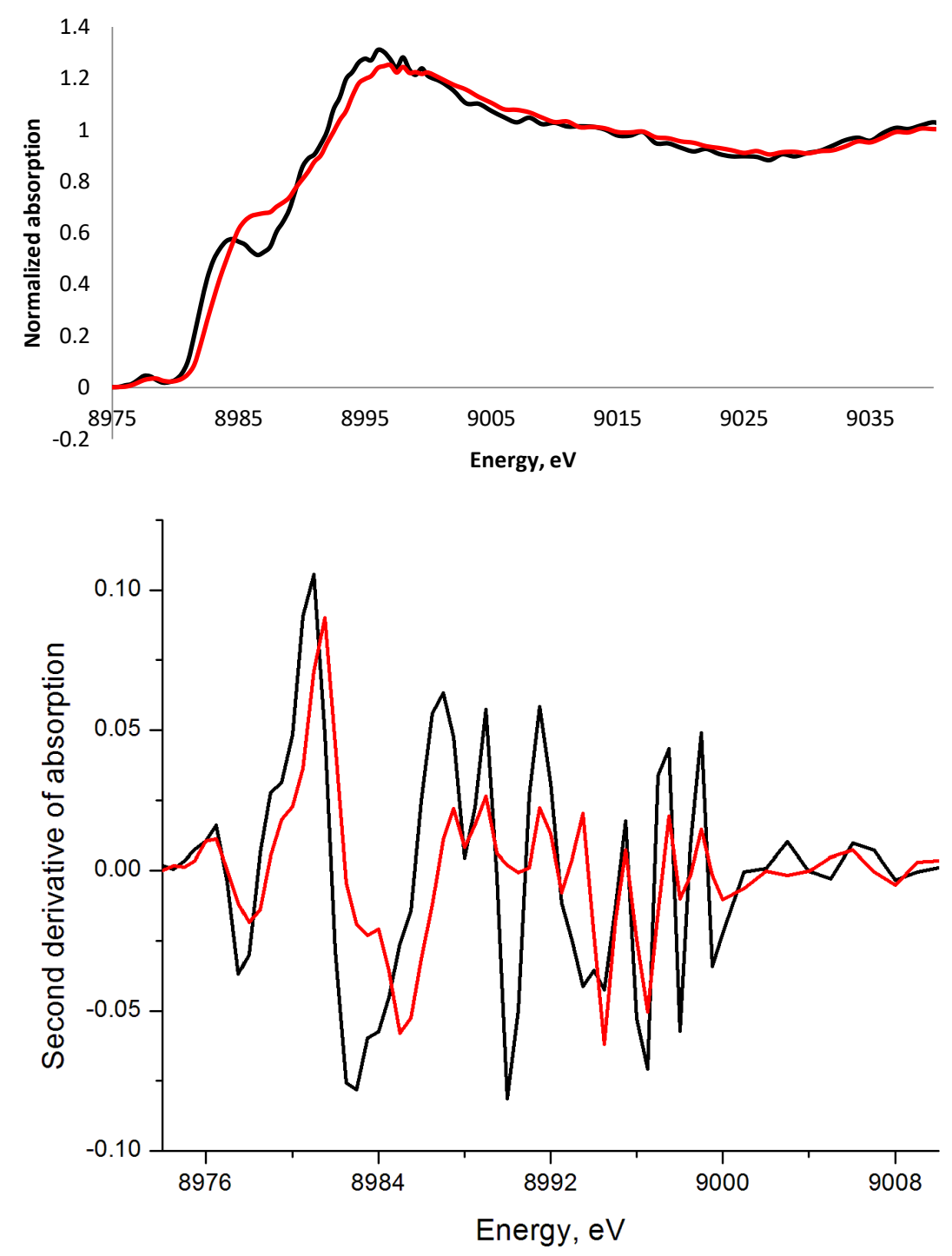

Figure 13. (Top) Cu K-edge X-ray absorption spectrum of [1-] (black) and [1] (red) and the second derivate of the spectra (bottom). 


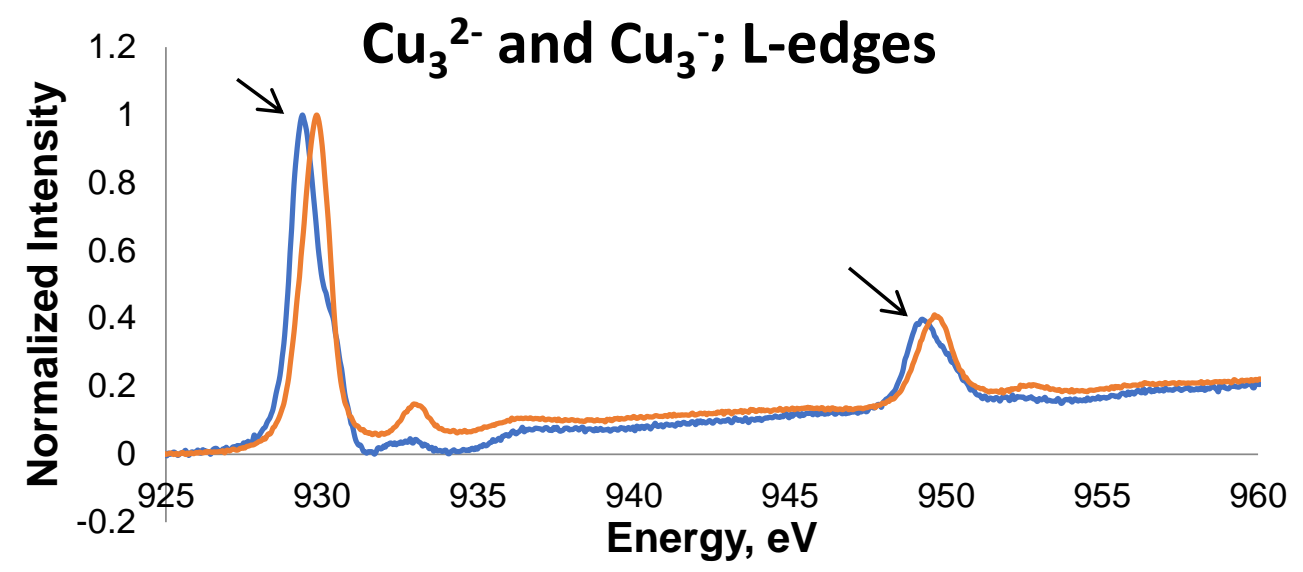

Figure 14. L-edges of $\mathrm{Cu}_{3}{ }^{2-}$ (orange) and $\mathrm{Cu}_{3}{ }^{-}$(blue). ${ }^{117}$

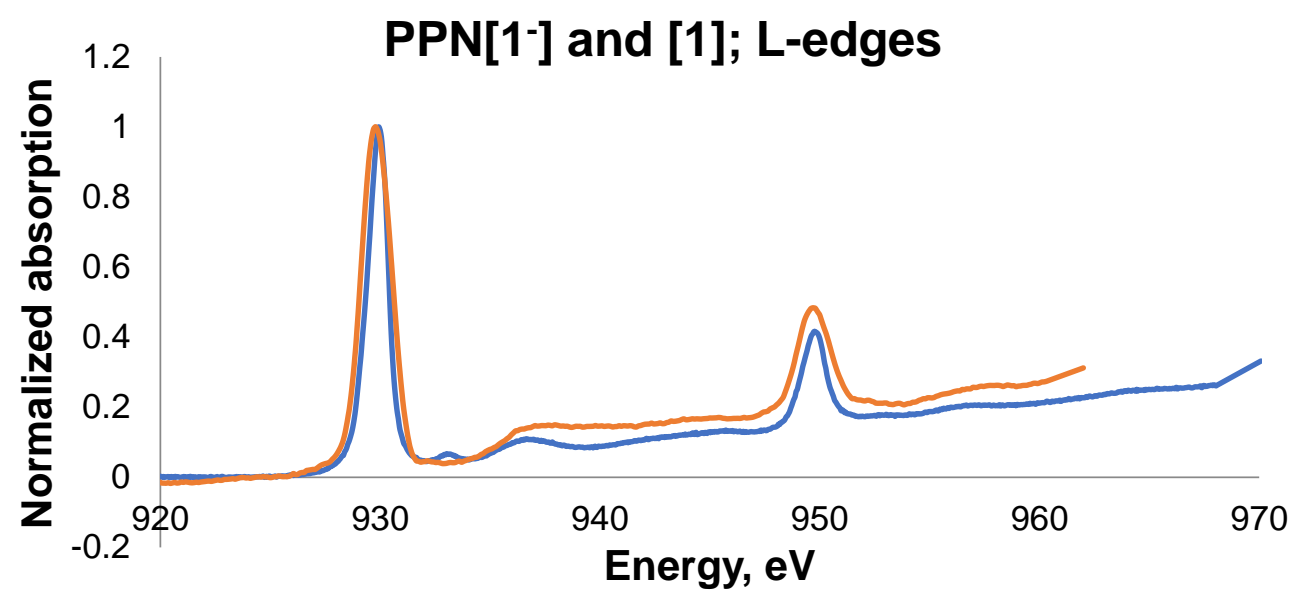

Figure 15. L-edges of PPN[1] (orange) and [1] (blue).

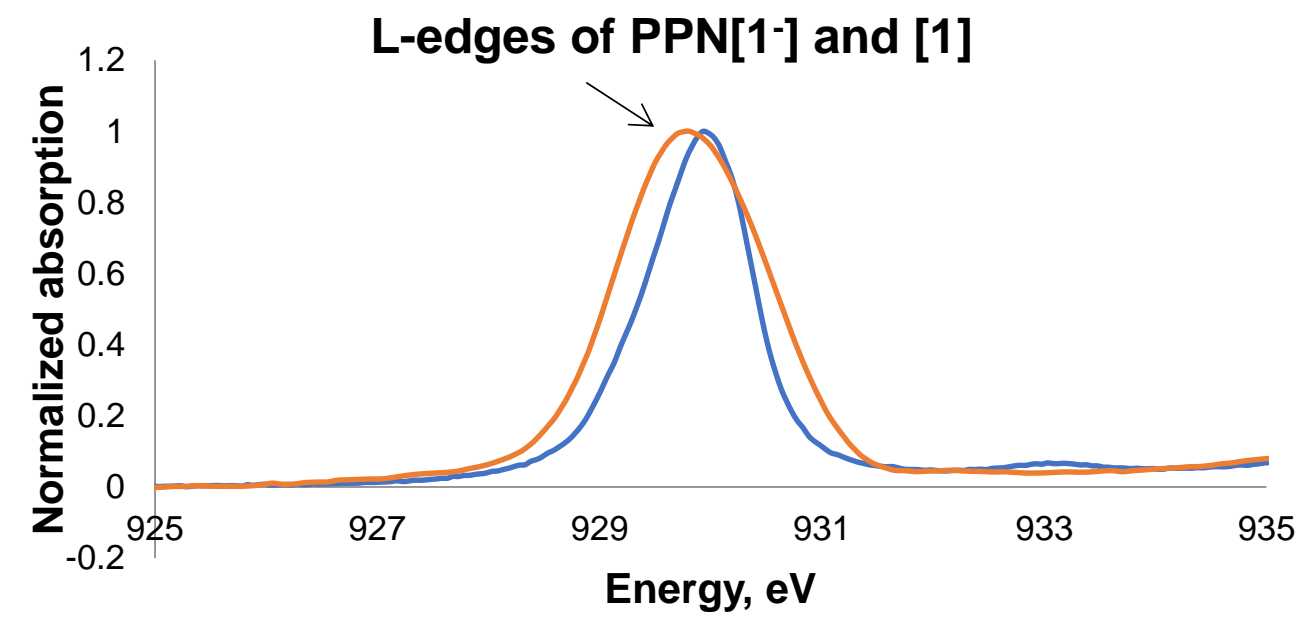

Figure 16. Close-up of shift in L-edges of PPN[1-] (orange) and [1] (blue). 


\subsubsection{NMR}

The NMR of [1] (Figure 17) is vastly different from [1]. The paramagnetic shift of [1] is almost nonexistent, with all of the peaks falling in or near the aromatic region. The peaks do not match the free ligands, indicating that the NMR is indeed of [1]. The NMR spectrum also contain peaks for benzoate/benzoic acid and PPN, as well as minor peaks from unoxidized [1-]. However, the NMR was sufficiently clean to identify the protons corresponding to [1]. The NMR and comparison of the proton signals from [1] and [1] can be seen in Table 3 (labels seen in Scheme 9). The smaller paramagnetic shift indicates the spin density is father away from the protons in [1].

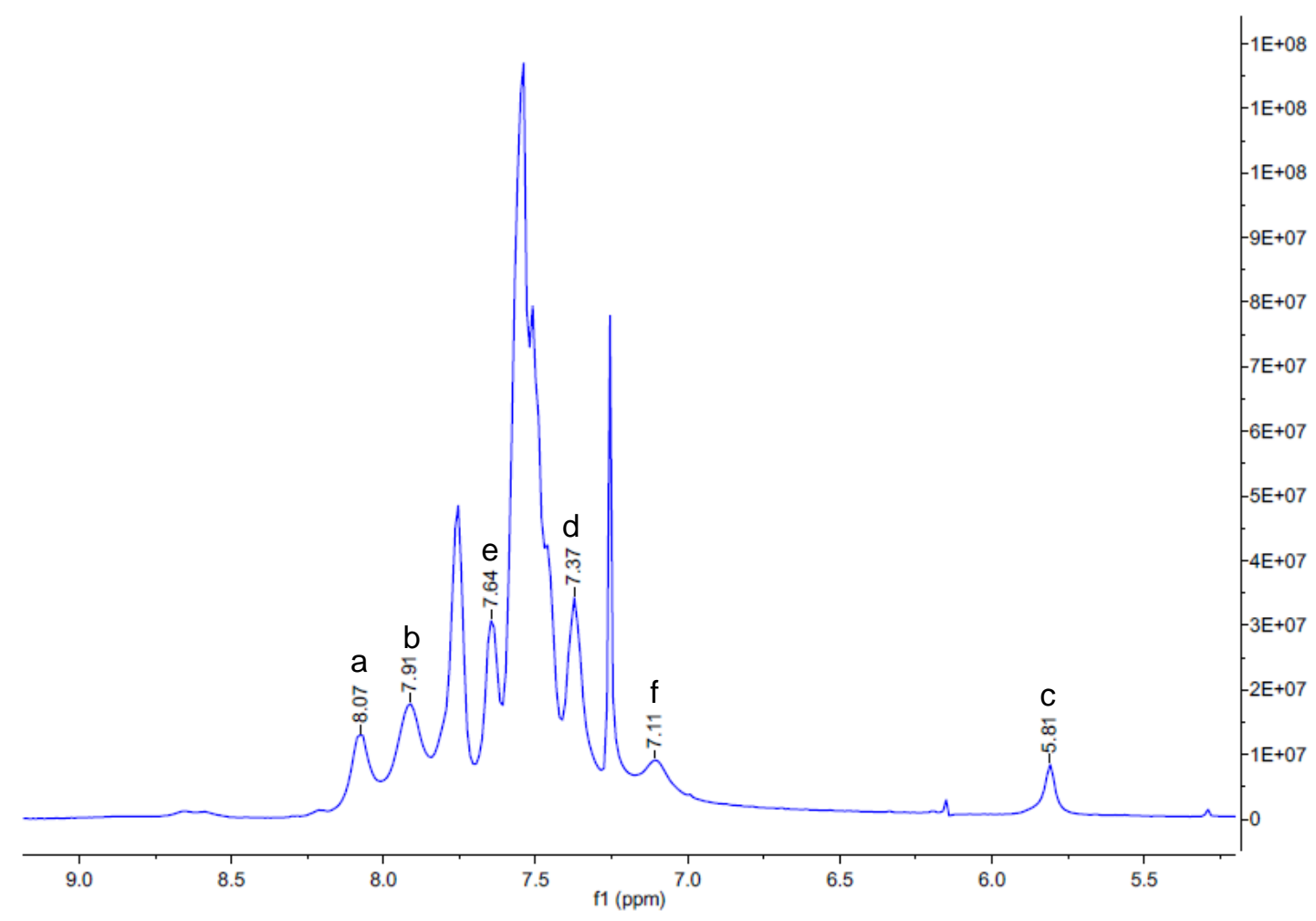

Figure 17. NMR of [1] 


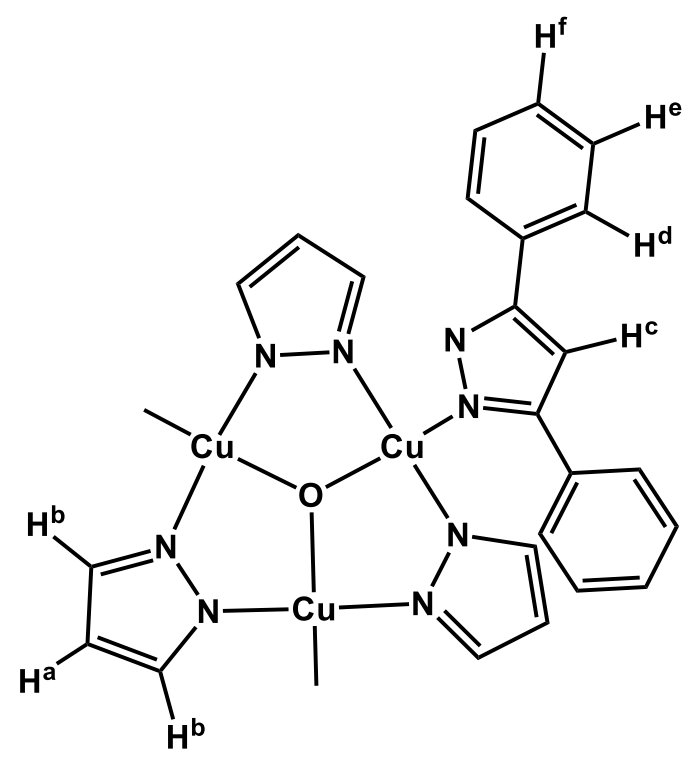

Scheme 9. Proton labels for PPN[1-] and [1]

Table 3. Proton shifts for PPN[1-] and [1]

\begin{tabular}{|c|c|c|c|c|c|c|}
\hline & $\mathrm{H}^{\mathrm{a}}$ & $\mathrm{H}^{\mathrm{b}}$ & $\mathrm{H}^{\mathrm{c}}$ & $\mathrm{H}^{\mathrm{d}}$ & $\mathrm{H}^{\mathrm{e}}$ & $\mathrm{H}^{\dagger}$ \\
\hline PPN[1] & 35.35 & 18.86 & 28.67 & 11.93 & & \\
\hline$[1]$ & 8.07 & 7.91 & 5.81 & 7.37 & 7.64 & 7.11 \\
\hline
\end{tabular}

\subsubsection{Far-IR}

The far-IR (Figure 18) does not show any shift in the $\mathrm{Cu}-\mathrm{O}$ bond absorption. Although, this is not unreasonable. Since the copper atoms of one subunit is only reduced by 0.165 electrons the strength of the $\mathrm{Cu}-\mathrm{O}$ bond will not be very different from PPN[1-]. What can be noted from the IR is the reduction in width of the peaks in the aromatic distortion frequencies, $675-775 \mathrm{~cm}^{-1}$, and shows that the counterions of PPN[1-] are no longer present, indicating that the IR spectrum is, in fact, of [1]. 


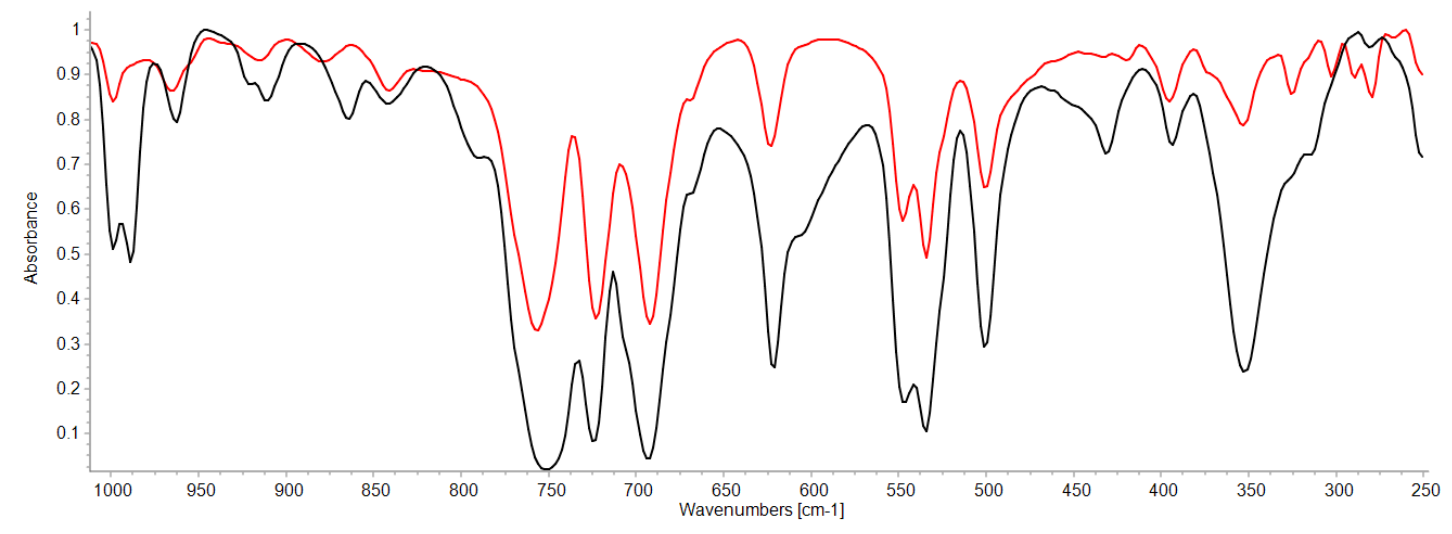

Figure 18. IR and Far IR of PPN[1]] (black) and [1] (red).

\subsection{Conclusions}

Here we present solid evidence that there is a possibility that Cu6-pyrazolato motifs could functional as water oxidation catalysts. The crystal structure the MV-Cu6 compound shows that the distance between the two $\mu_{3}-\mathrm{O}$ ligands is reduced by approximately $0.3 \AA$, to $3.17(1)$. The combined van der Waals radii of the two oxygen atoms 3.04, very close to the crystallographic distance of [1]. The reduction of the $\mathrm{O} \cdots \mathrm{O}$ distance, suggests that upon further oxidation, and perhaps functionalization of the pyrazolates, the $\mathrm{O}$ atoms can be brought close enough for O- $\mathrm{p}_{z}$ overlap to occur. The Cu K-edge XAS indicates that the charge is delocalized among all the $\mathrm{Cu}$ atoms. The NMR shows a remarkedly reduced paramagnetic shift.

Preliminary magnetics and DFT being performs by our collaborators point to an increased spin density on the oxygen ligands (Figure 19). 


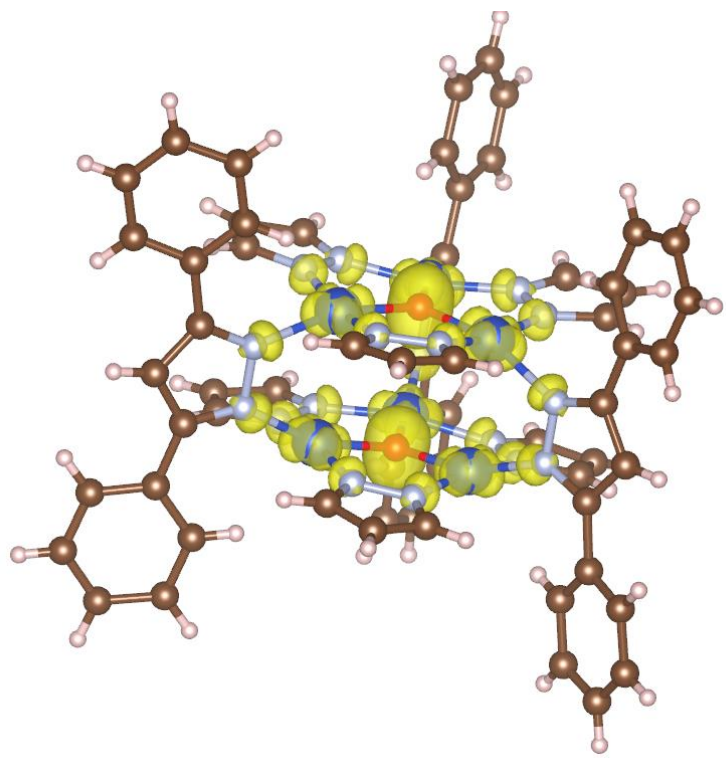

Figure 19. Qualitative map of spin density on [1]. 
Chapter 3 : Coordination polymers based on pyrazole-4-carboxaldehydecontaining $\mathrm{Cu}_{3} \mathrm{~N}_{6}$ metallacycles as building units. ${ }^{118}$

\subsection{Introduction:}

In pursuit of the aim of my research, a flexible motif needed to be synthesized. Therefore, pyrazoles with a formyl group at the 4' position were used to create the $\mathrm{Cu}_{3}$ subunits with the idea of further modification using condensation reactions. The $\mathrm{Cu}_{3}$ subunits with terminal $\mathrm{Cl}^{-}$ligands and an overall $2^{-}$charge were synthesized and isolated. When reacted with $m$-xylene diamine or 1,4diaminobutane, an insoluble powder was obtained. Originally thought to be a polymer, the reaction was repeated by adding the reactants, on a $0.25 \mathrm{mmol}$ scale, dropwise over the course of 4 hours into $500 \mathrm{~mL}$ of DCM to prevent polymerization. The same insoluble powder was obtained, which led to the conclusion that the product may be insoluble because of the overall charge of the resulting product. Thus, a positively charged variation with terminal pyridines and an overall charge of $1^{+}$was seen as a possible solution to the insolubility problem (Scheme 10).

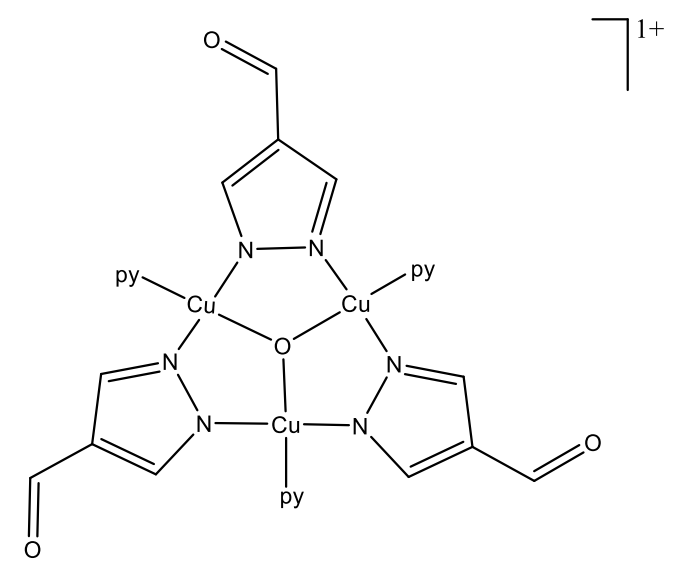

Scheme 10. Proposed trimer with terminal pyridine and an overall charge of $1^{+}$. 
During the crystallization step of the $\mathrm{Cu}_{3}$ subunits, it was discovered that the reaction had led to various coordination polymers. Studies of the polymers were pursued as they were possessed a rare Cu-aldehyde bond. And while the coordination chemistry of carbonyl compounds has been well explored in carboxylic acids, and less frequently in amides, aldehydes seldom feature in coordination complexes, except when completing a chelate bite. For example, pyridine-2-carboxaldehyde is a common chelate, whereas pyridine-bis-2,6carboxaldehyde has been used as a pincer ligand for metals in labile oxidation states. ${ }^{119-123}$ Aromatic aldehydes, e.g., benzaldehyde, tend to form few first row, $\sigma$-bonded coordination complexes, except with $\mathrm{Zn}(\mathrm{II}) .{ }^{120,124-133} \mathrm{In}$ a few cases, aldehydes bind $\mathrm{Zn}(\mathrm{II})$ stronger than some anionic ligands. ${ }^{134,135} \mathrm{~A}$ search in the Cambridge Structural Database for coordinated aldehydes (with $\mathrm{H}$-atoms on $\beta$ carbons) turns up approximately one hundred crystal structures, of which fewer than one half involve first row transition metal complexes with either a $\sigma$ - or $\pi-, \eta^{2}$ bound aldehyde. Some of the frequently encountered $\mathrm{Zn}$-aldehyde complexes have been studied as models of liver alcohol dehydrogenase. ${ }^{136,137}$ Magnetic exchange mediated by bridging, $\sigma-b o u n d-\mathrm{CH}(\mathrm{O})$ groups has been described in a manganese 2D-coordination polymer [O-Mn: $2.197(7) \AA] .{ }^{133}$ To the best of our knowledge, only four coordination polymers containing $\mathrm{CH}(\mathrm{O})$-bound $\mathrm{Cu}$ centers have been reported: Two containing only fairly long $\mathrm{Cu}-\mathrm{O}$ interactions of 2.723(7) $\AA^{120}$ and 2.877(3) $\AA,{ }^{138}$ while significantly shorter Cu-O bonds of $2.296(6) \AA$ and 2.005(4) $\AA$ were measured in the other two. ${ }^{139,140}$ Polynuclear Cu(II)-pyrazolato cluster chemistry is rich with nuclearities ranging from two to $34 .{ }^{141}$ 4-Subsituted 
pyrazolates typically yield trinuclear metallacycles: We and others have published pyrazolato complexes of the general formula $\left[\mathrm{Cu}_{3}\left(\mu_{3}-E\right)(\mu-4-\mathrm{R}-\mathrm{pz})_{3} \mathrm{X}_{3}\right]^{2}$, where $E=$ $\mathrm{O}, \mathrm{OH}, \mathrm{Cl}_{2}, \mathrm{Br}_{2}, \mathrm{OMe}, \mathrm{OEt} ; \mathrm{R}=\mathrm{H}, \mathrm{Cl}, \mathrm{Br}, \mathrm{NO}_{2}, \mathrm{Me}, \mathrm{Ph}, \mathrm{CH}(\mathrm{O}) ; \mathrm{X}=\mathrm{Cl}, \mathrm{Br}, \mathrm{SCN}$, $\mathrm{NO}_{2}, \mathrm{CF}_{3} \mathrm{CO}_{2}, \mathrm{PhCOO}$, py and $\mathrm{z}=1-, 2-, 1+$ or $2+.{ }^{46,142-145}$ The trinuclear subunits can also be strung together as structural building units (SBUs) with suitable linkers to form 1D-chains, 2D-sheets and 3D-lattices. ${ }^{29}$ We have also reported the pyrazole-4-carboxaldehyde-containing, 0D-complex $(\mathrm{PPN})_{3}\left[\mathrm{Cu}_{3}\left(\mu \mu_{3}-\mathrm{O}\right)(\mu-4-\mathrm{CH}(\mathrm{O})\right.$ pz $\left.{ }_{3} \mathrm{Cl}_{3}\right] \mathrm{Cl}^{142}$ Here, we are now showing that, in the absence of other terminal or bridging ligands, 4-CH(O)-pz can be used as a $\mu 3, \eta^{3}$-linker by itself to form extended networks. Specifically, we are reporting three new coordination polymers (CPs), [3] $\left(\mathrm{CF}_{3} \mathrm{SO}_{3}\right)_{2},[4]\left(\mathrm{CF}_{3} \mathrm{SO}_{3}\right)_{2}$ and $[5]\left(\mathrm{ClO}_{4}\right)_{2}$, constructed by assemblies of $\left[\mathrm{Cu}_{3}{ }_{3}(\mu 3-\mathrm{OH})(\mu-4-\mathrm{CH}(\mathrm{O})-\mathrm{pz})_{3}\right]^{2+}$ cations clipped together by short intermolecular $\mathrm{Cu}-(\mathrm{O}) \mathrm{HC}$ bonds, along with the corresponding Cl-terminated $\mathrm{SBU},\left(\mathbf{P h}_{4} \mathbf{P}\right)_{2}[\mathbf{1}]$, and one bipyridine-linked $\left.\mathrm{CP},{ }_{[2]}\right]\left(\mathrm{CF}_{3} \mathrm{SO}_{3}\right)_{2}$. Topological, geometrical and 3Dstructural properties of four extended network compounds are also discussed.

\subsection{Experimental:}

\subsubsection{Materials and Methods}

The $\mathrm{CuCl}_{2} \cdot 2 \mathrm{H}_{2} \mathrm{O}, \mathrm{Cu}\left(\mathrm{ClO}_{4}\right)_{2} \cdot 6 \mathrm{H}_{2} \mathrm{O}$, tetraphenylphosphonium chloride, 1,2bispyridylethylene (1,2-bpe, Acros), $\mathrm{Cu}\left(\mathrm{CF}_{3} \mathrm{SO}_{3}\right)_{2}$ (Alfa-Aesar), and 4$\mathrm{CH}(\mathrm{O})-\mathrm{pzH}$ (Combi Blocks, Inc.) were purchased from commercial sources and used without further purification. Solvents were purified using standard procedures. ${ }^{146}$ All reactions were conducted open to the atmosphere. 


\subsubsection{X-ray Crystallography}

Single crystals of the compounds were mounted on a MiteGen $\AA^{\circledR}$ CryoLoop ${ }^{\mathrm{TM}}$ or on a glass fiber and diffraction data were collected on a Bruker D8 Quest diffractometer equipped with a Photon 100 CMOS or a Bruker APEX II diffractometer with a SMART detector using Mo-Ka radiation. Data were collected using APEX 3 or APEX 2 suite; structure solution was obtained using intrinsic phasing with SHELXT. ${ }^{110}$ Data were refined by least-square methods available within SHELXL ${ }^{111}$ using the Olex2 interface. ${ }^{112}$ Electron densities corresponding to disordered interstitial solvent molecules were accounted for by using the MASK routine available within Olex2.

\subsubsection{X-ray Powder Diffraction}

Powders of samples were loaded in a capillary and mounted on the Bruker D8 Quest diffractometer and $360^{\circ}$ phi-scan images were collected. The scans were integrated using Fit2D to obtain powder patterns. ${ }^{33,34}$

\subsubsection{Topology}

Topological analysis was performed with the ToposPro program package and the TTD collection of periodic network topologies. ${ }^{147}$

\subsubsection{Void Volume}

Solvent accessible void volume for $[2]\left(\mathrm{CF}_{3} \mathrm{SO}_{3}\right)_{2}, \quad[4]\left(\mathrm{CF}_{3} \mathrm{SO}_{3}\right)_{2}$ and $[5]\left(\mathrm{ClO}_{4}\right)_{2}$ was calculated using Mercury program package. ${ }^{148}$ 


\subsubsection{IR data}

The FT-IR data were collected using an Agilent Technologies Cary 600 Series FT-IR spectrometer with 16 scans from $4000-500 \mathrm{~cm}^{-1}$. Data were analyzed using Spectragryph 1.2.10 software. ${ }^{149}$ Powdered samples were placed on the ATR stage and data were collected, then minimal acetonitrile was added to dissolve the compounds and data were collected from the resulting solutions.

\subsubsection{Thermogravimetric Analysis}

The TGA was performed with a TA instruments SDT Q600 from RT to 900 ${ }^{\circ} \mathrm{C}$ at a heating rate of $5^{\circ} \mathrm{C} / \mathrm{min}$ with $\mathrm{He}$ as the carrier gas.

\subsection{Synthesis}

\subsection{1. $\left(\mathrm{Ph}_{4} \mathrm{P}\right)_{2}\left[\mathrm{Cu}_{3}\left(\mu_{3}-\mathrm{O}\right)(\mu-4-\mathrm{CH}(\mathrm{O})-\mathrm{pz})_{3} \mathrm{Cl}_{3}\right],\left(\mathrm{Ph}_{4} \mathrm{P}\right)_{2}[1]$}

To Synthesize ( $\left.\mathbf{P h}_{4} \mathbf{P}\right)_{2}[1]$, $\mathrm{CuCl}_{2} \cdot 2 \mathrm{H}_{2} \mathrm{O}(1 \mathrm{mmol}, 170.5 \mathrm{mg}), 4-\mathrm{CH}(\mathrm{O})-\mathrm{pzH}(1$ mmol, $96.1 \mathrm{mg}) \mathrm{NaOH}\left(2 \mathrm{mmol}, 80 \mathrm{mg}\right.$, and $\mathrm{Ph}_{4} \mathrm{PCl}(0.66 \mathrm{mmol}, 262.4 \mathrm{mg})$ were mixed in $25 \mathrm{~mL} \mathrm{CH} \mathrm{Cl}_{2}$ overnight. The mixture was filtered to remove excess $\mathrm{NaOH}$ and $\mathrm{NaCl}$. The filtrate was concentrated under reduced pressure and crushed out with diethyl ether. The resulting solid was filtered off and air-dried overnight. X-ray quality single crystals $(0.21 \mathrm{mmol}, 277 \mathrm{mg}$; yield $65 \%$ ) were grown by slow diethyl ether vapor diffusion into a $\mathrm{CH}_{2} \mathrm{Cl}_{2}$ solution of $\left(\mathrm{Ph}_{4} \mathrm{P}\right)_{2}[1]$. 


\subsection{2. $\left[\mathrm{Cu}_{3}\left(\mu_{3}-\mathrm{OH}\right)(\mu-4-\mathrm{CH}(\mathrm{O})-\mathrm{pz})_{3}(\mu-1,2-\mathrm{bpe})_{2}(1,2-\mathrm{bpe})_{2}\left(\mathrm{H}_{2} \mathrm{O}\right)\right]\left(\mathrm{CF}_{3} \mathrm{SO}_{3}\right)_{2}$ $.3 \mathrm{H}_{2} \mathrm{O},[2]\left(\mathrm{CF}_{3} \mathrm{SO}_{3}\right)_{2}$}

To synthesize [2] $\left(\mathrm{CF}_{3} \mathrm{SO}_{3}\right)_{2}, \mathrm{Cu}\left(\mathrm{CF}_{3} \mathrm{SO}_{3}\right)_{2}(0.60 \mathrm{mmol}, 225 \mathrm{mg}), 4-\mathrm{CH}(\mathrm{O})-$ $\mathrm{pzH}(0.56 \mathrm{mmol}, 53 \mathrm{mg})$ and $\mathrm{NaOH}(0.94 \mathrm{mmol}, 38 \mathrm{mg})$ were mixed in 25 $\mathrm{mL} \mathrm{MeOH.} \mathrm{1,2-bpe} \mathrm{(0.96} \mathrm{mmol,} 187 \mathrm{mg}$ ) was dissolved in $25 \mathrm{~mL} \mathrm{MeOH}$ and was added dropwise to the Cu salt solution over $2 \mathrm{~h}$. The reaction mixture was stoppered and stirred overnight at room temperature. A small amount of brown precipitate was filtered off and the filtrate was allowed to evaporate slowly to yield blue-green crystals $(0.11 \mathrm{mmol}, 181 \mathrm{mg}$; yield $57 \%)$ of [2] $\left(\mathrm{CF}_{3} \mathrm{SO}_{3}\right)_{2}$ over two weeks. Analysis calculated for $\mathrm{C}_{62} \mathrm{H}_{58} \mathrm{~N}_{14} \mathrm{Cu}_{3} \mathrm{O}_{14} \mathrm{~F}_{6} \mathrm{~S}_{2}$ : C, 46.78; H, 3.67; N, 12.32. Found: C, 46.63; H, 3.66; N, 12.34.

\subsection{3. $\left\{\left[\mathrm{Cu}_{3}\left(\mu_{3}-\mathrm{OH}\right)(\mu-4-\mathrm{CH}(\mathrm{O})-\mathrm{pz})_{3}\left(\mathrm{H}_{2} \mathrm{O}\right)_{3}\right]\left(\mathrm{CF}_{3} \mathrm{SO}_{3}\right)_{2}\right\}_{n},[3]\left(\mathrm{CF}_{3} \mathrm{SO}_{3}\right)_{2}$}

To syntheize [3] $\left(\mathrm{CF}_{3} \mathrm{SO}_{3}\right)_{2}, \mathrm{Cu}\left(\mathrm{CF}_{3} \mathrm{SO}_{3}\right)_{2}(1 \mathrm{mmol}, 361 \mathrm{mg}), 4-\mathrm{CH}(\mathrm{O})-\mathrm{pzH}(1$ mmol, $96 \mathrm{mg}$ ) and $\mathrm{NaOH}(2 \mathrm{mmol}, 80 \mathrm{mg}$ ) were mixed in $25 \mathrm{~mL}$ of pyridine overnight at room temperature. The reaction mixture was filtered, and the solvent was removed under reduced pressure. The residue was suspended in $10 \mathrm{~mL}$ of THF and filtered $(0.08 \mathrm{mmol}, 66 \mathrm{mg}$; yield $24 \%)$. X-ray quality dark-blue single crystals of [3] $\left(\mathrm{CF}_{3} \mathrm{SO}_{3}\right)_{2}$ were obtained after one week.

\subsection{4. $\left\{\left[\mathrm{Cu}_{3}\left(\mu_{3}-\mathrm{OH}\right)(\mu-4-\mathrm{CH}(\mathrm{O})-\mathrm{pz})_{3}(\mathrm{py})_{3}\right]\left(\mathrm{CF}_{3} \mathrm{SO}_{3}\right)_{2}\right\}_{n},[4]\left(\mathrm{CF}_{3} \mathrm{SO}_{3}\right)_{2}$}

The coordination polymer $[4]\left(\mathrm{CF}_{3} \mathrm{SO}_{3}\right)_{2}$ was obtained as was an impurity of the synthesis of $[3]\left(\mathrm{CF}_{3} \mathrm{SO}_{3}\right)_{2}$ and was isolated as a few a X-ray quality crystals from the bulk powder of [3] $\left(\mathrm{CF}_{3} \mathrm{SO}_{3}\right)_{2}$. 


\subsection{5. $\left\{\left[\mathrm{Cu}_{3}\left(\mu_{3}-\mathrm{OH}\right)(\mu-4-\mathrm{CH}(\mathrm{O})-\mathrm{pz})_{3}\right]\left(\mathrm{ClO}_{4}\right)_{2}\right\}_{n},[5]\left(\mathrm{ClO}_{4}\right)_{2}$}

The coordination polymer $[5]\left(\mathrm{ClO}_{4}\right)_{2}$ was prepared using the same procedure as [3] $\left(\mathrm{CF}_{3} \mathrm{SO}_{3}\right)_{2}$, using $\mathrm{Cu}\left(\mathrm{ClO}_{4}\right)_{2} \cdot 6 \mathrm{H}_{2} \mathrm{O}(1 \mathrm{mmol}, 370 \mathrm{mg})$ instead of $\mathrm{Cu}\left(\mathrm{CF}_{3} \mathrm{SO}_{3}\right)_{2}$. X-ray quality crystals were obtained by slow diffusion of diethyl ether vapor into a THF solution of $[5]\left(\mathrm{ClO}_{4}\right)_{2}(0.23 \mathrm{mmol}, 162 \mathrm{mg}$; yield $70 \%)$.

\subsection{Crystallography}

Crystallographic details on the compounds discussed here are summarized in Table 4 and selected bond lengths and angles are listed in Table 5. [2] $\left(\mathrm{CF}_{3} \mathrm{SO}_{3}\right)_{2}$, [3] $\left(\mathrm{CF}_{3} \mathrm{SO}_{3}\right)_{2}$, and $[5]\left(\mathrm{ClO}_{4}\right)_{2}$ contained interstitial solvent molecules that were removed using the SQUEEZE protocol available with PLATON. ${ }^{150}$ The amount of solvent molecules was determined from a combination TGA and elemental analyses. In $[2]\left(\mathrm{CF}_{3} \mathrm{SO}_{3}\right)_{2}$, the $\left(\mu_{3}-\mathrm{OH}\right)$ is located on a $C_{2}$-axis and coplanar with the three $\mathrm{Cu}$-atoms. However, its thermal ellipsoid is vertically elongated, indicating that the pyramidal $\mathrm{OH}$ group is disordered among two sites, above and below the Сuз-plane. 
Table 4. Crystallographic data parameters for compounds in Chapter 2

\begin{tabular}{|c|c|c|c|c|c|}
\hline Compound & $\left(\mathrm{Ph}_{4} \mathrm{P}\right)_{2}[1]$ & {$[2]\left(\mathrm{CF}_{3} \mathrm{SO}_{3}\right)_{2}$} & {$[3]\left(\mathrm{CF}_{3} \mathrm{SO}_{3}\right)_{2}$} & {$[4]\left(\mathrm{CF}_{3} \mathrm{SO}_{3}\right)_{2}$} & {$[5]\left(\mathrm{ClO}_{4}\right)_{2}$} \\
\hline Formula & $\begin{array}{c}\mathrm{C}_{60} \mathrm{H}_{49} \mathrm{Cl}_{3} \mathrm{Cu} \\
{ }_{3} \mathrm{~N}_{6} \mathrm{O}_{4} \mathrm{P}_{2}\end{array}$ & $\begin{array}{c}\mathrm{C}_{62} \mathrm{H}_{49} \mathrm{Cu}_{3} \mathrm{~F}_{6} \\
\mathrm{~N}_{14} \mathrm{O}_{13} \mathrm{~S}_{2}\end{array}$ & $\begin{array}{c}\mathrm{C}_{28} \mathrm{H}_{20} \mathrm{Cu}_{6} \\
\mathrm{~F}_{12} \mathrm{~N}_{12} \mathrm{O}_{29} \mathrm{~S}_{4}\end{array}$ & $\begin{array}{c}\mathrm{C}_{38} \mathrm{H}_{40} \mathrm{Cu}_{6} \\
\mathrm{~F}_{12} \mathrm{~N}_{14} \mathrm{O}_{20} \mathrm{~S}_{4}\end{array}$ & $\begin{array}{c}\mathrm{C}_{12} \mathrm{H}_{9} \mathrm{Cl}_{2} \mathrm{Cu}_{3} \\
\mathrm{~N}_{6} \mathrm{O}_{12}\end{array}$ \\
\hline$f_{\mathrm{w}}(\mathrm{amu})$ & 1276.96 & 1566.89 & 1726.04 & 1740.24 & 689.78 \\
\hline $\begin{array}{c}\text { Temperature } \\
(\mathrm{K})\end{array}$ & 293(2) & $296(2)$ & $296(2)$ & $293(2)$ & $296(2)$ \\
\hline Size $\left(\mathrm{mm}^{3}\right)$ & $\begin{array}{c}0.31 \times 0.12 \times \\
0.05\end{array}$ & $\begin{array}{c}0.27 \times 0.26 \times \\
0.23\end{array}$ & $\begin{array}{c}0.10 \times 0.17 \times \\
0.17\end{array}$ & $\begin{array}{c}0.54 \times 0.46 \times \\
0.24\end{array}$ & $\begin{array}{c}0.28 \times 0.28 \times \\
0.18\end{array}$ \\
\hline $\begin{array}{l}\text { Crystal } \\
\text { System }\end{array}$ & Triclinic & Monoclinic & Monoclinic & $\begin{array}{l}\text { Ortho- } \\
\text { rhombic }\end{array}$ & Cubic \\
\hline Space group & $\overline{P \overline{1}}$ & $C 2 / c$ & $P 2_{1} / \mathrm{n}$ & $P$ na2 1 & $\overline{4} 3 d$ \\
\hline$a(\breve{A})$ & $12.858(1)$ & $11.903(1)$ & 18.9259(8) & $17.989(1)$ & $23.8296(8)$ \\
\hline$b(\dot{A})$ & $13.770(1)$ & $25.050(2)$ & $15.1550(7)$ & 17.989(1) & $23.8296(8)$ \\
\hline$c(\hat{A})$ & 18.617(2) & $23.801(2)$ & 20.6283(9) & $24.289(2)$ & $23.8296(8)$ \\
\hline$\alpha\left(^{\circ}\right)$ & $76.345(1)$ & 90 & 90 & 90 & 90 \\
\hline$\beta\left(^{\circ}\right)$ & 75.103(1) & $97.605(1)$ & $91.700(1)$ & 90 & 90 \\
\hline$V\left(^{\circ}\right)$ & $66.284(1)$ & 90 & 90 & 90 & 90 \\
\hline$V\left(\AA^{3}\right)$ & 2883.3(4) & $7034(1)$ & $5914.0(5)$ & $7860.3(8)$ & $13531.6(1)$ \\
\hline$Z$ & 2 & 4 & 4 & 4 & 16 \\
\hline$\rho_{\text {calc }}\left(\mathrm{g} \mathrm{cm}^{-3}\right)$ & 1.471 & 1.480 & 1.936 & 1.471 & 1.354 \\
\hline$\mu\left(\mathrm{mm}^{-1}\right)$ & 1.343 & 1.044 & 2.390 & 1.792 & 2.074 \\
\hline Total data & 33257 & 40230 & 1574738 & 146084 & 140252 \\
\hline $\begin{array}{l}\text { Unique data } \\
\text { (Rint) }\end{array}$ & $\begin{array}{c}13010 \\
(0.0285)\end{array}$ & $\begin{array}{c}8364 \\
(0.0252)\end{array}$ & $\begin{array}{c}12220 \\
(0.0441)\end{array}$ & $\begin{array}{c}16148 \\
(0.0351)\end{array}$ & $\begin{array}{c}2327 \\
(0.0488)\end{array}$ \\
\hline $2 \Theta$ range $\left(^{\circ}\right)$ & $\begin{array}{c}3.832 \text { to } \\
55.312\end{array}$ & $\begin{array}{l}4.00 \text { to } \\
46.48\end{array}$ & $\begin{array}{c}5.728 \text { to } \\
53.01\end{array}$ & $\begin{array}{c}5.518 \text { to } \\
52.92\end{array}$ & $\begin{array}{c}6.398 \text { to } \\
52.832\end{array}$ \\
\hline $\begin{array}{l}\text { Goodness of } \\
\text { fit (GOF) }\end{array}$ & 1.025 & 1.034 & 1.040 & 1.038 & 1.068 \\
\hline $\begin{array}{c}R_{1} / w R_{2}(I> \\
2 \sigma(I))\end{array}$ & $\begin{array}{l}0.0393 / \\
0.0970\end{array}$ & $\begin{array}{l}0.0637 / \\
0.1799\end{array}$ & $\begin{array}{l}0.0508 / \\
0.1384\end{array}$ & $\begin{array}{l}0.0371 / \\
0.0935\end{array}$ & $\begin{array}{l}0.0349 / \\
0.0930\end{array}$ \\
\hline $\begin{array}{l}R_{1} / w R_{2} \text { (all } \\
\text { data) }\end{array}$ & $\begin{array}{l}0.0679 / \\
0.1104\end{array}$ & $\begin{array}{l}0.0817 / \\
0.1961\end{array}$ & $\begin{array}{l}0.0673 / \\
0.1510\end{array}$ & $\begin{array}{l}0.0416 / \\
0.0970\end{array}$ & $\begin{array}{l}0.0383 / \\
0.0963\end{array}$ \\
\hline
\end{tabular}


Table 5. Selected bond lengths and angles for complexes 1-5 in chapter 2

\begin{tabular}{|c|c|c|c|c|c|}
\hline & {$[1]^{2-}$} & {$[2]^{2+}$} & {$[3]^{2+}$} & {$[4]^{2+}$} & {$[5]^{2+}$} \\
\hline $\mathrm{Cu}-\mu_{3}-\mathrm{O}(\mathrm{H})$ & $\begin{array}{c}1.887(2)- \\
1.899(2)\end{array}$ & $\begin{array}{l}1.978(2)- \\
1.986(4)\end{array}$ & $\begin{array}{l}1.986(3)- \\
2.030(3)\end{array}$ & $\begin{array}{l}1.981(4)- \\
2.009(4)\end{array}$ & $2.000(4)$ \\
\hline Cu-N & $\begin{array}{c}1.948(2)- \\
1.963(2)\end{array}$ & $\begin{array}{l}1.951(2)- \\
1.984(3)\end{array}$ & $\begin{array}{c}1.936(4)- \\
1960(4)\end{array}$ & $\begin{array}{l}1932(5)- \\
2002(4)\end{array}$ & $1.93(1)$ \\
\hline Cu-L & $\begin{array}{l}2.283(1)- \\
2.315(1)\end{array}$ & $2.099(4)$ & $\begin{array}{l}1.982(3) \\
2.023(3)\end{array}$ & $\begin{array}{l}2.010(6)- \\
2.017(4)\end{array}$ & $\mathrm{N} / \mathrm{A}$ \\
\hline Cu-bpe & $\mathrm{N} / \mathrm{A}$ & $\begin{array}{l}2.045(3) \\
2.493(4)\end{array}$ & $\mathrm{N} / \mathrm{A}$ & $\mathrm{N} / \mathrm{A}$ & $\mathrm{N} / \mathrm{A}$ \\
\hline O-Cu-Bpe & $N / A$ & $159.2(1)$ & $\mathrm{N} / \mathrm{A}$ & $\mathrm{N} / \mathrm{A}$ & $\mathrm{N} / \mathrm{A}$ \\
\hline O.C.Cu-plane & $\mathrm{N} / \mathrm{A}$ & $\mathrm{N} / \mathrm{A}$ & $0.517,0.534$ & $0.508,0.567$ & 0.603 \\
\hline $\mathrm{Cu}-\mathrm{OClO}_{3} / \mathrm{OTf}$ & $\mathrm{N} / \mathrm{A}$ & $\mathrm{N} / \mathrm{A}$ & $\begin{array}{l}2.427(5)- \\
2.565(5)\end{array}$ & $\begin{array}{l}2.19(1)- \\
2.497(7)\end{array}$ & $\begin{array}{l}2.579(3) \\
2.726(5)\end{array}$ \\
\hline $\mathrm{Cu}-\mathrm{O}-\mathrm{Cu}$ & $\begin{array}{l}118.5(1)- \\
120.7(1)\end{array}$ & $120.0(1)$ & $\begin{array}{l}110.0(1)- \\
115.5(2)\end{array}$ & $\begin{array}{l}110.5(2)- \\
118.1(2)\end{array}$ & $111.1(2)$ \\
\hline $\mathrm{N}-\mathrm{Cu}-\mathrm{N}$ & $\begin{array}{l}160.3(1)- \\
176.5(1)\end{array}$ & $\begin{array}{c}169.3(1)- \\
177.3(2)\end{array}$ & $\begin{array}{c}169.7(2)- \\
179.5(2)\end{array}$ & $\begin{array}{l}167.8(2)- \\
177.9(2)\end{array}$ & $175.7(2)$ \\
\hline $\mathrm{O}-\mathrm{Cu}-\mathrm{O}$ & $\mathrm{N} / \mathrm{A}$ & $\mathrm{N} / \mathrm{A}$ & $\begin{array}{l}167.5(1)- \\
175.5(1)\end{array}$ & $\begin{array}{l}165.5(2)- \\
178.6(2)\end{array}$ & $171.1(2)$ \\
\hline O-Cu-L & $\begin{array}{l}158.1(1)- \\
170.3(1)\end{array}$ & $180.0(1)$ & $\begin{array}{c}174.3(1)- \\
178.6(1)\end{array}$ & $\begin{array}{l}\text { 162.1(2), } \\
178.2(2)\end{array}$ & $\mathrm{N} / \mathrm{A}$ \\
\hline $\begin{array}{c}\mathrm{C}=\mathrm{O}(\mathrm{Cu}- \\
\text { bound })\end{array}$ & $N / A$ & $\mathrm{~N} / \mathrm{A}$ & $\begin{array}{l}1.239(6) \\
1.234(6)\end{array}$ & $\begin{array}{c}1.177(8)- \\
1.256(8)\end{array}$ & $1.226(7)$ \\
\hline $\mathrm{C}=\mathrm{O}($ free $)$ & $\begin{array}{l}1.19(2)- \\
1.204(4)\end{array}$ & $\begin{array}{l}1.156(6) \\
1.202(8)\end{array}$ & $\begin{array}{l}1.183(8), \\
1.204(7), \\
1.202(8)\end{array}$ & $\mathrm{N} / \mathrm{A}$ & $\mathrm{N} / \mathrm{A}$ \\
\hline$(\mathrm{C}=\mathrm{O}) \mathrm{O}-\mathrm{Cu}$ & $N / A$ & $\mathrm{~N} / \mathrm{A}$ & $2.020(3)$ & $\begin{array}{l}1.973(4)- \\
2.479(5)\end{array}$ & $1.982(4)$ \\
\hline
\end{tabular}




\subsection{Results and Discussions}

\subsubsection{Synthesis}

All five compounds form by self-assembly, upon mixing a $\mathrm{Cu}$ (II) salt, 4$\mathrm{CH}(\mathrm{O})-\mathrm{pzH}, \mathrm{NaOH}$, a counterion and pyridine or 1,2-bpe in an organic solvent. The only discrete trinuclear complex is $\left(\mathbf{P h}_{4} \mathbf{P}\right)_{2}[\mathbf{1}]$ and has terminal chloride ligands instead of a bridging linker. Coordination polymer [2] $\left(\mathrm{CF}_{3} \mathrm{SO}_{3}\right)_{2}$ was obtained in a soluble form only from a dilute reaction mixture to which the linker was added slowly; Fast addition of the linker forces rapid precipitation of $[2]\left(\mathrm{CF}_{3} \mathrm{SO}_{3}\right)_{2}$ as an amorphous solid whose composition was determined by elemental analysis. Crystals of $[2]\left(\mathrm{CF}_{3} \mathrm{SO}_{3}\right)_{2}$ were formed in good yield by slow evaporation of the filtrate. In the structures of $\left(\mathbf{P h}_{4} \mathbf{P}\right)_{2}[\mathbf{1}]$ and $[2]\left(\mathrm{CF}_{3} \mathrm{SO}_{3}\right)_{2}$, the $4-\mathrm{CH}(\mathrm{O})$ substituents are spectator groups.

In the absence of competing ligands (such as $\mathrm{Cl}$ in $\left(\mathbf{P h}_{4} \mathbf{P}\right)_{2}$ [1] and 1,2-bpe in [2] $\left.\left(\mathrm{CF}_{3} \mathrm{SO}_{3}\right)_{2}\right)$, the formyl group participates in completing the coordination sphere of the $\mathrm{Cu}^{2+}$. The only 1D-chain in this series of compounds is [3] $\left(\mathrm{CF}_{3} \mathrm{SO}_{3}\right)_{2}$, as two of the three $\mathrm{Cu}$-centers of its trinuclear SBU are terminated by water ligands. In $[4]\left(\mathrm{CF}_{3} \mathrm{SO}_{3}\right)_{2}$ one of the $\mathrm{Cu}$-centers is terminated by pyridine. Interestingly, $[3]\left(\mathrm{CF}_{3} \mathrm{SO}_{3}\right)_{2}$ and $[5]\left(\mathrm{ClO}_{4}\right)_{2}$ formed from reaction mixtures that also contained pyridine, yet no pyridine molecule was coordinated to the Cu centers. 


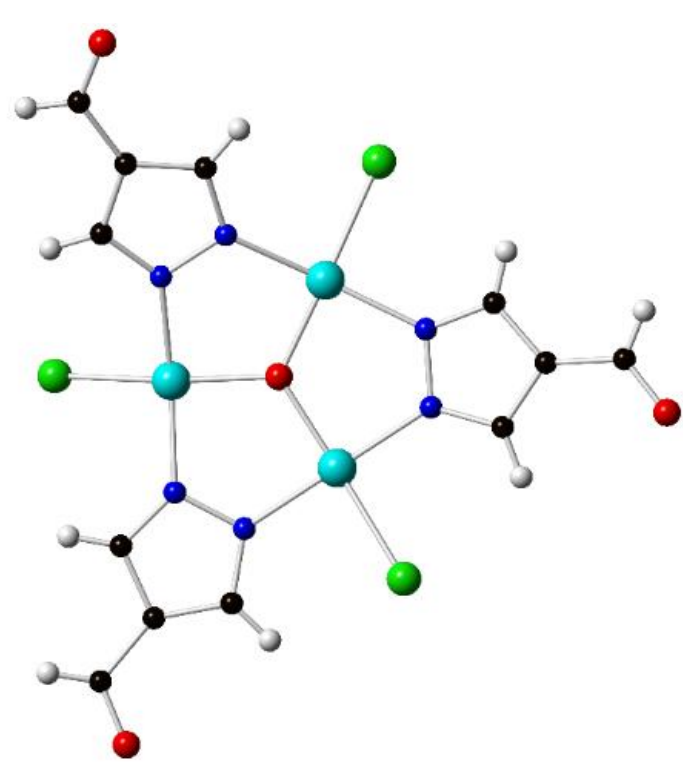

Figure 20. Ball-and-stick diagram of $\mathbf{1}^{2-}$, counter cation omitted for clarity. Color coding: Blue, $\mathrm{Cu}$; green, $\mathrm{Cl}$; red, $\mathrm{O}$; light blue, $\mathrm{N}$, black, $\mathrm{C}$ and pink, $\mathrm{H}$.

\subsubsection{Crystal Structure Descriptions}

\subsubsection{1. $\left(\mathrm{Ph}_{4} \mathrm{P}\right)_{2}[1]$}

Compound $\left(\mathbf{P h}{ }_{4} \mathbf{P}\right)_{2}[\mathbf{1}]$ crystallizes in the triclinic $P \overline{\mathbf{1}}$ space group with the whole trinuclear complex in the asymmetric unit (Figure 20). Its bond lengths and angles are unexceptional (Table 5) and in agreement with several similar trinuclear $\mathrm{Cu}(\mathrm{II})$ pyrazolates in the literature. ${ }^{46}$ The carbonyl C-O bonds are 1.194(1) - 1.204(4) $\AA$ long.

\subsubsection{2. $[2]\left(\mathrm{CF}_{3} \mathrm{SO}_{3}\right)_{2}$}

Compound [2] $\left(\mathrm{CF}_{3} \mathrm{SO}_{3}\right)_{2}$ crystallizes in the monoclinic $\mathrm{C} 2 / \mathrm{c}$ space group with one half molecule in the asymmetric unit. $A C_{2}$ axis passes through one of the Cu-atoms and the center of a pyrazole ring, bisecting the molecule and imposing a crystallographic disorder on one carbonyl group. The dangling carbonyl groups 
in this compound are non-coordinating, with typical C-O double bond lengths of 1.156(6) and 1.202(8) $\AA$. The Cu-centers are in 5-coordinate square pyramidal geometry. One of the bidentate bpe ligands links two $\mathrm{Cu}_{3}-\mathrm{SBU}$ s and one is terminal (i.e., monodentate, non-catenating). One of the terminal positions is also occupied by a water molecule, which in turn is $\mathrm{H}$-bonded to the non-catenating bpe linker $(\mathrm{OH} \cdots \mathrm{N}$ distance: $2.802(5) \AA ̊$ ). A crystal packing diagram shows parallel pillars along the crystallographic $c$-axis with no $\pi-\pi$ interactions between adjacent pyridyl rings of the 1,2-bpe linkers (ring centroid-to-centroid distances: 3.661 and $3.714 \AA$ ). In the literature, 1,2-bpe has been reported as a component of pillared structures in some soft-porous materials. ${ }^{151}$ In addition to the common 3D network structures in dia topology, [2] $\left(\mathrm{CF}_{3} \mathrm{SO}_{3}\right)_{2}$ is 3-fold interpenetrated (

Figure 21), as is quite common among lattices containing long bis-pyridyl linkers. ${ }^{152,153}$ Due to interpenetration, the void volume of this lattice is only $5.8 \%$. Pairs of adjacent $\mathrm{C}=\mathrm{C}$ bonds in [2] $\left(\mathrm{CF}_{3} \mathrm{SO}_{3}\right)_{2}$ are only $3.791(6) \AA$ and $3.603(6) \AA$ apart. Vittal et al. have reported Single-Crystal-to-Single-Crystal cycloaddition reactions under similar conditions $(3.79,3.77$ and $3.99 \AA) .{ }^{154}$ 


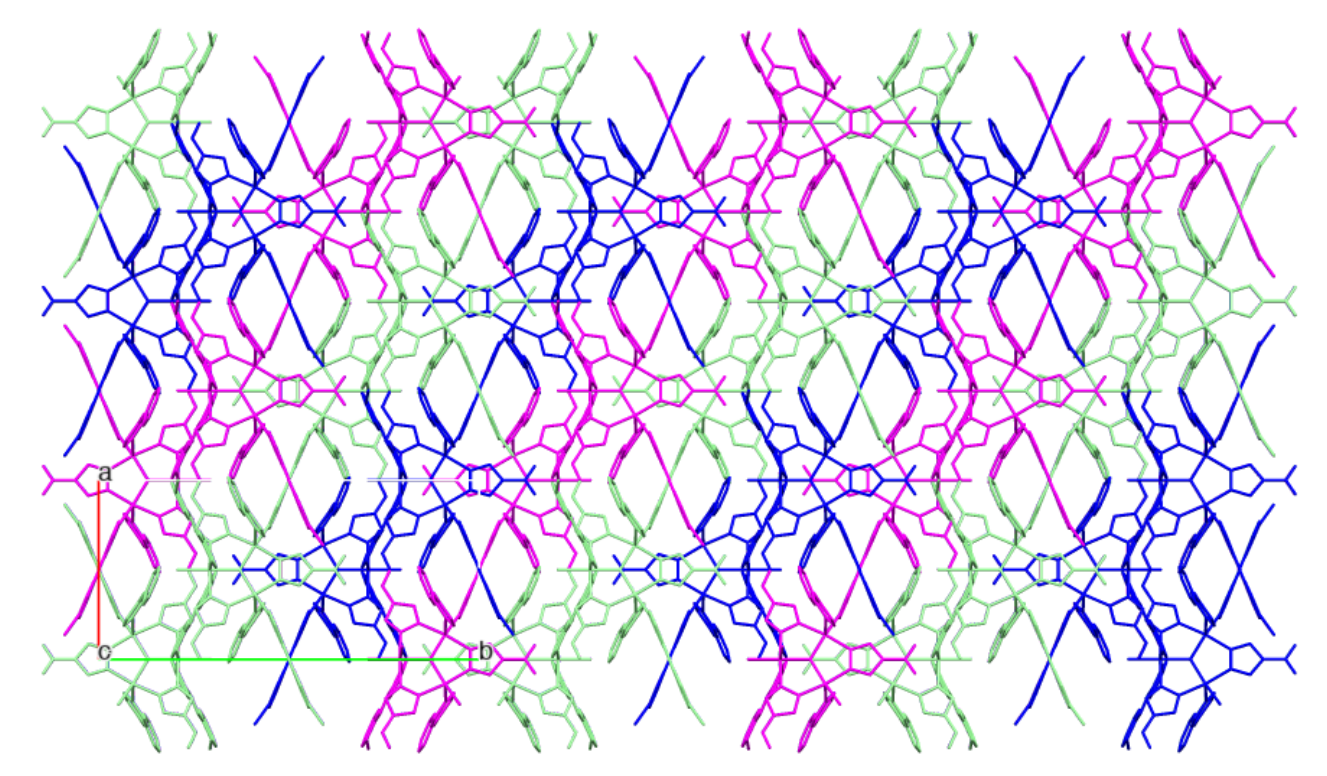

Figure 21. Diagram of three-fold interpenetration of $\mathbf{2}^{2+}$ viewed along the crystallographic c-axis. $\mathrm{H}$-atoms and counter anions are not shown for clarity.

\subsection{Topology of $[2]\left(\mathrm{CF}_{3} \mathrm{SO}_{3}\right)_{2}$}

The underlying topology of $[2]\left(\mathrm{CF}_{3} \mathrm{SO}_{3}\right)_{2}$, is a 3 -nodal $3,4,5-\mathrm{C}$ net of $3,4,5 \mathrm{~T} 174$ topological type (Figure 22). The connectivity of the copper clusters in $[2]^{2+}$ is described by the 4-c uninodal net of dia topological type (Figure 23). The coordination polymer structure comprises three interpenetrating networks, which are related by translations along the [100] direction, thus being characterized by interpenetration Class la. ${ }^{155}$ 


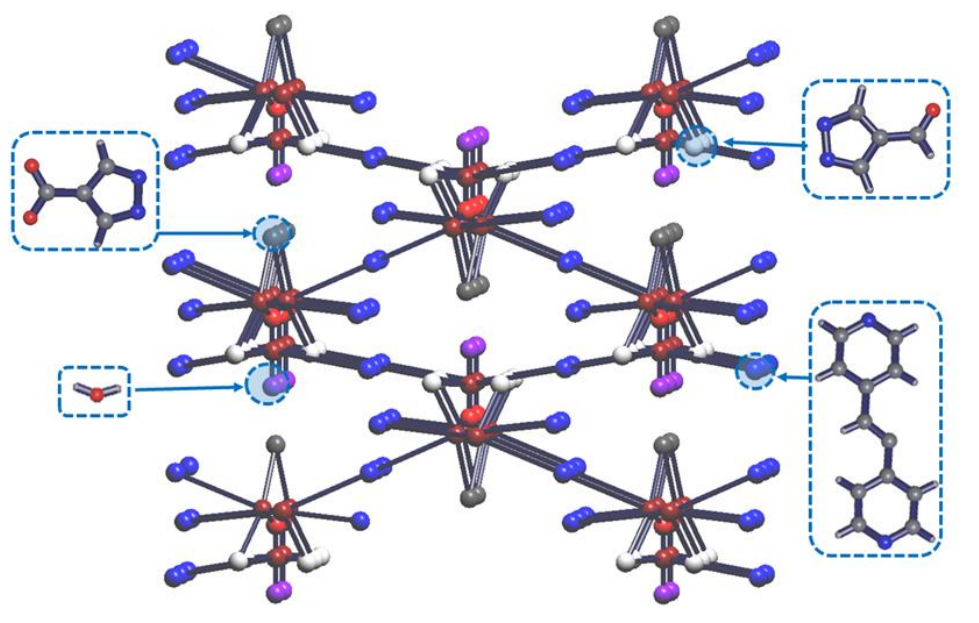

$a$

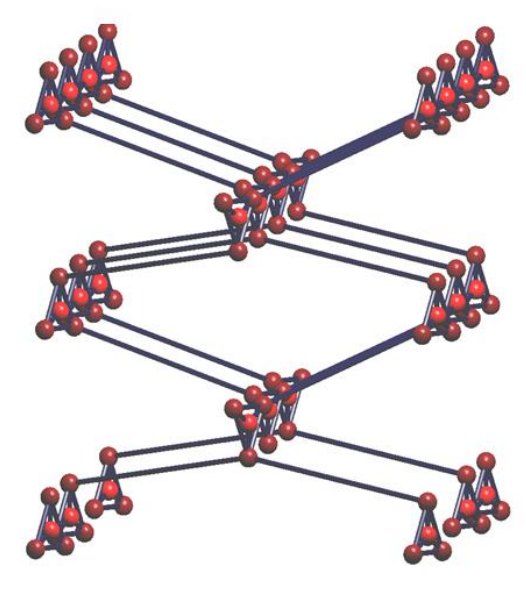

$b$

Figure 22. Standard representation of $\mathbf{2}^{2+}$ : a) The net obtained after primary simplification; b) The 3,4,5-c underlying net of 3,4,5T174 topological type obtained after secondary simplification procedure.

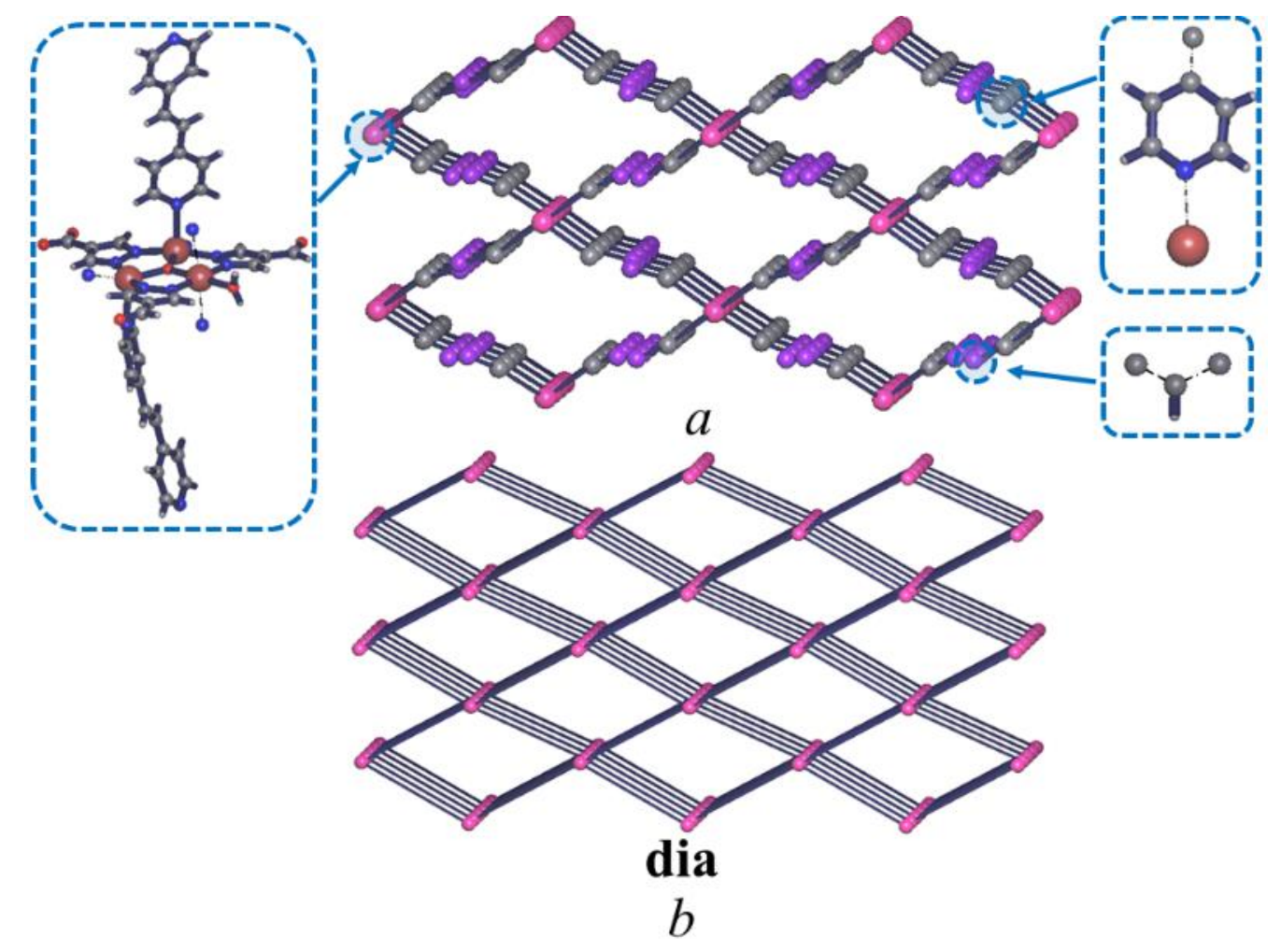

Figure 23. Underlying net of $\mathbf{2}^{2+}$ obtained by the cluster representation procedure at 6-rings: a) Dissection of the structure by means of the cluster simplification procedure as implemented in ToposPro; b) The 4-c underlying net of dia topological type obtained. 


\subsubsection{3. $[3]\left(\mathrm{CF}_{3} \mathrm{SO}_{3}\right)_{2}$}

Compound [3] $\left(\mathrm{CF}_{3} \mathrm{SO}_{3}\right)_{2}$ crystallizes in the monoclinic $P 21 /$ n space group, with two $\mathrm{Cu}_{3} \mathrm{SBU}$ in the asymmetric unit, connected via the carbonyl oxygen of the 4-CH(O)-pz ligand forming an 1D chain. Two of its three Cucenters are terminated by water molecules, preventing extension into $2 \mathrm{D}$ - or 3D-network (Figure 24). The overall backbone structure of the Cu3-units is similar to that found in the literature with other $\mathrm{Cu}_{3} \mathrm{~N}_{6}$ metallacycles and the two $\mu_{3}-\mathrm{O}(\mathrm{H})$ are located $0.536(1)$ and $0.516(1) \AA$ above their respective $\mathrm{Cu}_{3}-$ planes. The $\mathrm{Cu}$-centers are all 5 -coordinate in a square pyramidal $\mathrm{N}_{2} \mathrm{O}_{3}$ environment. Axial coordination is provided by a $\mathrm{CF}_{3} \mathrm{SO}_{3}$ counter-anion, while pyrazolato- $\mathrm{N}, \mu_{3}-\mathrm{O}$ and water or the carbonyl-O atoms are in the equatorial plane. As mentioned earlier, carbonyl groups of two (out of six) 4$\mathrm{CH}(\mathrm{O})-\mathrm{pz}$ are involved in catenation, causing elongation of the $\mathrm{C}-\mathrm{O}$ bond distances of the coordinating carbonyl groups: 1.234(1) $\AA$ and 1.239(1) $\AA$, while the $\mathrm{C}-\mathrm{O}$ bonds of non-coordinating carbonyl groups are shorter than $1.210 \AA$ and close to a typical C-O bond in an aldehyde and also those seen in $\mathbf{1}^{2-}$. While $3 \mathrm{D}$ structures are fairly common with $\mathrm{Cu}_{3}$-pyrazolato subunits, 1D chains and 2D sheets are rather uncommon, with just a few examples in the literature reported by us and others. ${ }^{93,156-167}$ The two $\mathrm{Cu}_{3}-\mathrm{SBU}$ differ from each other in that two loosely associated water molecules are coordinated perpendicular to the Cu4-Cu5-Cu6 subunit. 

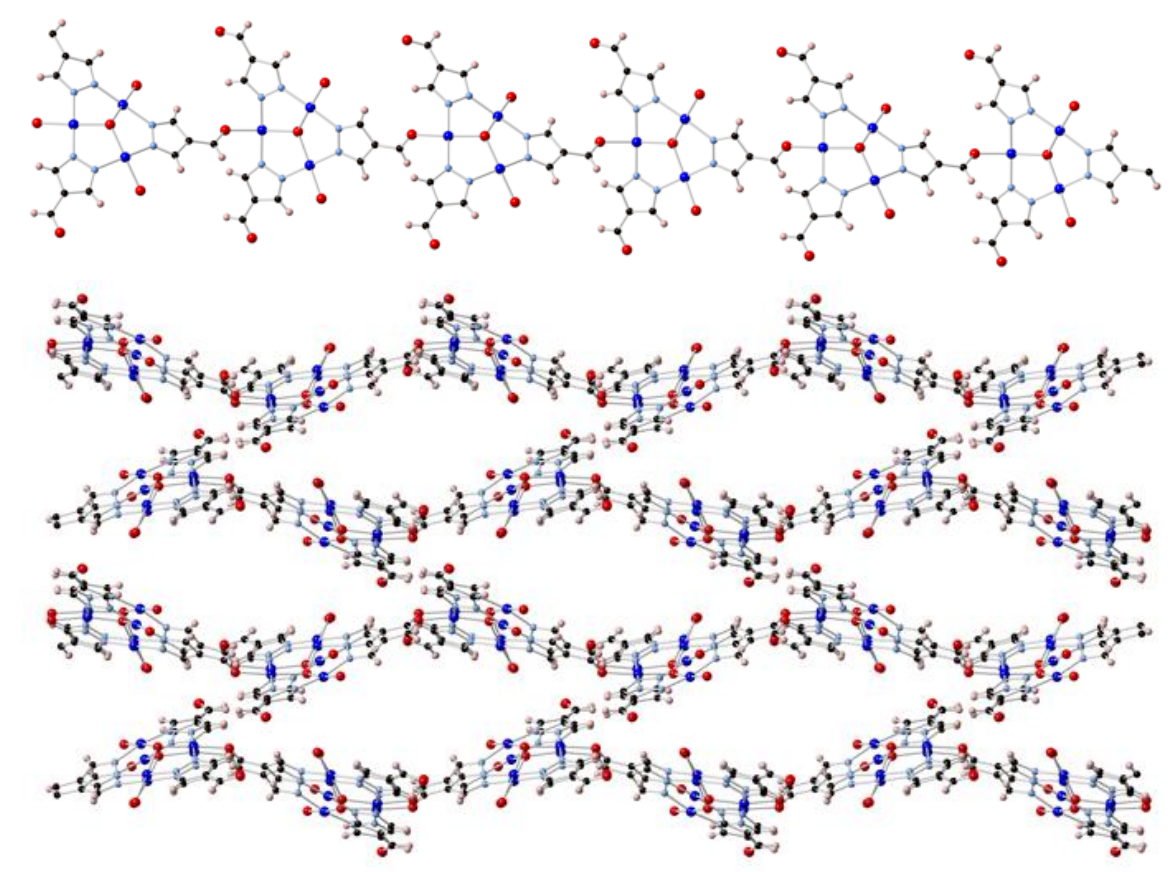

Figure 24. Molecular structures of one of the chains of $\mathbf{3}^{2+}$ (top); Packing diagram showing the wave-like arrangement parallel to the crystallographic a-axis (bottom). $\mathrm{CF}_{3} \mathrm{SO}_{3}$ anions are not shown. Color coding: Blue, $\mathrm{Cu}$; red, O; light blue, $\mathrm{N}$, black, $\mathrm{C}$ and pink, $\mathrm{H}$.

\subsubsection{4. $[4]\left(\mathrm{CF}_{3} \mathrm{SO}_{3}\right)_{2}$}

Compound [4] $\left(\mathrm{CF}_{3} \mathrm{SO}_{3}\right)_{2}$ has a 3D-network structure that crystallizes in the orthorhombic Pna2 1 space group with two $\mathrm{Cu}_{3} \mathrm{SBU}$ in the asymmetric unit (Figure 25). The $\mathrm{Cu}_{3} \mathrm{~N}_{6}$ metallacycles have Cu-centers with either a 5coordinated square pyramidal or a pseudo-octahedral geometry. The axial positions are generally occupied by triflate ions with bond distances of 2.19(1)-2.497(7) $\AA$. An interesting feature of $[4]\left(\mathrm{CF}_{3} \mathrm{SO}_{3}\right)_{2}$ is that all carbonyl groups are involved in catenation and all but two C-O distances are over 1.2 $\AA$. The two shorter carbonyl C-O bonds of 1.177(8) $\AA$ and 1.179(9) are weakly coordinating at the axial position of $\mathrm{Cu}$ atoms at 2.315(5) $\AA$ and 
2.479(5) $\AA$, respectively. These two bonds are $\sim 0.3-0.4 \AA$ longer than the other $\mathrm{CO}-\mathrm{Cu}$ bond distances. The shortest $\mathrm{CO}-\mathrm{Cu}$ bond in $[4]\left(\mathrm{CF}_{3} \mathrm{SO}_{3}\right)_{2}$ is 1.973(4) $\AA$, far shorter than analogous $\mathrm{Cu}-\mathrm{OC}$ bonds hitherto reported. ${ }^{120,138-}$ 140 The solvent accessible void volume is $2982.98 \AA^{3}(29 \%)$. The structure differs from that of $[5]\left(\mathrm{ClO}_{4}\right)_{2}$ (vide infra) in the pyridine coordination. The $\mathrm{Cu}_{3}\left(\mu_{3}-\mathrm{OH}\right)$-unit is also similar to those found in the literature ${ }^{145}$ with the $\mu_{3}-$ $\mathrm{O}(\mathrm{H})$-located $0.560(4)$ and $0.508(4) \AA$ above the $\mathrm{Cu}_{3}$-planes.

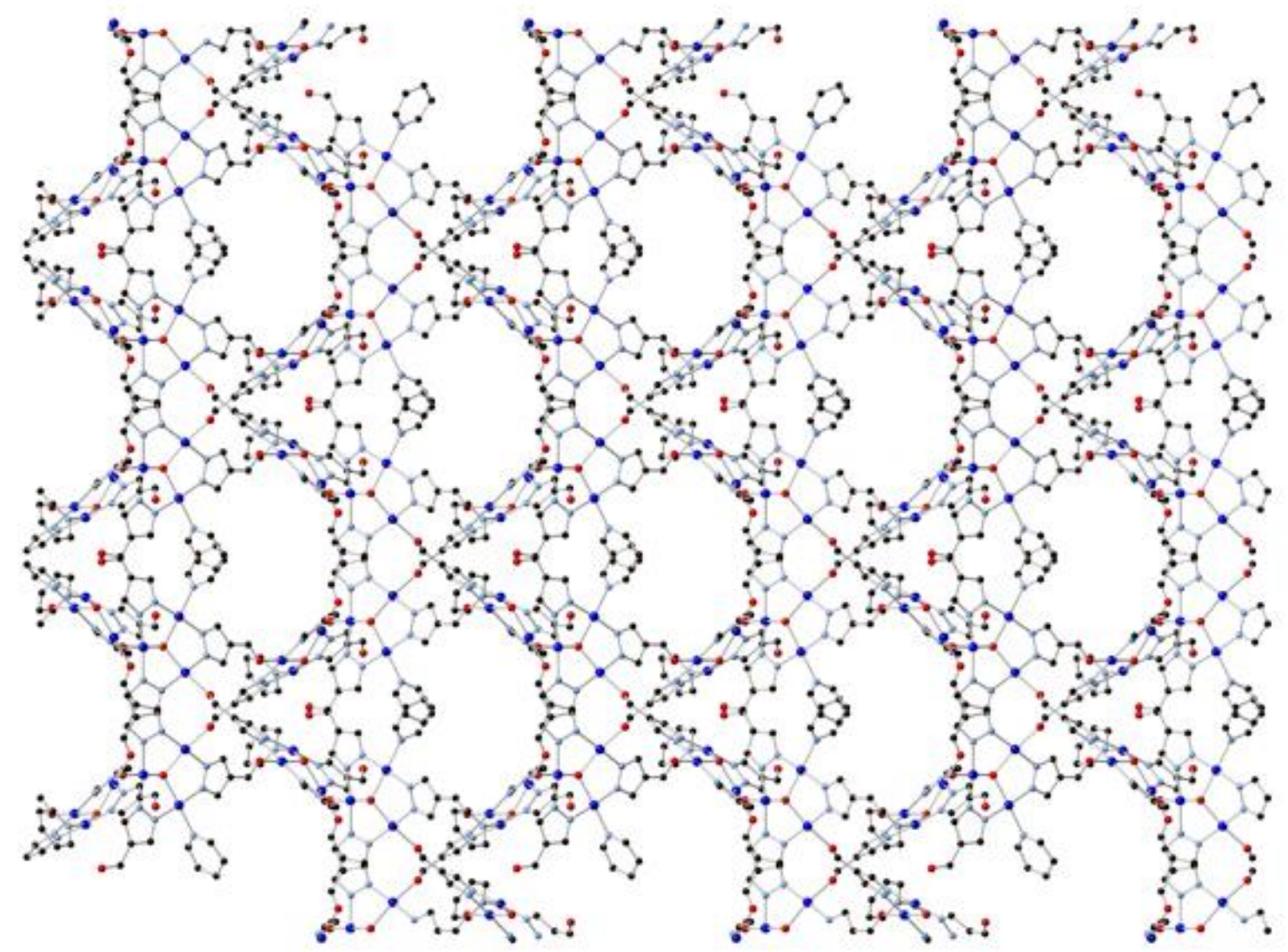

Figure 25. Molecular packing diagram for $\mathbf{4}^{2+}$ viewed along the crystallographic aaxis. Color coding: Blue, $\mathrm{Cu}$; red, $\mathrm{O}$; light blue, $\mathrm{N}$ and black, $\mathrm{C}$. $\mathrm{H}$-atoms and counter anions are not shown for clarity. 


\subsection{Topology of $[4]\left(\mathrm{CF}_{3} \mathrm{SO}_{3}\right)_{2}$}

In the standard simplification procedure, ${ }^{155}$ the $\mathrm{Cu}$ atoms are shown, while ligands are represented by their centers of mass, keeping the connectivity with their neighbors (Figure 26a). Upon secondary simplification of the obtained net, by removing of the 0 - and 1-coordinated ligands (nodes) and replacing the 2-coordinated ligands (nodes, or bridge structural groups) by net edges. The resulting topology is a 14 -nodal $3^{8}, 4^{2}, 5^{4}-c$ net. The point symbol for this net is $\left\{3 \cdot 4^{2}\right\}_{2}\{3 \cdot 8 \cdot 9\}_{2}\left\{3^{2} \cdot 4^{2} \cdot 5 \cdot 6 \cdot 8 \cdot 9 \cdot 10^{2}\right\}_{2}\left\{3^{2} \cdot 4^{2} \cdot 5 \cdot 6 \cdot 8 \cdot 9^{2} \cdot 10\right\}\left\{3^{2} \cdot 4^{2} \cdot 5 \cdot 6 \cdot 8^{2} \cdot 9 \cdot 10\right\}\{4 \cdot 8 \cdot 10$ \}$\{4 \cdot 8 \cdot 9\}\left\{4 \cdot 8^{2}\right\}_{2}\left\{42 \cdot 5 \cdot 8 \cdot 10^{2}\right\}\left\{4^{2} \cdot 5 \cdot 8^{2} \cdot 10\right\}$, and is not contained in the TOPOS Topological Database. (Figure 26b).

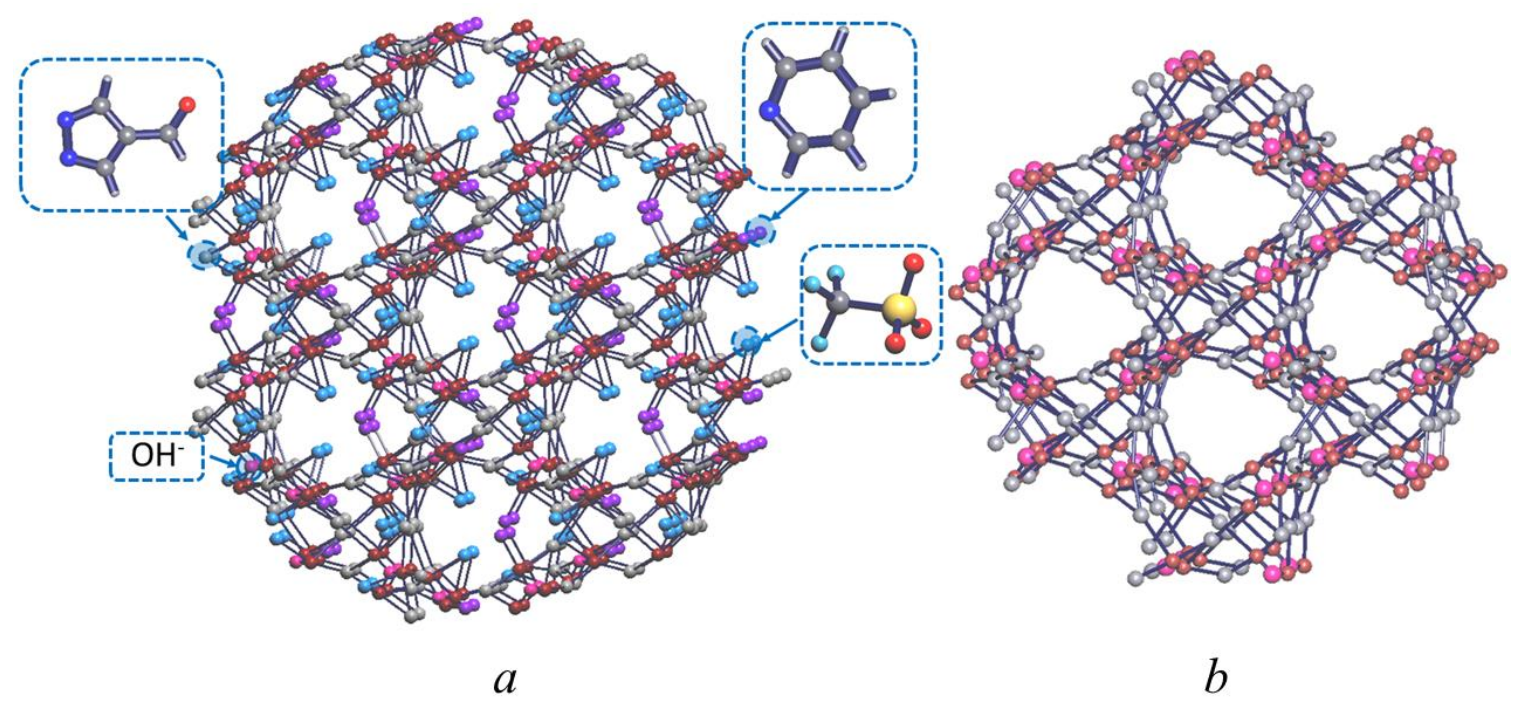

Figure 26. Standard representation of $4^{2+}$ : a) The 14 -nodal $3^{8}, 4^{2}, 5^{4}-\mathrm{c}$ net obtained after primary simplification. Red spheres correspond to copper atoms, purple spheres represent hydroxyl anions, grey spheres - 4- $\mathrm{CH}(\mathrm{O})$-pz ligands and violet spheres - pyridine molecule; b) The underlying net of new topological type obtained after secondary simplification procedure. 
Using a structure simplification procedure in ToposPro, the $\mathrm{C}_{16} \mathrm{H}_{12} \mathrm{~N}_{6} \mathrm{O}_{7} \mathrm{~F}_{6} \mathrm{~S}_{2} \mathrm{Cu}_{3}$ were identified as having the connectivity described by the 6-c uninodal net of the sol topological type (Figure 27). ${ }^{155}$ There is only one other CP that shows this topology. ${ }^{168}$

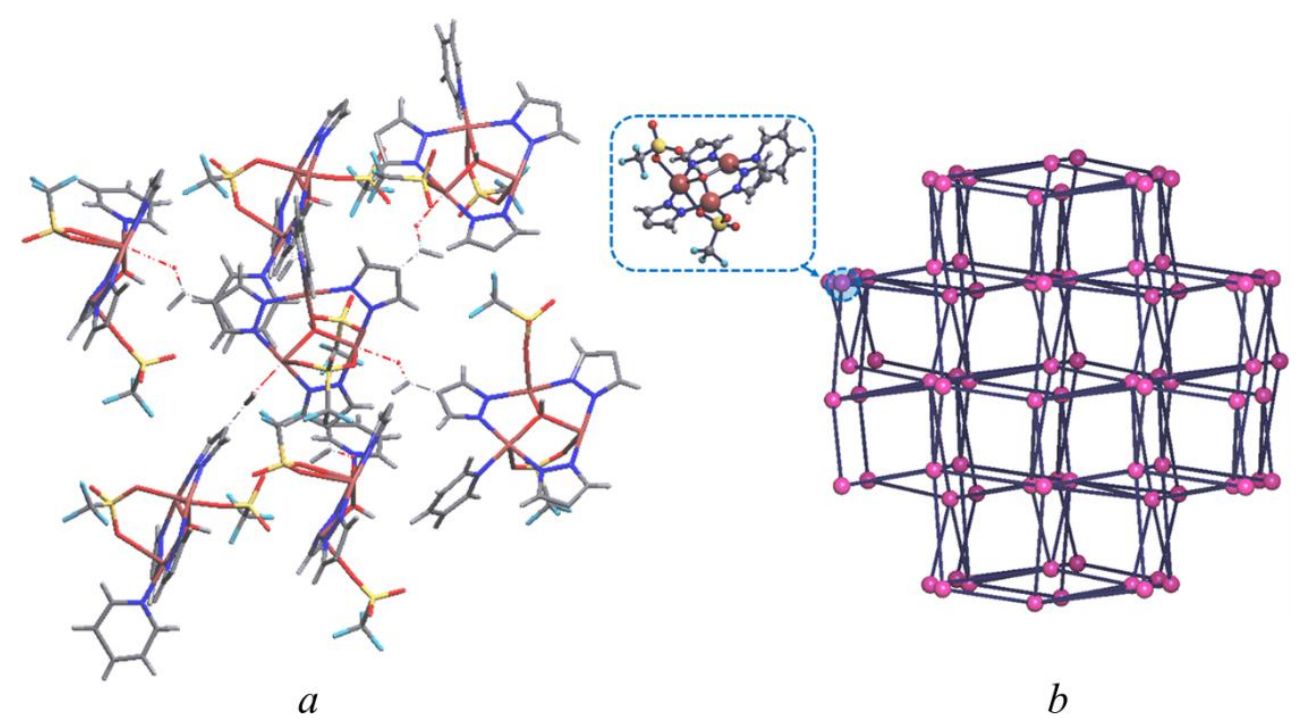

Figure 27. Underlying net of $\mathbf{4}^{2+}$ obtained by the cluster representation procedure at 6-rings: a) Dissection of the structure to clusters by ToposPro; b) The 6-c underlying net of the sol topological type obtained after secondary simplification procedure.

\subsubsection{5. $[5]\left(\mathrm{ClO}_{4}\right)_{2}$}

Compound [5] $\left(\mathrm{ClO}_{4}\right)_{2}$, another 3D polymer, crystallizes in the highly symmetric cubic space group $\overline{4} 3 \mathrm{~d}$ with the asymmetric unit containing onethird of the $\mathrm{Cu}_{3} \mathrm{SBU}$, i.e., one $\mathrm{Cu}^{2+}$, one 4-CH(O)-pz', one-third $\mu{ }^{-}-\mathrm{OH}^{-}$and two-thirds $\mathrm{ClO}_{4}^{-}$counter anion. In the extended structure, all carbonyl groups are involved in Cu-coordination (Figure 28) with CO-Cu bonds of 1.982(4) $\AA$, the second shortest bond among the structures reported here, and a long C- 
O bond of $1.226(7) \AA$. The structure is characterized by six contacts around the $\mathrm{Cu}_{3} \mathrm{SBU}$, three dative bonds to neighboring SBUs, and three dative bonds from neighboring SBUs. The solvent accessible void volume is $4294.78 \AA^{3}(31.7 \%)$.

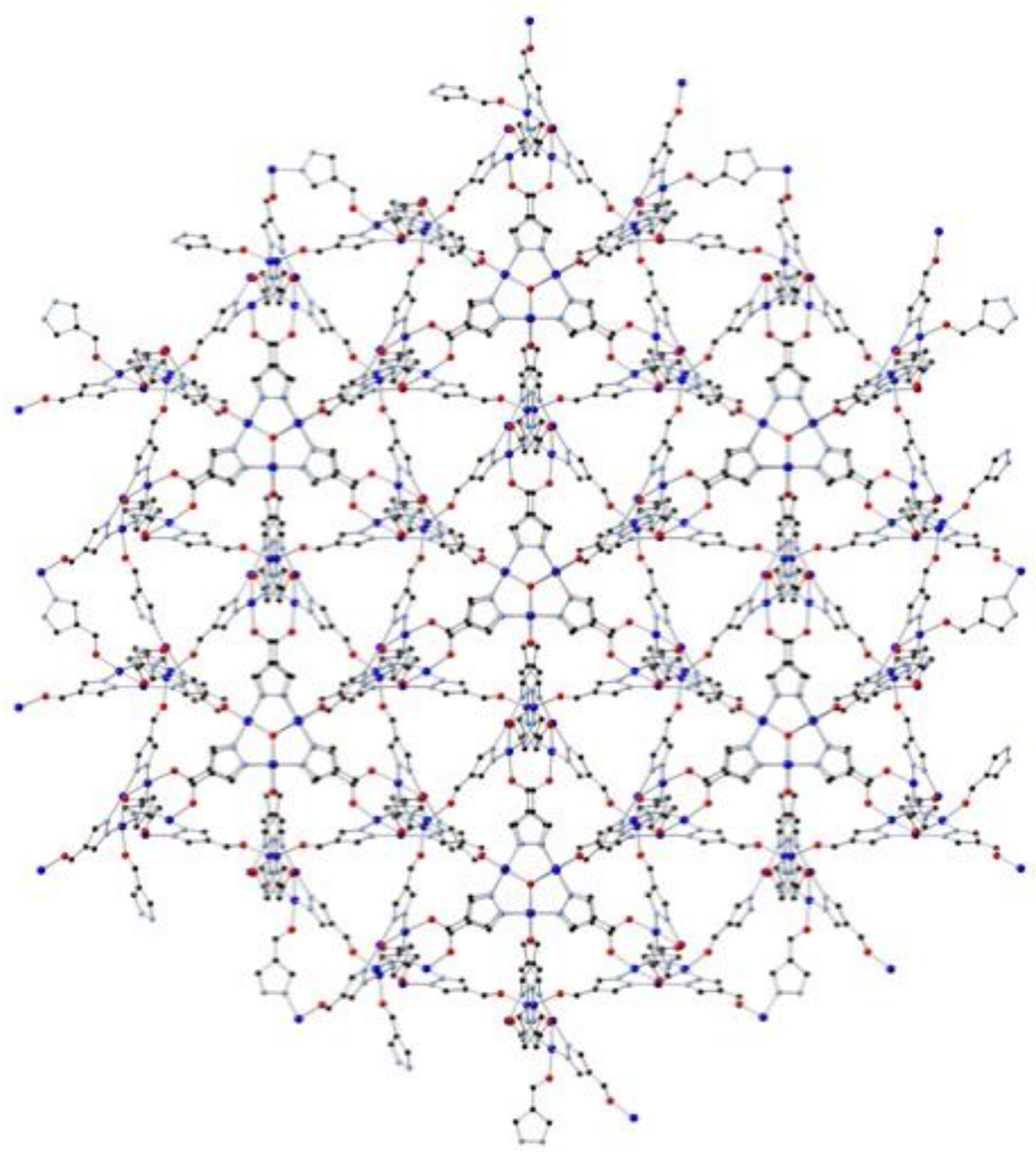

Figure 28. Molecular packing diagram of $\mathbf{5}^{2+}$ viewed along the crystallographic [111] plane. Counter anions and $\mathrm{H}$-atoms are not shown for clarity. Color coding: Blue, Cu; red, O; light blue, N, and black, C. 


\subsection{Topology of $[5]\left(\mathrm{ClO}_{4}\right)_{2}$}

After procedure for simplification of the network, described for $[4]\left(\mathrm{CF}_{3} \mathrm{SO}_{3}\right)_{2}$, a 3-nodal 3,3,4-c net is determined; this connectivity is not encountered in the Topos Topologic Database (Figure 29). The point symbol for the net is $\left\{4 \cdot 8^{2}\right\}_{3}\left\{4^{2} \cdot 6 \cdot 8^{2} \cdot 10\right\}_{3}\left\{4^{3}\right\}$.

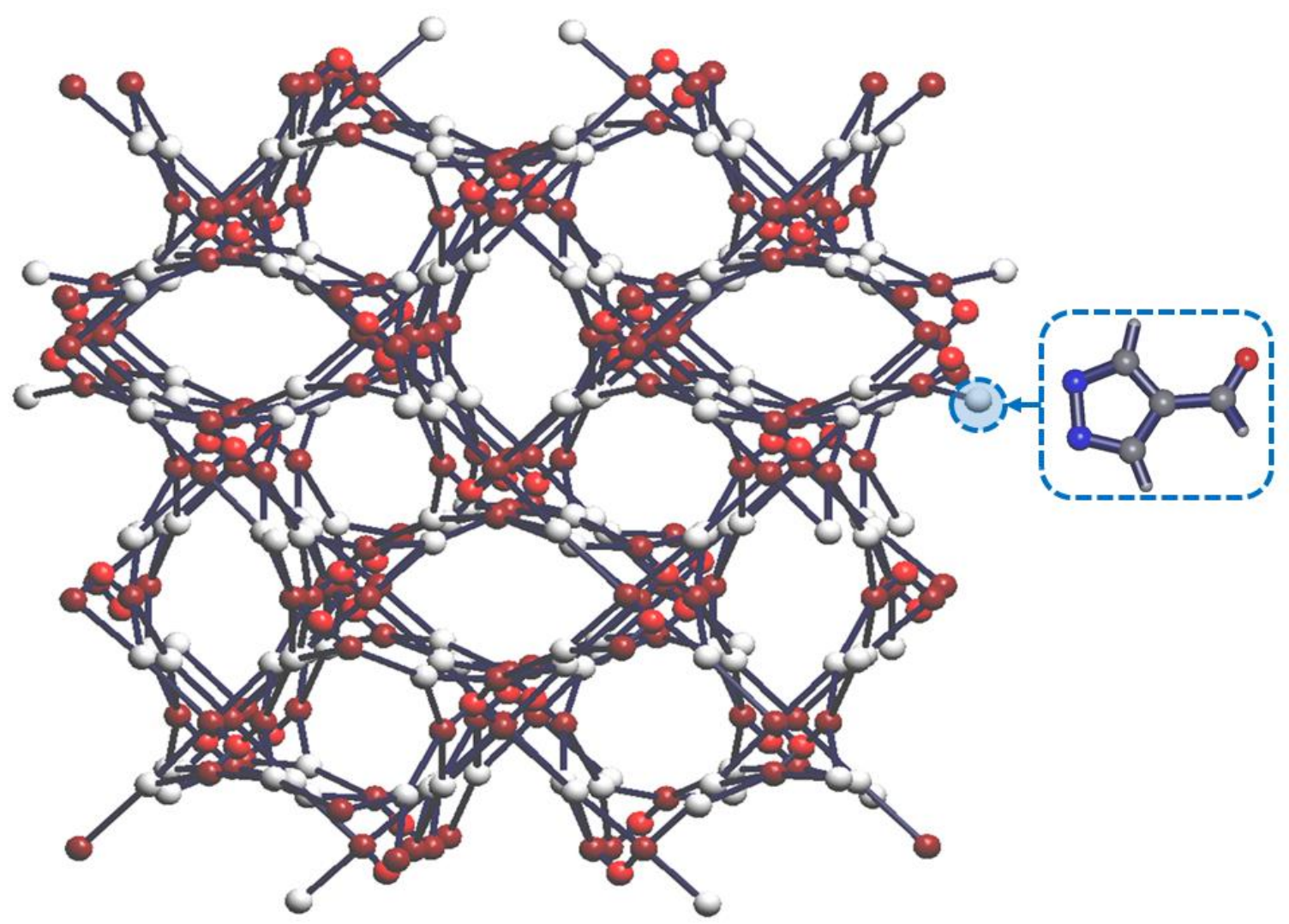

Figure 29. Standard representation of $5^{2+}$ : the 3,3,4-c underlying net of unknown topological type obtained after secondary simplification procedure.

Cluster simplification revealed that the net created by $\mathrm{C}_{9} \mathrm{H}_{6} \mathrm{~N}_{6} \mathrm{OCu}$ clusters is described by the 6-c uninodal net of the bcs topological type (Figure 30). ${ }^{155}$ There are two other CPs that display bcs topology. ${ }^{169,170}$ 


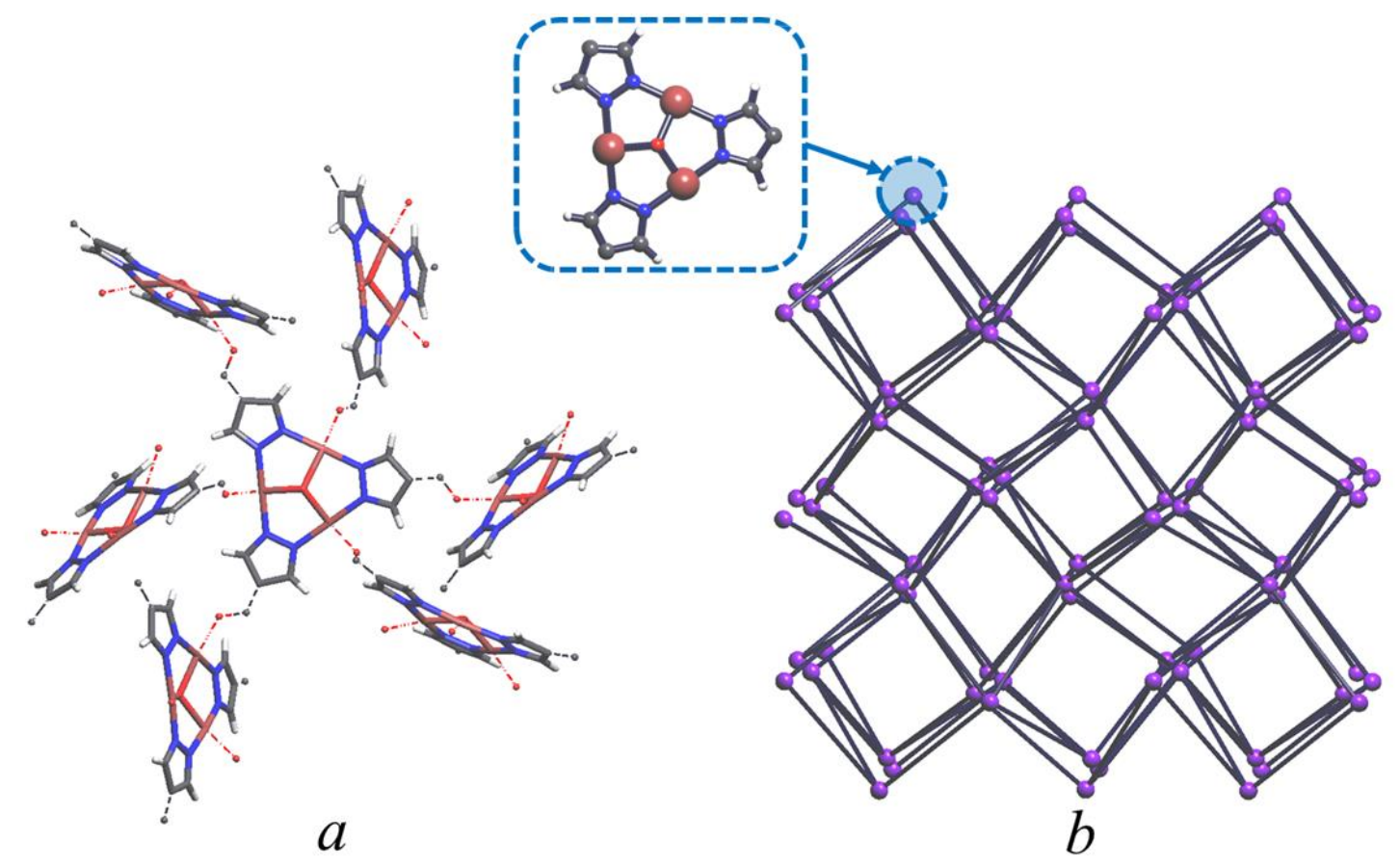

Figure 30 . Underlying net of $\mathbf{5}^{\mathbf{2}+}$ obtained by the cluster representation procedure at 5-rings: a) Dissection of the structure to clusters by ToposPro; b) The 6-c underlying net of the bcs topological type obtained after secondary simplification procedure.

\subsubsection{Powder X-Ray Diffraction Patterns}

The powder diffractions of bulk [2] $\left(\mathrm{CF}_{3} \mathrm{SO}_{3}\right)_{2}$ and $[5]\left(\mathrm{ClO}_{4}\right)_{2}$ match well with the simulated patterns, Figure 31 and Figure 33, respectively. Single crystals

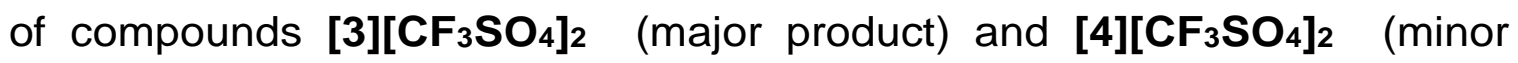
product) were isolated from the same reaction mixture. The experimental diffraction pattern of bulk reaction product reflects this and is a good match to the overlapping simulated patterns of the two components(Figure 32). 


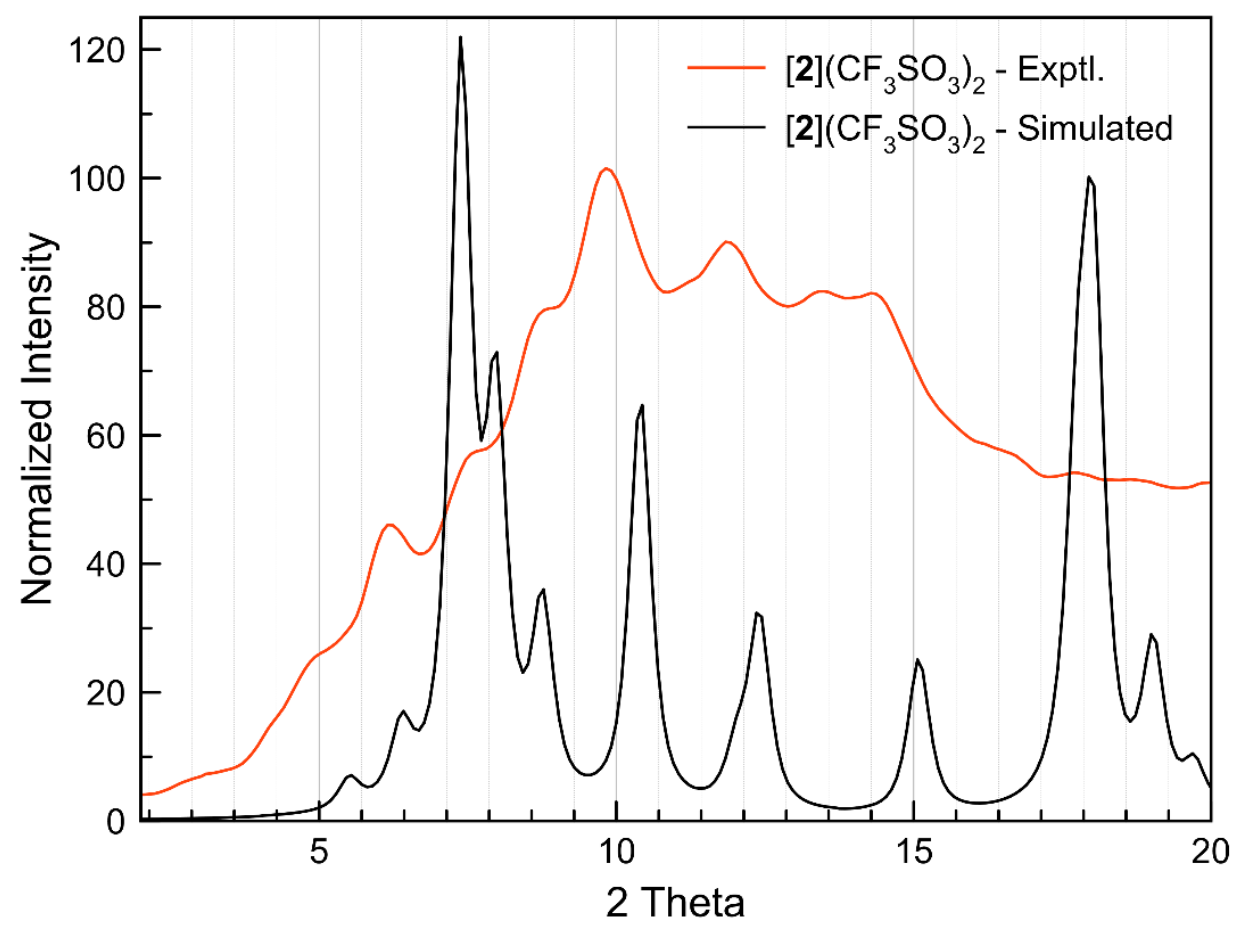

Figure 31. Powder diffraction of [2]( $\left.\mathrm{CF}_{3} \mathrm{SO}_{3}\right)_{2}$. Red, experimental; black, simulated

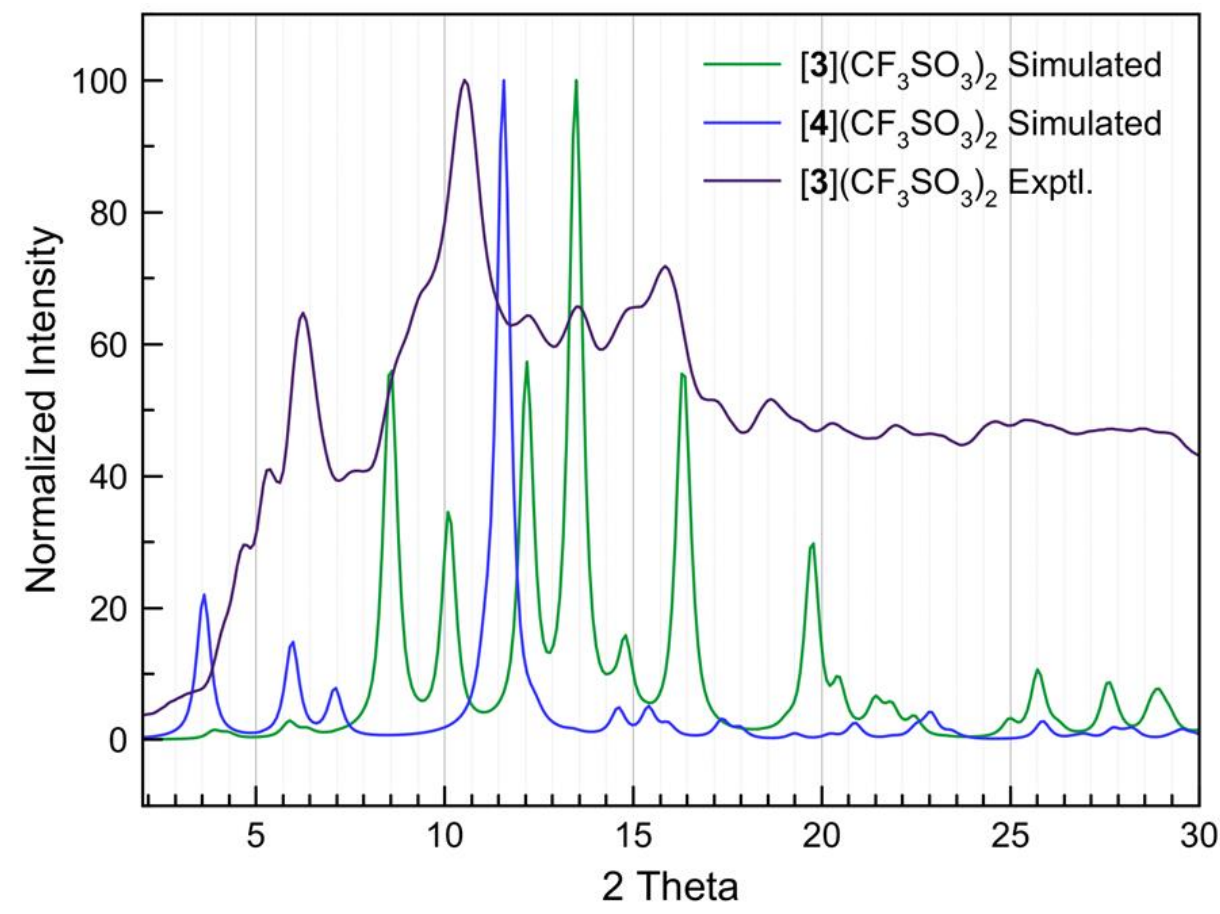

Figure 32. Powder diffraction of [3] $\left(\mathrm{CF}_{3} \mathrm{SO}_{3}\right)_{2}$. Experimental, purple; simulated pattern of [3] $\left(\mathrm{CF}_{3} \mathrm{SO}_{3}\right)_{2}$, green; simulated pattern of [4] $\left(\mathrm{CF}_{3} \mathrm{SO}_{3}\right)_{2}$, blue. 


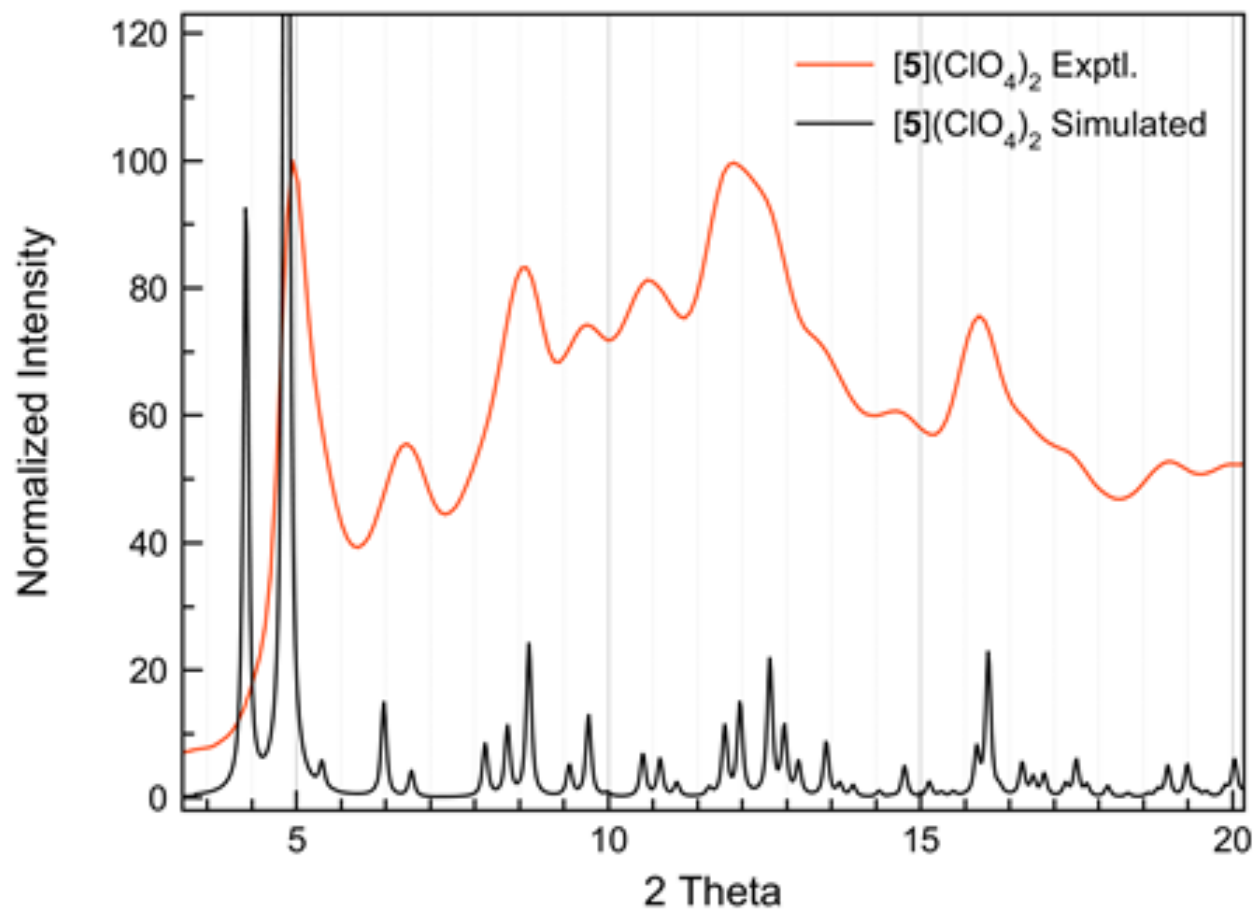

Figure 33. Powder pattern (red) of $[5]\left(\mathrm{ClO}_{4}\right)_{2}$ compared to the simulate (green).

\subsubsection{Thermogravimetric Analysis}

Thermogravimetric analyses of $[2]\left(\mathrm{CF}_{3} \mathrm{SO}_{3}\right)_{2},[3]\left(\mathrm{CF}_{3} \mathrm{SO}_{3}\right)_{2}$ and $[5](\mathrm{ClO} 4) 2$ indicate that all three release solvent molecules before decomposition. Approximately 5 weight \% of [2] $\left(\mathrm{CF}_{3} \mathrm{SO}_{3}\right)_{2}$ is lost at $<95{ }^{\circ} \mathrm{C}$ corresponding to two interstitial $\mathrm{MeOH}$ molecules, followed by decomposition at $\sim 230 \stackrel{\circ}{ } \mathrm{C}$. Approximately 10 weight $\%$ of $[3]\left(\mathrm{CF}_{3} \mathrm{SO}_{3}\right)_{2}$ and $[5]\left(\mathrm{ClO}_{4}\right)_{2}$ is lost at $<95 \stackrel{\circ}{\circ} \mathrm{C}$ corresponding to five $\mathrm{H} 2 \mathrm{O}$ and one THF molecules, respectively. Upon further heating, [3] $\left(\mathrm{CF}_{3} \mathrm{SO}_{3}\right)_{2}$ undergoes an additional $~ 10$ weight $\%$ loss, then decays sharply at $510^{\circ} \mathrm{C}$. Compound $[5]\left(\mathrm{ClO}_{4}\right)_{2}$ behaves similarly to [2] $\left(\mathrm{CF}_{3} \mathrm{SO}_{3}\right)_{2}$ (Figure 34). 


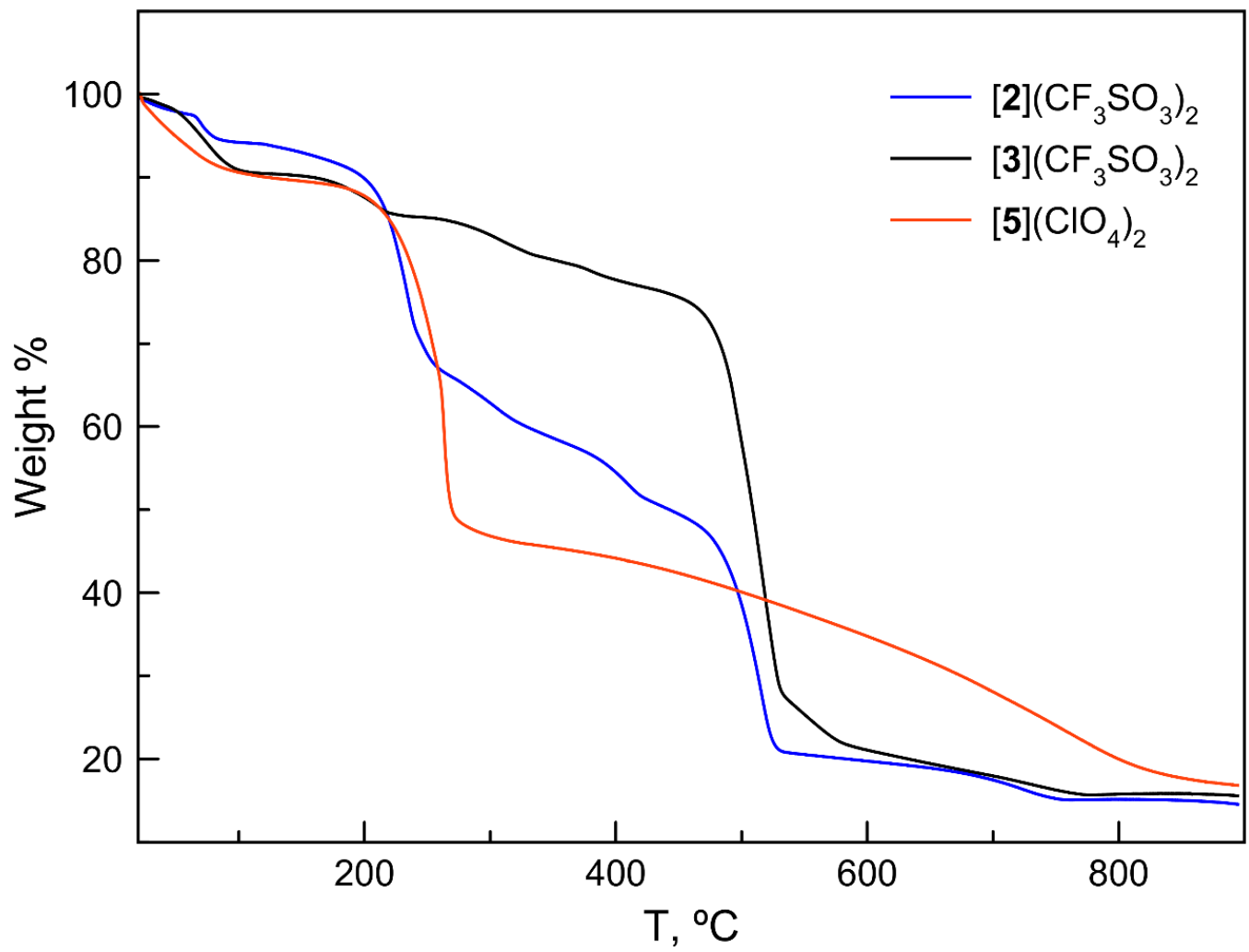

Figure 34. TGA of $[2]\left(\mathrm{CF}_{3} \mathrm{SO}_{3}\right)_{2}$ (blue), [3] $\left(\mathrm{CF}_{3} \mathrm{SO}_{3}\right)_{2}$ (black) and [5] $\left(\mathrm{ClO}_{4}\right)_{2}$ (red).

\subsection{Experimental Applications}

As proof of concept that the synthesis of lattices $3^{2+}$ and $5^{2+}$ (and presumably also $\left.[4]\left(\mathrm{CF}_{3} \mathrm{SO}_{3}\right)_{2}\right)$ can be reversed while maintaining intact the $\mathrm{Cu}_{3}-\mathrm{SBUs}$, their dissolution was studied by IR and the ${ }^{1} \mathrm{H}-\mathrm{NMR}$ spectra were examined. Compound [3] $\left(\mathrm{CF}_{3} \mathrm{SO}_{3}\right)_{2}$ displays absorptions in the IR spectrum for both coordinated $\left(1616 \mathrm{~cm}^{-1}\right)$ and uncoordinated $\left(1663 \mathrm{~cm}^{-1}\right)$ carbonyl groups. Upon dissolution in acetonitrile, a slight, but visible, color change occurred and only one carbonyl absorption appeared at $1680 \mathrm{~cm}^{-1}$ (Figure 35). The IR spectrum of $[5]\left(\mathrm{ClO}_{4}\right)_{2}$ shows one carbonyl absorption at $1614 \mathrm{~cm}^{-1}$, 
associated with the coordinated aldehyde. Once [5] $\left(\mathrm{ClO}_{4}\right)_{2}$ was dissolved in acetonitrile, this band shifted to $1675 \mathrm{~cm}^{-1}$ (Figure 36), indicating that the aldehyde was no longer coordinated. Coordination polymer [2] $\left(\mathrm{CF}_{3} \mathrm{SO}_{3}\right)_{2}$ is not soluble in MeCN, its IR spectrum showing only the $1668 \mathrm{~cm}^{-1}$ absorption corresponding to uncoordinated $\mathrm{CH}(\mathrm{O})$ groups (Figure 37). The NMR spectrum of $[5]\left(\mathrm{ClO}_{4}\right)_{2}$ in $\mathrm{CD}_{3} \mathrm{CN}$ has two paramagnetically shifted resonances at $37.69 \mathrm{ppm}\left(1 \mathrm{H}, \mathrm{w}_{1 / 2}=1033 \mathrm{~Hz}, \mathrm{C}(\mathrm{O}) \mathrm{H}\right)$ and $19.85 \mathrm{ppm}(2 \mathrm{H}$, $\left.\mathrm{w}_{1 / 2}=312 \mathrm{~Hz}, \mathrm{H}^{3,5}\right)$ corresponding to $\mathrm{a} \mathrm{Cu}{ }_{3}$-pyrazolato complex (Figure 38). The chemical shifts of these resonances are similar to those of analogous $\mathrm{Cu}_{3}$ compounds we have previously reported, ${ }^{142}$ clearly indicating the presence of a trinuclear species in the solution of $[5]\left(\mathrm{ClO}_{4}\right)_{2}$.

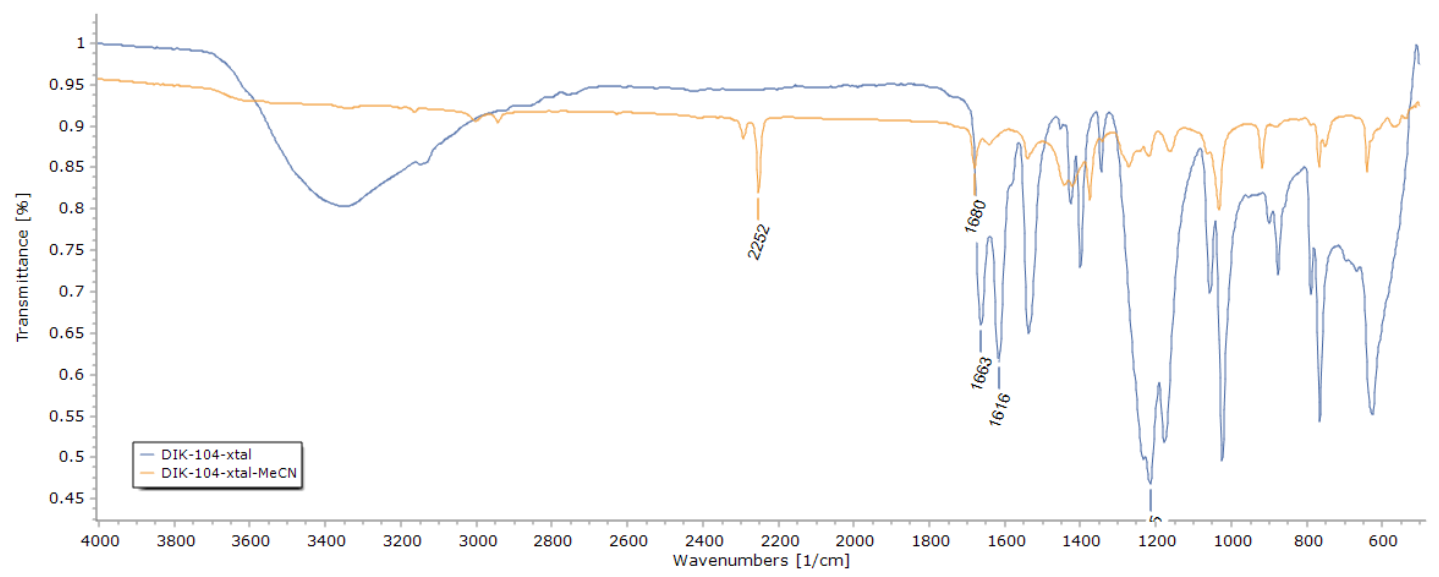

Figure 35. IR of [3] $\left(\mathrm{CF}_{3} \mathrm{SO}_{3}\right)_{2}$ before (blue) and after (orange) adding acetonitrile. 


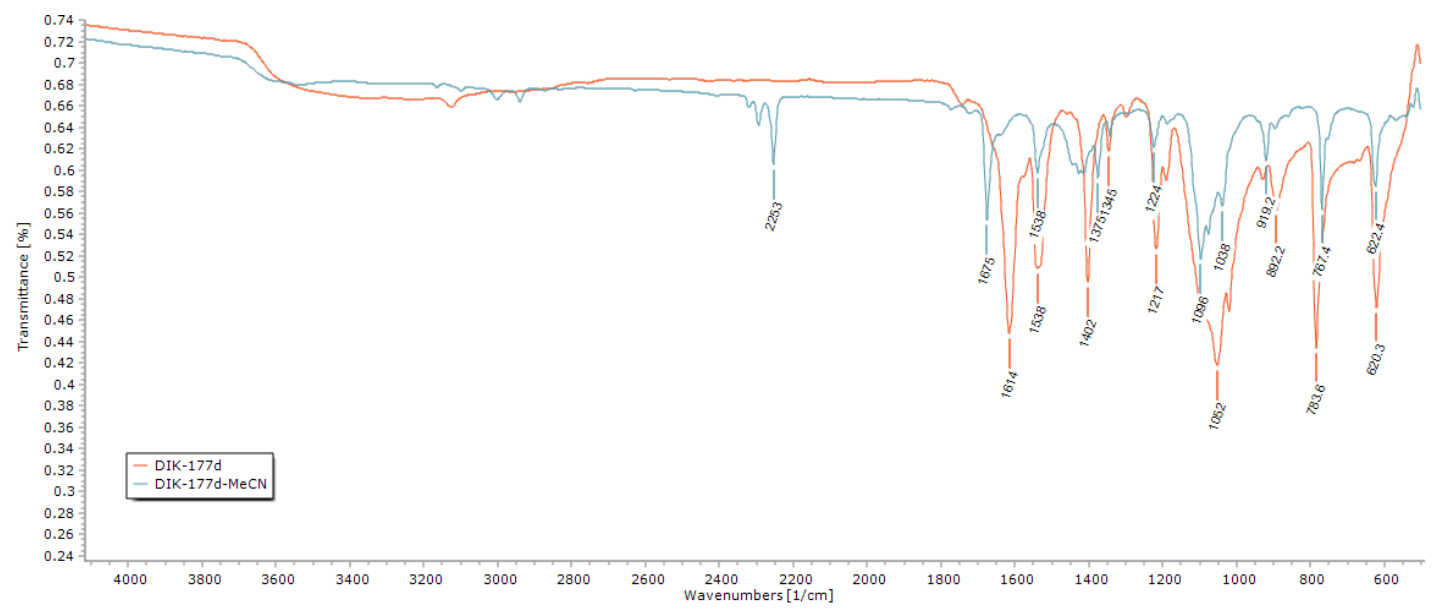

Figure 36. IR of [5] $\left(\mathrm{ClO}_{4}\right)_{2}$ before (blue) and after (red) adding acetonitrile.

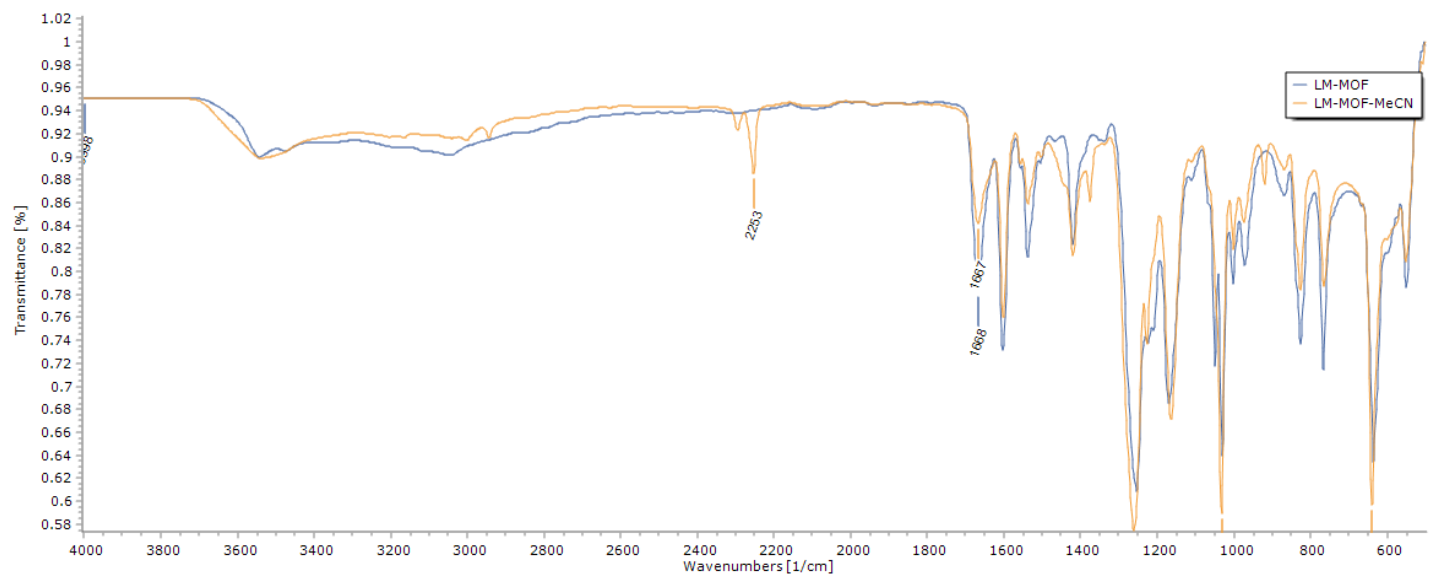

Figure 37. IR of [2] $\left(\mathrm{CF}_{3} \mathrm{SO}_{3}\right)_{2}$ before (blue) and after (orange) adding acetonitrile. 


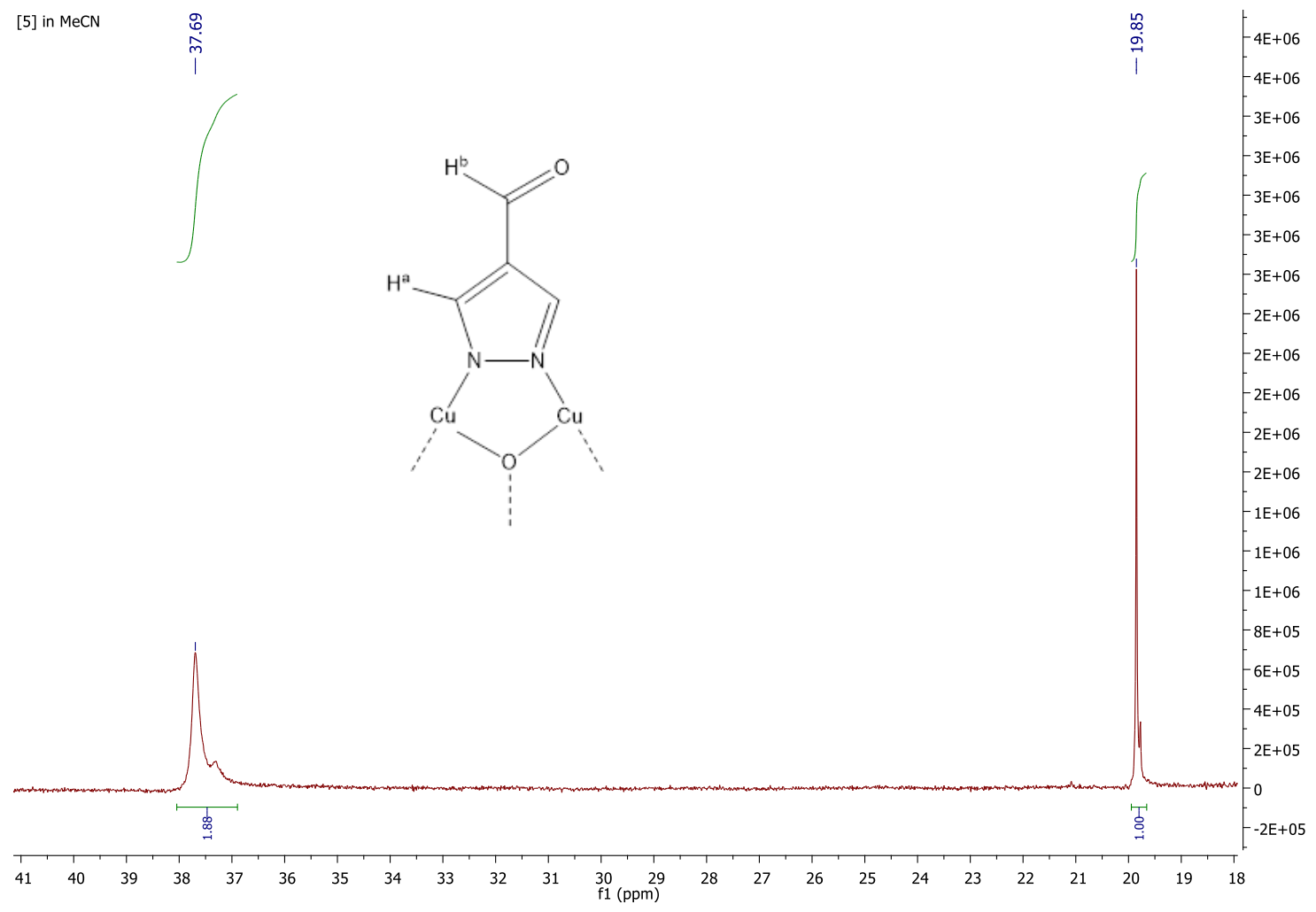

Figure 38. ${ }^{1} \mathrm{H}$ NMR of $[5]\left(\mathrm{ClO}_{4}\right)_{2}$ in acetonitrile- $d^{3}$

\subsection{Conclusions}

By reporting the first three $\mathrm{CPs}$ based on $\mathrm{Cu}_{3}$-4-formyl pyrazolate metallacycles, we have shown that formyl groups can be exploited as ligands for $\mathrm{Cu}$ (II) centers (even in the absence of chelation, such as seen with pyridine-2-carboxaldehyde) and further exploited this property towards catenation of the trinuclear SBUs. The extended network structures exhibit uncommon topologies, such as sol and bcs (in $4^{2+}$ and $\mathbf{5}^{2+}$, respectively). When competing, stronger-coordinating ligands are present, the aldehyde groups remain free and either catenation is accomplished through other bridging ligands (e.g., 1,2-bpe in $\mathbf{2}^{2+}$ ), or 0-D Cu 3 complexes are formed 
when terminal ligands (e.g., chlorides in $\mathbf{1}^{2-}$ ) are present. Finally, we have shown that the assembly of the $\mathrm{Cu}_{3}-\mathrm{SBU}$ into the formyl-linked CPs $3^{2+}$ $\mathbf{5}^{2+}$ is reversible (Scheme 11).

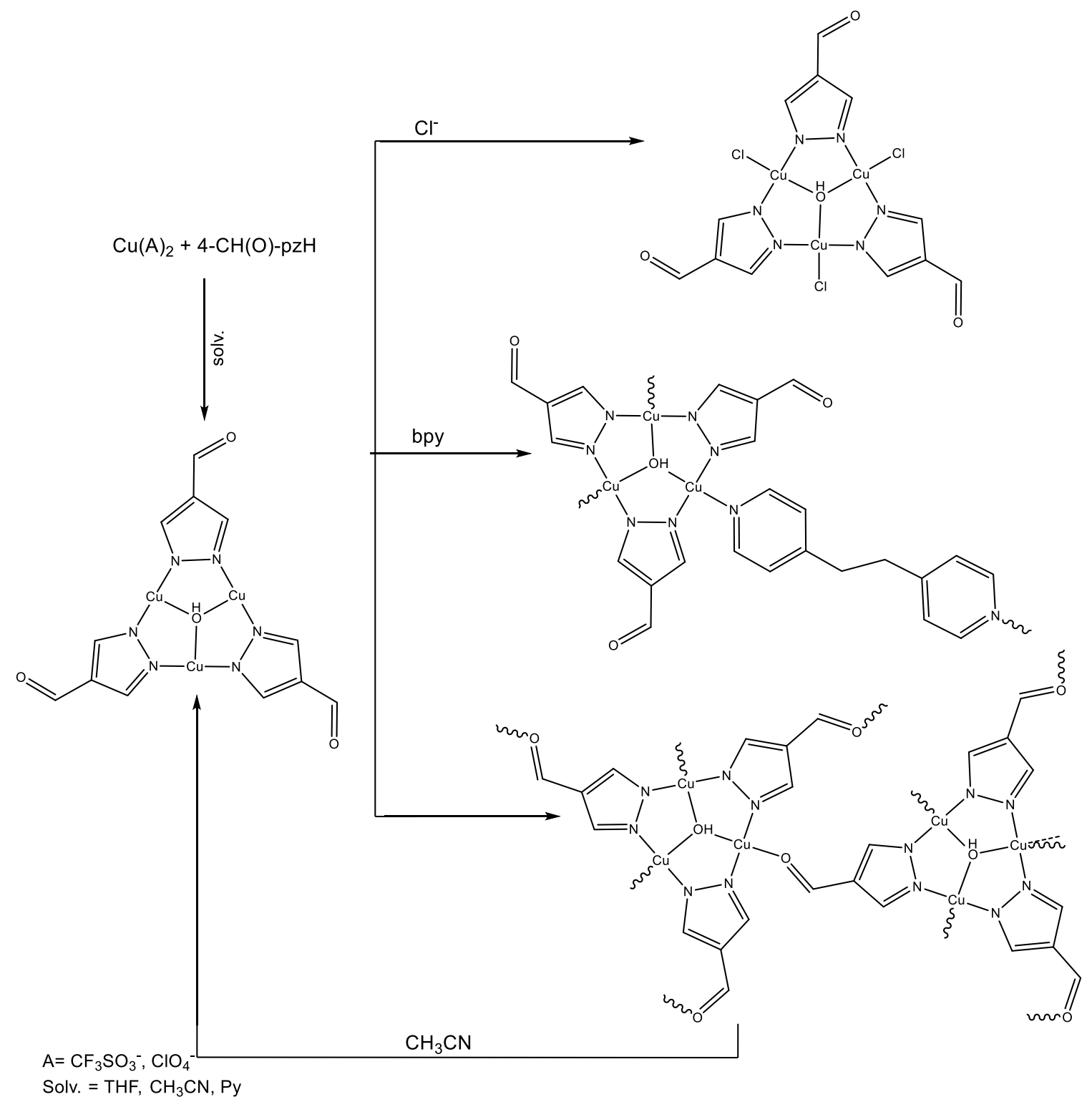

Scheme 11. Reaction pathway determined in the study. 
Chapter 4 : Synthesis and Characterization of Hexanuclear Interacting Prismatic Pyrazolato Open-Cage Complexes (HIPPŌs); Structural, VT-NMR, Magnetic, and Far-IR Studies

\subsection{Introduction}

For years, various groups have been on a quest to characterize metal-metal interaction of copper complexes comprised of trigonal $\mathrm{Cu}_{3}$ subunits. Specifically, how the various connections, such as covalent or supramolecular interactions, between the copper clusters effect the magnetics, EPR, NMR, and redox processes. This quest started in 2002 when Kamiyama et al. synthesized the first trigonal prismatic $\mathrm{Cu}_{6}$ pyrazolato complex. ${ }^{171}$ What makes these complexes so interesting is the electronic tunability of ligands and the plethora of ways to connect the $\mathrm{Cu}_{3}$ subunits together. The connectivity found in literature (Scheme 12) include supramolecular conjugation through weakly binding facially oriented counterions (a), ${ }^{172,173}$ a hydrogen being shared by two $\mu_{3}-\mathrm{O}$ (b), ${ }^{174}$ coordinated carboxylates orienting the subunits linearly (c),$^{51}$ carboxylates orienting the subunits facially (d), ${ }^{51}$ a terminal anion weakly binding a neighboring $\mathrm{Cu}_{3}(\mathrm{e}),{ }^{175}$ through direct $\mu$ pyrazolate bridging ligands (f), ${ }^{47,48,170}$ a single halide (g), ${ }^{177}$ direct $\mu$-pyrazole bridges and an encapsulated halogen (h), 171,53,55 a coordinated copper atom (i), ${ }^{178}$ or pyrazoles and another ligand (j). ${ }^{176}$ 

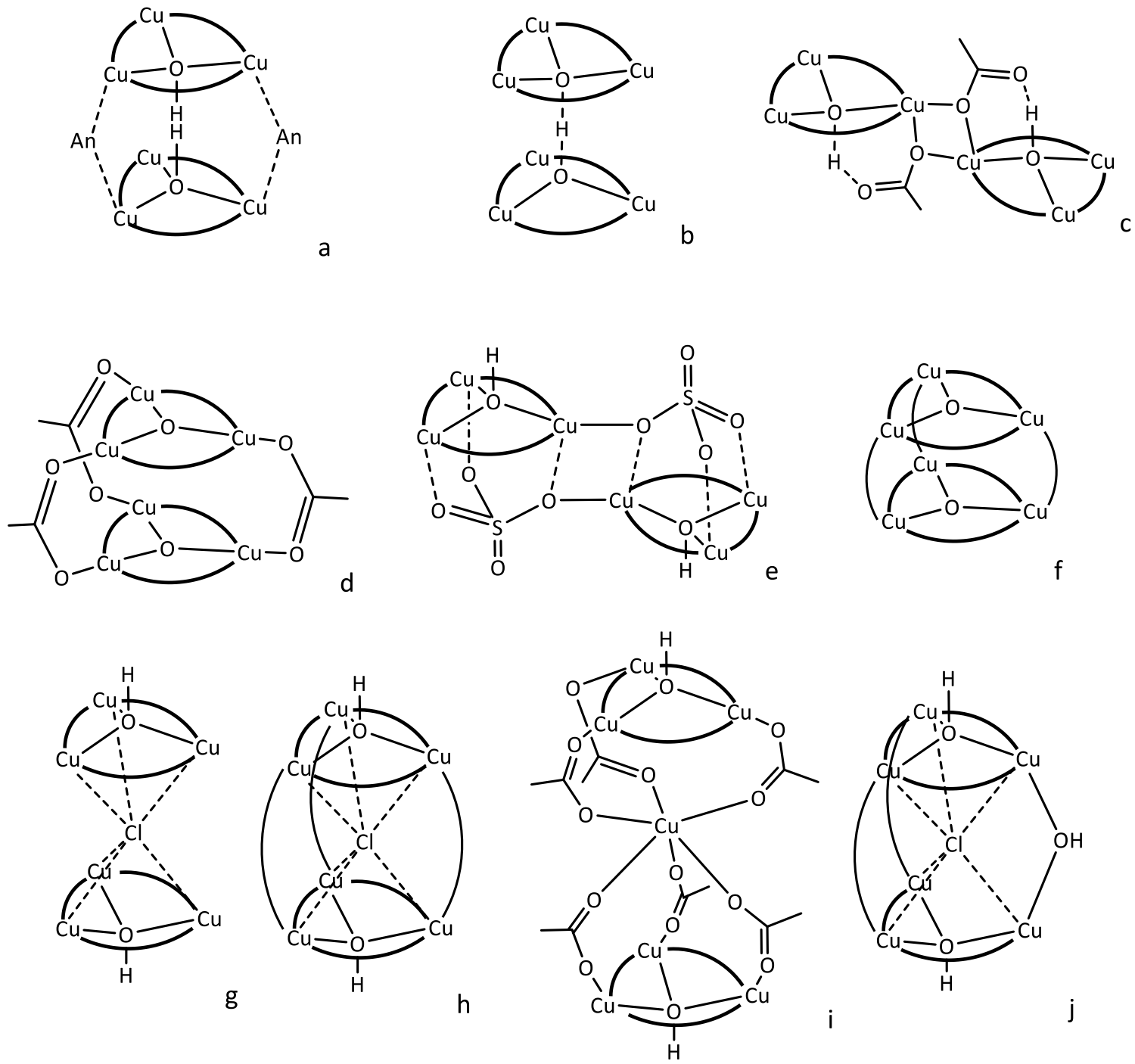

$\overbrace{0}^{\mathrm{An}}=\mathrm{NO}_{3^{-}}, \mathrm{ClO}_{4^{-}}$, or $\mathrm{Cl}^{-} \quad\left(=\mathrm{pzH}^{*}\right.$

Scheme 12. Representations of the various motifs of $\mathrm{Cu}_{6}$ present in literature.

The magnetic interactions in Сuз-pyrazolato subunits are complicated by spin frustration, with the magnetic relationship being dictated by the $\mu_{3}$-capping ligand. The magnetic interaction switches from antiferromagnetic to ferromagnetic occurring as the $\mu_{3}$-capping ligand rises above the basal plane to make more acute 
angles with the copper centers, with the transition occurring at $\phi=92^{\circ} .44,45$ What is less understood however, is how the Cu3 subunits interact when connected in various ways. What is known so far is that when the $\mathrm{Cu}_{3}$ subunits are interacting through supramolecular interactions, there is a weak antiferromagnetic coupling between the $\mathrm{Cu}_{3}$ subunits ${ }^{172,174,177}$ and direct pyrazolate bridging leads to strong antiferromagnetic coupling between the $\mathrm{Cu}_{3}$ subunits. ${ }^{48,53,171}$ Furthermore, encapsulating an ion inside a $\mathrm{Cu}_{6}$ cage leads to significantly weaker antiferromagnetic coupling within each subunit as it pushes the $\mu_{3}-\mathrm{OH}$ ligand farther out of the basal plane, ${ }^{53}$ and unsymmetric ligands, specifically ones that lead to a non-parallel basal plane reduce the antiferromagnetic coupling between the $\mathrm{Cu}_{3}$ subunits. ${ }^{176}$ However, there are many more ways one can imagine connecting $\mathrm{Cu}_{3}$ subunits. Another aspect of these compounds that has been grievously neglected is the Far-IR absorptions, which are diagnostic of $\mathrm{Cu}$ halogen, Cu-oxygen or Cu-nitrogen bond strengths, with no far-IR data in the literature even in regards to simple $\mathrm{Cu}_{3}$-pyrazolato complexes, of which, the first motif was reported in 1983. ${ }^{180}$ Far-IR assignments of $\mathrm{Cu}-\mathrm{N}, \mathrm{O}$, or $\mathrm{X}$ bonds are rare for all Cu-complexes, especially involving bridging ligands, with only a few studies being conducted. ${ }^{181-187}$ Here, we present the first open-cage Hexanuclear Interacting Prismatic Pyrazolato Open-cage complexes, "HIPPOs", which have a structure reminiscent of "Pac-Man" complexes, ${ }^{188,189}$ with $\mathrm{Cu}_{6}$ compound having the most similar structure being reported by Coronado. ${ }^{176}$ In this paper the crystals structures of various HIPPOs are discussed as well as magnetic susceptibility, NMR and the Far-IR absorptions of HIPPOs and related complexes. 


\subsection{Experimental}

\subsubsection{Materials and Methods}

All reagents were purchased from commercial sources and used without further purification. 4- $\mathrm{Ph}-\mathrm{pz} \mathrm{H},{ }^{190}$ 4- $\mathrm{Cl}-\mathrm{pz} \mathrm{H},{ }^{191}$ and compounds [1] and PPN[2] were synthesized according to published procedures. ${ }^{49,53}$ Solvents were purified using standard procedures. ${ }^{146} \mathrm{CuCl}_{2} \cdot 2 \mathrm{H}_{2}{ }^{18} \mathrm{O}$ was prepared by drying $\mathrm{CuCl}_{2} \cdot 2 \mathrm{H}_{2} \mathrm{O}$ in an oven at $125^{\circ} \mathrm{C}$ overnight until the brown anhydrate was obtained, then $\mathrm{H}_{2}{ }^{18} \mathrm{O}$ was added to the salt. $\mathrm{Na}{ }^{18} \mathrm{OH}$ was prepared by adding $\mathrm{H}_{2}{ }^{18} \mathrm{O}$ to $\mathrm{Na}$ metal under argon. All reactions were performed under $\mathrm{N}_{2}$ unless mentioned otherwise. Elemental analysis was performed at Galbraith Laboratories, Inc.

\subsubsection{Variable Low-Temperature NMR}

${ }^{1} \mathrm{H}-\mathrm{NMR}$ was recorded in acetone- $\mathrm{d}_{6}$, THF- $\mathrm{d}_{8}$, or $\mathrm{CD}_{2} \mathrm{Cl}_{2}$ in a Bruker Avance 400 NMR spectrometer. $T_{2}$ times were calculated using the equation $T_{2}^{*}=1 /\left(w_{\frac{1}{2}} \pi\right)$, assuming $T_{2} \sim T_{2}^{*}$, where $w_{\frac{1}{2}}$ is width-at-half-height, at room temperature unless otherwise noted.

\subsubsection{IR and Far-IR}

Far-IR data were collected using an Agilent Technologies Cary 600 Series FTIR spectrometer with 4 scans from 3500-250 cm-1. Data were analyzed using Spectragryph 1.2.10 software. ${ }^{149}$ The samples were mixed with cesium iodide salt, at an approximate 1:10 ratio, and ground into a fine powder. The powder was pressed into a pellet and was used for IR collection. 


\subsubsection{Computational Methods for Calculated IR}

The geometry optimizations and frequency calculations of all copper complexes have been carried out by Dr. Daniel Belisario Lara using DFT with the B3LYP functional included with the GAUSSIAN-09 package. ${ }^{192}$ Non-metal atoms were calculated using a triple- $\zeta$ valence polarized basis set. Copper atoms were treated using the LANL2DZ basis effective core potentials. ${ }^{193}$ Comparisons were calculated between treating the copper atoms at the B3LYP/TVZP level and the B3LYP/LANDL2DZ level, with closer agreement on both bond distances and frequencies found with the effective core potential. The $\mathrm{Cu}-\mathrm{Cl}$ distances were found to be overestimated by $0.1-0.5 \AA$ when compared to values obtained via Xray diffraction. Bond distances for other components and ligands showed similar deviations in agreement with accepted values. Frequencies were typically in agreement to experimental data by $30 \mathrm{~cm}^{-1}$, except for one frequency associated with $\mathrm{Cu}-\mathrm{Cl}$. The peak shapes of simulated spectra were reasonable approximations of the experimental data. Counterions were not included in the calculations in order to off-set some of the computational cost of these relatively large complexes. Phenyl rings attached to pyrazolate were substituted with hydrogen atoms to further offset computational time.

\subsubsection{Magnetic Data Acquisition}

Temperature-dependent $(T=1.9-300 \mathrm{~K}, \mathrm{~B}=1.0 \mathrm{~T})$ and field-dependent $(\mathrm{B}=0-$ $9 \mathrm{~T}, T=2,5$ and $10 \mathrm{~K}$ ) magnetization measurements were performed by $\mathrm{Dr}$. R. 
Herchel using a PPMS Dynacool VSM magnetometer (Quantum Design). The magnetic data were corrected for the diamagnetism of the constituent atoms.

\subsubsection{Theoretical Calculations for Magnetic Data}

The DFT theoretical calculations were carried out with the ORCA 3.0 computational package. ${ }^{194}$ The B3LYP functional was used for calculations of the isotropic exchange constants $J,{ }^{195-197}$ following the Ruiz approach, ${ }^{198,199}$ by comparing the energies of high-spin and broken-symmetry spin states. The relativistic effects were treated with the $0^{\text {th }}$ order regular approximation (ZORA) using a relativistic version of the polarized triple-x quality basis set, ZORA-def2TZVP(-f) for $\mathrm{Cu}, \mathrm{N}, \mathrm{Cl}$ and $\mathrm{O}$ atoms, and ZORA-def2-SVP basis set for $\mathrm{C}$ and $\mathrm{H}$ atoms. ${ }^{200}$ The calculations utilized the RI approximation with the decontracted auxiliary SARC/J Coulomb fitting basis set ${ }^{201}$ and the chain-of-spheres (RIJCOSX) approximation to exact exchange as implemented in ORCA. ${ }^{202,203}$ Increased integration grids (Grid5 and Gridx5 in ORCA convention) and tight SCF convergence criteria were used in all calculations. The molecular fragment used in the calculations was extracted from the experimental X-ray structure. The calculated spin density was visualized with VESTA 3 program. ${ }^{204}$

\subsubsection{X-ray Crystallography}

Single crystals of the compounds were mounted on a MiteGen ${ }^{\circledR}$ CryoLoop ${ }^{\mathrm{TM}}$ or on a glass fiber and diffraction data were collected on a Bruker D8 Quest diffractometer equipped with a Photon 100 CMOS or a Bruker APEX II diffractometer with a SMART detector using Mo-Ka radiation. Data were 
collected using APEX 3 suite; structure solution was obtained using intrinsic phasing with SHELXT. ${ }^{110}$ Data were refined by least-square methods available within SHELXL ${ }^{111}$ using the Olex2 interface. ${ }^{112}$ Electron densities corresponding to disordered interstitial solvent molecules were accounted for by using the MASK routine available within Olex2.

\subsection{Synthetic procedures}

\subsection{1. $\mathrm{H}-, \mathrm{Cl}-$ and $\mathrm{Br}-\mathrm{HIPPO}$}

The H-, Cl-, and Br-HIPPO, TPP $\left[\left\{\mathrm{Cu}_{3}\left(\mu_{3}-\mathrm{OH}\right)(\mu-4-\mathrm{R}-\mathrm{pz})_{3} \mathrm{Cl}\right\}_{2}(\mu-4-\mathrm{R}-\mathrm{pz})_{2}\left(\mu_{4}-\mathrm{Cl}\right)\right.$, ( $\mathrm{R}=\mathrm{H}$ for H-HIPPO, $\mathrm{Cl}$ for $\mathrm{Cl}-\mathrm{HIPPO}$, and $\mathrm{Br}$ for $\mathrm{Br}-\mathrm{HIPPO}$ ) were synthesized on a $1 \mathrm{mmol}$ scale with $3: 2: 11: 1$ ratio of $\mathrm{CuCl}_{2} \cdot 2 \mathrm{H}_{2} \mathrm{O}$, the appropriate $1 \mathrm{H}$-pyrazole, $\mathrm{NaOH}$, and tetraphenylphosphonium chloride, respectively. The reactants were stirred overnight in $25 \mathrm{~mL}$ THF under a blanket of $\mathrm{N}_{2}$. The reaction mixtures were then collected, and the filtrate was concentrated using a rotary evaporator. The product was crushed out by the addition of diethyl ether or hexane. The product was collected by suction filtration and allowed to air dry overnight. The powdered sample was collected and redissolved in $4 \mathrm{~mL}$ THF and then $\sim 7.5 \mathrm{~mL}$ of toluene was added to the solution. The solutions were then layered with $15 \mathrm{~mL}$ of hexane and allowed to crystallize. The CI-HIPPO was obtained in $71.7 \%$ yield with respect to $\mathrm{Cu}$. The Br-HIPPO and H-HIPPO were obtained in 32.4 and $34 \%$ yields, respectively. 
Elemental analysis for $\mathrm{Ph}_{4} \mathrm{P}\left[\left\{\mathrm{Cu}_{3}\left(\mu_{3}-\mathrm{OH}\right)(\mu-4-\mathrm{Cl}-\mathrm{pz})_{3} \mathrm{Cl}\right\}_{2}\left[\mu \mu_{4}-\mathrm{Cl}\right]\right\}(\mu-4-\mathrm{Cl}-\mathrm{pz}) 2 \cdot$ thf, Compound 2, $\left(\mathrm{C}_{52} \mathrm{H}_{46} \mathrm{Cl}_{11} \mathrm{Cu}_{6} \mathrm{~N}_{16} \mathrm{O}_{3} \mathrm{P}\right)$, calculated/found (\%): C, 35.79/36.06; $\mathrm{H}$, 2.66/2.85; N, 12.84/12.84.

\subsubsection{Ph-HIPPO}

The synthesis of $\left[\left\{\mathrm{Cu}_{3}\left(\mu_{3}-\mathrm{OH}\right)(\mu-4-\mathrm{Ph}-\mathrm{pz})_{3} \mathrm{Cl}\right\}_{2}(\mu-4-\mathrm{Ph}-\mathrm{pz})_{2}(\mu-\mathrm{Cl}), \quad \mathrm{Ph}-\mathrm{HIPPO}\right.$, was carried out on a $0.2 \mathrm{mmol}$ scale in $15 \mathrm{~mL}$ of $\mathrm{MeCN}$, using a 1:1:1:2 ratio of $\mathrm{CuCl}_{2} \cdot 2 \mathrm{H}_{2} \mathrm{O}$, 4-Ph-pzH, pyridine, and $\mathrm{NaOH}$. It was stirred for 4 hours and subsequently filtered using suction. The filtrate was allowed to stand until all solvents evaporated and X-ray quality crystals of Ph-HIPPO were obtained after 2-3 weeks. The Ph-Hippo was obtained in $50.1 \%$ yield with respect to $\mathrm{Cu}$. Elemental analysis for $\left[\left\{\mathrm{Cu}_{3}\left(\mu_{3}-\mathrm{OH}\right)(\mu-4-\mathrm{Ph}-\mathrm{Pz})_{3} \mathrm{pyCl}\right\}_{2}\left(\mu_{2}-\mathrm{Cl}\right)(\mu-4-\mathrm{Ph}-\mathrm{pz})\right]$, $\left(\mathrm{C}_{73} \mathrm{H}_{61} \mathrm{Cl}_{3} \mathrm{Cu}_{6} \mathrm{~N}_{16} \mathrm{O}_{2}\right) \cdot 2 \mathrm{NaCl} \cdot \mathrm{MeCN}$ calculated/found (\%): C, 49.56/48.7; $\mathrm{H}$, 3.77/3.87; N, 13.10/13.34.

\subsection{3. ${ }^{18} \mathrm{O}-\mathrm{H}-\mathrm{HIPPO}$}

The synthesis of TPP $\left[\left\{\mathrm{Cu}_{3}\left(\mu_{3^{-}}{ }^{18} \mathrm{OH}\right)(\mu-4-\mathrm{R}-\mathrm{pz})_{3} \mathrm{Cl}\right\}_{2}(\mu-\mathrm{pz})_{2}\left(\mu_{4}-\mathrm{Cl}\right)\right.$ used specially prepared reagents on a $1 \mathrm{mmol}$ scale with $3: 2: 11: 1$ ratio of $\mathrm{CuCl}_{2} \cdot 2 \mathrm{H}_{2}{ }^{18} \mathrm{O}, 1 \mathrm{H}$ pyrazole, $\mathrm{Na}^{18} \mathrm{OH}$, and tetraphenylphosphonium chloride, respectively. Before use, the pyrazole was placed in a desiccator for a week. The reagents were stirred overnight in $25 \mathrm{ml}$ of dry, degassed THF under a blanket of argon with a $50 \mu \mathrm{l}$ aliquot of $\mathrm{H}_{2}{ }^{18} \mathrm{O}$. The resulting solution was filtered and set for diethyl ether vapor diffusion which yielded X-ray quality crystals of $\operatorname{TPP}\left[\left\{\mathrm{Cu}_{3}\left(\mu_{3}-{ }^{18} \mathrm{OH}\right)(\mu-4-\mathrm{R}-\right.\right.$ $\left.\mathrm{pz})_{3} \mathrm{Cl}\right\}_{2}(\mu-\mathrm{pz})_{2}\left(\mu_{4}-\mathrm{Cl}\right)$ after two days. The crystalline product yield was $22.8 \%$. 


\subsection{Results}

\subsubsection{Crystallography}

\subsubsection{1. $\mathrm{H}-, \mathrm{Cl}-$, and $\mathrm{Br}-\mathrm{HIPPO}$}

Three HIPPOs, $\mathbf{H}-, \mathbf{C l}-$, and $\mathbf{B r}-\mathrm{HIPPO}$ consist of two triangular $\mathrm{Cu}_{3}(\mu-4-\mathrm{R}-\mathrm{pz})-$ subunits held together by two bridging $\mu-4-\mathrm{R}-\mathrm{pz}$ ligands and a $\mu_{4}-\mathrm{Cl}$. This structural feature is unique in this series of complexes. The H-HIPPO (Figure 39), Cl-HIPPO (Figure 40) and Br-HIPPO (Figure 41) crystalized in the triclinic $P \overline{\mathbf{1}}$ space group and are isostructural. The asymmetric unit encompasses an entire molecule with the TPP counter ion tucked inside the cage opening (Figure 42). In H-HIPPO, a THF solvent molecule is hydrogen bonded to the $\mu_{3}$-hyrdoxo proton on one of the subunits. Crystallographic details are listed in Table 6, with selected bond lengths listed in Table 7.

In all three of these structures a $\mu_{4}-\mathrm{Cl}$ ligand resides within the "jaws" of the complex, with Cu-Cl bond lengths between 2.560(1) and 3.040(1). The $\mu_{3}-\mathrm{OH}$ ligands sit 0.555 to $0.608 \AA$ above the plane, which is in agreement with previous literature. ${ }^{53,179}$ The two panes formed by the $\mathrm{Cu}$ atoms of the trimer subunits form 73.9, 66.8, and 66. $1^{\circ}$ angles for H-HIPPO, Cl-HIPPO, and Br-HIPPO, respectively 


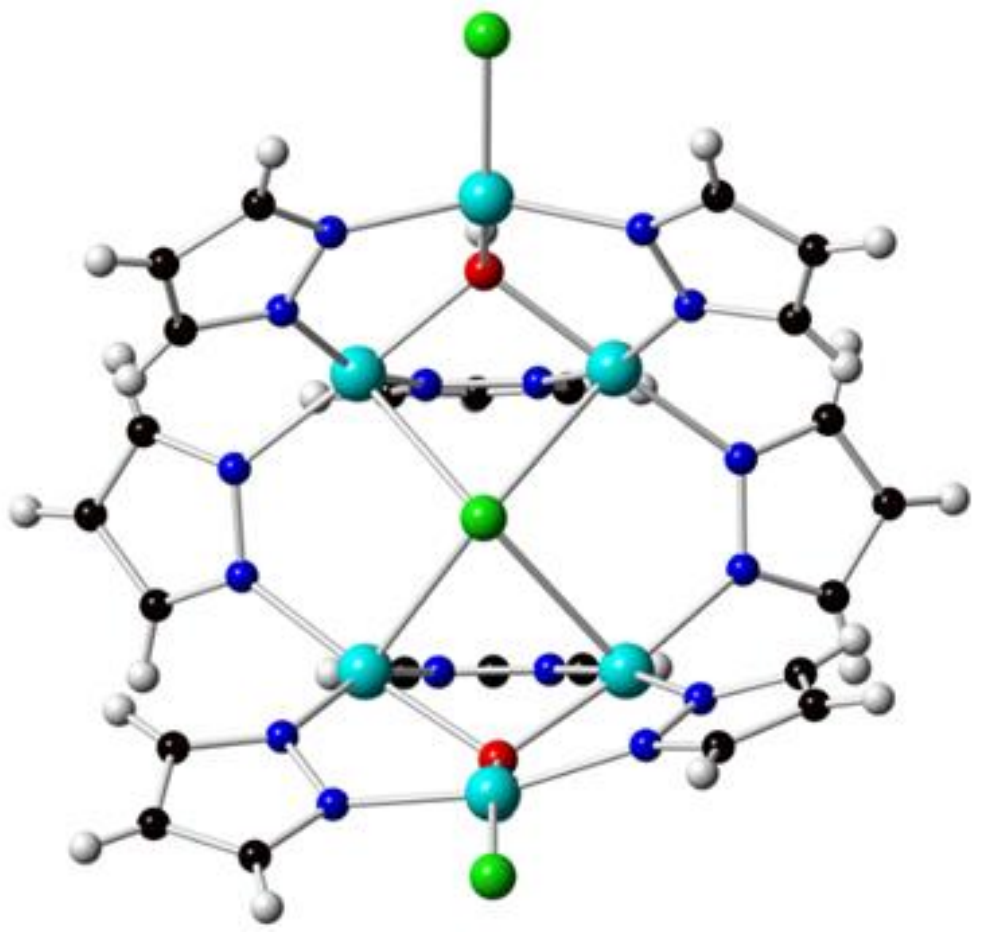

Figure 39. H-HIPPO - front view. Color code: Black, C; Grey, H; Red, O; Blue, N; Cyan, $\mathrm{Cu}$; Green, $\mathrm{Cl}$. Counter anions omitted for clarity.

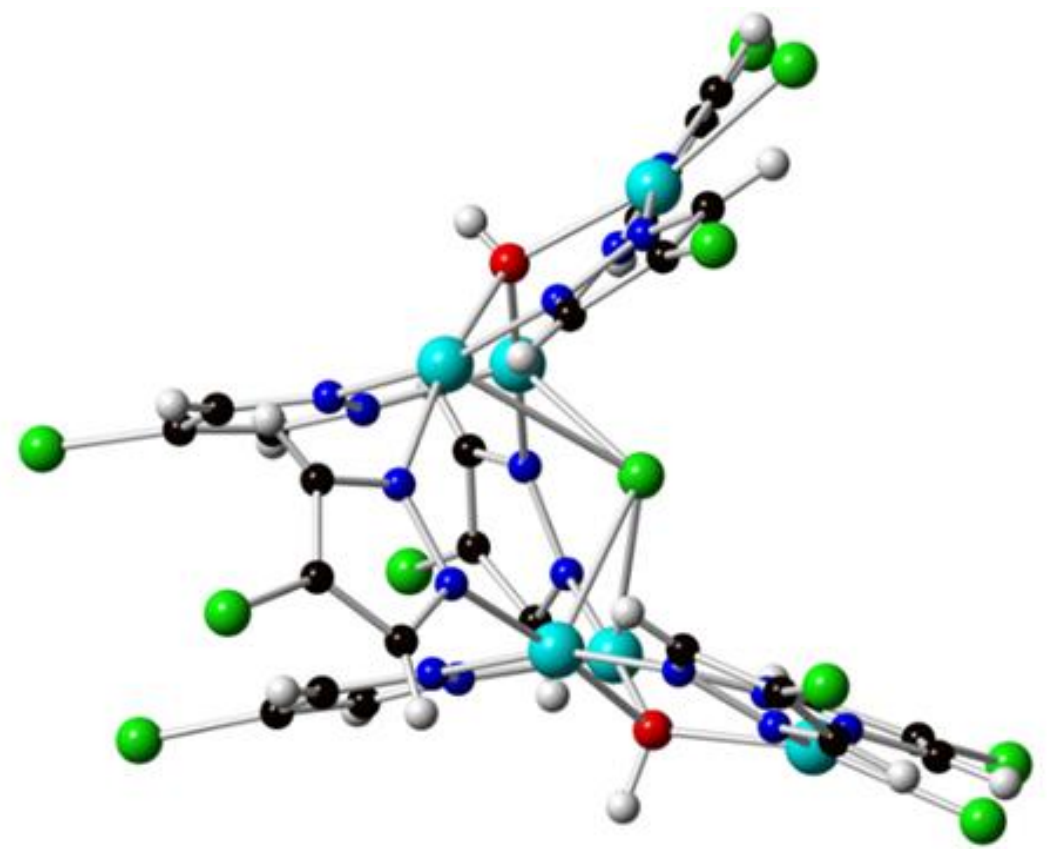

Figure 40. CI-HIPPO - side view. Color code: Black, C; Grey, H; Red, O; Blue, N; Cyan, $\mathrm{Cu}$; Green, $\mathrm{Cl}$. Counter anions omitted for clarity. 


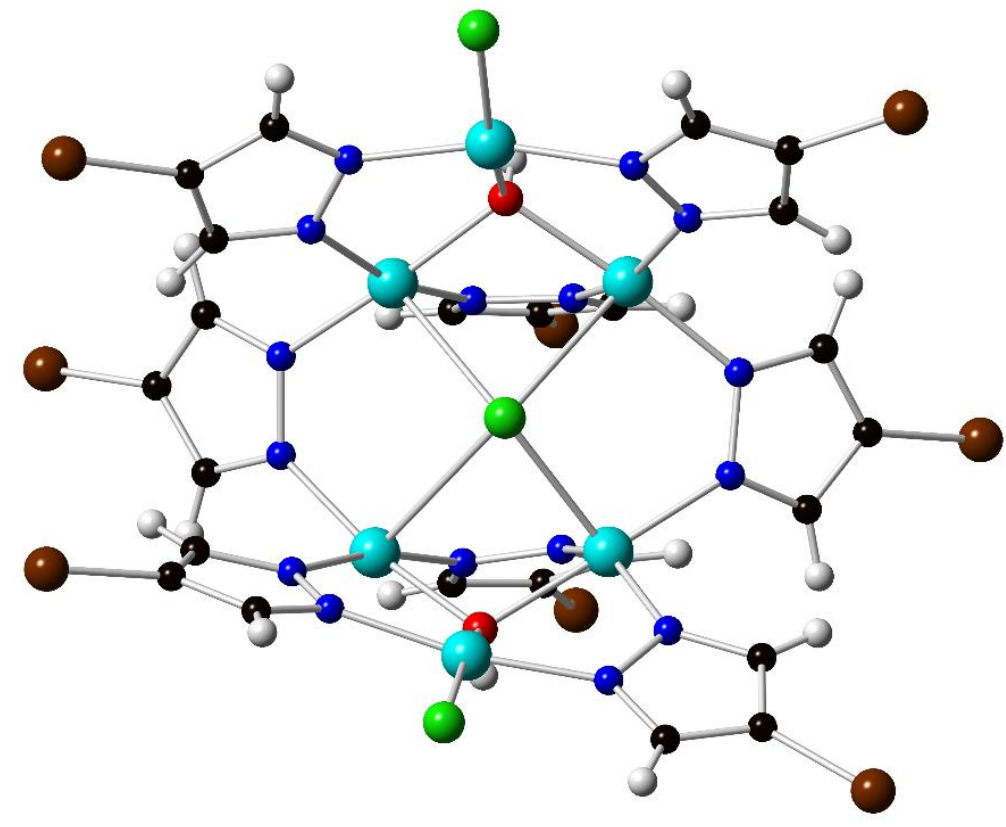

Figure 41. Br-HIPPO - front view. Color code: Black, C; Grey, H; Red, O; Blue, $\mathrm{N}$; Cyan, $\mathrm{Cu}$; Green, $\mathrm{Cl}$. Counter anions omitted for clarity.

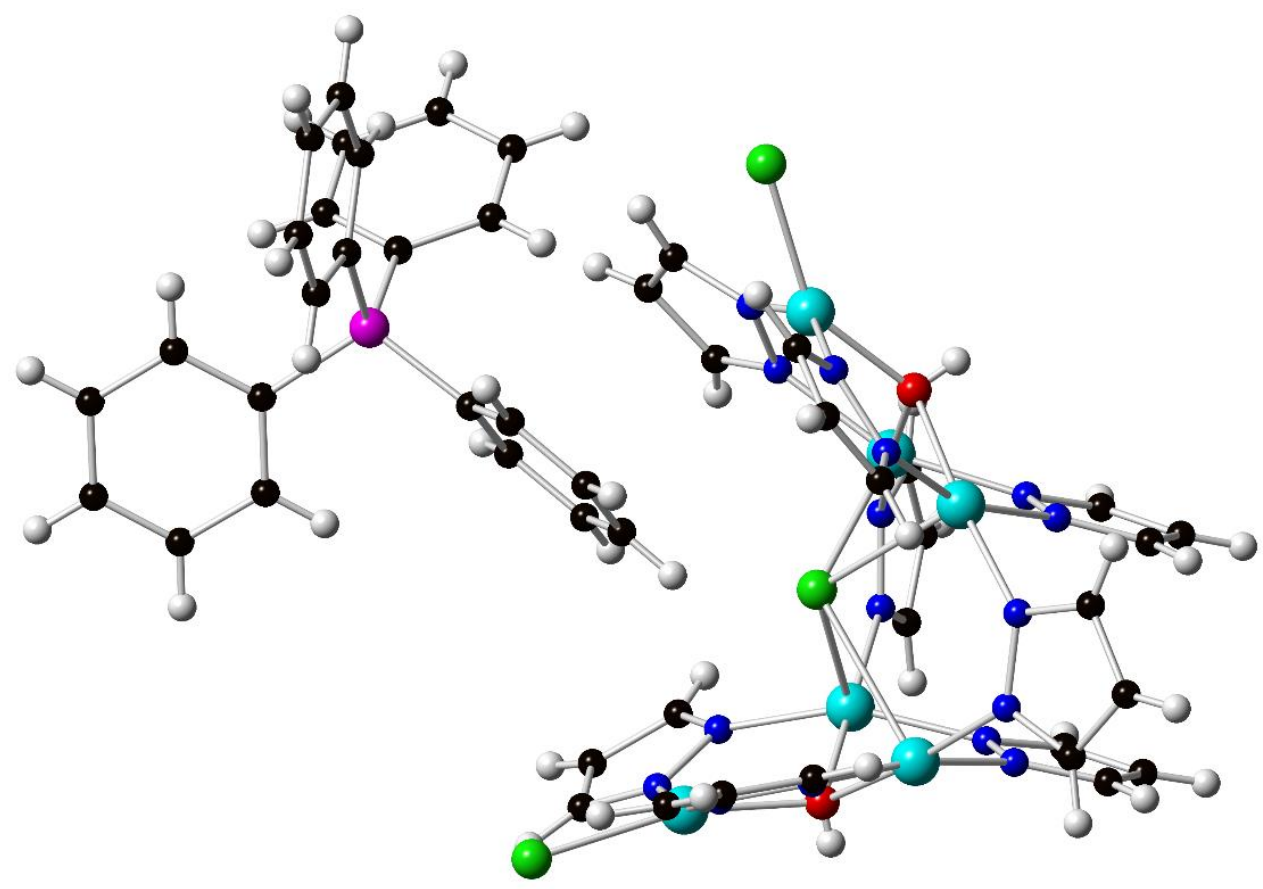

Figure 42. Counter ion placement in H-HIPPO. 


\subsubsection{Ph-HIPPO}

The Ph-HIPPO (Figure 43) crystalizes in space group $P_{\mathrm{bcn}}$ with one half of the molecule in the asymmetric unit. The copper trimers in Ph-HIPPO are bridged by a single 4-phenylpyrazolate ligand, the Cu-N bond length of 2.026(3) $\AA$. The other two $\mathrm{Cu}$ atoms are terminated by a chloride and pyridine in each subunit. The Ph-HIPPO has a $\mathrm{Cl}^{-}$in between the two trigonal trimers similar to the other HIPPOs, it is only bound to four of $\mathrm{Cu}$ atoms, two have a $\mathrm{Cu}-\mathrm{Cl}$ bond length of

2.668(1) $\AA$, the other two have a bond length of 2.941(2) $\AA$. The non-bonded Cu$\mathrm{Cl}$ distances are $\quad 3.535(1) \AA$. This $\mathrm{Cl}$-atom bridges diagonally across the opening with an angle of $159.51(7)^{\circ}$. The $\mu_{3}-\mathrm{OH}$ ligands sit $0.589 \AA$ above the plane, again similar to literature. ${ }^{179}$ The $\mathrm{Cu}$ plane in the singly bridged Ph-Hippo is at a $31.2^{\circ}$ angle, much closer to being cofacial than in the other HIPPOs.

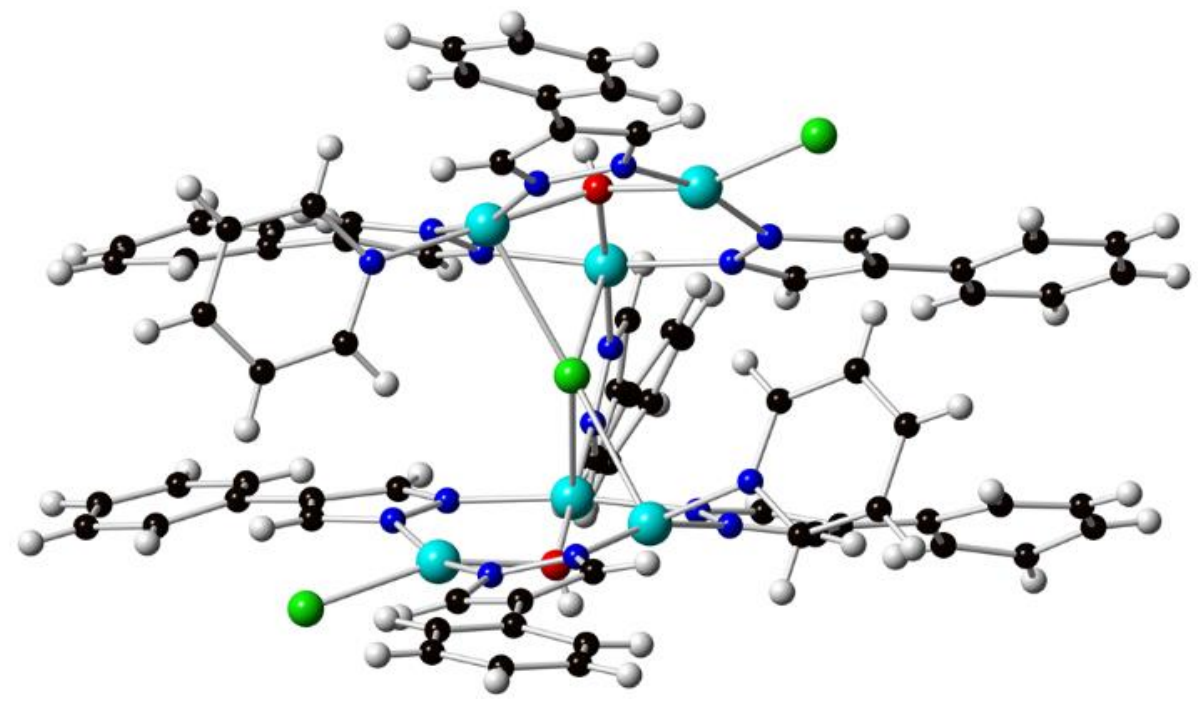

Figure 43. Ph-HIPPO - front view. Color code: Black, C; Grey, H; Red, O; Blue, N; Cyan, $\mathrm{Cu}$; Green, $\mathrm{Cl}$. 
Table 6. Crystal parameters for chapter 4.

\begin{tabular}{|c|c|c|c|c|}
\hline $\begin{array}{c}\text { Identification } \\
\text { code }\end{array}$ & H-HIPPO & CI-HIPPO & Br-HIPPO & Ph-HIPPO \\
\hline Formula & $\begin{array}{c}\mathrm{C}_{112} \mathrm{H}_{124} \mathrm{Cl}_{6} \mathrm{Cu}_{12} \\
\mathrm{~N}_{32} \mathrm{O}_{8} \mathrm{P}_{2}\end{array}$ & $\begin{array}{c}\mathrm{C}_{48} \mathrm{H}_{38} \mathrm{Cl}_{11} \mathrm{Cu}_{6} \\
\mathrm{~N}_{16} \mathrm{O}_{2} \mathrm{P}\end{array}$ & $\begin{array}{l}\mathrm{C}_{96} \mathrm{H}_{76} \mathrm{Br}_{16} \mathrm{Cl}_{6} \\
\mathrm{Cu}_{12} \mathrm{~N}_{32} \mathrm{O}_{4} \mathrm{P}_{2}\end{array}$ & $\begin{array}{c}\mathrm{C}_{73} \mathrm{H}_{61} \mathrm{Cl}_{3} \mathrm{Cu}_{6} \\
\mathrm{~N}_{16} \mathrm{O}_{2}\end{array}$ \\
\hline $\mathrm{fw}(\mathrm{amu})$ & 3083.54 & 1673.10 & 4057.56 & 1681.96 \\
\hline Size $\left(\mathrm{mm}^{3}\right)$ & $\begin{array}{c}0.30 \times 0.21 \times \\
0.19\end{array}$ & $\begin{array}{c}0.20 \times 0.13 \times \\
0.12\end{array}$ & $\begin{array}{c}0.84 \times 0.39 \times \\
0.16\end{array}$ & $\begin{array}{c}0.26 \times 0.21 \times \\
0.10\end{array}$ \\
\hline Temperature (K) & $293(2)$ & 301.24 & 299.23 & 273.15 \\
\hline Crystal system & triclinic & triclinic & triclinic & orthorhombic \\
\hline Space group & $P \overline{\mathbf{1}}$ & $P \overline{\mathbf{1}}$ & $P \overline{\mathbf{1}}$ & $P_{\mathrm{bcn}}$ \\
\hline $\mathrm{a}(\AA \AA \AA)$ & $12.043(1)$ & $13.5291(7)$ & $13.737(1)$ & 18.284 \\
\hline $\mathrm{b}(\AA \AA)$ & $17.014(2)$ & $16.0367(9)$ & $16.191(1)$ & $21.158(4)$ \\
\hline$c(\AA)$ & 17.162(2) & 17.2368(9) & $17.272(1)$ & $18.284(3)$ \\
\hline$\alpha\left(^{\circ}\right)$ & $101.787(3)$ & 109.995(2) & $110.347(2)$ & 90 \\
\hline$\beta\left(^{\circ}\right)$ & $100.776(3)$ & $92.558(2)$ & $93.031(2)$ & 90 \\
\hline$Y\left(^{\circ}\right)$ & 106.228(3) & 103.732(2) & 104.189(2) & 90 \\
\hline 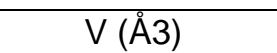 & $3191.6(6)$ & $3381.3(3)$ & $3451.6(4)$ & 7073.1(2) \\
\hline $\mathrm{z}$ & 2 & 2 & 2 & 4 \\
\hline Pcalc $\left(\mathrm{g} / \mathrm{cm}^{3}\right.$ & 1.604 & 1.643 & 1.952 & 1.579 \\
\hline $\mathrm{M}\left(\mathrm{mm}^{-1}\right)$ & 2.171 & 2.360 & 6.633 & 1.944 \\
\hline Total data & 45811 & 43290 & 41176 & 114916 \\
\hline $\begin{array}{l}\text { unique data } \\
\left.\text { ( } R_{\text {int }}\right)\end{array}$ & $15909(0.0686)$ & $13912(0.0336)$ & $14006(0.0328)$ & $7433(0.0826)$ \\
\hline $2 \Theta$ range $\left(^{\circ}\right)$ & 5.628 to 56.788 & 5.586 to 52.98 & 5.998 to 52.79 & 5.89 to 53.428 \\
\hline $\begin{array}{l}\text { Goodness of fit } \\
\text { (GOF) }\end{array}$ & 0.986 & 1.038 & 1.054 & 1.035 \\
\hline $\begin{array}{c}\mathrm{R}_{1} / \mathrm{wR} \mathrm{R}_{2}(\mathrm{I}> \\
2 \sigma(\mathrm{I}))\end{array}$ & $0.0522 / 0.1087$ & $0.0449 / 0.0887$ & $0.0465 / 0.1094$ & $0.0546 / 0.1140$ \\
\hline $\mathrm{R}_{1} / \mathrm{wR}_{2}$ (all data) & $0.1186 / 0.1323$ & $0.0763 / 0.0986$ & $0.0745 / 0.1204$ & $0.1005 / 0.1340$ \\
\hline
\end{tabular}


Table 7. Selected interatomic lengths $(\AA)$ and angles $\left({ }^{\circ}\right)$ for chapter 4 .

\begin{tabular}{|c|c|c|c|c|}
\hline Parameter & H-HIPPO & CI-HIPPO & Br-HIPPO & Ph-HIPPO \\
\hline $\left.\mathrm{Cu}--\mu_{3}-\mathrm{O}(\mathrm{H})\right)$ & $1.938(3)-2.033(3)$ & $\begin{array}{l}1.963(2)- \\
2.050(3)\end{array}$ & $\begin{array}{l}1.956(3)- \\
2.047(3)\end{array}$ & $\begin{array}{l}1.977(3)- \\
2.022(3)\end{array}$ \\
\hline $\begin{array}{c}\text { Cu-N } \\
\text { (intra-trimer) }\end{array}$ & $1.939(3)-1.970(3)$ & $\begin{array}{l}1.937(3)- \\
1.977(3)\end{array}$ & $\begin{array}{l}1.929(4)- \\
1.979(4)\end{array}$ & $\begin{array}{l}1.937(4)- \\
1.958(3)\end{array}$ \\
\hline $\begin{array}{c}\text { Cu-N } \\
\text { (inter-trimer) }\end{array}$ & $1.962(3)-1.995(3)$ & 1979(3)-1991(3) & $\begin{array}{l}1.976(4)- \\
1.987(4)\end{array}$ & $2.026(3)$ \\
\hline Cu-Cl(terminal) & $2.246(1), 2.263(1)$ & $\begin{array}{l}2.246(1), \\
2.254(1)\end{array}$ & $\begin{array}{l}2.244(1)- \\
2.247(1)\end{array}$ & $2.271(1)$ \\
\hline $\mathrm{Cu}--\mu_{4 / 2}-\mathrm{Cl}$ & $2.584(1), 2.869(1)$ & $\begin{array}{l}2.5598(9)- \\
3.038(1)\end{array}$ & $\begin{array}{l}2.546(1)- \\
3.040(1)\end{array}$ & $\begin{array}{c}2.6677(6), \\
2.941(2)\end{array}$ \\
\hline $\begin{array}{c}\mu_{3}-\mathrm{O}(\mathrm{H}) \cdots(\mathrm{Cu} 3- \\
\text { plane })\end{array}$ & $0.590(3), 0.607(4)$ & $\begin{array}{l}0.555(2) \\
0.608(3)\end{array}$ & $\begin{array}{l}0.561(3) \\
0.605(3)\end{array}$ & $0.588(4)$ \\
\hline $\begin{array}{l}\mathrm{Cu} \cdots \mathrm{Cu} \\
\text { (inter-rear) }\end{array}$ & $\begin{array}{l}3.6044(8), \\
3.6536(8)\end{array}$ & $\begin{array}{l}3.6288(6) \\
3.6321(6)\end{array}$ & $\begin{array}{l}3.6301(7) \\
3.6352(7)\end{array}$ & $3.607(1)$ \\
\hline $\begin{array}{l}\mathrm{Cu} \cdots \mathrm{Cu} \\
\text { (inter-front) }\end{array}$ & $7.203(1)$ & $6.8924(6)$ & $6.8681(8)$ & $5.235(1)$ \\
\hline $\begin{array}{c}\mathrm{Cu} \cdots \mathrm{Cu} \\
\text { (intra-trimer) }\end{array}$ & $\begin{array}{l}3.1027(6)- \\
34066(8)\end{array}$ & $\begin{array}{l}3.1718(7)- \\
3.4231(7)\end{array}$ & $\begin{array}{l}3.1745(9)- \\
3.4125(9)\end{array}$ & $\begin{array}{l}3.2235(9)- \\
3.4078(9)\end{array}$ \\
\hline $0 \cdots 0$ & $5.906(5)$ & $5.785(3)$ & $5.783(4)$ & $5.819(8)$ \\
\hline $\begin{array}{c}\mathrm{Cu}-\mathrm{Cl}-\mathrm{Cu} \\
\text { (intra-trimer) }\end{array}$ & $69.23(3), 71.73(3)$ & $\begin{array}{l}68.83(1)- \\
71.69(3)\end{array}$ & $\begin{array}{l}\text { 68.78(3)- } \\
71.87(3)\end{array}$ & $69.97(3)$ \\
\hline $\begin{array}{c}\mathrm{Cu}-\mathrm{Cl}-\mathrm{Cu} \\
\text { (inter-trimer) }\end{array}$ & $81.79(3), 86.16(3)$ & $\begin{array}{l}\text { 77.45(0), } \\
88.13(3)\end{array}$ & $\begin{array}{l}\text { 77.89(3)- } \\
88.01(4)\end{array}$ & $\begin{array}{l}71.65(2) \\
75.65(5)\end{array}$ \\
\hline Cu-Cl-Cu (trans) & $\begin{array}{l}122.68(4), \\
125.40(4)\end{array}$ & $\begin{array}{l}121.95(4) \\
122.33(8)\end{array}$ & $\begin{array}{l}122.37(4) \\
122.49(5)\end{array}$ & $159.51(5)$ \\
\hline $\mathrm{Cu}-\mathrm{O}-\mathrm{Cu}$ & $100.6(1)-118.1(1)$ & $\begin{array}{l}103.9(1)- \\
119.4(1)\end{array}$ & $\begin{array}{l}103.9(1)- \\
119.6(2)\end{array}$ & $\begin{array}{l}105.8(2)- \\
116.9(2)\end{array}$ \\
\hline $\mathrm{N}-\mathrm{Cu}-\mathrm{N}$ & $153.8(1)-170.6(1)$ & $\begin{array}{l}147.8(1)- \\
169.6(1)\end{array}$ & $\begin{array}{l}147.0(2)- \\
170.3(2)\end{array}$ & $\begin{array}{l}163.9(2)- \\
172.4(2)\end{array}$ \\
\hline O-Cu-L & $146.1(1)-176.0(1)$ & $\begin{array}{c}162.63(8)- \\
178.2(1)\end{array}$ & $\begin{array}{l}159.5(1)- \\
178.6(2)\end{array}$ & $\begin{array}{l}159.4(1)- \\
176.3(2)\end{array}$ \\
\hline Cu plane angle & 73.9 & 66.8 & 66.1 & 31.2 \\
\hline
\end{tabular}




\subsubsection{NMR}

\subsubsection{NMR of H-HIPPO}

The NMR spectrum of H-HIPPO (Figure 44)has peak integration 3:2:2:2:2:2:1:1:1 with the two additional peaks corresponding to the THF that is hydrogen-bonded to $\mathrm{H}$-Hippo. The peak for $\mathrm{H}^{\mathrm{c}}(36.87 \mathrm{ppm})$ envelopes the $\mathrm{OH}$ proton peak throughout the temperature range examined which leads to an integration of three protons. $H^{a}$ and $H^{b}(36.48$, slopes are -0.023 and -0.087 respectively) are overlapped at RT and separate by $-5^{\circ} \mathrm{C}$. There are three peaks between 39 and $41 \mathrm{ppm}$ at room temperature, which correspond to the THF $\left(\mathrm{H}^{\mathrm{h}}\right.$ and $\left.\mathrm{H}^{\mathrm{i}}\right)$ and $\mathrm{H}^{\mathrm{d}}$, however when the temperature is decreased they become overlapped and appear as two peaks. $\mathrm{H}^{f}$ and $\mathrm{H}^{\mathrm{g}}$ are assigned to 56.64 and $53.81 \mathrm{ppm}$, respectively. The last peak, $\mathrm{H}^{\mathrm{e}}$, is assigned to $52.91 \mathrm{ppm}$. The peaks were assigned based on distance from the bridging pyrazolates, as the spin density is through the two pyrazolates as opposed to three in previous literature, ${ }^{49}$ which is assumed to push the relative shift farther upfield. The NMR spectra can be seen in Figure 44, with the proton names in Scheme 13. The shifts, slopes, and $T_{2}$ times are listed in Table 8. 


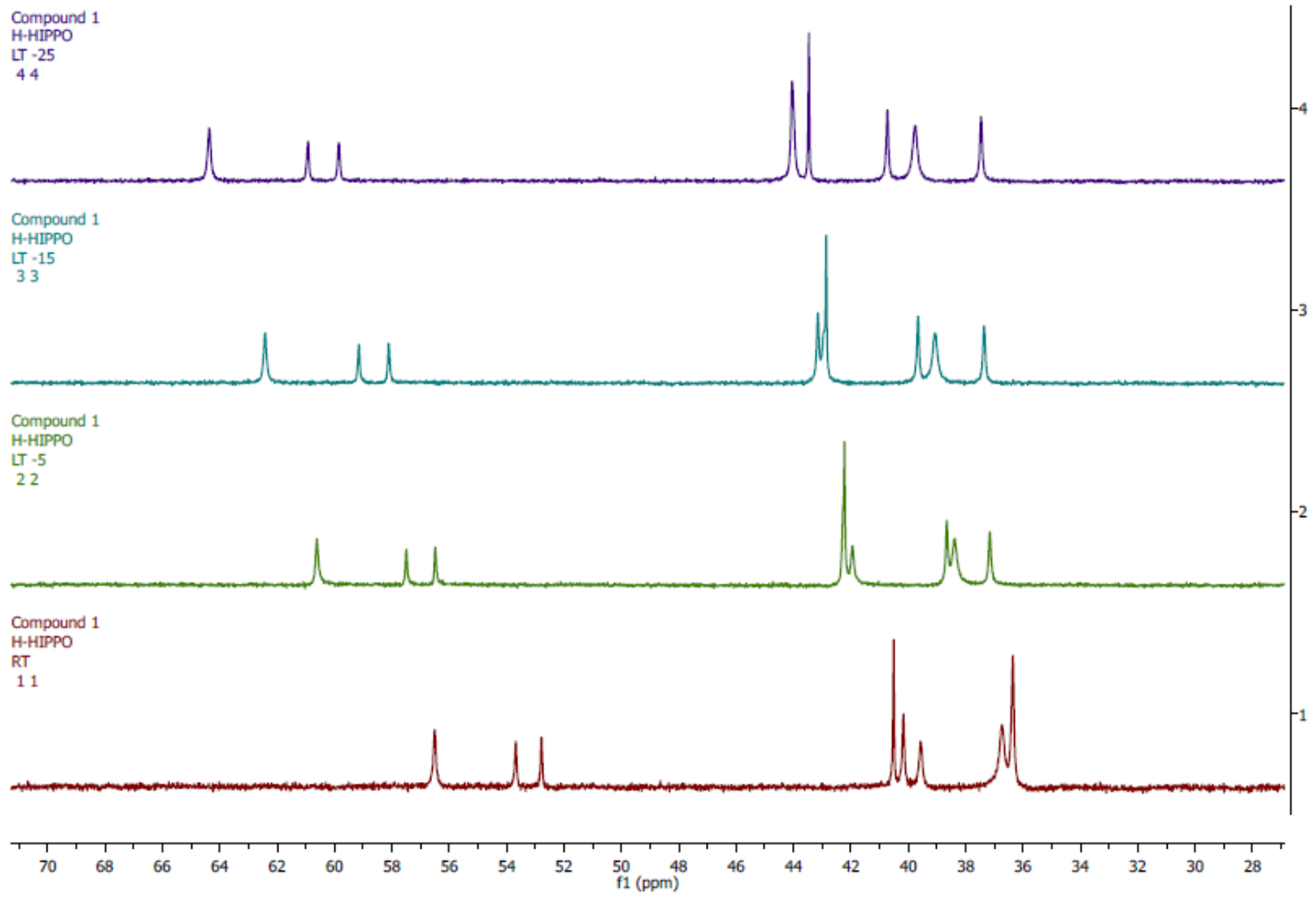

Figure 44. Variable Low-Temperature NMR plot of H-HIPPO. Red, RT; green, $-5^{\circ} \mathrm{C}$; blue, $-15^{\circ} \mathrm{C}$, purple $-25^{\circ} \mathrm{C}$.

Table 8. NMR shifts (ppm) of H-HIPPO, with $\mathrm{T}_{2}$ times, shifts, and slope.

\begin{tabular}{|c|c|c|c|c|c|c|}
\hline \multirow{2}{*}{ Proton } & \multirow{2}{*}{$\begin{array}{l}\mathrm{T}_{2} \text { at } \mathrm{RT} \\
\text { (seconds) }\end{array}$} & \multicolumn{4}{|c|}{ Temperature } & \multirow{2}{*}{$\begin{array}{c}\text { Slope } \\
\left(\mathrm{ppm} /{ }^{\circ} \mathrm{C}\right)\end{array}$} \\
\hline & & $20^{\circ} \mathrm{C}$ & $-5^{\circ} \mathrm{C}$ & $-15^{\circ} \mathrm{C}$ & $-25^{\circ} \mathrm{C}$ & \\
\hline $\mathrm{H}^{\mathrm{a}}$ & $0.0849^{*}$ & 36.48 & 37.27 & 37.47 & 37.57 & -0.023 \\
\hline $\mathrm{H}^{\mathrm{b}}$ & $0.0849^{*}$ & 36.48 & 38.78 & 39.77 & 40.80 & -0.087 \\
\hline $\mathrm{H}^{\mathrm{c}}$ & 0.0353 & 36.87 & 38.50 & 39.19 & 39.87 & -0.061 \\
\hline $\mathrm{H}^{\mathrm{d}}$ & 0.0571 & 39.69 & 42.07 & 43.04 & 44.15 & -0.090 \\
\hline $\mathrm{He}^{\mathrm{e}}$ & 0.1208 & 52.91 & 56.61 & 58.22 & 59.95 & -0.142 \\
\hline $\mathrm{H}^{f}$ & 0.0739 & 56.64 & 60.73 & 62.53 & 64.47 & -0.157 \\
\hline $\mathrm{H}^{\mathrm{g}}$ & 0.1083 & 53.81 & 57.61 & 59.27 & 61.03 & -0.145 \\
\hline $\mathrm{H}^{\mathrm{h}}$ & 0.0924 & 40.30 & 42.40 & 43.26 & 44.15 & -0.078 \\
\hline $\mathrm{H}^{\mathrm{i}}$ & 0.1653 & 40.64 & 42.34 & 42.97 & 43.57 & -0.060 \\
\hline
\end{tabular}




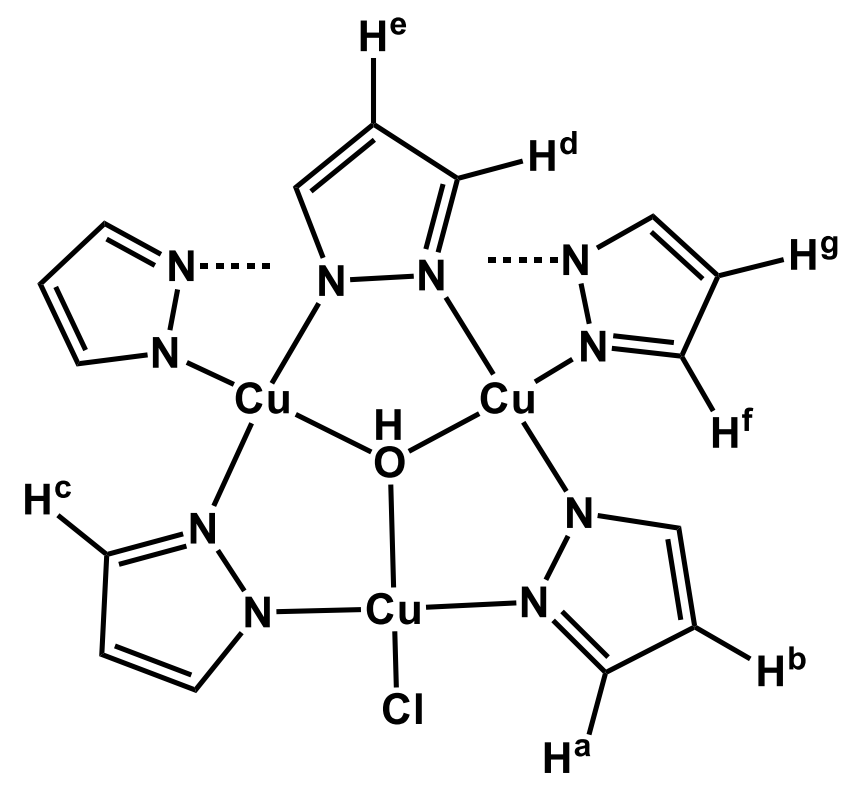

Scheme 13. Proton labels for H-HIPPO.

\subsubsection{NMR of CI-HIPPO}

The ${ }^{1} \mathrm{H}$ NMR spectrum of Cl-HIPPO is similar to the one of $\mathbf{H}$-HIPPO, however it has fewer peaks, due to the 4' position $\mathrm{Cl}$ and the lack of a THF molecule. The $\mathrm{Cl}$ HIPPO shows a 2:2:2:2:1 ratio for the 18 protons a, $c, d$, $f$ and the $\mathrm{OH}$ proton peak. The NMR spectrum of Cl-HIPPO shows five peaks at RT. There are two welldefined peaks at $58.72 \mathrm{ppm}$ and $41.30 \mathrm{ppm}$, which have a 2:2 integration. There are also three overlapping peaks, around $39.5 \mathrm{ppm}$ that integrates to 5 protons. These peaks resolve throughout the temperature range investigated. The presence of $\mathrm{Cl}$ in the 4' position allowed for easy assignment of the $\mu_{3}-\mathrm{OH}$ group, as it only integrates to half of the other peaks, and its relative shift and slope confirm the assignment for H-HIPPO. The other protons are assigned by the distance from the bridging pyrazolates, in the same manner as H-HIPPO. This leads to $\mathrm{H}^{\mathrm{a}}$ being the least shifted. The three signals at approximately $39-40.5$ 
ppm are overlapping at RT but are resolved at $-5^{\circ} \mathrm{C}$. The NMR spectra can be seen in Figure 45. Proton labels are listed in Scheme 14. The shifts, slopes, and $T_{2}$ times are listed in Table 9.

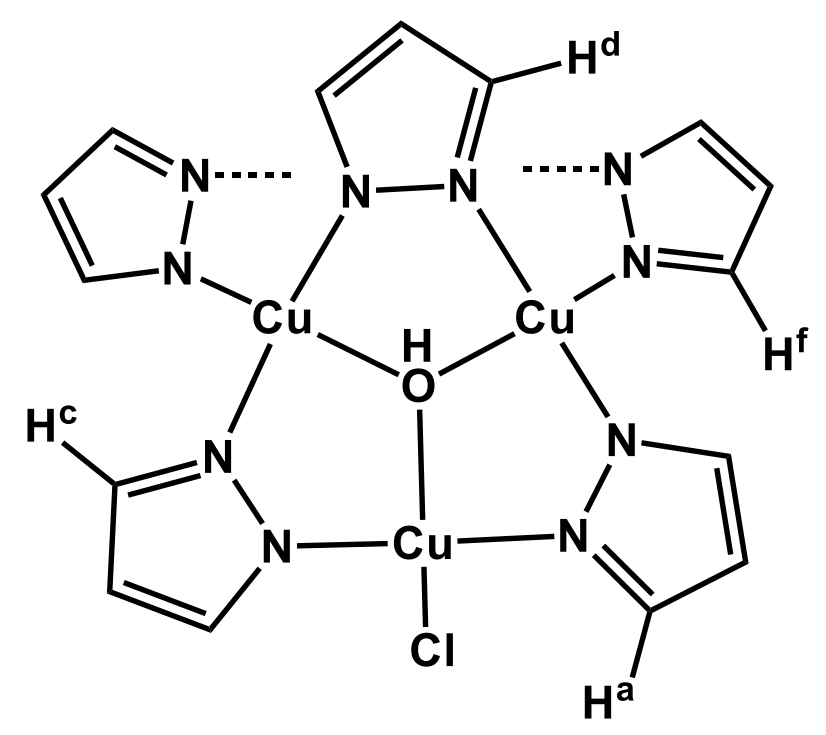

Scheme 14. Proton labels for CI-HIPPO.

Table 9. NMR shifts (ppm) of CI-HIPPO, with $\mathrm{T}_{2}$ times, shifts, and slope.

\begin{tabular}{|c|c|c|c|c|c|c|}
\hline \multirow{2}{*}{ Proton } & \multirow{2}{*}{$\begin{array}{l}\mathrm{T} 2 \text { at RT } \\
\text { (seconds) }\end{array}$} & \multicolumn{4}{|c|}{ Temperature } & \multirow{2}{*}{$\begin{array}{c}\text { Slope } \\
\left(\mathrm{ppm} /{ }^{\circ} \mathrm{C}\right)\end{array}$} \\
\hline & & $20^{\circ} \mathrm{C}$ & $-5^{\circ} \mathrm{C}$ & $-15^{\circ} \mathrm{C}$ & $-23^{\circ} \mathrm{C}$ & \\
\hline $\mathrm{Ha}$ & 0.0628 & 39.71 & 40.77 & 41.08 & 41.23 & -0.034 \\
\hline $\mathrm{Hc}$ & 0.0365 & 39.90 & 42.47 & 43.49 & 44.48 & -0.075 \\
\hline $\mathrm{Hd}$ & 0.0483 & 41.41 & 43.49 & 44.27 & 44.97 & -0.096 \\
\hline $\mathrm{Hf}$ & 0.0628 & 58.68 & 62.80 & 64.52 & 66.12 & -0.156 \\
\hline $\mathrm{OH}$ & 0.0430 & 39.30 & 40.99 & 41.61 & 42.13 & -0.060 \\
\hline
\end{tabular}




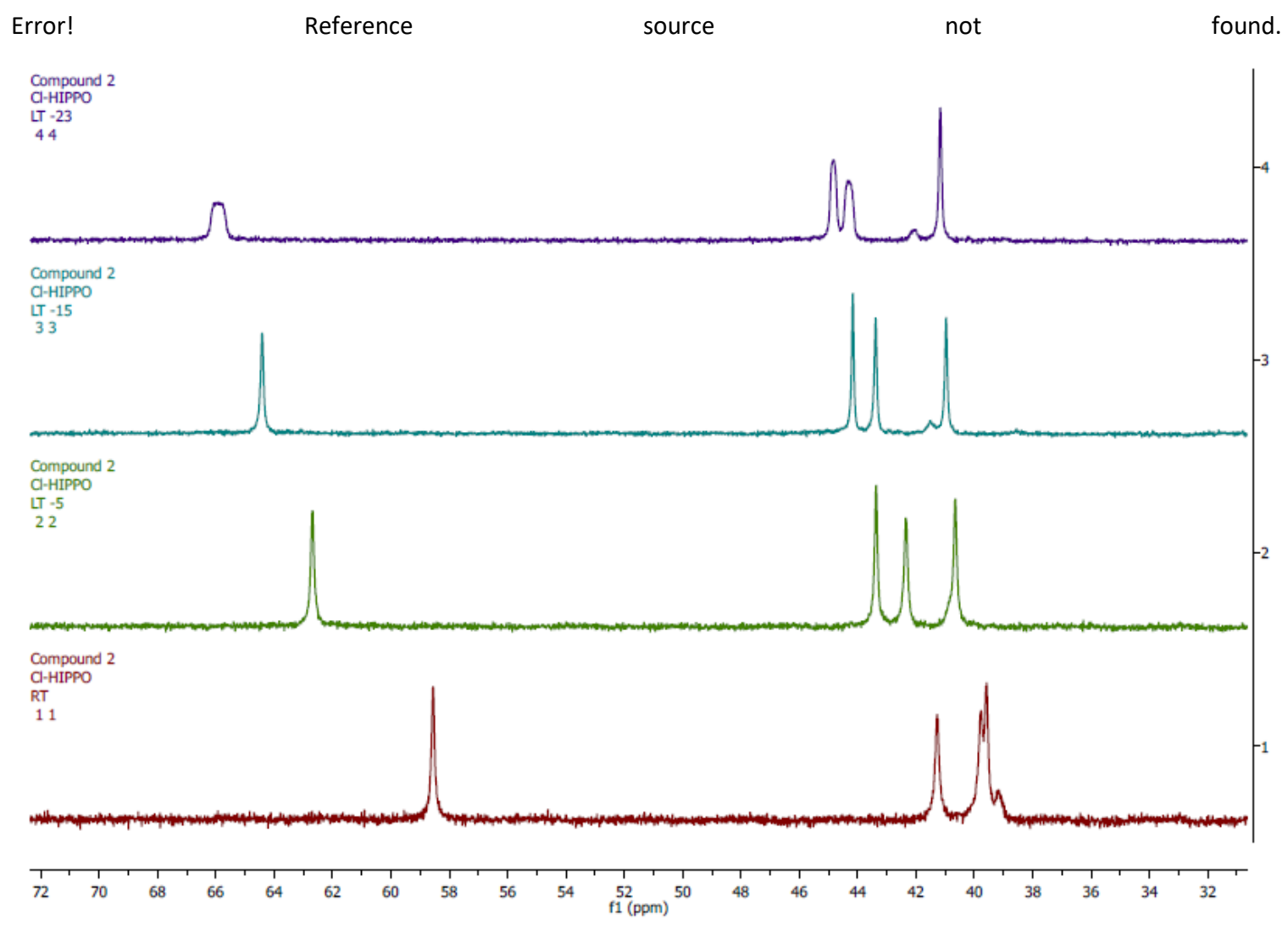

Figure 45. Variable Low-Temperature NMR plot of Cl-HIPPO. Red, RT; green, $-5^{\circ} \mathrm{C}$; blue, $-15^{\circ} \mathrm{C}$, purple $-23^{\circ} \mathrm{C}$.

\subsubsection{NMR of Ph-HIPPO}

The NMR spectrum of Ph-HIPPO has many overlapping peaks in the aromatic region. It appears that many of the protons are not heavily affected by paramagnetic shift, and the resulting spectra are overlapping peaks and multiplets (Figure 46), with one peak around 38 ppm (Figure 47) that integrates to 5 protons. However, peak assignments and $\mathrm{T}_{2}$ calculations were not possible. 


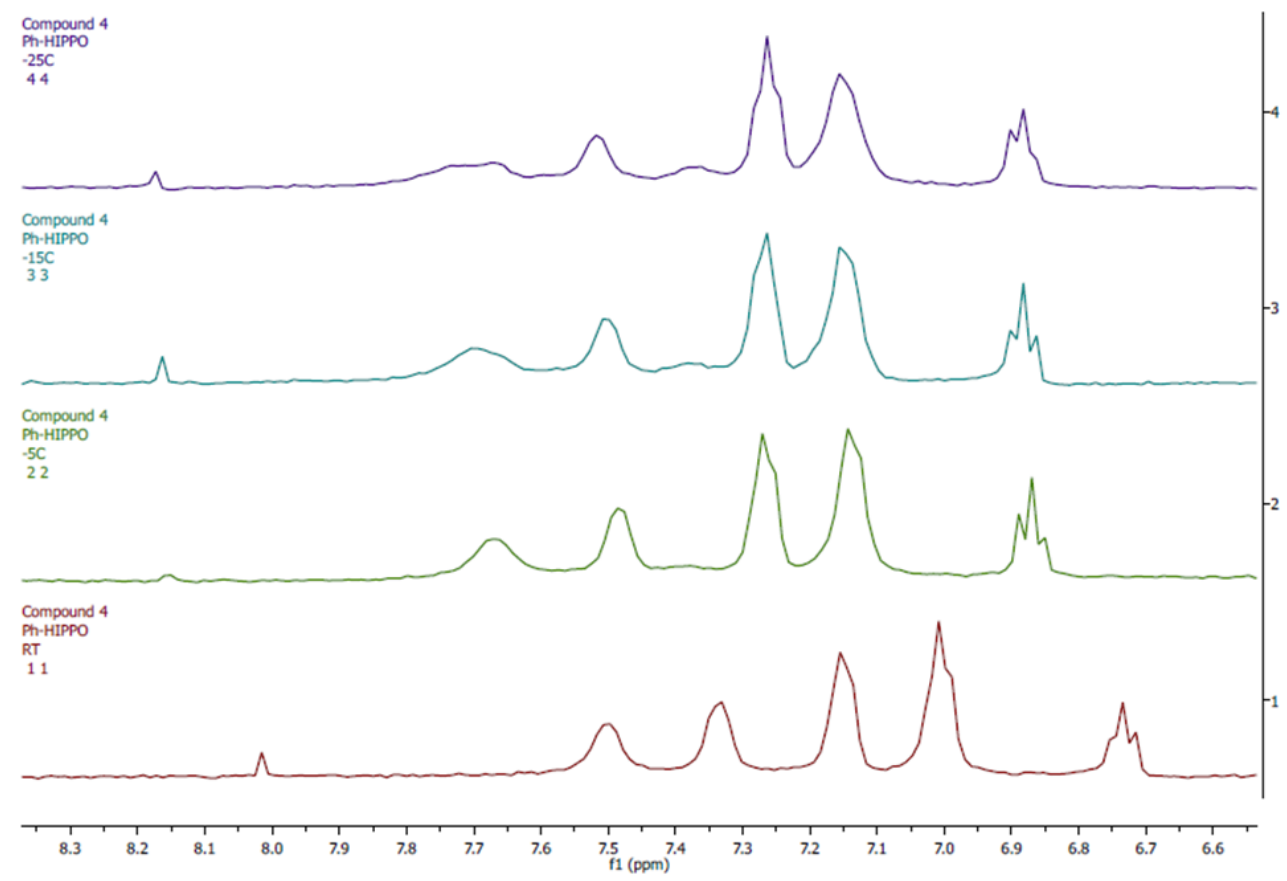

Figure 46. Variable Low-Temperature NMR plot (downfield) of Ph-HIPPO. Red, RT; green, $-5^{\circ} \mathrm{C}$; blue, $-15^{\circ} \mathrm{C}$, purple $-25^{\circ} \mathrm{C}$.

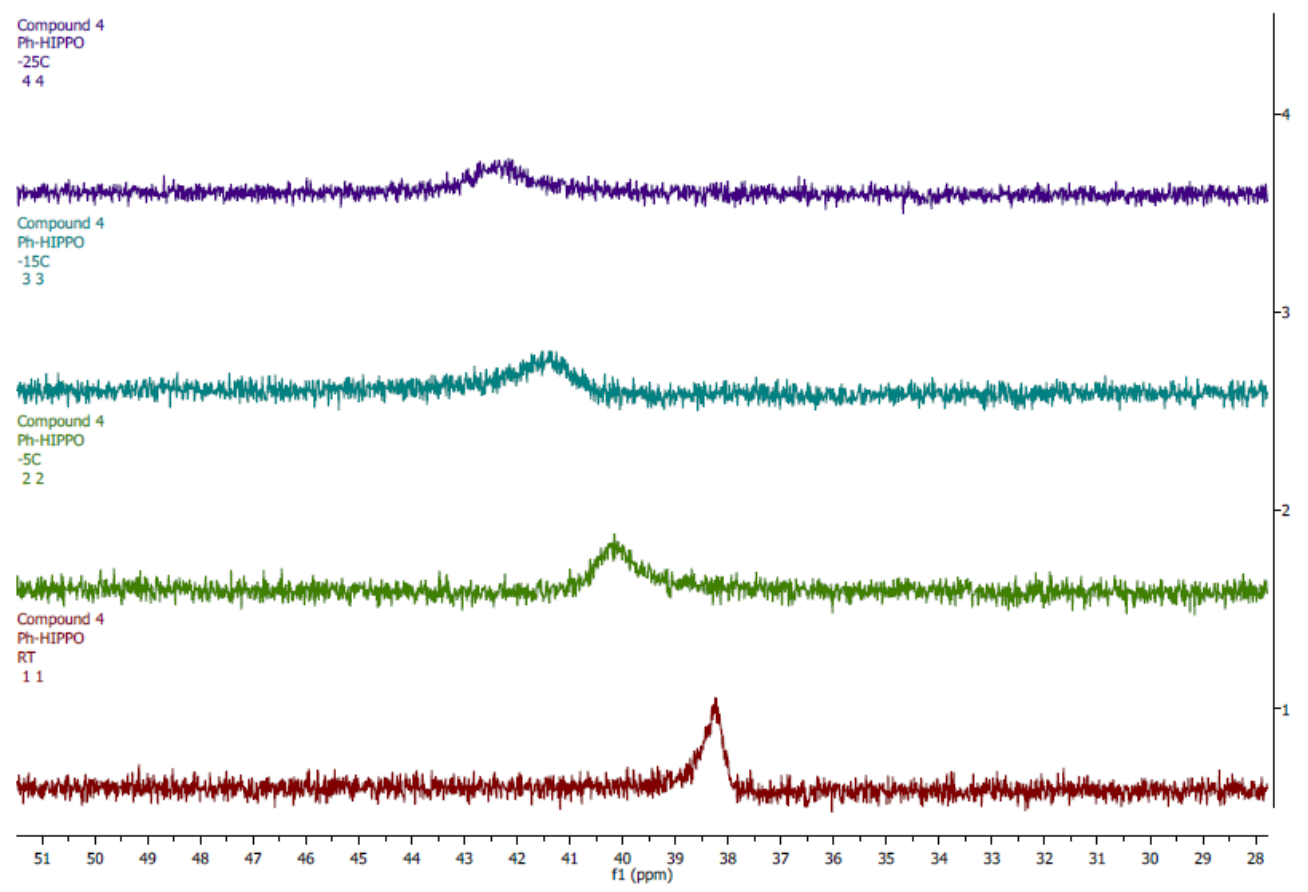

Figure 47. Variable Low-Temperature NMR plot (upfield) of Ph-HIPPO. Red, RT; green, $-5{ }^{\circ} \mathrm{C}$; blue, $-15^{\circ} \mathrm{C}$, purple $-25^{\circ} \mathrm{C}$. 


\subsubsection{NMR of [1]}

The NMR spectrum of compound [1] shows most proton signals to be significantly shifted downfield compared to the parent $\mathrm{Cu}_{6}$ PPN[2]. This shift could be attributed to the encapsulated $\mathrm{F}^{-}$ion as $\mathrm{H}$-HIPPO and $\mathrm{Cl}-\mathrm{HIPPO}$ are also shifted in the same direction, albeit to a smaller extent, which could be due to the partial encapsulation, the larger $\mathrm{Cu}-\mathrm{O}-\mathrm{Cu}$ angles, or the difference in electronegativity of the encapsulated ion. Compound [1] shows the $\mathrm{OH}$ proton peak at a very high shift, 70.69, in $\mathrm{CH}_{2} \mathrm{Cl}_{2}$ which with H-HIPPO and Cl-HIPPO is the first time a $\mathrm{OH}$ proton signals has been observed in hexanuclear $\mathrm{Cu}$ complexes. Perhaps the most interesting information from the spectra is the slopes of $\mathrm{H}^{c}$ and $\mathrm{H}^{d}$ are slightly positive. The peaks were assigned using the RT spectrum and previous literature. ${ }^{53}$ The differences in relative shift, slope, and $T_{2}$ are listed in Table 10 with the NMR spectra at the various temperatures shown in Figure 48 and Figure 49. The proton labels are listed in Scheme 15.

Table 10. NMR of [1], with $T_{2}$ times, shifts, and slope.

\begin{tabular}{|c|c|c|c|c|c|c|}
\hline \multirow{2}{*}{ Proton } & \multirow{2}{*}{$\begin{array}{l}\mathrm{T}_{2} \text { at } \mathrm{RT} \\
\text { (seconds) }\end{array}$} & \multicolumn{4}{|c|}{ Temperature } & \multirow{2}{*}{$\begin{array}{c}\text { Slope } \\
\left(\mathrm{ppm} /{ }^{\circ} \mathrm{C}\right)\end{array}$} \\
\hline & & $20^{\circ} \mathrm{C}$ & $-5^{\circ} \mathrm{C}$ & $-15^{\circ} \mathrm{C}$ & $-25^{\circ} \mathrm{C}$ & \\
\hline $\mathrm{H}^{\mathrm{a}}$ & 0.1745 & 47.03 & 50.22 & 51.38 & 52.61 & -0.113 \\
\hline $\mathrm{H}^{\mathrm{b}}$ & 0.1083 & 33.81 & 35.55 & 36.23 & 36.94 & -0.063 \\
\hline $\mathrm{H}^{\mathrm{c}}$ & 0.1795 & 7.67 & 7.64 & 7.64 & 7.63 & 0.001 \\
\hline $\mathrm{H}^{\mathrm{d}}$ & 0.1745 & 8.07 & 8.06 & 8.04 & 8.03 & 0.001 \\
\hline $\mathrm{H}^{\mathrm{e}}$ & 0.0751 & 17.18 & 17.97 & 18.29 & 18.65 & -0.030 \\
\hline $\mathrm{H}^{\dagger}$ & 0.1964 & 9.00 & 9.09 & 9.13 & 9.17 & -0.003 \\
\hline $\mathrm{OH}$ & 0.1102 & 70.69 & 74.53 & 76.01 & 77.56 & -0.139 \\
\hline
\end{tabular}




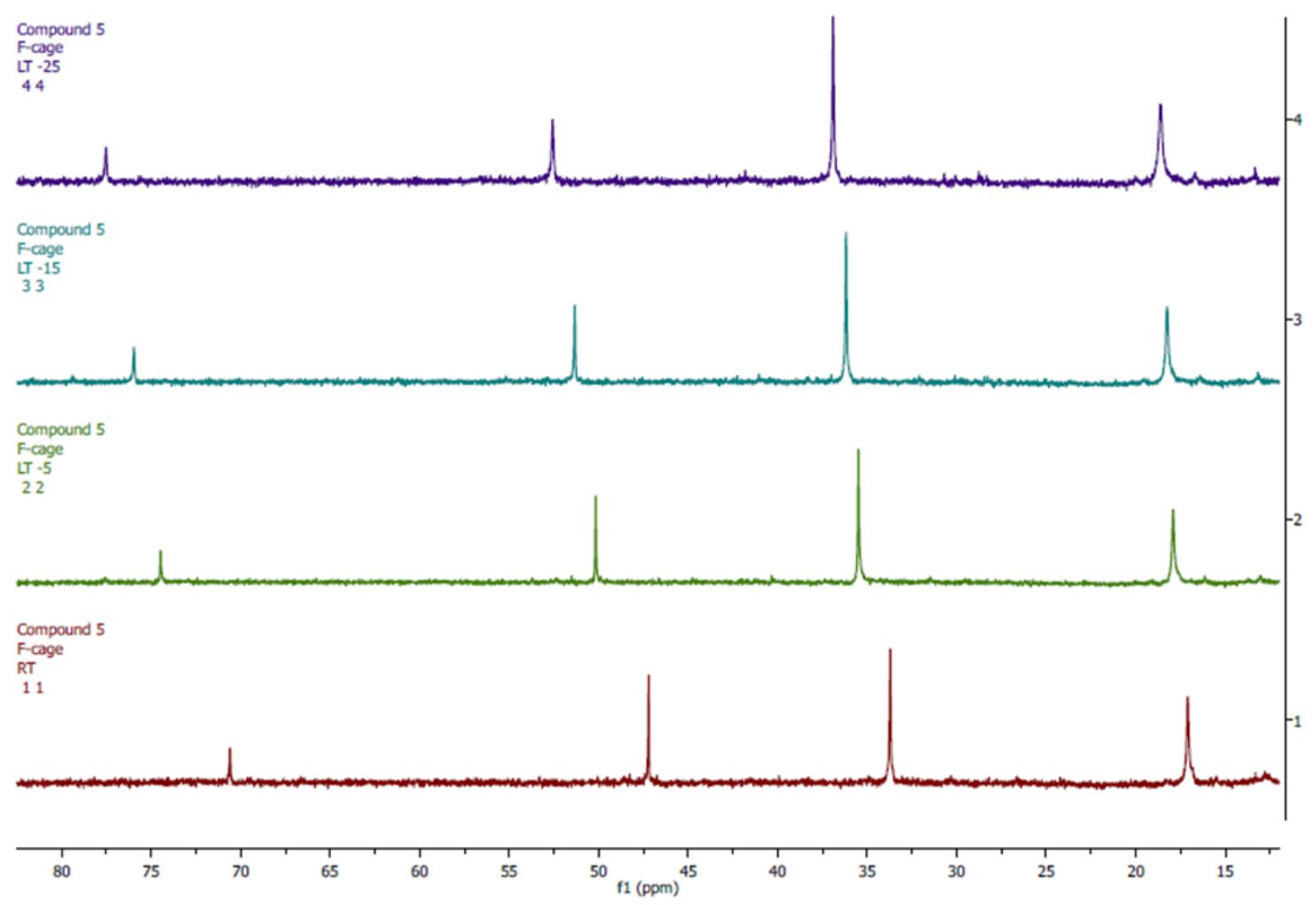

Figure 48. Variable Low-Temperature NMR plot (upfield) of [1]. Red, RT; green, $-5^{\circ} \mathrm{C}$; blue, $-15^{\circ} \mathrm{C}$, purple $-25^{\circ} \mathrm{C}$. 


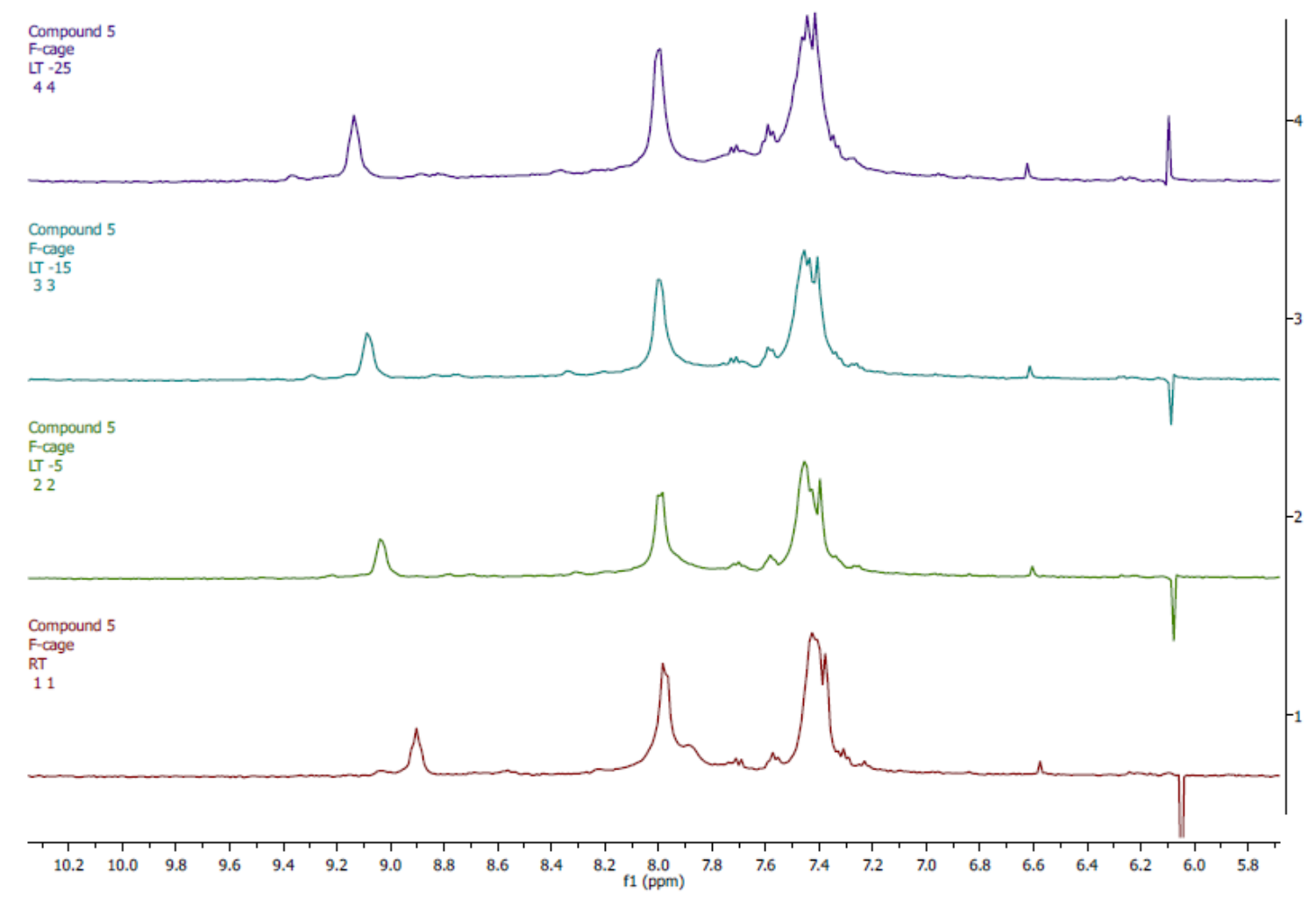

Figure 49. Variable Low-Temperature NMR plot (downfield) of compound 5. Red, RT; green, $-5^{\circ} \mathrm{C}$; blue, $-15^{\circ} \mathrm{C}$, purple $-25^{\circ} \mathrm{C}$.

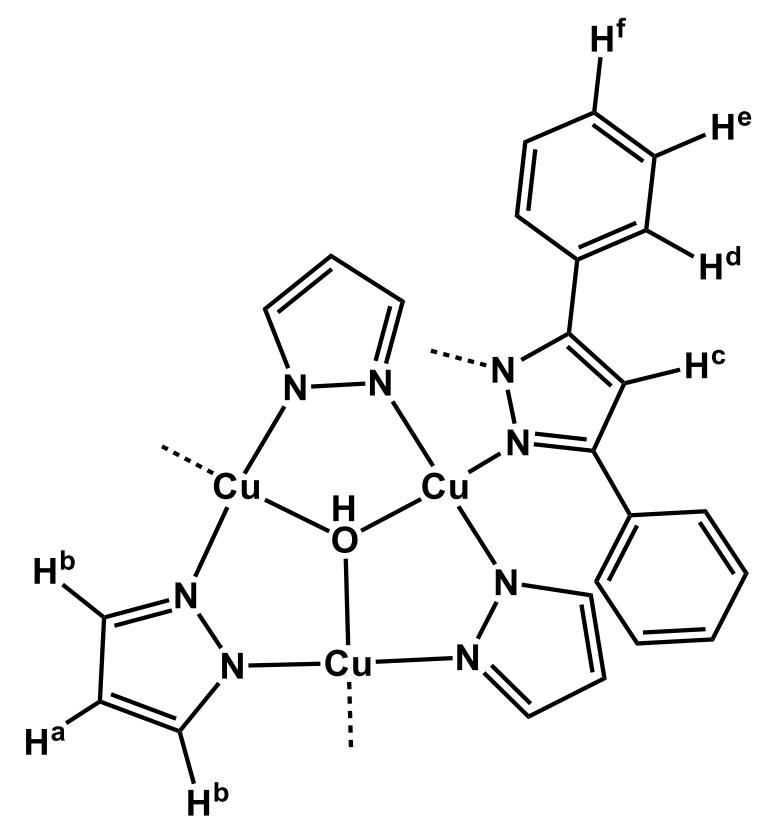

Scheme 15. Proton labels for compound [1]. 


\subsubsection{NMR of PPN[2]}

PPN[2] has shifts and slopes that differ significantly from the derivative compounds. Most likely due to the lack of encapsulated anion. The decrease in temperature shifts all the peaks downfield, although $\mathrm{H}^{d}$ and $\mathrm{H}^{f}$ are only very slightly shifted over the range. The shifts mirror [1], which is explained by their location on the phenyl rings which are far from the paramagnetic centers and are unaffected by paramagnetism. However, $\mathrm{H}^{\mathrm{c}}$ has the second largest slope, -0.107 , which is in contrast to the most comparable compound, [1], where the shift is 0.001 . Peaks were assigned using RT spectra and literature assignments. ${ }^{49}$ The proton labels are shown in Scheme 16, differences in relative shift, slope, and $T_{2}$ are listed in Table 11 with the NMR spectra at the various temperatures shown in Figure 50 and Figure 51.

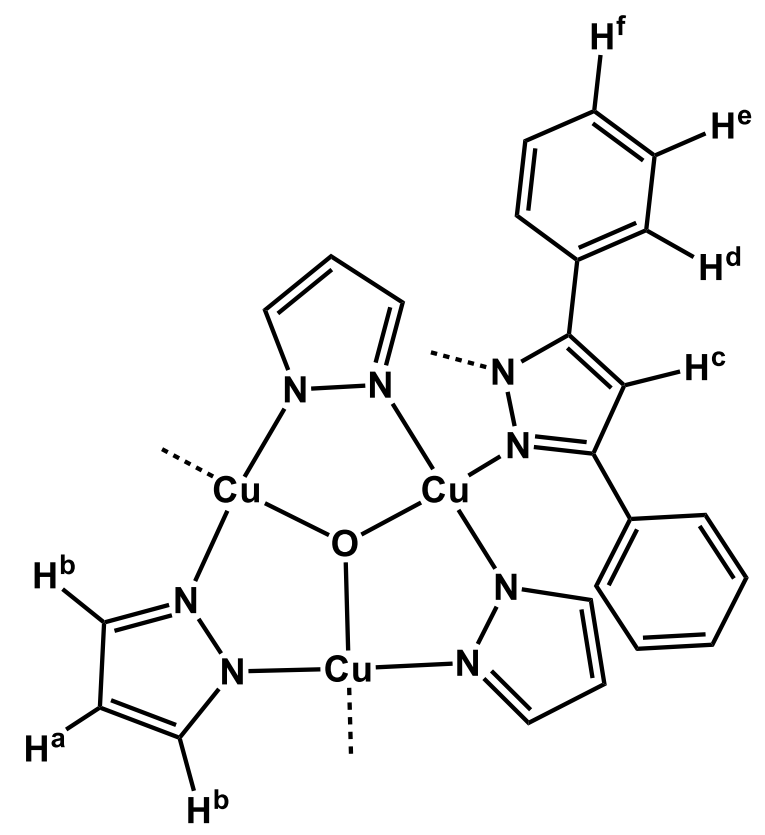

Scheme 16. Proton labels for PPN[2]. 
Table 11. NMR of PPN[2], with $\mathrm{T}_{2}$ times, shifts, and slope.

\begin{tabular}{|c|c|c|c|c|c|c|}
\hline \multirow{2}{*}{ Proton } & \multirow{2}{*}{$\begin{array}{c}\mathrm{T}_{2} \text { at } \mathrm{RT} \\
(\text { seconds })\end{array}$} & \multicolumn{4}{|c|}{ Temperature } & $\begin{array}{c}\text { Slope } \\
\left(\mathrm{ppm} /{ }^{\circ} \mathrm{C}\right)\end{array}$ \\
\cline { 3 - 6 } & & $20^{\circ} \mathrm{C}$ & $-5^{\circ} \mathrm{C}$ & $-15^{\circ} \mathrm{C}$ & $-25^{\circ} \mathrm{C}$ & \\
\hline $\mathrm{H}^{\mathrm{a}}$ & 0.2094 & 35.50 & 38.96 & 40.52 & 42.23 & -0.135 \\
\hline $\mathrm{H}^{\mathrm{b}}$ & 0.1337 & 18.17 & 19.70 & 20.42 & 21.24 & -0.061 \\
\hline $\mathrm{H}^{\mathrm{c}}$ & 0.2856 & 27.96 & 30.46 & 31.80 & 33.36 & -0.107 \\
\hline $\mathrm{H}^{\mathrm{d}}$ & $0.1904^{*}$ & 7.70 & 7.74 & 7.75 & 7.77 & -0.001 \\
\hline $\mathrm{H}^{\mathrm{e}}$ & 0.0582 & 11.82 & 12.18 & 12.35 & 12.53 & -0.014 \\
\hline $\mathrm{H}^{\mathrm{f}}$ & $0.1571^{*}$ & 8.01 & 8.12 & 8.16 & 8.18 & -0.004 \\
\hline
\end{tabular}

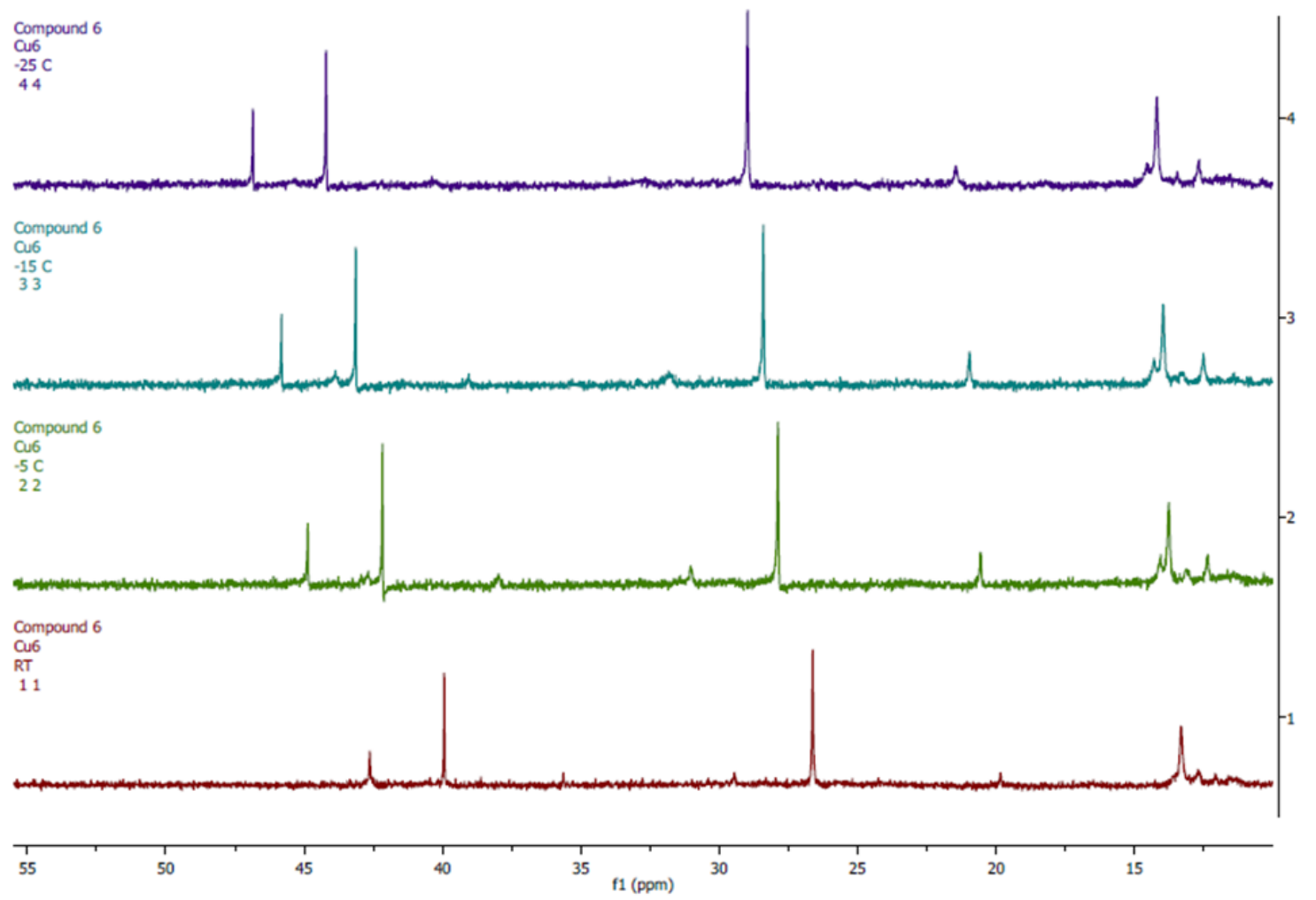

Figure 50. Variable Low-Temperature NMR plot (upfield) of PPN[2]. Red, RT; green, $-5^{\circ} \mathrm{C}$; blue, $-15^{\circ} \mathrm{C}$, purple $-25^{\circ} \mathrm{C}$. 


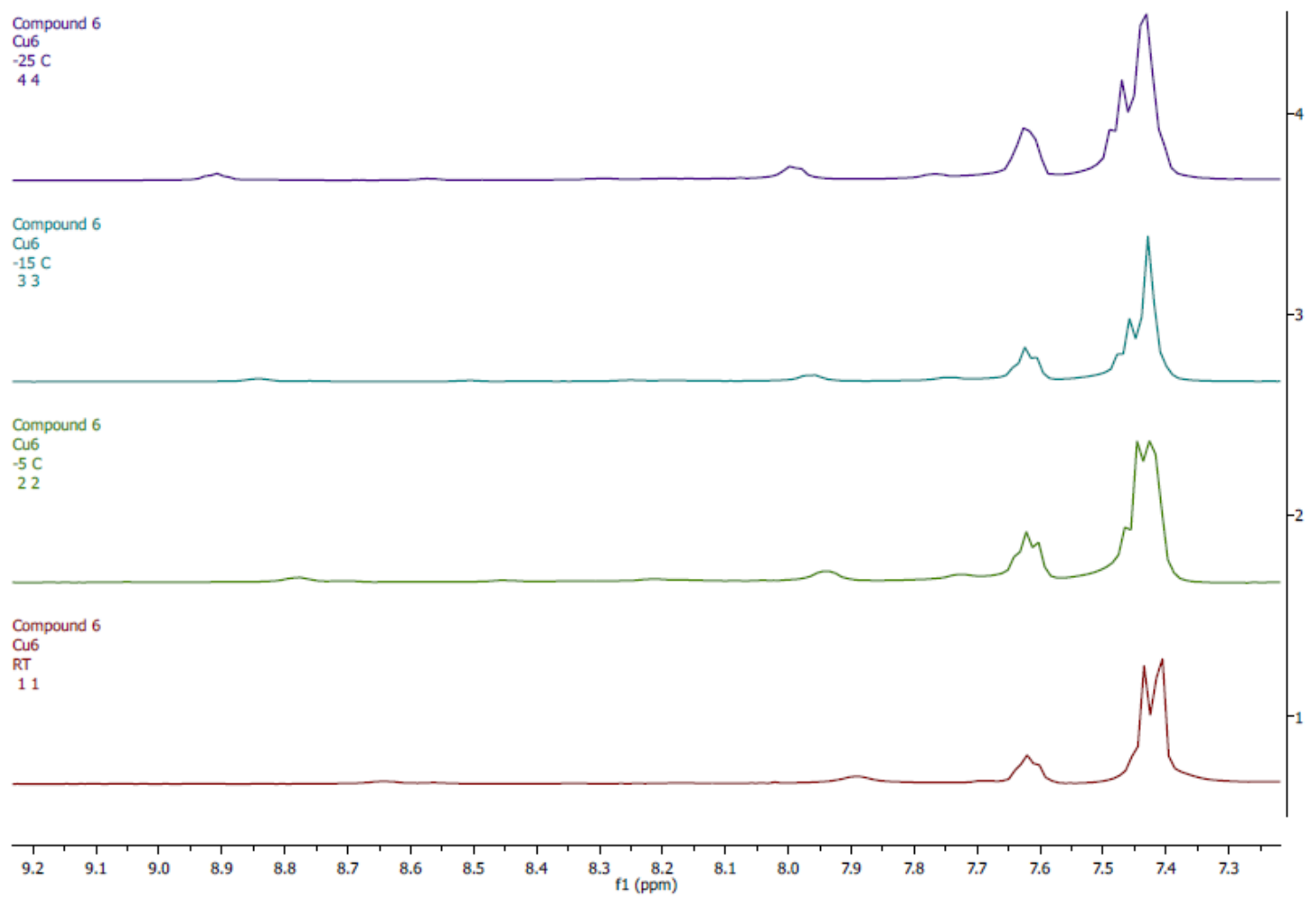

Figure 51. Variable Low-Temperature NMR plot (downfield) of PPN[2]. Red, RT; green, $-5^{\circ} \mathrm{C}$; blue, $-15^{\circ} \mathrm{C}$, purple $-25^{\circ} \mathrm{C}$.

\subsubsection{IR Analysis}

\subsubsection{IR of H-HIPPO}

There are three absorptions of importance in the spectrum of H-HIPPO (Figure 52). Two absorptions are medium-strong absorptions at $282 \mathrm{~cm}^{-1}$ and $352 \mathrm{~cm}^{-1}$ which correspond to the terminal chloride and $\mathrm{Cu}-\mathrm{N}$ stretch respectively. There is another medium strength absorption at $500 \mathrm{~cm}^{-1}$ that corresponds to another $\mathrm{Cu}$ $\mathrm{N}$ stretch. The peaks correspond well to the range described in previous literature. Another two peaks at $542 \mathrm{~cm}^{-1}$ and $528 \mathrm{~cm}^{-1}$ correspond to $\mathrm{Cu}-\mathrm{O}$ stretch and 
vibrations. This is confirmed by ${ }^{18} \mathrm{O}$ substitution (selected portion of IR shown in Figure 53) and DFT calculations.

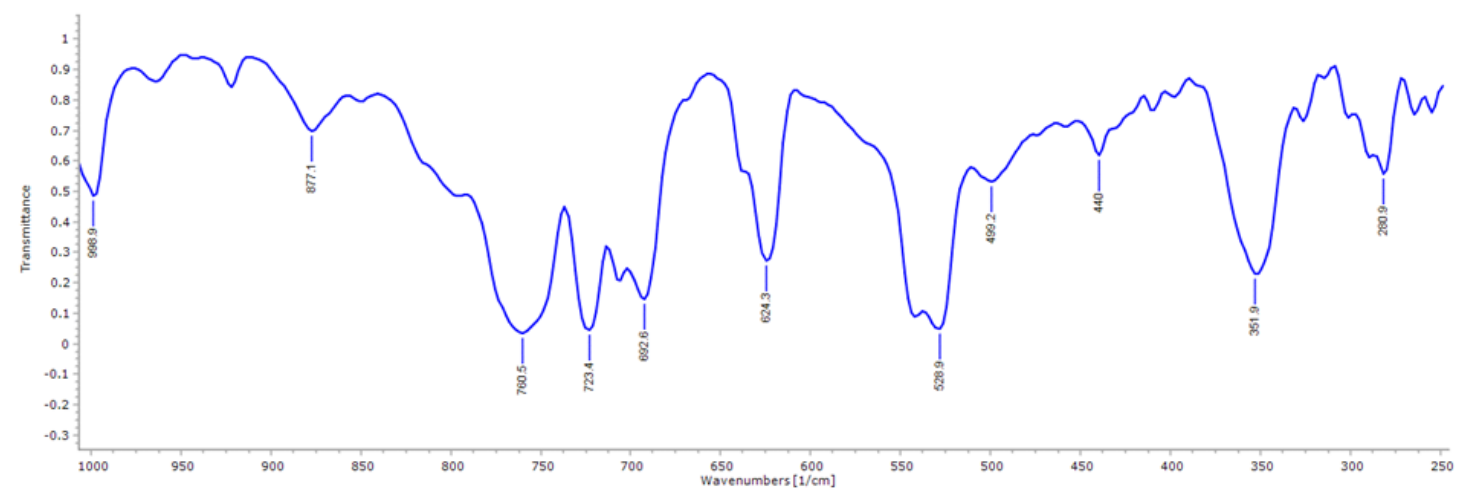

Figure 52. Far-IR of H-HIPPO.

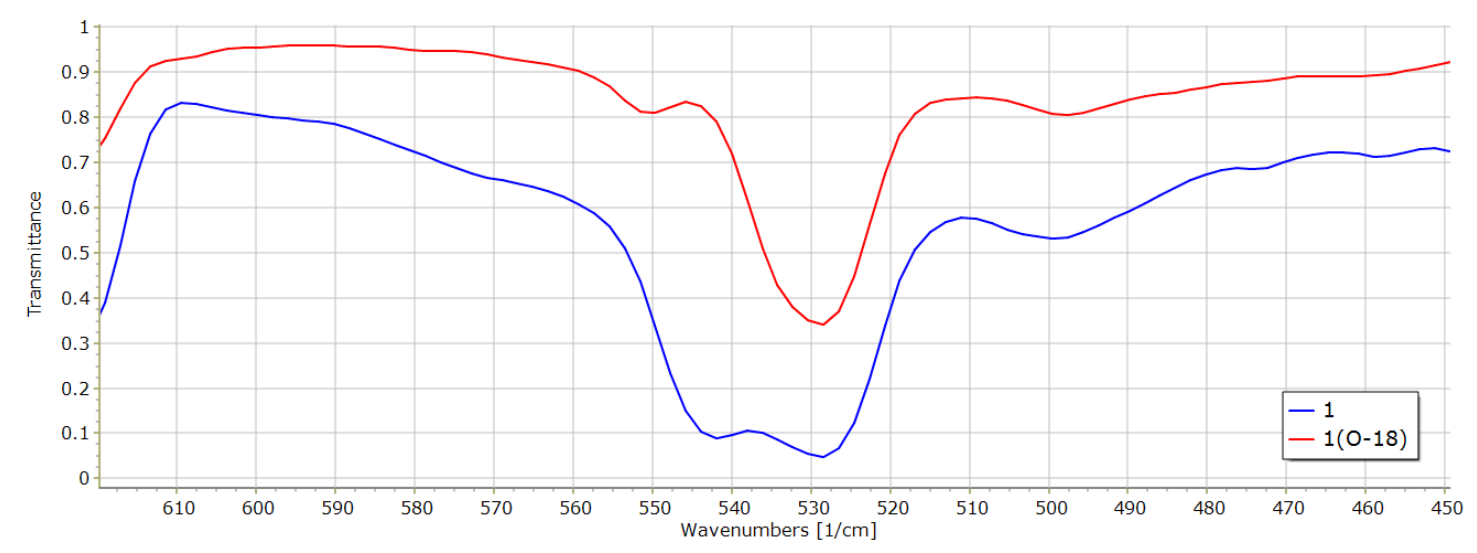

Figure 53. IR Cu-O stretching bands for ${ }^{16} \mathrm{O}$ - and ${ }^{18} \mathrm{O}-\mathrm{H}-\mathrm{HIPPO}$.

\subsubsection{Far-IR of Cl-HIPPO}

The IR spectra of Cl-HIPPO (Figure 54) shows an absorption at $295 \mathrm{~cm}^{-1}$, which corresponds to Cu-N stretch and is confirmed by the calculations (simulated spectra shown in Figure 55) which places two absorptions at $301.71 \mathrm{~cm}^{-1}$ and $306.46 \mathrm{~cm}^{-1}$, the latter is coupled with pyrazolate distortions. Calculations place 
two more Cu-N absorptions at $504.16 \mathrm{~cm}^{-1}$ and $506.22 \mathrm{~cm}^{-1}$ which have merged into one observed peak that appears at $529 \mathrm{~cm}^{-1}$. The peak at $319 \mathrm{~cm}^{-1}$, which is a Cu-O stretch coupled with pyrazole distortions, DFT places at $309.86 \mathrm{~cm}^{-1}$. Additionally, calculations show that there are Cu-O absorptions at $346.63,452.77$ and 455.12. These peaks are seen in the experimental spectrum as a weak peak at 337.3 and a broad peak with a shoulder at 483 . At $263 \mathrm{~cm}^{-1}$ a Cu-Cl absorption coupled with Cu-N is observed, DFT places this at 239.00 . Additionally, there is a shoulder at $280 \mathrm{~cm}^{-1}$ which corresponds to two calculated stretches, 256.57 and $256.92 \mathrm{~cm}^{-1}$, associated with Cu-Cl, Cu-N coupled modes. At $250 \mathrm{~cm}^{-1}$, at the edge of the capabilities of our instrument, the start of an absorption is noticeable, DFT indicates that the peak corresponds to $\mathrm{Cu}-\mathrm{Cl}$ and calculates two frequencies at 208.89 and $212.47 \mathrm{~cm}^{-1}$.

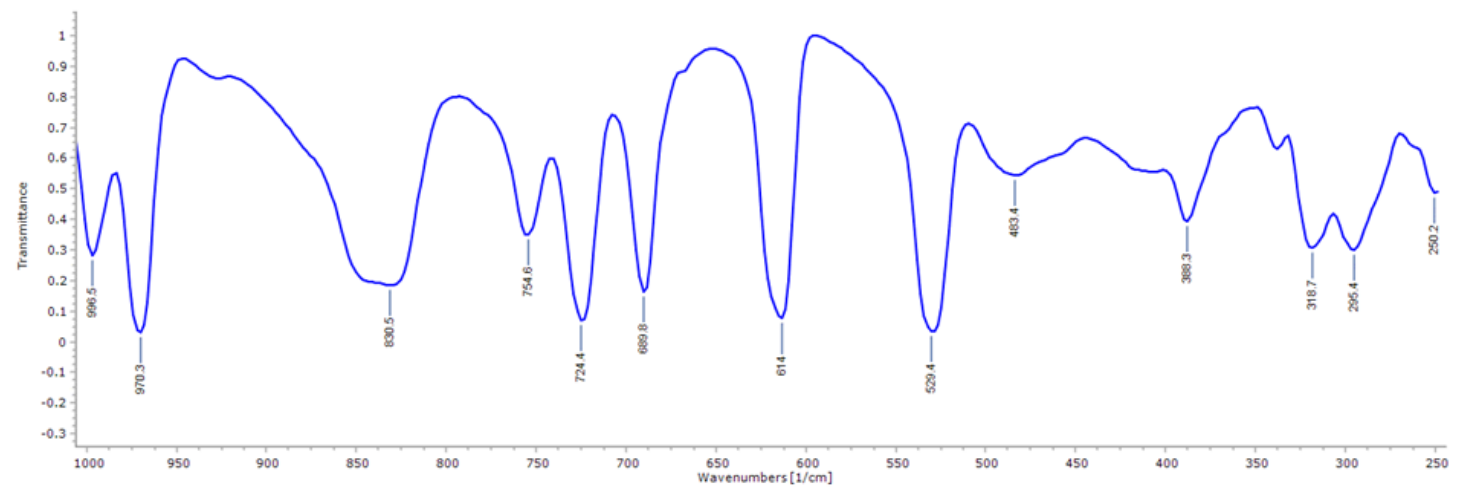

Figure 54. Far-IR of CI-HIPPO. 


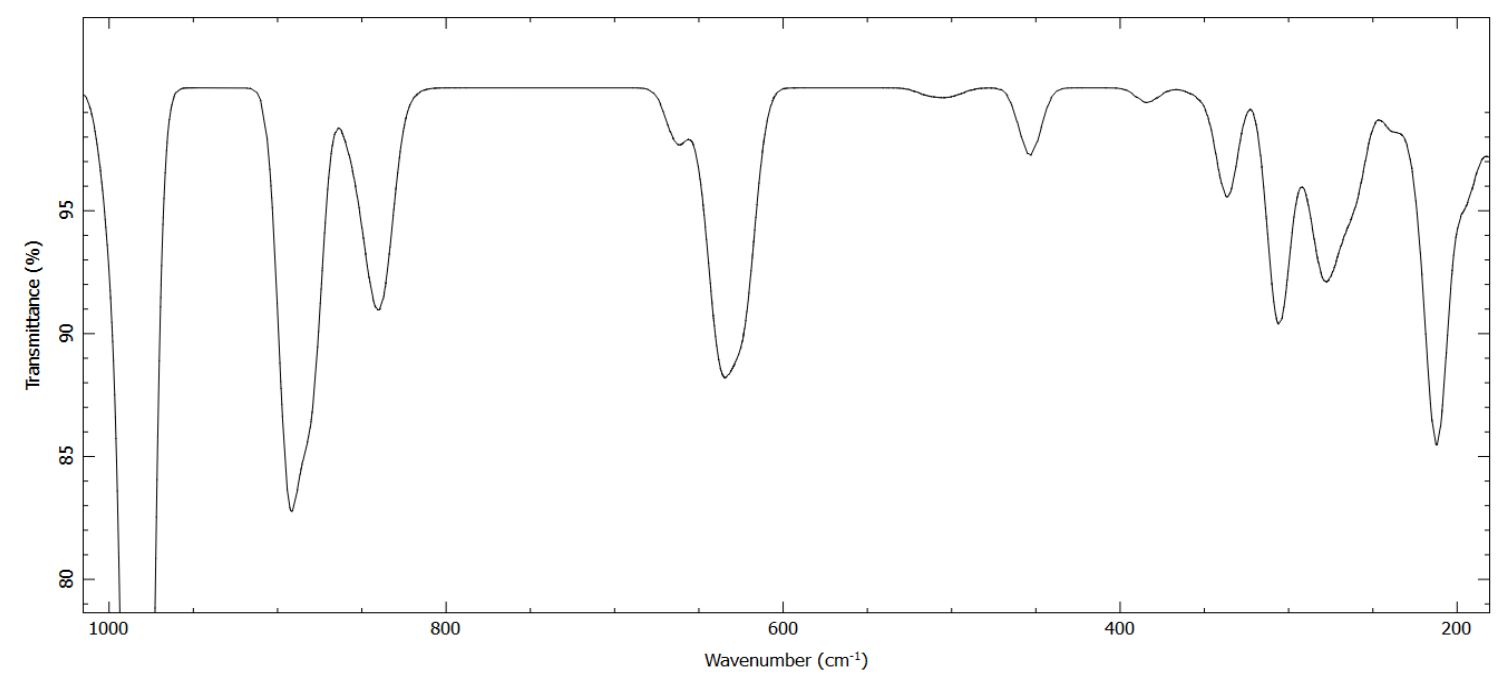

Figure 55. Simulated spectra of CI-HIPPO determined by DFT.

\subsubsection{Far-IR of Ph-HIPPO}

In the spectrum of Ph-HIPPO (Figure 56), calculations place two peaks at 277.58 $\mathrm{cm}^{-1}$ and $277.91 \mathrm{~cm}^{-1}$ observed as a single peak at $280 \mathrm{~cm}^{-1}$, corresponding to a Cu-N stretch. Calculated frequencies at $337.73 \mathrm{~cm}^{-1}, 339.5 \mathrm{~cm}^{-1}, 344.86 \mathrm{~cm}^{-1}$, and $346.22 \mathrm{~cm}^{-1}$, can be seen as a peak at $341.5 \mathrm{~cm}^{-1}$ with a shoulder at $353 \mathrm{~cm}^{-1}$. Absorptions associated with $\mathrm{Cu}-\mathrm{O}$ bonds are seen $374.7 \mathrm{~cm}^{-1}$ and strong absorption at $430 \mathrm{~cm}^{-1}$ with a slight inflection at $442.3 \mathrm{~cm}^{-1}$, the calculated absorptions are at $440.58,445.16$, which have pyrazolate distortions, and 447.03 $\mathrm{cm}^{-1}$. The Cu-Cl absorption that appears at $251.4 \mathrm{~cm}^{-1}$ corresponds to a calculated frequency coupled with pyrazolate distortions at $242.89 \mathrm{~cm}^{-1}$. There is also a small, rounded absorption at $305 \mathrm{~cm}^{-1}$, which corresponds to $\mathrm{Cu}-\mathrm{Cl}, \mathrm{Cu}-\mathrm{O}$ coupled modes calculated to be at $311.87 \mathrm{~cm}^{-1}$ and $313.77 \mathrm{~cm}^{-1}$. 


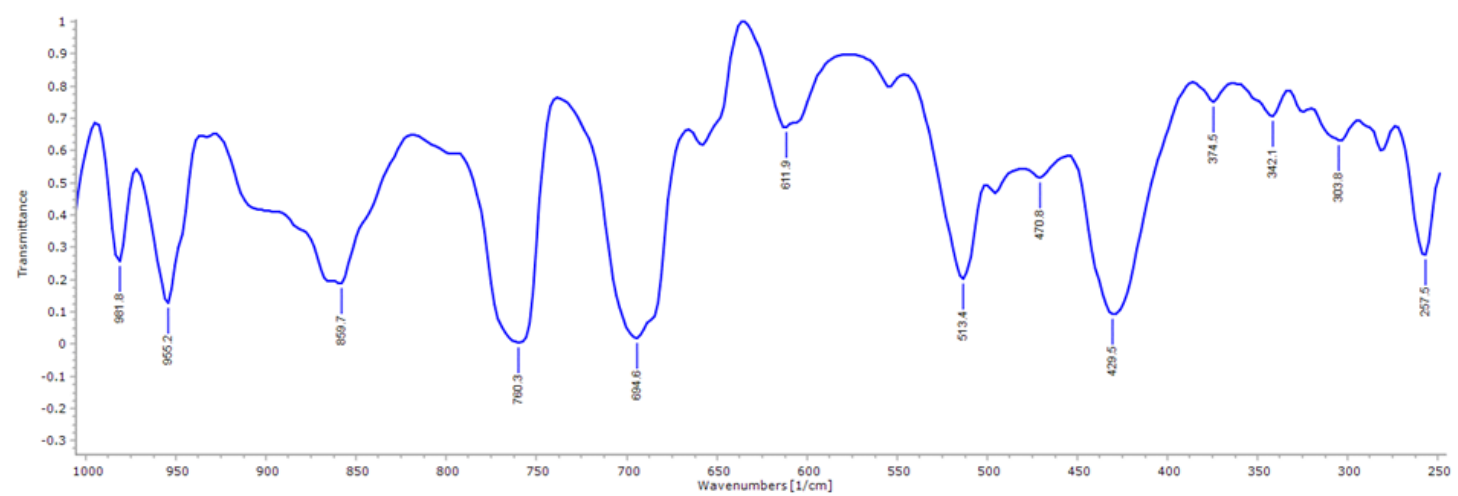

Figure 56. Far-IR of Ph-HIPPO.

\subsubsection{Far-IR of [1]}

The spectra of [1] (Figure 57), lacks an absorption in the terminal Cl range, which is to be expected. The Cu-N stretch appears at $364 \mathrm{~cm}^{-1}$. A much weaker absorption at $534 \mathrm{~cm}^{-1}$ corresponding the $\mathrm{Cu}-\mathrm{O}$ bonds.

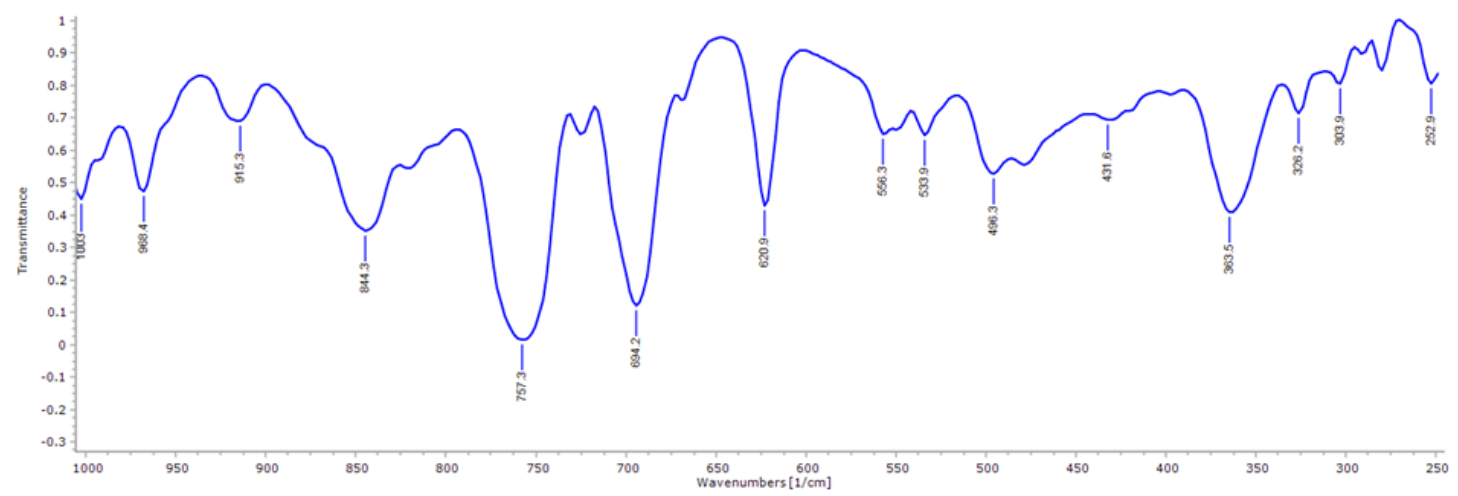

Figure 57. Far-IR of [1].

\subsubsection{Far-IR of PPN[2]}

The spectrum of PPN[2] (Figure 58) has peaks associated with Cu-N stretches at 282 (a small peak), 314.5 (a shoulder), and $353 \mathrm{~cm}^{-1}$ with a inflection at $341 \mathrm{~cm}^{-1}$. The calculated peaks for Cu-N stretch are shown at $294.84 \mathrm{~cm}^{-1}, 313.83 \mathrm{~cm}^{-1}$, 
$341.85 \mathrm{~cm}^{-1}, 345.7 \mathrm{~cm}^{-1}, 347.59 \mathrm{~cm}^{-1}$, and $353.83 \mathrm{~cm}^{-1}$. The peaks at $345.7 \mathrm{~cm}^{-1}$, $347.59 \mathrm{~cm}^{-1}$, and $353.83 \mathrm{~cm}^{-1}$ are seen as one large broad peak in the experimental spectrum. There are four $\mathrm{Cu}-\mu_{3}-\mathrm{O}$ absorptions seen in the experimental spectrum. One medium absorption at $433 \mathrm{~cm}^{-1}$, and three strong absorptions at $501 \mathrm{~cm}^{-1}, 534.9 \mathrm{~cm}^{-1}$, and $546.9 \mathrm{~cm}^{-1}$. The calculated absorptions for the $\mathrm{Cu}-\mu_{3}-\mathrm{O}$ stretches are at $427.05 \mathrm{~cm}^{-1}, 487.28 \mathrm{~cm}^{-1}, 506.2 \mathrm{~cm}^{-1}$, and 520.2 $\mathrm{cm}^{-1}$, respectively.

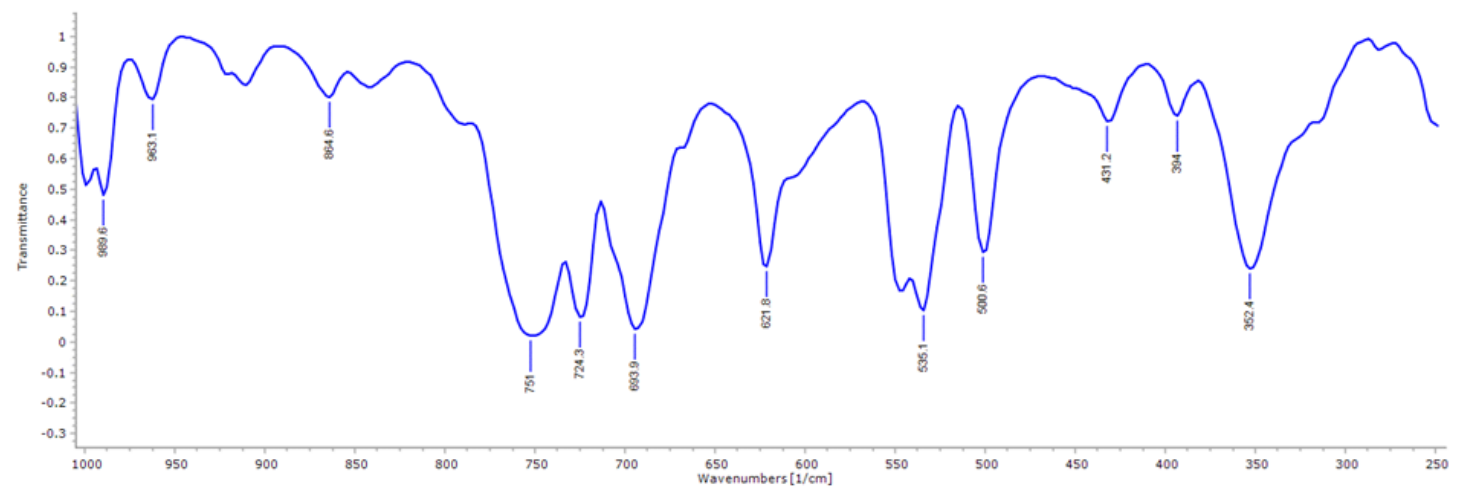

Figure 58. Far-IR of PPN[2].

\subsubsection{IR Compared to Literature Values}

Overall, the IR absorption frequencies are in agreement with previous literature, which place the vibration frequency for $\mathrm{Cu}-\mathrm{Cl}$ bonds at 218-345 $\mathrm{cm}^{-1},{ }^{181,182,185,187,191,205,206} \mathrm{Cu}-\mathrm{N}$ at 183-421 $\mathrm{cm}^{-1},{ }^{181,206,207}$ and $\mathrm{Cu}-\mathrm{O}$ at 529-594 $\mathrm{cm}^{-1} .{ }^{182,183,187}$ Observed and calculated data for Cl-HIPPO, Ph-HIPPO, and PPN[2] are listed on Table 12. 
Table 12. Comparison of calculated absorptions and observed absorptions. * indicates coupling with $\mathrm{pz}^{-}$deformation.

\begin{tabular}{|c|c|c|c|c|c|c|}
\hline \multirow{2}{*}{ Bond } & \multicolumn{2}{|c|}{ CI-HIPPO } & \multicolumn{2}{|c|}{ Ph-HIPPO } & \multicolumn{2}{|c|}{ PPN[2] } \\
\hline & Calculated & Exptl & Calculated & Exptl & Calculated & Exptl \\
\hline $\mathbf{C u}-\mathbf{N}$ & 227.81 & $B / R$ & $\begin{array}{l}277.58 \\
277.91\end{array}$ & 280 & $\begin{array}{c}233.22 \\
\text { (bridging) } \\
237.16\end{array}$ & $B / R$ \\
\hline $\mathbf{C u}-\mathbf{N}$ & $\begin{array}{c}301.71 \\
306.46^{*}\end{array}$ & 295 & $\begin{array}{c}337.73 \\
339.5 \\
344.86 \\
346.22\end{array}$ & $\begin{array}{c}341.5 \\
353\end{array}$ & 294.84 & 282 \\
\hline $\mathrm{Cu}-\mathrm{N}$ & $\begin{array}{l}504.16 \\
506.22\end{array}$ & 529.3 & $\mathrm{~N} / \mathrm{A}$ & $\mathrm{N} / \mathrm{A}$ & $\begin{array}{c}313.83 \\
\text { (bridging) }\end{array}$ & 314.5 \\
\hline $\mathbf{C u}-\mathbf{N}$ & N/A & $\mathrm{N} / \mathrm{A}$ & $\mathrm{N} / \mathrm{A}$ & N/A & $\begin{array}{c}341.58 \\
345.7 \\
347.59 \\
353.83 \\
\end{array}$ & $\begin{array}{l}341 \\
353\end{array}$ \\
\hline $\mathrm{Cu}-\mathrm{O}$ & $N / A$ & $\mathrm{~N} / \mathrm{A}$ & $\begin{array}{l}375.9: \\
379.71\end{array}$ & 374.7 & 427.05 & 433 \\
\hline Cu-O & $309.86^{*}$ & 319 & $\begin{array}{c}440.58^{\star} \\
445.16^{\star} \\
447.03\end{array}$ & $\begin{array}{c}430 \\
442.3\end{array}$ & 487.28 & 501 \\
\hline $\mathrm{Cu}-\mathrm{O}$ & 346.63 & 337.3 & $N / A$ & $\mathrm{~N} / \mathrm{A}$ & 506.2 & 534.9 \\
\hline $\mathrm{Cu}-\mathrm{O}$ & $\begin{array}{l}452.77 \\
455.12\end{array}$ & $457: 483$ & $\mathrm{~N} / \mathrm{A}$ & $\mathrm{N} / \mathrm{A}$ & 520.2 & 546.9 \\
\hline $\mathrm{Cu}-\mathrm{Cl}$ & $\begin{array}{l}208.89 \\
212.47 \\
\end{array}$ & 250 & $264.9^{*}$ & 251.4 & $\mathrm{~N} / \mathrm{A}$ & $\mathrm{N} / \mathrm{A}$ \\
\hline $\begin{array}{l}\mathrm{Cu}-\mathrm{O} \\
\mathrm{Cu}-\mathrm{N} \\
\end{array}$ & 223.75 & N/A & $\mathrm{N} / \mathrm{A}$ & $\mathrm{N} / \mathrm{A}$ & N/A & $\mathrm{N} / \mathrm{A}$ \\
\hline $\begin{array}{l}\mathrm{Cu}-\mathrm{Cl} \\
\mathrm{Cu}-\mathrm{N}\end{array}$ & 208.89 & $\mathrm{~B} / \mathrm{R}$ & $\begin{array}{c}234.4 \\
237.3 \\
242.89\end{array}$ & $\mathrm{~B} / \mathrm{R}$ & $\mathrm{N} / \mathrm{A}$ & $\mathrm{N} / \mathrm{A}$ \\
\hline $\begin{array}{l}\mathrm{Cu}-\mathrm{Cl} \\
\mathrm{Cu}-\mathrm{N}\end{array}$ & 239.0 & 262.8 & $N / A$ & $\mathrm{~N} / \mathrm{A}$ & N/A & $\mathrm{N} / \mathrm{A}$ \\
\hline $\begin{array}{l}\mathrm{Cu}-\mathrm{Cl} \\
\mathrm{Cu}-\mathrm{N}\end{array}$ & $\begin{array}{l}256.57 \\
256.92\end{array}$ & 280 & $N / A$ & $\mathrm{~N} / \mathrm{A}$ & $\mathrm{N} / \mathrm{A}$ & $N / A$ \\
\hline $\begin{array}{l}\mathrm{Cu}-\mathrm{Cl} \\
\mathrm{Cu}-\mathrm{O}\end{array}$ & $\mathrm{N} / \mathrm{A}$ & $\mathrm{N} / \mathrm{A}$ & $\begin{array}{l}311.87 \\
313.77\end{array}$ & 305 & $\mathrm{~N} / \mathrm{A}$ & $\mathrm{N} / \mathrm{A}$ \\
\hline
\end{tabular}

\subsubsection{Magnetics}

The magnetic properties were deeply studied for selected compounds, Cl-HIPPO

and Ph-HIPPO, by acquiring temperature and field dependent magnetization data as showed in Figure 59. The room temperature values of the effective magnetic 
moment $\left(\mu_{\text {eff }}\right)$ are $4.28 \mu_{\mathrm{B}}$ for Cl-HIPPO and $3.85 \mu_{\mathrm{B}}$ for Ph-HIPPO and these values are close to the theoretical values of $4.24 \mu_{\mathrm{B}}$ for six non-interacting $\mathrm{Cu}$ (II) ions with $S_{i}=1 / 2$ and $g_{i}=2.0$. The $\mu_{\text {eff }}$ is continuously decreasing on lowering the temperature down to ca $50 \mathrm{~K}$ and then significant drop of $\mu_{\text {eff }}$ is observed down to values of $0.47 \mu_{\mathrm{B}}$ for $\mathrm{Cl}$-HIPPO and $1.67 \mu_{\mathrm{B}}$ for Ph-HIPPO at $T=1.9 \mathrm{~K}$. This magnetic behaviour reflects strong antiferromagnetic exchange interactions within each $\mathrm{Cu}_{3}\left(\mu_{3}-\mathrm{OH}\right)$ triangles resulting in $S_{\text {triangle }}=1 / 2$ spin state and further weak antiferromagnetic exchange between these two triangles leading to $S=0$ molecular ground state. Here we can expect that difference on low temperature magnetism is related to strength of the antiferromagnetic exchange between each $\mathrm{Cu}_{3}\left(\mu_{3}-\mathrm{OH}\right)$ triangles in Cl-HIPPO and Ph-HIPPO reflecting their structural differences. Moreover, the triangular systems of $\mathrm{Cu}(\mathrm{II}),{ }^{48,53,208} \mathrm{Ni}(\mathrm{II}),{ }^{209} \mathrm{Fe}(\mathrm{III})^{210}$ complexes possessing large antiferromagnetic exchange are well known to exhibit also the magnetic anisotropy of $S=1 / 2$ ground state due to the antisymmetric exchange interaction also known as Dzyaloshinsky-Moriya interaction. ${ }^{211}$ Therefore, the following spin Hamiltonian was postulated to interpret magnetism of Cl-HIPPO

$\widehat{H}=-J_{1}\left(\boldsymbol{S}_{1} \cdot \boldsymbol{S}_{2}+\boldsymbol{S}_{1} \cdot \boldsymbol{S}_{3}+\boldsymbol{S}_{4} \cdot \boldsymbol{S}_{5}+\boldsymbol{S}_{4} \cdot \boldsymbol{S}_{6}\right)-J_{1 b}\left(\boldsymbol{S}_{2} \cdot \boldsymbol{S}_{3}+\boldsymbol{S}_{5} \cdot \boldsymbol{S}_{6}\right)-J_{2}\left(\boldsymbol{S}_{2} \cdot \boldsymbol{S}_{5}+\right.$ $\left.\boldsymbol{S}_{3} \cdot \boldsymbol{S}_{6}\right)+d \cdot\left(\boldsymbol{S}_{1} \times \boldsymbol{S}_{2}+\boldsymbol{S}_{2} \times \boldsymbol{S}_{3}+\boldsymbol{S}_{3} \times \boldsymbol{S}_{1}+\boldsymbol{S}_{4} \times \boldsymbol{S}_{5}+\boldsymbol{S}_{5} \times \boldsymbol{S}_{6}+\boldsymbol{S}_{6} \times \boldsymbol{S}_{4}\right)+\mu_{B} B$. $\boldsymbol{g} \cdot \sum_{i=1}^{6} \boldsymbol{S}_{i}$

Equation 6

and Ph-HIPPO 
$\widehat{H}=-J_{1}\left(\boldsymbol{S}_{1} \cdot \boldsymbol{S}_{2}+\boldsymbol{S}_{2} \cdot \boldsymbol{S}_{3}+\boldsymbol{S}_{1^{\prime}} \cdot \boldsymbol{S}_{2^{\prime}}+\boldsymbol{S}_{2^{\prime}} \cdot \boldsymbol{S}_{3^{\prime}}\right)-J_{1 b}\left(\boldsymbol{S}_{1} \cdot \boldsymbol{S}_{3}+\boldsymbol{S}_{1^{\prime}} \cdot \boldsymbol{S}_{3^{\prime}}\right)-$ $J_{2}\left(\boldsymbol{S}_{1} \cdot \boldsymbol{S}_{1^{\prime}}\right)+d \cdot\left(\boldsymbol{S}_{1} \times \boldsymbol{S}_{2}+\boldsymbol{S}_{2} \times \boldsymbol{S}_{3}+\boldsymbol{S}_{3} \times \boldsymbol{S}_{1}+\boldsymbol{S}_{1^{\prime}} \times \boldsymbol{S}_{2^{\prime}}+\boldsymbol{S}_{2^{\prime}} \times \boldsymbol{S}_{3^{\prime}}+\boldsymbol{S}_{3^{\prime}} \times \boldsymbol{S}_{1^{\prime}}\right)+$ $\mu_{B} \boldsymbol{B} \cdot \boldsymbol{g} \cdot \sum_{i=1}^{6} \boldsymbol{S}_{i} \quad$ Equation 7

where the isotropic exchange parameters $J_{1}$ and $J_{1 b}$ are characterizing magnetic coupling with $\mathrm{Cu}_{3}\left(\mu_{3}-\mathrm{OH}\right)$ triangles and $J_{2}$ between two triangles, the antisymmetric exchange is characterized by vector parameter $\mathbf{d}=\left(d_{x}, d_{y}, d_{z}\right)$, which was simplified thanks to Moriya symmetry rules ${ }^{212}$ to $\mathbf{d}=\left(0,0, d_{z}\right)$. Next, the molar magnetization was calculated from the partition function $Z$ as

$$
M_{\mathrm{mol}}(\theta, \varphi)=N_{A} k T \frac{\partial \ln Z}{\partial B_{\theta, \varphi}}
$$

Equation 8

and finally, the averaged molar magnetization was calculated as an integral average to properly simulated powder sample magnetic measurements

$$
M_{\mathrm{mol}}=\frac{1}{4 \pi} \int_{\varphi=0}^{2 \pi} \int_{\theta=0}^{\pi} M_{\mathrm{mol}}(\theta, \varphi) \sin \theta d \theta d \varphi
$$

Equation 9

where the magnetic field vector is defined with the help of the spherical coordinates.

The both temperature and field dependent magnetization data were fitted simultaneously and the best-fitted parameters for CI-HIPPO are $J_{1}=-240 \mathrm{~cm}^{-1}$, $J_{1 b}=-225 \mathrm{~cm}^{-1}, J_{2}=-26 \mathrm{~cm}^{-1},\left|d_{z}\right|=17.0 \mathrm{~cm}^{-1}$ with an isotropic $g$-factor $\mathrm{g}=2.65$, and for Ph-HIPPO are $J_{1}=-208 \mathrm{~cm}^{-1}, J_{1 b}=-145 \mathrm{~cm}^{-1}, J_{2}=-17 \mathrm{~cm}^{-1},\left|d_{z}\right|=34.3$ $\mathrm{cm}^{-1}$ with an isotropic $g$-factor $\mathrm{g}=2.22$ (Figure 59). Also, the temperature- 
independent magnetism was treated with fixed value of $\square \mathrm{TIP}=0.88 \times 10^{-9} \mathrm{~m}^{3} \mathrm{~mol}^{-1}$ per copper atom.
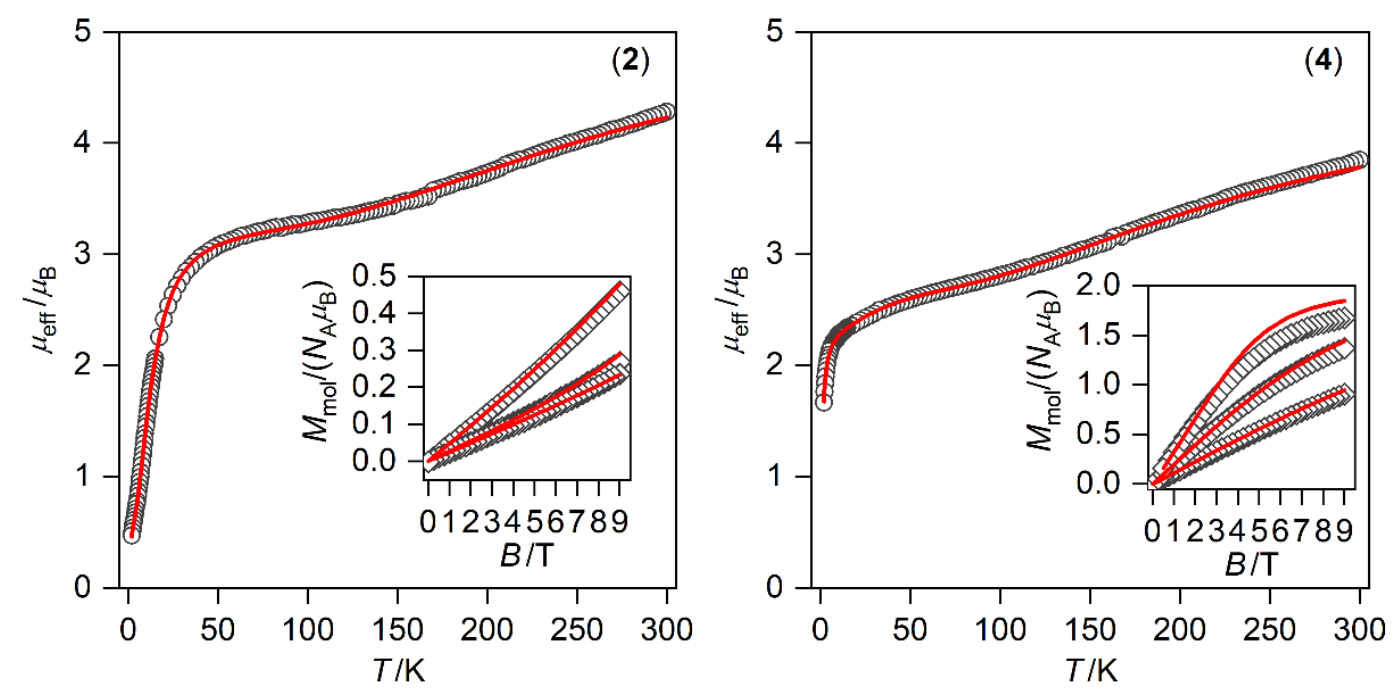

Figure 59. Magnetic properties of compounds 2 and $\mathbf{4}$. Each plot shows the temperature dependence of the effective magnetic moment and in the inset, the isothermal magnetizations measured at $T=2,5$ and $10 \mathrm{~K}$ are given.

Experimental data - empty symbols, full red lines - calculated data with spin Hamiltonian in eq. 1 and parameters in the text.

The analysis of the experimental data confirmed strong antiferromagnetic coupling within $\mathrm{Cu}_{3}\left(\mu_{3}-\mathrm{OH}\right)$ triangles mediated by pyrazolato and hydroxo bridging ligands. Interestingly, there is sizeable difference in $J_{2}$ between Cl-HIPPO and Ph-HIPPO, which most probably can be assigned to difference in the electronic properties of pyrazolato bridging ligands with chloro or phenyl substituent.

\subsubsection{Theoretical calculations}

To support our analysis of the magnetic data of Cl-HIPPO and Ph-HIPPO, the Density Functional Theory (DFT) theoretical calculations were performed aiming to estimate the isotropic exchange parameters $\mathrm{J}$. Based on our previous 
experience with polynuclear systems, B3LYP functional was chosen and the Ruiz's approach for calculation of $\int$ s were followed employing the broken-symmetry DFT calculations with computational package ORCA 3.0.

In case of compound 2, the spin Hamiltonian was formulated as

$\widehat{H}=-J_{12}\left(\boldsymbol{S}_{1} \cdot \boldsymbol{S}_{2}\right)-J_{13}\left(\boldsymbol{S}_{1} \cdot \boldsymbol{S}_{3}\right)-J_{23}\left(\boldsymbol{S}_{2} \cdot \boldsymbol{S}_{3}\right)-J_{45}\left(\boldsymbol{S}_{4} \cdot \boldsymbol{S}_{5}\right)-J_{46}\left(\boldsymbol{S}_{4} \cdot \boldsymbol{S}_{6}\right)-J_{56}\left(\boldsymbol{S}_{5} \cdot\right.$ $\left.\boldsymbol{S}_{6}\right)-J_{25}\left(\boldsymbol{S}_{2} \cdot \boldsymbol{S}_{5}\right)-J_{36}\left(\boldsymbol{S}_{3} \cdot \boldsymbol{S}_{6}\right)$

Equation 10

and several broken-symmetry spin states were calculated and compared to the energy of high-spin state, which enabled us to derive these equations for the values of the isotropic exchange parameters in equation 11 as

$$
\begin{aligned}
& J_{12}=\left(\Delta_{1}-\Delta_{3}-\Delta_{5}+\Delta_{25}+\Delta_{123}\right) / 2 \\
& J_{23}=\left(-\Delta_{1}+\Delta_{2}+\Delta_{3}-\Delta_{123}\right) / 2 \\
& J_{13}=\left(\Delta_{1}+\Delta_{3}+\Delta_{5}-\Delta_{25}-\Delta_{123}\right) / 2 \\
& J_{45}=\left(-\Delta_{2}+\Delta_{4}-\Delta_{6}+\Delta_{25}+\Delta_{123}\right) / 2 \\
& J_{56}=\left(-\Delta_{4}+\Delta_{5}+\Delta_{6}-\Delta_{123}\right) / 2 \\
& J_{46}=\left(-\Delta_{2}-\Delta_{4}-\Delta_{6}+\Delta_{25}+\Delta_{123}\right) / 2 \\
& J_{25}=\left(\Delta_{2}+\Delta_{5}-\Delta_{25}\right) / 2 \\
& J_{36}=\left(-\Delta_{2}-\Delta_{5}+\Delta_{25}+2 \Delta_{123}\right) / 2
\end{aligned}
$$

Equation 11

As a result, we obtained the isotropic exchange parameters of CI-HIPPO as $J_{12}=$ $-100 \mathrm{~cm}^{-1}, J_{23}=-86 \mathrm{~cm}^{-1}, J_{13}=-240 \mathrm{~cm}^{-1}, J_{45}=-171 \mathrm{~cm}^{-1}, J_{56}=-111 \mathrm{~cm}^{-1}, J_{46}=$ $-168 \mathrm{~cm}^{-1}, J_{25}=-23.4 \mathrm{~cm}^{-1}, J_{36}=-38.9 \mathrm{~cm}^{-1}$.

The similar procedure was applied to compound Ph-HIPPO with spin Hamiltonian defined as 
$\widehat{H}=-J_{12}\left(\boldsymbol{S}_{1} \cdot \boldsymbol{S}_{2}+\boldsymbol{S}_{1^{\prime}} \cdot \boldsymbol{S}_{2^{\prime}}\right)-J_{13}\left(\boldsymbol{S}_{1} \cdot \boldsymbol{S}_{3}+\boldsymbol{S}_{1^{\prime}} \cdot \boldsymbol{S}_{3^{\prime}}\right)-J_{23}\left(\boldsymbol{S}_{2} \cdot \boldsymbol{S}_{3}+\boldsymbol{S}_{2^{\prime}} \cdot \boldsymbol{S}_{3^{\prime}}\right)-$ $J_{11^{\prime}}\left(\boldsymbol{S}_{1} \cdot \boldsymbol{S}_{1^{\prime}}\right)$

Equation 12

and the relationships for $\mathcal{J}$ s were derived as

$J_{12}=\left(\Delta_{11^{\prime}}+\Delta_{22^{\prime}}-\Delta_{33^{\prime}}\right) / 4$

$J_{23}=\left(-\Delta_{11^{\prime}}+\Delta_{22^{\prime}}+\Delta_{33^{\prime}}\right) / 4$

$J_{13}=\left(\Delta_{11^{\prime}}-\Delta_{22^{\prime}}+\Delta_{33^{\prime}}\right) / 4$

$J_{11^{\prime}}=\Delta_{123}$

Consequently, the isotropic exchange parameters were derived as $J_{12}=-174$ $\mathrm{cm}^{-1}, J_{23}=-124 \mathrm{~cm}^{-1}, J_{13}=-141 \mathrm{~cm}^{-1}, J_{11}=-221 \mathrm{~cm}^{-1}$.

Generally, the DFT calculations showed large antiferromagnetic exchange within each $\mathrm{Cu}_{3}\left(\mu_{3}-\mathrm{OH}\right)$ triangles both in Cl-HIPPO and Ph-HIPPO. Moreover, there is obvious magneto-structural correlation between $\mathrm{Cu}-\mathrm{O}-\mathrm{Cu}$ angle and the value of the respective $\mathrm{J}$-parameter as showed in Figure 60 and it holds that the larger angle which $\mathrm{Cu}-\mathrm{O}-\mathrm{Cu}$, the stronger antiferromagnetic exchange was calculated. Next, the values of inter-triangular exchange $\left(J_{25}\right.$ and $\left.J_{36}\right)$ are quite reasonable for Cl-HIPPO and follows the analysis of the experimental magnetic data, however, the situation is very different for Ph-HIPPO, where $J_{11}$ ' adopted very large value incompatible with the experiment. 


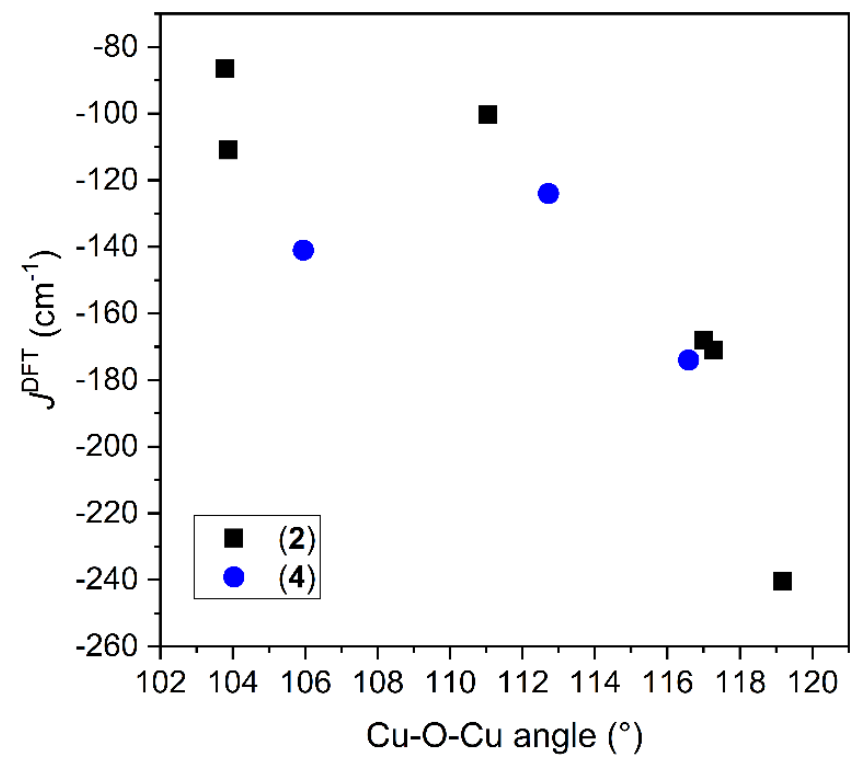

Figure 60. The magneto-structural correlation between the angle $\mathrm{Cu}-\mathrm{O}-\mathrm{Cu}$ in $\mathrm{Cu}_{3}\left(\mu_{3}-\mathrm{OH}\right)$ triangles of $\mathbf{C l}-\mathrm{HIPPO}$ and $\mathbf{P h}$-HIPPO extracted from X-ray structures and magnetic coupling parameters $J$ calculated by DFT using B3LYP functional.

\subsection{Conclusions}

Here the first four open cage $\mathrm{Cu}_{6}$ motifs are reported. This shows that $\mathrm{Cu}$ pyrazolate motifs can exploited in new ways. Furthermore, we characterize for the first time $\mathrm{Cu}-\mathrm{O}, \mathrm{Cu}-\mathrm{N}$, and $\mathrm{Cu}-\mathrm{Cl}$ bonds in Cu-pyrazolate compounds. Magnetic susceptibility was measured for the new motifs and will be compared to other $\mathrm{Cu}_{6}$ compounds and supramolecular $\mathrm{Cu}_{3}$ compounds to further understand how the magnetics are affected by the distance, connectivity, and angle of the Cus subunits. Variable low-temperature NMR studies were also conducted. 


\section{Summary and Future Work}

The purpose of this project was to determine if a $\mathrm{Cu}_{6}$ motif could function as a water oxidation catalyst. Toward this end, $\mathrm{Cu}_{6}$ has been oxidized and characterized in a mixed-valent state. The data support the conclusion that a $\mathrm{Cu}_{6}$ motif could be used as a WOC, due to the evidence that significant spin density is located on the $\mu_{3}$-oxo ligands. Furthermore, the crystal structures of the parent $\mathrm{Cu}_{6}$ and the MV-Cu6 show that upon oxidation, the central $\mu_{3}-\mathrm{O}$ ligands move $\sim 0.3 \AA ̊$ closer.

The attempted synthesis of an elusive positively charged of a Сuз compound with 4-formyl-pzH and terminal pyridine led to novel $\mathrm{Cu}_{3}$ coordination polymers with rare Cu-aldehyde coordination and new topology.

Finally, two new open-cage $\mathrm{Cu}_{6}$ motifs have been synthesized and characterized. The open-cage motifs were characterized using variable lowtemperature NMR, magnetic susceptibility, and IR spectroscopy. The IRspectra have been used to characterize the various copper bonds that have never been investigated in copper-pyrazolate motifs.

In future studies, it will be vital to synthesize a flexible rigid Cu6 motif. While such complexes eluded this study, there are many synthetic techniques that could still be employed, such as using the Cu-CPs presented here as a starting material for the flexible $\mathrm{Cu}_{6}$ motifs. It was demonstrated that with coordinating solvents, the coordination polymers can be broken apart into the $\mathrm{Cu}_{3}$ subunits. 
After the synthesis for flexible a Cu6 has been perfected, the synthesis should be modified to allow for a flexible two pillar an open-cage variation that will facilitate the release of the generated $\mathrm{O}_{2}{ }^{2-}$ ion. 


\section{References}

(1) Lewis, N. S.; Nocera, D. G. Powering the Planet: Chemical Challenges in Solar Energy Utilization. PNAS 2006, 103 (43), 15729-15735. https://doi.org/10.1073/pnas.0603395103.

(2) Dincă, M.; Surendranath, Y.; Nocera, D. G. Nickel-Borate OxygenEvolving Catalyst That Functions under Benign Conditions. PNAS 2010, 107 (23), 10337-10341. https://doi.org/10.1073/pnas.1001859107.

(3) Kanan, M. W.; Surendranath, Y.; Nocera, D. G. Cobalt-Phosphate Oxygen-Evolving Compound. Chem. Soc. Rev. 2008, 38 (1), 109-114. https://doi.org/10.1039/B802885K.

(4) Fillol, J. L.; Codolà, Z.; Garcia-Bosch, I.; Gómez, L.; Pla, J. J.; Costas, M. Efficient Water Oxidation Catalysts Based on Readily Available Iron Coordination Complexes. Nat. Chem. 2011, 3 (10), 807-813. https://doi.org/10.1038/nchem.1140.

(5) Tributsch, H. Multi-Electron Transfer Catalysis for Energy Conversion Based on Abundant Transition Metals. Electrochim. Acta 2007, 52 (6), 2302-2316. https://doi.org/10.1016/j.electacta.2006.03.111.

(6) Najafpour, M. M. Amorphous Manganese-Calcium Oxides as a Possible Evolutionary Origin for the CaMn4 Cluster in Photosystem II. Orig. Life Evol. Biosph. 2011, 41 (3), 237-247. https://doi.org/10.1007/s11084-0109224-z.

(7) Sauer, K.; Yachandra, V. K. A Possible Evolutionary Origin for the $\mathrm{Mn}_{4}$ Cluster of the Photosynthetic Water Oxidation Complex from Natural $\mathrm{MnO}_{2}$ Precipitates in the Early Ocean. PNAS 2002, 99 (13), 8631-8636. https://doi.org/10.1073/pnas.132266199.

(8) Hocking, R. K.; Brimblecombe, R.; Chang, L.-Y.; Singh, A.; Cheah, M. H.; Glover, C.; Casey, W. H.; Spiccia, L. Water-Oxidation Catalysis by Manganese in a Geochemical-like Cycle. Nat. Chem. 2011, 3 (6), 461466. https://doi.org/10.1038/nchem.1049.

(9) Umena, Y.; Kawakami, K.; Shen, J.-R.; Kamiya, N. Crystal Structure of Oxygen-Evolving Photosystem II at a Resolution of $1.9 \AA$ A . Nature 2011, 473 (7345), 55-60. https://doi.org/10.1038/nature09913. 
(10) Cox, N.; Pantazis, D. A.; Neese, F.; Lubitz, W. Biological Water Oxidation. Acc. Chem. Res. 2013, 46 (7), 1588-1596.

https://doi.org/10.1021/ar3003249.

(11) Singh, A.; Spiccia, L. Water Oxidation Catalysts Based on Abundant 1st Row Transition Metals. Coord. Chem. Rev. 2013, 257 (17), 2607-2622. https://doi.org/10.1016/j.ccr.2013.02.027.

(12) Duan, L.; Bozoglian, F.; Mandal, S.; Stewart, B.; Privalov, T.; Llobet, A.; Sun, L. A Molecular Ruthenium Catalyst with Water-Oxidation Activity Comparable to That of Photosystem II. Nat. Chem. 2012, 4 (5), 418-423. https://doi.org/10.1038/nchem.1301.

(13) Kikuchi, T.; Tanaka, K. Mechanistic Approaches to Molecular Catalysts for Water Oxidation. Eur. J. Inorg. Chem. 2014, 2014 (4), 607-618. https://doi.org/10.1002/ejic.201300716.

(14) Datta, D.; Chakravorty, A. Electron Transfer in Authentic Triangular Copper(II) Trimers with Cu3X (X = Oxygen or Hydroxy) Core. The Cull2CullI-Cull3 and Cull3-CuCulCull2 Couples. Inorg. Chem. 1982, 21 (1), 363-368. https://doi.org/10.1021/ic00131a065.

(15) Lewandowska-Andralojc, A.; Polyansky, D. E.; Zong, R.; Thummel, R. P.; Fujita, E. Enabling Light-Driven Water Oxidation via a Low-Energy RulVO Intermediate. Phys. Chem. Chem. Phys. 2013, 15 (33), 14058-14068. https://doi.org/10.1039/C3CP52038B.

(16) Liu, X.; Wang, F. Transition Metal Complexes That Catalyze Oxygen Formation from Water: 1979-2010. Coord. Chem. Rev. 2012, 256 (11), 1115-1136. https://doi.org/10.1016/j.ccr.2012.01.015.

(17) Li, X.; Chen, G.; Schinzel, S.; Siegbahn, P. E. M. A Comparison between Artificial and Natural Water Oxidation. Dalton Trans. 2011, 40 (42), 11296-11307. https://doi.org/10.1039/C1DT11323B.

(18) Barnett, S. M.; Goldberg, K. I.; Mayer, J. M. A Soluble Copper-Bipyridine Water-Oxidation Electrocatalyst. Nat. Chem. 2012, 4 (6), 498-502. https://doi.org/10.1038/nchem.1350.

(19) Siewert, I. Proton-Coupled Electron Transfer Reactions Catalysed by 3d Metal Complexes. Chem. Eur. J. 2015, 21 (43), 15078-15091. https://doi.org/10.1002/chem.201501684. 
(20) Mirzakulova, E.; Khatmullin, R.; Walpita, J.; Corrigan, T.; Vargas-Barbosa, N. M.; Vyas, S.; Oottikkal, S.; Manzer, S. F.; Hadad, C. M.; Glusac, K. D. Electrode-Assisted Catalytic Water Oxidation by a Flavin Derivative. Nat. Chem. 2012, 4 (10), 794-801. https://doi.org/10.1038/nchem.1439.

(21) Olaya, A. J.; Schaming, D.; Brevet, P.-F.; Nagatani, H.; Zimmermann, T.; Vanicek, J.; Xu, H.-J.; Gros, C. P.; Barbe, J.-M.; Girault, H. H. SelfAssembled Molecular Rafts at Liquid|Liquid Interfaces for Four-Electron Oxygen Reduction. J. Am. Chem. Soc. 2012, 134 (1), 498-506. https://doi.org/10.1021/ja2087322.

(22) Sala, X.; Maji, S.; Bofill, R.; García-Antón, J.; Escriche, L.; Llobet, A. Molecular Water Oxidation Mechanisms Followed by Transition Metals: State of the Art. Acc. Chem. Res. 2014, 47 (2), 504-516. https://doi.org/10.1021/ar400169p.

(23) Siegbahn, P. E. M. Structures and Energetics for O2 Formation in Photosystem II. Acc. Chem. Res. 2009, 42 (12), 1871-1880. https://doi.org/10.1021/ar900117k.

(24) McGrady, J. E.; Stranger, R. Redox-Induced Formation and Cleavage of $\mathrm{O}-\mathrm{O} \sigma$ and $\pi$ Bonds in a Peroxo-Bridged Manganese Dimer: A Density Functional Study. Inorg. Chem. 1999, 38 (3), 550-558. https://doi.org/10.1021/ic981253k.

(25) Li, X.; Siegbahn, P. E. M. Water Oxidation Mechanism for Synthetic CoOxides with Small Nuclearity. J. Am. Chem. Soc. 2013, 135 (37), 1380413813. https://doi.org/10.1021/ja4053448.

(26) Codolà, Z.; Cardoso, J. M. S.; Royo, B.; Costas, M.; Lloret-Fillol, J. Highly Effective Water Oxidation Catalysis with Iridium Complexes through the Use of NalO4. Chem. Eur. J. 2013, 19 (22), 7203-7213. https://doi.org/10.1002/chem.201204568.

(27) Matheu, R.; Ertem, M. Z.; Benet-Buchholz, J.; Coronado, E.; Batista, V. S.; Sala, X.; Llobet, A. Intramolecular Proton Transfer Boosts Water Oxidation Catalyzed by a Ru Complex. J. Am. Chem. Soc. 2015, 137 (33), 10786-10795. https://doi.org/10.1021/jacs.5b06541.

(28) Cox, N.; Retegan, M.; Neese, F.; Pantazis, D. A.; Boussac, A.; Lubitz, W. Electronic Structure of the Oxygen-Evolving Complex in Photosystem II Prior to O-O Bond Formation. Science 2014, 345 (6198), 804-808. https://doi.org/10.1126/science.1254910. 
(29) Solomon, E. I.; Sundaram, U. M.; Machonkin, T. E. Multicopper Oxidases and Oxygenases. Chem. Rev. 1996, 96 (7), 2563-2606.

https://doi.org/10.1021/cr950046o.

(30) Solomon, E. I.; Sarangi, R.; Woertink, J. S.; Augustine, A. J.; Yoon, J.; Ghosh, $\mathrm{S} . \mathrm{O}_{2}$ and $\mathrm{N}_{2} \mathrm{O}$ Activation by Bi-, Tri-, and Tetranuclear $\mathrm{Cu}$ Clusters in Biology. Acc. Chem. Res. 2007, 40 (7), 581-591. https://doi.org/10.1021/ar600060t.

(31) Chan, S. I.; Lu, Y.-J.; Nagababu, P.; Maji, S.; Hung, M.-C.; Lee, M. M.; Hsu, I.-J.; Minh, P. D.; Lai, J. C.-H.; Ng, K. Y.; et al. Efficient Oxidation of Methane to Methanol by Dioxygen Mediated by Tricopper Clusters. Angew. Chem. Int. Ed. 2013, 52 (13), 3731-3735. https://doi.org/10.1002/anie.201209846.

(32) Silva, C. S.; Durão, P.; Fillat, A.; Lindley, P. F.; Martins, L. O.; Bento, I. Crystal Structure of the Multicopper Oxidase from the Pathogenic Bacterium Campylobacter Jejuni CGUG11284: Characterization of a Metallo-Oxidase. Metallomics 2012, 4 (1), 37-47. https://doi.org/10.1039/C1MT00156F.

(33) Solomon, E. I.; Augustine, A. J.; Yoon, J. $\mathrm{O}_{2}$ Reduction to $\mathrm{H}_{2} \mathrm{O}$ by the Multicopper Oxidases. Dalton Trans. 2008, No. 30, 3921-3932. https://doi.org/10.1039/b800799c.

(34) Augustine, A. J.; Kjaergaard, C.; Qayyum, M.; Ziegler, L.; Kosman, D. J.; Hodgson, K. O.; Hedman, B.; Solomon, E. I. Systematic Perturbation of the Trinuclear Copper Cluster in the Multicopper Oxidases: The Role of Active Site Asymmetry in Its Reduction of $\mathrm{O}_{2}$ to $\mathrm{H}_{2} \mathrm{O}$. J. Am. Chem. Soc. 2010, 132 (17), 6057-6067. https://doi.org/10.1021/ja909143d.

(35) Zhukhlistova, N. E.; Zhukova, Yu. N.; Lyashenko, A. V.; Zaĭtsev, V. N.; Mikhaĭlov, A. M. Three-Dimensional Organization of Three-Domain Copper Oxidases: A Review. Crystallogr. Rep. 2008, 53 (1), 92-109. https://doi.org/10.1134/S1063774508010124.

(36) Lee, S.-K.; George, S. D.; Antholine, W. E.; Hedman, B.; Hodgson, K. O.; Solomon, E. I. Nature of the Intermediate Formed in the Reduction of $\mathrm{O}_{2}$ to $\mathrm{H}_{2} \mathrm{O}$ at the Trinuclear Copper Cluster Active Site in Native Laccase. $J$. Am. Chem. Soc. 2002, 124 (21), 6180-6193. https://doi.org/10.1021/ja0114052. 
(37) Chalupský, J.; Neese, F.; Solomon, E. I.; Ryde, U.; Rulíšek, L. Multireference $A b$ Initio Calculations on Reaction Intermediates of the Multicopper Oxidases. Inorg. Chem. 2006, 45 (26), 11051-11059. https://doi.org/10.1021/ic0619512.

(38) Rulíšek, L.; Ryde, U. Theoretical Studies of the Active-Site Structure, Spectroscopic and Thermodynamic Properties, and Reaction Mechanism of Multicopper Oxidases. Coord. Chem. Rev. 2013, 257 (2), 445-458. https://doi.org/10.1016/j.ccr.2012.04.019.

(39) Ivnitski, D. M.; Khripin, C.; Luckarift, H. R.; Johnson, G. R.; Atanassov, P. Surface Characterization and Direct Bioelectrocatalysis of Multicopper Oxidases. Electrochim. Acta 2010, 55 (24), 7385-7393. https://doi.org/10.1016/j.electacta.2010.07.026.

(40) Komori, H.; Sugiyama, R.; Kataoka, K.; Higuchi, Y.; Sakurai, T. An OCentered Structure of the Trinuclear Copper Center in the Cys500Ser/Glu506Gln Mutant of CueO and Structural Changes in Low to High X-Ray Dose Conditions. Angew. Chem. Int. Ed. 2012, 51 (8), 18611864. https://doi.org/10.1002/anie.201107739.

(41) Yoon, J.; Solomon, E. I. Electronic Structures of Exchange Coupled Trigonal Trimeric Cu(II) Complexes: Spin Frustration, Antisymmetric Exchange, Pseudo-A Terms, and Their Relation to $\mathrm{O}_{2}$ Activation in the Multicopper Oxidases. Coord. Chem. Rev. 2007, 251 (3-4), 379-400. https://doi.org/10.1016/j.ccr.2006.04.012.

(42) Komori, H.; Sugiyama, R.; Kataoka, K.; Miyazaki, K.; Higuchi, Y.; Sakurai, $\mathrm{T}$. New Insights into the Catalytic Active-Site Structure of Multicopper Oxidases. Acta Crystallogr. D 2014, 70, 772-779. https://doi.org/10.2210/pdb4ner/pdb.

(43) Vancoillie, S.; Chalupský, J.; Ryde, U.; Solomon, E. I.; Pierloot, K.; Neese, F.; Rulíšek, L. Multireference Ab Initio Calculations of $g$ Tensors for Trinuclear Copper Clusters in Multicopper Oxidases. J. Phys. Chem. $B$ 2010, 114 (22), 7692-7702. https://doi.org/10.1021/jp103098r.

(44) Mezei, G.; Raptis, R. G.; Telser, J. Trinuclear, Antiferromagnetically Coupled Cull Complex with an EPR Spectrum of Mononuclear Cull: Effect of Alcoholic Solvents. Inorg. Chem. 2006, 45 (22), 8841-8843. https://doi.org/10.1021/ic061186r. 
(45) Boča, R.; Dlháň, L.; Mezei, G.; Ortiz-Pérez, T.; Raptis, R. G.; Telser, J. Triangular, Ferromagnetically-Coupled $\mathrm{Cu}_{3}{ }_{3}$-Pyrazolato Complexes as Possible Models of Particulate Methane Monooxygenase (PMMO). Inorg. Chem. 2003, 42 (19), 5801-5803. https://doi.org/10.1021/ic0344416.

(46) Angaridis, P. A.; Baran, P.; Boča, R.; Cervantes-Lee, F.; Haase, W.; Mezei, G.; Raptis, R. G.; Werner, R. Synthesis and Structural Characterization of Trinuclear $\mathrm{Cu}^{\text {Il }}$-Pyrazolato Complexes Containing $\mu_{3}-$ $\mathrm{OH}, \mu_{3}-\mathrm{O}$, and $\mu_{3}-\mathrm{Cl}$ Ligands. Magnetic Susceptibility Study of $[\mathrm{PPN}]_{2}\left[\left(\mu_{3}-\right.\right.$ O) $\mathrm{Cu}_{3}\left(\mu-\mathrm{pz}_{3} \mathrm{Cl}_{3}\right.$. Inorg. Chem. 2002, 41 (8), 2219-2228. https://doi.org/10.1021/ic010670l.

(47) Mezei, G.; McGrady, J. E.; Raptis, R. G. First Structural Characterization of a Delocalized, Mixed-Valent, Triangular $\mathrm{Cu}_{3}{ }^{7+}$ Species: Chemical and Electrochemical Oxidation of $\mathrm{a} \mathrm{Cu}_{3}\left(\mu_{3}-\mathrm{O}\right)$ Pyrazolate and Electronic Structure of the Oxidation Product. Inorg. Chem. 2005, 44 (21), 72717273. https://doi.org/10.1021/ic050729e.

(48) Zueva, E. M.; Petrova, M. M.; Herchel, R.; Trávníček, Z.; Raptis, R. G.; Mathivathanan, L.; McGrady, J. E. Electronic Structure and Magnetic Properties of a Trigonal Prismatic Cull 6 Cluster. Dalton Trans. 2009, 0 (30), 5924-5932. https://doi.org/10.1039/B907805C.

(49) Mezei, G.; Rivera-Carrillo, M.; Raptis, R. G. Trigonal-Prismatic Cull $6^{-}$ Pyrazolato Cages: Structural and Electrochemical Study, Evidence of Charge Delocalisation. Dalton Trans. 2007, No. 1, 37-40. https://doi.org/10.1039/B615018G.

(50) Rivera-Carrillo, M.; Chakraborty, I.; Mezei, G.; Webster, R. D.; Raptis, R. G. Tuning of the $\left[\mathrm{Cu}_{3}(\mu-\mathrm{O})\right]^{4+5+}$ Redox Couple: Spectroscopic Evidence of Charge Delocalization in the Mixed-Valent $\left[\mathrm{Cu}_{3}(\mu-\mathrm{O})\right]^{5+}$ Species. Inorg. Chem. 2008, 47 (17), 7644-7650. https://doi.org/10.1021/ic800531y.

(51) Mezei, G.; Rivera-Carrillo, M.; Raptis, R. G. Effect of Copper-Substitution on the Structure and Nuclearity of $\mathrm{Cu}(\mathrm{II})$-Pyrazolates: From Trinuclear to Tetra-, Hexa- and Polynuclear Complexes. Inorganica Chim. Acta 2004, 357 (12), 3721-3732. https://doi.org/10.1016/j.ica.2004.05.022.

(52) Mathivathanan, L.; Rivera-Carrillo, M.; Raptis, R. G. Three New Multinuclear Motifs in $\mathrm{Cu}(\mathrm{II})$-Pyrazolate Chemistry. Inorganica Chim. Acta 2012, 391, 201-205. https://doi.org/10.1016/j.ica.2012.05.027. 
(53) Mathivathanan, L.; Al-Ameed, K.; Lazarou, K.; Trávníček, Z.; Sanakis, Y.; Herchel, R.; McGrady, J. E.; Raptis, R. G. A Trigonal Prismatic Cu6Pyrazolato Complex Containing a $\mu_{6}-\mathrm{F}$ Ligand. Dalton Trans. 2015, 44 (47), 20685-20691. https://doi.org/10.1039/C5DT03892H.

(54) Mathivathanan, L.; Cruz, R.; Raptis, R. G. A [Cuз $\left.\left(\mu_{3}-\mathrm{O}\right)\right]$-Pyrazolate Metallacycle with Terminal Nitrate Ligands Exhibiting Point Group Symmetry 3. Acta Crystallogr. E 2016, 72 (4), 492-494. https://doi.org/10.1107/S2056989016003741.

(55) Shi, K.; Mathivathanan, L.; Raptis, R. G. Crystal Structure of $\mu_{6}$-ChloridoNona-kis-( $\mu$-4-Chloro-pyrazolato)Bis- $\mu_{3}-$ Methoxo-Hexa-copper(II). Acta Crystallogr. E 2017, 73 (2), 266-269. https://doi.org/10.1107/S2056989017001189.

(56) Robin, M. B.; Day, P. Mixed Valence Chemistry-A Survey and Classification. In Advances in Inorganic Chemistry and Radiochemistry; Emeléus, H. J., Sharpe, A. G., Eds.; Academic Press, 1968; Vol. 10, pp 247-422. https://doi.org/10.1016/S0065-2792(08)60179-X.

(57) Allen, G. C.; Hush, N. S. Intervalence-Transfer Absorption. Part 1. Qualitative Evidence for Intervalence-Transfer Absorption in Inorganic Systems in Solution and in the Solid State. In Progress in Inorganic Chemistry; John Wiley \& Sons, Ltd, 2007; pp 357-389. https://doi.org/10.1002/9780470166093.ch6.

(58) Hush, N. S. Intervalence-Transfer Absorption. Part 2. Theoretical Considerations and Spectroscopic Data. In Progress in Inorganic Chemistry; John Wiley \& Sons, Ltd, 2007; pp 391-444. https://doi.org/10.1002/9780470166093.ch7.

(59) Collman, J. P.; Marrocco, M.; Denisevich, P.; Koval, C.; Anson, F. C. Potent Catalysis of the Electroreduction of Oxygen to Water by Dicobalt Porphyrin Dimers Adsorbed on Graphite Electrodes. J. Electroanal. Chem. 1979, 101 (1), 117-122. https://doi.org/10.1016/S00220728(79)80085-6.

(60) Collman, J. P.; Elliott, C. M.; Halbert, T. R.; Tovrog, B. S. Synthesis and Characterization of "Face-to-Face" Porphyrins. PNAS 1977, 74 (1), 1822. https://doi.org/10.1073/pnas.74.1.18.

(61) Rosenthal, J.; Pistorio, B. J.; Chng, L. L.; Nocera, D. G. Aerobic Catalytic Photooxidation of Olefins by an Electron-Deficient Pacman Bisiron(III) $\mu$ - 
Oxo Porphyrin. J. Org. Chem. 2005, 70 (5), 1885-1888.

https://doi.org/10.1021/jo048570v.

(62) Chang, C. J.; Loh, Z.-H.; Shi, C.; Anson, F. C.; Nocera, D. G. Targeted Proton Delivery in the Catalyzed Reduction of Oxygen to Water by

Bimetallic Pacman Porphyrins. J. Am. Chem. Soc. 2004, 126 (32), 1001310020. https://doi.org/10.1021/ja049115j.

(63) Rosenthal, J.; Luckett, T. D.; Hodgkiss, J. M.; Nocera, D. G.

Photocatalytic Oxidation of Hydrocarbons by a Bis-Iron(III)- $\mu$-Oxo Pacman Porphyrin Using $\mathrm{O}_{2}$ and Visible Light. J. Am. Chem. Soc. 2006, 128 (20), 6546-6547. https://doi.org/10.1021/ja058731s.

(64) Devoille, A. M. J.; Love, J. B. Double-Pillared Cobalt Pacman Complexes: Synthesis, Structures and Oxygen Reduction Catalysis. Dalton Trans. 2011, 41 (1), 65-72. https://doi.org/10.1039/C1DT11424G.

(65) Askarizadeh, E.; Yaghoob, S. B.; Boghaei, D. M.; Slawin, A. M. Z.; Love, J. B. Tailoring Dicobalt Pacman Complexes of Schiff-Base Calixpyrroles towards Dioxygen Reduction Catalysis. Chem. Commun. 2010, 46 (5), 710-712. https://doi.org/10.1039/B923189G.

(66) Volpe, M.; Hartnett, H.; Leeland, J. W.; Wills, K.; Ogunshun, M.; Duncombe, B. J.; Wilson, C.; Blake, A. J.; McMaster, J.; Love, J. B. Binuclear Cobalt Complexes of Schiff-Base Calixpyrroles and Their Roles in the Catalytic Reduction of Dioxygen. Inorg. Chem. 2009, 48 (12), 51955207. https://doi.org/10.1021/ic9001175.

(67) Love, J. B. A Macrocyclic Approach to Transition Metal and Uranyl Pacman Complexes. Chem. Commun. 2009, 0 (22), 3154-3165. https://doi.org/10.1039/B904189C.

(68) Chang, C. J.; Loh, Z.-H.; Deng, Y.; Nocera, D. G. The Pacman Effect: A Supramolecular Strategy for Controlling the Excited-State Dynamics of Pillared Cofacial Bisporphyrins. Inorg. Chem. 2003, 42 (25), 8262-8269. https://doi.org/10.1021/ic034750w.

(69) Leeland, J. W.; Slawin, A. M. Z.; Love, J. B. Mononuclear and MixedMetal Dimethyltin Pacman Complexes of a Schiff-Base Pyrrole Macrocycle. Organometallics 2010, 29 (4), 714-716. https://doi.org/10.1021/om901081h. 
(70) Arnold, P. L.; Hollis, E.; Nichol, G. S.; Love, J. B.; Griveau, J.-C.; Caciuffo, R.; Magnani, N.; Maron, L.; Castro, L.; Yahia, A.; et al. Oxo-

Functionalization and Reduction of the Uranyl lon through LanthanideElement Bond Homolysis: Synthetic, Structural, and Bonding Analysis of a Series of Singly Reduced Uranyl-Rare Earth 5f1-4fn Complexes. J. Am. Chem. Soc. 2013, 135 (10), 3841-3854.

https://doi.org/10.1021/ja308993g.

(71) Oliveri, C. G.; Nguyen, S. T.; Mirkin, C. A. A Highly Modular and Convergent Approach for the Synthesis of Stimulant-Responsive Heteroligated Cofacial Porphyrin Tweezer Complexes. Inorg. Chem. 2008, 47 (7), 2755-2763. https://doi.org/10.1021/ic702150y.

(72) Arnold, P. L.; Patel, D.; Pécharman, A.-F.; Wilson, C.; Love, J. B. Equatorial Ligand Substitution by Hydroxide in Uranyl Pacman Complexes of a Schiff-Base Pyrrole Macrocycle. Dalton Trans. 2010, 39 (14), 35013508. https://doi.org/10.1039/B922115H.

(73) Arnold, P. L.; Pécharman, A.-F.; Lord, R. M.; Jones, G. M.; Hollis, E.; Nichol, G. S.; Maron, L.; Fang, J.; Davin, T.; Love, J. B. Control of OxoGroup Functionalization and Reduction of the Uranyl lon. Inorg. Chem. 2015, 54 (7), 3702-3710. https://doi.org/10.1021/acs.inorgchem.5b00420.

(74) Connolly, E. A.; Leeland, J. W.; Love, J. B. Mono- and Dinuclear Macrocyclic Calcium Complexes as Platforms for Mixed-Metal Complexes and Clusters. Inorg. Chem. 2016, 55 (2), 840-847. https://doi.org/10.1021/acs.inorgchem.5b02289.

(75) Guilard, R.; Lopez, M. A.; Tabard, A.; Richard, P.; Lecomte, C.; Brandes, S.; Hutchison, J. E.; Collman, J. P. Synthesis and Characterization of Novel Cobalt Aluminum Cofacial Porphyrins. First Crystal and Molecular Structure of a Heterobimetallic Biphenylene Pillared Cofacial Diporphyrin. J. Am. Chem. Soc. 1992, 114 (25), 9877-9889. https://doi.org/10.1021/ja00051a021.

(76) Pognon, G.; Wytko, J. A.; Weiss, J. Unsymmetrical Calix[4]Arene Bisporphyrin Pacman. Org. Lett. 2007, 9 (5), 785-788. https://doi.org/10.1021/ol062945c.

(77) Guilard, R.; Jérôme, F.; Gros, C. P.; Barbe, J.-M.; Ou, Z.; Shao, J.; Kadish, K. M. Synthesis of an Anthracenyl Bridged Porphyrin-Corrole Bismacrocycle. Physicochemical and Electrochemical Characterisation of 
the Biscobalt $\mu$-Superoxo Derivative. Comptes Rendus Acad. Sci. IIC 2001, 4 (3), 245-254. https://doi.org/10.1016/S1387-1609(00)01226-3.

(78) Karaman, R.; Jeon, S.; Almarsson, O.; Bruice, T. C. Symmetrical and Unsymmetrical Quadruply Aza Bridged Closely Interspaced Cofacial Bis(5,10,15,20-Tetraphenylporphyrins). 3. Interplanar Distances, Proton NMR Chemical Shifts, and the Catalysis of the Electrochemical Reduction of Oxygen. J. Am. Chem. Soc. 1992, 114 (12), 4899-4905. https://doi.org/10.1021/ja00038a066.

(79) Karaman, R.; Almarsson, O.; Blasko, A.; Bruice, T. C. Design, Synthesis, and Characterization of a "Shopping Basket" Bisporphyrin. The First Examples of Triply Bridged Closely Interspaced Cofacial Porphyrin Dimers. J. Org. Chem. 1992, 57 (7), 2169-2173. https://doi.org/10.1021/jo00033a049.

(80) Chen, W.-H.; Yan, J.-M.; Tagashira, Y.; Yamaguchi, M.; Fujita, K. Cage Molecules with Multiple Recognition Cavities: Quadruply CyclodextrinLinked Cofacial Porphyrins. Tetrahedron Lett. 1999, 40 (5), 891-894. https://doi.org/10.1016/S0040-4039(98)02475-7.

(81) Le Mest, Y.; L’Her, M.; Hendricks, N. H.; Kim, K.; Collman, J. P. Electrochemical and Spectroscopic Properties of Dimeric Cofacial Porphyrins with Nonelectroactive Metal Centers. Delocalization Processes in the Porphyrin $\pi$-Cation-Radical Systems. Inorg. Chem. 1992, 31 (5), 835-847. https://doi.org/10.1021/ic00031a028.

(82) Cadenbach, T.; Pankhurst, J. R.; Hofmann, T. A.; Curcio, M.; Arnold, P. L.; Love, J. B. Macrocyclic Platforms for the Construction of Tetranuclear Oxo and Hydroxo Zinc Clusters. Organometallics 2015, 34 (11), 26082613. https://doi.org/10.1021/om501244n.

(83) Volpe, M.; Reid, S. D.; Blake, A. J.; Wilson, C.; Love, J. B. Early Transition Metal Complexes of Dinucleating Pacman Ligands: X-Ray Crystal Structures of Mixed-Valence VIII/VIV Complexes. Inorganica Chim. Acta 2007, 360 (1), 273-280. https://doi.org/10.1016/j.ica.2006.07.058.

(84) Duan, P.-C.; Wang, Z.-Y.; Chen, J.-H.; Yang, G.; Raptis, R. G. Trigonal Prismatic $\mathrm{Cu}(\mathrm{I})$ and $\mathrm{Ag}(\mathrm{I})$ Pyrazolato Nanocage Hosts: Encapsulation of $S_{8}$ and Hydrocarbon Guests. Dalton Trans. 2013, 42 (42), 14951-14954. https://doi.org/10.1039/C3DT51332G. 
(85) Li, H.; Eddaoudi, M.; Groy, T. L.; Yaghi, O. M. Establishing Microporosity in Open Metal-Organic Frameworks: Gas Sorption Isotherms for $\mathrm{Zn}(\mathrm{BDC})$ (BDC = 1,4-Benzenedicarboxylate). J. Am. Chem. Soc. 1998, 120 (33), 8571-8572. https://doi.org/10.1021/ja981669x.

(86) Biradha, K.; Ramanan, A.; Vittal, J. J. Coordination Polymers Versus Metal-Organic Frameworks. Cryst. Growth Des. 2009, 9 (7), 2969-2970. https://doi.org/10.1021/cg801381p.

(87) Batten, S. R.; Champness, N. R.; Chen, X.-M.; Garcia-Martinez, J.; Kitagawa, S.; Öhrström, L.; O'Keeffe, M.; Suh, M. P.; Reedijk, J. Coordination Polymers, Metal-Organic Frameworks and the Need for Terminology Guidelines. CrystEngComm 2012, 14 (9), 3001-3004. https://doi.org/10.1039/C2CE06488J.

(88) Batten, S. R.; Champness, N. R.; Chen, X.-M.; Garcia-Martinez, J.; Kitagawa, S.; Öhrström, L.; O'Keeffe, M.; Paik, S. M.; Reedijk, J. Terminology of Metal-Organic Frameworks and Coordination Polymers (IUPAC Recommendations 2013). Pure Appl. Chem. 2013, 85 (8), 17151724. https://doi.org/10.1351/PAC-REC-12-11-20.

(89) Kalmutzki, M. J.; Hanikel, N.; Yaghi, O. M. Secondary Building Units as the Turning Point in the Development of the Reticular Chemistry of MOFs. Sci. Adv. 2018, 4 (10), eaat9180. https://doi.org/10.1126/sciadv.aat9180.

(90) Akhtar, S.; Bala, S.; De, A.; Das, K. S.; Adhikary, A.; Jyotsna, S.; Poddar, P.; Mondal, R. Designing Multifunctional MOFs Using the Inorganic Motif $\left[\mathrm{Cu}_{3}\left(\mu_{3}-\mathrm{OH}\right)(\mu-\mathrm{Pyz})\right]$ as an SBU and Their Properties. Cryst. Growth Des. 2019, 19 (2), 992-1004. https://doi.org/10.1021/acs.cgd.8b01540.

(91) Zhang, H.; Lu, Y.; Zhang, Z.; Wang, E. A Three-Dimensional MetalOrganic Framework Based on Hexanuclear Copper Units with Unsaturated Cull Centers. Inorg. Chem. Commun. 2012, 17, 9-12. https://doi.org/10.1016/j.inoche.2011.11.040.

(92) Bala, S.; Bhattacharya, S.; Goswami, A.; Adhikary, A.; Konar, S.; Mondal, R. Designing Functional Metal-Organic Frameworks by Imparting a Hexanuclear Copper-Based Secondary Building Unit Specific Properties: Structural Correlation With Magnetic and Photocatalytic Activity. Cryst. Growth Des. 2014, 14 (12), 6391-6398. https://doi.org/10.1021/cg501226v. 
(93) Mathivathanan, L.; Torres-King, J.; Primera-Pedrozo, J. N.; García-Ricard, O. J.; Hernández-Maldonado, A. J.; Santana, J. A.; Raptis, R. G. Selective $\mathrm{CO}_{2}$ Adsorption on Metal-Organic Frameworks Based on Trinuclear Cu3Pyrazolato Complexes: An Experimental and Computational Study. Cryst. Growth Des. 2013, 13 (6), 2628-2635. https://doi.org/10.1021/cg400382k.

(94) Halcrow, M. A. Pyrazoles and Pyrazolides-Flexible Synthons in SelfAssembly. Dalton Trans. 2009, 0 (12), 2059-2073. https://doi.org/10.1039/B815577A.

(95) Mezei, G.; Raptis, R. G. Effect of Pyrazole-Substitution on the Structure and Nuclearity of $\mathrm{Cu}(\mathrm{II})$-Pyrazolato Complexes. Inorganica Chim. Acta 2004, 357 (11), 3279-3288. https://doi.org/10.1016/j.ica.2004.03.016.

(96) Viciano-Chumillas, M.; Tanase, S.; Jongh, L. J. de; Reedijk, J. Coordination Versatility of Pyrazole-Based Ligands towards HighNuclearity Transition-Metal and Rare-Earth Clusters. Eur. J. Inorg. Chem. 2010, 2010 (22), 3403-3418. https://doi.org/10.1002/ejic.201000412.

(97) Wang, N.; Zheng, H.; Zhang, W.; Cao, R. Mononuclear First-Row Transition-Metal Complexes as Molecular Catalysts for Water Oxidation. Chinese J. Catal. 2018, 39 (2), 228-244. https://doi.org/10.1016/S18722067(17)63001-8.

(98) Parent, A. R.; Sakai, K. Progress in Base-Metal Water Oxidation Catalysis. ChemSusChem 2014, 7 (8), 2070-2080. https://doi.org/10.1002/cssc.201402322.

(99) Seidler-Egdal, R. K.; Nielsen, A.; Bond, A. D.; Bjerrum, M. J.; McKenzie, C. J. High Turnover Catalysis of Water Oxidation by Mn(II) Complexes of Monoanionic Pentadentate Ligands. Dalton Trans. 2011, 40 (15), 38493858. https://doi.org/10.1039/CODT01340D.

(100) Wang, D.; Groves, J. T. Efficient Water Oxidation Catalyzed by Homogeneous Cationic Cobalt Porphyrins with Critical Roles for the Buffer Base. PNAS 2013, 110 (39), 15579-15584.

https://doi.org/10.1073/pnas.1315383110.

(101) Cui, L.; Geng, Y.-F.; Leong, C. F.; Ma, Q.; D’Alessandro, D. M.; Deng, K.; Zeng, Q.-D.; Zuo, J.-L. Synthesis, Properties and Surface Self-Assembly of a Pentanuclear Cluster Based on the New $\pi$-Conjugated TTF-Triazole Ligand. Sci. Rep. 2016, 6, 25544. https://doi.org/10.1038/srep25544. 
(102) Xue, D.; Luo, S.-P.; Chen, Y.-Y.; Zhang, Z.-X.; Zhan, S.-Z. Synthesis, Characterization and Electrocatalytic Properties of a Tetranuclear Triazenido-Copper(I) Complex. Polyhedron 2017, 132, 105-111. https://doi.org/10.1016/j.poly.2017.04.035.

(103) Fernandes, C.; Bortoluzzi, A. J.; Szpoganicz, B.; Schwingel, E.; Neves, A. Synthesis, X-Ray Crystal Structure and Properties of a Novel Tetranuclear Unsymmetrical $\left(\mu-\mathrm{SO}_{4}\right)$ Copper(II) Complex: Relevance to $\mathrm{SO}_{2}$ Fixation. Inorganica Chim. Acta 2005, 358 (4), 997-1004. https://doi.org/10.1016/j.ica.2004.11.040.

(104) Cheng, Q.-R.; Zhou, H.; Pan, Z.-Q.; Chen, J.-Z. New Cu(II)4 and Zn(II)4 Complexes: Synthesis, Characterization and Magnetic and Biological Studies. Polyhedron 2011, 30 (6), 1171-1176. https://doi.org/10.1016/j.poly.2011.01.014.

(105) Cavicchioli, M.; Massabni, A. C.; da Costa Ferreira, A. M.; Castellano, E. E.; Crespi, M. S. Synthesis, Structure and Redox Properties of an Unexpected Trinuclear Copper(II) Complex with Aspartame: $\left[\mathrm{Cu}(\mathrm{Apm})_{2} \mathrm{Cu}\left(\mu-\mathrm{N}, \mathrm{O}: \mathrm{O}^{\prime}-\mathrm{Apm}\right)_{2}\left(\mathrm{H}_{2} \mathrm{O}\right) \mathrm{Cu}(\mathrm{Apm})_{2}\left(\mathrm{H}_{2} \mathrm{O}\right)\right] \cdot 5 \mathrm{H}_{2} \mathrm{O}$. Inorganica Chim. Acta 2005, 358 (15), 4431-4436. https://doi.org/10.1016/j.ica.2005.09.027.

(106) Neuba, A.; Flörke, U.; Meyer-Klaucke, W.; Salomone-Stagni, M.; Bill, E.; Bothe, E.; Höfer, P.; Henkel, G. The Trinuclear Copper(I) Thiolate Complexes[Cu$\left(\mathrm{Cu}_{3}(\mathrm{NGuaS})_{3}\right]^{0 / 1+}$ and Their Dimeric Variants $\left[\mathrm{Cu}_{6}(\mathrm{NGuaS})_{6}\right]^{1+/ 2+/ 3+}$ with Biomimetic Redox Properties. Angew. Chem. Int. Ed. 2011, 50 (19), 4503-4507. https://doi.org/10.1002/anie.201008076.

(107) Tu, C.; Shao, Y.; Gan, N.; Xu, Q.; Guo, Z. Oxidative DNA Strand Scission Induced by a Trinuclear Copper(II) Complex. Inorg. Chem. 2004, 43 (15), 4761-4766. https://doi.org/10.1021/ic049731g.

(108) Agnus, Y.; Louis, R.; Metz, B.; Boudon, C.; Gisselbrecht, J. P.; Gross, M. Trinuclear Copper(II) Hydroxo and Hexanuclear Copper(II) Oxo Complexes with the Ligand 3-(Benzylimino)Butanone 2-Oxime. Syntheses and Spectral, Structural and Redox Characteristics. Inorg. Chem. 1991, 30 (16), 3155-3161. https://doi.org/10.1021/ic00016a011.

(109) Sénèque, O.; Campion, M.; Douziech, B.; Giorgi, M.; Rivière, E.; Journaux, Y.; Mest, Y. L.; Reinaud, O. Supramolecular Assembly with Calix[6]Arene and Copper lons - Formation of a Novel Tetranuclear Core 
Exhibiting Unusual Redox Properties and Catecholase Activity. Eur. J. Inorg. Chem. 2002, 2002 (8), 2007-2014. https://doi.org/10.1002/10990682(200208)2002:8<2007::AID-EJIC2007>3.0.CO;2-Z.

(110) Sheldrick, G. M. SHELXT - Integrated Space-Group and Crystal-Structure Determination. Acta Crystallogr. 2015, 71 (1), 3-8. https://doi.org/10.1107/S2053273314026370.

(111) Sheldrick, G. M. Crystal Structure Refinement with SHELXL. Acta Crystallogr. Sect. C 2015, 71 (1), 3-8. https://doi.org/10.1107/S2053229614024218.

(112) Dolomanov, O. V.; Bourhis, L. J.; Gildea, R. J.; Howard, J. a. K.; Puschmann, H. OLEX2: A Complete Structure Solution, Refinement and Analysis Program. J. Appl. Crystallogr. 2009, 42 (2), 339-341. https://doi.org/10.1107/S0021889808042726.

(113) DuBois, J. L.; Mukherjee, P.; Collier, A. M.; Mayer, J. M.; Solomon, E. I.; Hedman, B.; Stack, T. D. P.; Hodgson, K. O. Cu K-Edge XAS Study of the $\left[\mathrm{Cu}_{2}(\mu-\mathrm{O})_{2}\right]$ Core: Direct Experimental Evidence for the Presence of $\mathrm{Cu}(\mathrm{III})$. J. Am. Chem. Soc. 1997, 119 (36), 8578-8579. https://doi.org/10.1021/ja9717673.

(114) DuBois, J. L.; Mukherjee, P.; Stack, T. D. P.; Hedman, B.; Solomon, E. I.; Hodgson, K. O. A Systematic K-Edge X-Ray Absorption Spectroscopic Study of $\mathrm{Cu}$ (III) Sites. J. Am. Chem. Soc. 2000, 122 (24), 5775-5787. https://doi.org/10.1021/ja993134p.

(115) De Nadaï, C.; Demourgues, A.; Grannec, J. K and LIII-Edge XAS Studies of $\mathrm{Ni}$-, $\mathrm{Cu}$ - and Pd-Fluorides in High Oxidation States. Nucl. Instrum. Methods Phys. Res. B 1997, 133 (1), 1-7. https://doi.org/10.1016/S0168583X(97)00466-7.

(116) Pratesi, A.; Giuli, G.; Cicconi, M. R.; Della Longa, S.; Weng, T.-C.; Ginanneschi, M. Dioxygen Oxidation $\mathrm{Cu}(\mathrm{II}) \rightarrow \mathrm{Cu}(\mathrm{III})$ in the Copper Complex of Cyclo(Lys-DHis-BAla-His): A Case Study by EXAFS and XANES Approach. Inorg. Chem. 2012, 51 (15), 7969-7976. https://doi.org/10.1021/ic201469h.

(117) Mathivathanan, L. Redox-Active Cu-Pyrazolate Secondary Building Units for the Construction of Metal-Organic Frameworks, University of Puerto Rico - Rio Piedras, 2013. 
(118) Kreiger, D. I.; Mathivathanan, L.; Raptis, R. Coordination Polymers Based on Pyrazole-4-Carboxaldehyde-Containing $\mathrm{Cu}_{3} \mathrm{~N}_{6}$ Metallacycles as Building Units. CrystEngComm 2019. https://doi.org/10.1039/C9CE00421A.

(119) Müller, B.; Vahrenkamp, H. Zinc Complexes of Chelating Aldehydes. Eur. J. Inorg. Chem. 1999, 1999 (1), 137-144. https://doi.org/10.1002/(SICl)1099-0682(199901)1999:1<137::AIDEJIC137>3.0.CO;2-T.

(120) Xu, F.; Hu, B.; Wang, X.-X.; Geng, J.; Huang, W. Three Copper(II) Complexes of 4-Formylbenzoate Obtained from Degradation of the Schiff Base. J. Coord. Chem. 2012, 65 (12), 2201-2210. https://doi.org/10.1080/00958972.2012.689827.

(121) Alvarez, C. M.; García-Rodríguez, R.; Miguel, D. Pyridine-2Carboxaldehyde as Ligand: Synthesis and Derivatization of Carbonyl Complexes. Dalton Trans. 2007, No. 32, 3546. https://doi.org/10.1039/b702418e.

(122) Saravanabharathi, D.; Nethaji, M.; Samuelson, A. G. Is Copper(I) Really Soft? Probing the Hardness of $\mathrm{Cu}(\mathrm{I})$ with Pyridinecarboxaldehyde Ligands. J. Chem. Sci. 2002, 114 (4), 347-356. https://doi.org/10.1007/BF02703825.

(123) Kelson, E. P.; Phengsy, P. P.; Arif, A. M. A Chloro(2Pyridinecarboxaldehyde)(2,2':6',2"-Terpyridine)Ruthenium(II) Complex. Acta Crystallogr. C 2001, 57 (5), 517-519. https://doi.org/10.1107/S0108270101001305.

(124) Hwang, T.-Y.; Cho, J.-Y.; Jiang, M.-K.; Gau, H.-M. The Synthesis of [Ti(Oi-Pr) $\left.\mathrm{Cl}_{2}(\mathrm{PhCHO})(\mu-\mathrm{Cl})\right]_{2}$ and Its Reactions with Oxygen-Containing Ligands L ( $L=D M F$, DMSO, i-PrOH). The Crystal Structure of Ti(O-i$\mathrm{Pr}) \mathrm{Cl}_{3}(\mathrm{PhCHO})(\mathrm{i}-\mathrm{PrOH})$ and the $1 \mathrm{H}$ Variable-Temperature NMR Studies of Solution Structures of $\left[\mathrm{Ti}(\mathrm{O}-\mathrm{i}-\mathrm{Pr}) \mathrm{Cl}_{2}(\mathrm{PhCHO})(\mu-\mathrm{Cl})\right]_{2}$ and $\mathrm{Ti}(\mathrm{O}-\mathrm{i}-$ $\mathrm{Pr}) \mathrm{Cl}_{3}(\mathrm{PhCHO}) \mathrm{L}$. Inorganica Chim. Acta 2000, 303 (2), 190-198. https://doi.org/10.1016/S0020-1693(00)00033-5.

(125) Bochmann, M.; Webb, K. J.; Hursthouse, M. B.; Mazid, M. The First Stable Aldehyde and Ketone Complexes of Zinc: The Structure of $\left[\mathrm{Zn}\left(\mathrm{SeC}_{6} \mathrm{H}_{2} \mathrm{Bu}_{3}\right)_{2}\left(p-\mathrm{O}=\mathrm{CHC}_{6} \mathrm{H}_{4} \mathrm{OMe}\right)\right] 2$. Chem. Commun. 1991, $\mathrm{O}(24)$, 1735-1737. https://doi.org/10.1039/C39910001735. 
(126) Gau, H.-M.; Lee, C.-S.; Lin, C.-C.; Jiang, M.-K.; Ho, Y.-C.; Kuo, C.-N. Chemistry of $\mathrm{Ti}(\mathrm{O} \mathrm{Pr}) \mathrm{Cl}_{3}$ with Chloride and Oxygen-Containing Ligands: The Roles of Alkoxide and Solvents in the Six-Coordinate Titanium Complexes. J. Am. Chem. Soc. 1996, 118 (12), 2936-2941. https://doi.org/10.1021/ja952730q.

(127) Cozzi, P. G.; Solari, E.; Floriani, C.; Chiesi-Villa, A.; Rizzoli, C. Interaction Modes of Titanium Tetrachloride with the Carbonyl Functionality. Chem. Ber. 1996, 129 (11), 1361-1368. https://doi.org/10.1002/cber.19961291108.

(128) Cicero, R. L.; Protasiewicz, J. D. Is .Pi.-Back-Bonding Important for .Sigma.-Bound Aldehyde and Ketone Complexes? Synthesis and Structural Characterization of Aromatic Aldehyde Complexes of the $\left[\mathrm{CpFe}(\mathrm{CO})_{2}\right]^{+}$Cation. Organometallics 1995, 14 (10), 4792-4798. https://doi.org/10.1021/om00010a047.

(129) Müller, B.; Ruf, M.; Vahrenkamp, H. On the Nature of Zinc ChlorideAldehyde Interactions. Angew. Chem. Int. Ed. 1994, 33 (20), 2089-2090. https://doi.org/10.1002/anie.199420891.

(130) Byrn, M. P.; Curtis, C. J.; Hsiou, Y.; Khan, S. I.; Sawin, P. A.; Tendick, S. K.; Terzis, A.; Strouse, C. E. Porphyrin Sponges: Conservative of Host Structure in over 200 Porphyrin-Based Lattice Clathrates. J. Am. Chem. Soc. 1993, 115 (21), 9480-9497. https://doi.org/10.1021/ja00074a013.

(131) Garner, D. K.; Allred, R. A.; Tubbs, K. J.; Arif, A. M.; Berreau, L. M. Synthesis and Characterization of Mononuclear Zinc Aryloxide Complexes Supported by Nitrogen/Sulfur Ligands Possessing an Internal Hydrogen Bond Donor. Inorg. Chem. 2002, 41 (13), 3533-3541. https://doi.org/10.1021/ic020031q.

(132) Wang, Q.; Wang, D.-Q.; Sun, Y.-Y. Triaquachloridobis[4(Dimethylamino)Benzaldehyde-kOjNickel(II) Chloride. Acta Crystallogr. E 2007, 63 (11), m2819-m2819. https://doi.org/10.1107/S1600536807048684.

(133) Caneschi, A.; Gatteschi, D.; Sessoli, R. Magnetic Properties of a Layered Molecular Material Comprising Manganese Hexafluoroacetylacetonate and Nitronyl Nitroxide Radicals. Inorg. Chem. 1993, 32 (21), 4612-4616. https://doi.org/10.1021/ic00073a024. 
(134) Müller, B.; Vahrenkamp, H. Zinc-Aldehyde Complexes with Weakly Coordinating Anions. Eur. J. Inorg. Chem. 1999, 1999 (1), 117-127. https://doi.org/10.1002/(SICl)1099-0682(199901)1999:1<117::AIDEJIC117>3.0.CO;2-0.

(135) Müller, B.; Vahrenkamp, H. Aldehyde Complexes of Zinc Halides. Eur. J. Inorg. Chem. 1999, 1999 (1), 129-135. https://doi.org/10.1002/(SICl)1099-0682(199901)1999:1<129::AIDEJIC129>3.0.CO;2-P.

(136) Eklund, H.; Nordström, B.; Zeppezauer, E.; Söderlund, G.; Ohlsson, I.; Boiwe, T.; Söderberg, B.-O.; Tapia, O.; Brändén, C.-I.; Åkeson, Å. ThreeDimensional Structure of Horse Liver Alcohol Dehydrogenase at $2.4 \AA$ Resolution. J. Mol. Bio. 1976, 102 (1), 27-59. https://doi.org/10.1016/0022-2836(76)90072-3.

(137) Jeffrey, G. A. An Introduction to Hydrogen Bonding; Topics in physical chemistry; Oxford University Press: New York, 1997.

(138) Zeng, J.-L.; Jiang, Y.-M.; Yu, K.-B. A New One-Dimensional Coordination Polymer: $\left\{\left[\mathrm{Cu}\left(\mathrm{C}_{10} \mathrm{H}_{9} \mathrm{NO}_{5} \mathrm{~S}\right)\left(\mathrm{H}_{2} \mathrm{O}\right)\right] \cdot \mathrm{H}_{2} \mathrm{O}\right\}_{n}$. Acta Crystallogr. Sect. E 2003, 59 (12), m1137-m1139. https://doi.org/10.1107/S1600536803025649.

(139) Andersson, S.; Håkansson, M.; Jagner, S.; Nilsson, M.; Ullenius, C.; Urso, F.; Weidlein, J.; Zingaro, R. A. Structure of a Polymeric Complex Between Acrylaldehyde and Copper(I) Chloride. Acta Chem. Scand. A 1986, 40a, 58-62. https://doi.org/10.3891/acta.chem.scand.40a-0058.

(140) Xu, D.; Geng, J.; Dai, Y.; Peng, Y.-X.; Qian, H.-F.; Huang, W. PHControlled Synthesis of an Aromatic Triazene and Its Copper(II) Complexation Accompanied by an Unexpected Aromatic Ring Halogenation. Dyes Pigm. 2017, 136, 398-403. https://doi.org/10.1016/j.dyepig.2016.08.062.

(141) Hartman, C. K.; Mezei, G. Mapping the Intricate Reactivity of Nanojars toward Molecules of Varying Acidity and Their Conjugate Bases Leading To Exchange of Pyrazolate Ligands. Inorg. Chem. 2017, 56 (17), 1060910624. https://doi.org/10.1021/acs.inorgchem.7b01593.

(142) Rivera-Carrillo, M.; Chakraborty, I.; Mezei, G.; Webster, R. D.; Raptis, R. G. Tuning of the $\left[\mathrm{Cu}_{3}(\mu-\mathrm{O})\right]^{4+5+}$ Redox Couple: Spectroscopic Evidence of Charge Delocalization in the Mixed-Valent $\left[\mathrm{Cu}_{3}(\mu-\mathrm{O})\right]^{5+}$ Species. Inorg. Chem. 2008, 47 (17), 7644-7650. https://doi.org/10.1021/ic800531y. 
(143) Mathivathanan, L.; Boudalis, A. K.; Turek, P.; Pissas, M.; Sanakis, Y.; Raptis, R. G. Interactions between $\mathrm{H}$-Bonded $\left[\mathrm{Cu}_{3}\left(\mu_{3}-\mathrm{OH}\right)\right]$ Triangles; a Combined Magnetic Susceptibility and EPR Study. Phys. Chem. Chem. Phys. 2018, 20 (25), 17234-17244. https://doi.org/10.1039/C8CP02643B.

(144) Mezei, G.; McGrady, J. E.; Raptis, R. G. First Structural Characterization of a Delocalized, Mixed-Valent, Triangular $\mathrm{Cu}_{3}{ }^{7+}$ Species: Chemical and Electrochemical Oxidation of a Cull $3\left(\mu_{3}-\mathrm{O}\right)$ Pyrazolate and Electronic Structure of the Oxidation Product. Inorg. Chem. 2005, 44 (21), 72717273. https://doi.org/10.1021/ic050729e.

(145) Pettinari, C.; Masciocchi, N.; Pandolfo, L.; Pucci, D. Tuning the Functional Properties of Metal Complexes Containing Polytopic Heteroaromatic Nitrogen Ligands. Chem. Eur. J. 2010, 16 (4), 1106-1123. https://doi.org/10.1002/chem.200901923.

(146) Armarego, W. L. F.; Chai, C. L. L. Purification of Laboratory Chemicals, 6th ed.; Elsevier/Butterworth-Heinemann: Amsterdam ; Boston, 2009.

(147) Blatov, V. A.; Shevchenko, A. P.; Proserpio, D. M. Applied Topological Analysis of Crystal Structures with the Program Package ToposPro Cryst. Growth Des. 2014, 14 (7), 3576-3586. https://doi.org/10.1021/cg500498k.

(148) Macrae, C. F.; Bruno, I. J.; Chisholm, J. A.; Edgington, P. R.; McCabe, P.; Pidcock, E.; Rodriguez-Monge, L.; Taylor, R.; van de Streek, J.; Wood, P. A. Mercury CSD 2.0 - New Features for the Visualization and Investigation of Crystal Structures. J. Appl. Crystallogr. 2008, 41 (2), 466470. https://doi.org/10.1107/S0021889807067908.

(149) Menges, F. Spectragryph.

(150) Spek, A. L. Structure Validation in Chemical Crystallography. Acta Crystallogr. D 2009, 65 (2), 148-155. https://doi.org/10.1107/S090744490804362X.

(151) Kitagawa, S.; Kitaura, R.; Noro, S. Functional Porous Coordination Polymers. Angew. Chem. Int. Ed. 2004, 43 (18), 2334-2375. https://doi.org/10.1002/anie.200300610.

(152) Mathivathanan, L.; Torres-King, J.; Primera-Pedrozo, J. N.; García-Ricard, O. J.; Hernández-Maldonado, A. J.; Santana, J. A.; Raptis, R. G. Selective CO2 Adsorption on Metal-Organic Frameworks Based on Trinuclear Cu3- 
Pyrazolato Complexes: An Experimental and Computational Study. Cryst. Growth Des. 2013, 13 (6), 2628-2635. https://doi.org/10.1021/cg400382k.

(153) Di Nicola, C.; Garau, F.; Gazzano, M.; Guedes da Silva, M. F. C.; Lanza, A.; Monari, M.; Nestola, F.; Pandolfo, L.; Pettinari, C.; Pombeiro, A. J. L. New Coordination Polymers and Porous Supramolecular Metal Organic Network Based on the Trinuclear Triangular Secondary Building Unit $\left[\mathrm{Cu}_{3}\left(\mu_{3}-\mathrm{OH}\right)(\mu-\mathrm{pz})_{3}\right]^{2+}$ and 4,4'-Bypiridine. $1^{\circ}$. Cryst. Growth Des. 2012, 12 (6), 2890-2901. https://doi.org/10.1021/cg300080a.

(154) Mir, M. H.; Koh, L. L.; Tan, G. K.; Vittal, J. J. Single-Crystal to SingleCrystal Photochemical Structural Transformations of Interpenetrated 3D Coordination Polymers by [2+2] Cycloaddition Reactions. Angew. Chem. Int. Ed. 2010, 49 (2), 390-393. https://doi.org/10.1002/anie.200905898.

(155) Alexandrov, E. V.; Blatov, V. A.; Kochetkov, A. V.; Proserpio, D. M. Underlying Nets in Three-Periodic Coordination Polymers: Topology, Taxonomy and Prediction from a Computer-Aided Analysis of the Cambridge Structural Database. CrystEngComm 2011, 13 (12), 3947. https://doi.org/10.1039/c0ce00636j.

(156) Zhan, S.-Z.; Li, M.; Ng, S. W.; Li, D. Luminescent Metal-Organic Frameworks (MOFs) as a Chemopalette: Tuning the Thermochromic Behavior of Dual-Emissive Phosphorescence by Adjusting the Supramolecular Microenvironments. Chem. Eur. J. 2013, 19 (31), 1021710225. https://doi.org/10.1002/chem.201204632.

(157) Hou, L.; Shi, W.-J.; Wang, Y.-Y.; Wang, H.-H.; Cui, L.; Chen, P.-X.; Shi, Q.-Z. Trinuclear-Based Copper(I) Pyrazolate Polymers: Effect of Trimer $\pi-$ Acid $\cdots$ Halide/Pseudohalide Interactions on the Supramolecular Structure and Phosphorescence. Inorg. Chem. 2011, 50 (1), 261-270. https://doi.org/10.1021/ic101901w.

(158) Casarin, M.; Corvaja, C.; Di Nicola, C.; Falcomer, D.; Franco, L.; Monari, M.; Pandolfo, L.; Pettinari, C.; Piccinelli, F. One-Dimensional and TwoDimensional Coordination Polymers from Self-Assembling of Trinuclear Triangular Cu(II) Secondary Building Units. Inorg. Chem. 2005, 44 (18), 6265-6276. https://doi.org/10.1021/ic050678l.

(159) Di Nicola, C.; Forlin, E.; Garau, F.; Gazzano, M.; Lanza, A.; Monari, M.; Nestola, F.; Pandolfo, L.; Pettinari, C.; Zorzi, A.; et al. Coordination Polymers Based on the Trinuclear Triangular Secondary Building Unit 
$\left[\mathrm{Cu}_{3}\left(\mu_{3}-\mathrm{OH}\right)(\mu-\mathrm{pz})_{3}\right]^{2+}(\mathrm{pz}=$ Pyrazolate $)$ and Succinate Anion. Cryst. Growth Des. 2013, 13 (1), 126-135. https://doi.org/10.1021/cg3012712.

(160) Di Nicola, C.; Garau, F.; Gazzano, M.; Lanza, A.; Monari, M.; Nestola, F.; Pandolfo, L.; Pettinari, C. Interaction of the Trinuclear Triangular Secondary Building Unit $\left[\mathrm{Cu}_{3}\left(\mu_{3}-\mathrm{OH}\right)(\mu-\mathrm{pz})_{3}\right]^{2+}$ with 4,4'-Bipyridine. Structural Characterizations of New Coordination Polymers and Hexanuclear Cul Clusters. 2० . Cryst. Growth Des. 2015, 15 (3), 12591272. https://doi.org/10.1021/cg501647r.

(161) Rivera-Carrillo, M.; Chakraborty, I.; Raptis, R. G. Systematic Synthesis of a Metal Organic Framework Based on Triangular $\mathrm{Cu}_{3}\left(\mu_{3}-\mathrm{OH}\right)$ Secondary Building Units: From a 0-D Complex to a 1-D Chain and a 3-D Lattice. Cryst. Growth Des. 2010, 10 (6), 2606-2612. https://doi.org/10.1021/cg100060p.

(162) Grzywa, M.; Denysenko, D.; Schaller, A.; Kalytta-Mewes, A.; Volkmer, D. Flexible Chiral Pyrazolate-Based Metal-Organic Framework Containing Saddle-Type $\mathrm{Cu}_{4}{ }_{4}($ Pyrazolate) 4 Units. CrystEngComm 2016, 18 (40), 7883-7893. https://doi.org/10.1039/C6CE01594H.

(163) Contaldi, S.; Di Nicola, C.; Garau, F.; Karabach, Y. Yu.; Martins, L. M. D. R. S.; Monari, M.; Pandolfo, L.; Pettinari, C.; Pombeiro, A. J. L. New Coordination Polymers Based on the Triangular $\left[\mathrm{Cu}_{3}\left(\mu_{3}-\mathrm{OH}\right)(\mu-\mathrm{pz})_{3}\right]^{2+}$ Unit and Unsaturated Carboxylates. Dalton Trans. 2009, No. 25, 4928. https://doi.org/10.1039/b823370e.

(164) Almotawa, R. M.; Aljomaih, G.; Trujillo, D. V.; Nesterov, V. N.; Rawashdeh-Omary, M. A. New Coordination Polymers of Copper(I) and Silver(I) with Pyrazine and Piperazine: A Step Toward "Green" Chemistry and Optoelectronic Applications. Inorg. Chem. 2018, 57 (16), 9962-9976. https://doi.org/10.1021/acs.inorgchem.8b01131.

(165) Condello, F.; Garau, F.; Lanza, A.; Monari, M.; Nestola, F.; Pandolfo, L.; Pettinari, C. Synthesis and Structural Characterizations of New Coordination Polymers Generated by the Interaction Between the Trinuclear Triangular SBU $\left[\mathrm{Cu}_{3}\left(\mu_{3}-\mathrm{OH}\right)(\mu-\mathrm{pz})_{3}\right]^{2+}$ and 4,4'-Bipyridine. $3^{\circ}$. Cryst. Growth Des. 2015, 15 (10), 4854-4862. https://doi.org/10.1021/acs.cgd.5b00661.

(166) Massignani, S.; Scatena, R.; Lanza, A.; Monari, M.; Condello, F.; Nestola, F.; Pettinari, C.; Zorzi, F.; Pandolfo, L. Coordination Polymers from Mild Condition Reactions of Copper(II) Carboxylates with Pyrazole (Hpz). 
Influence of Carboxylate Basicity on the Self-Assembly of the [ $\mathrm{Cu}_{3}\left(\mu_{3}-\right.$ $\left.\mathrm{OH})(\mu-\mathrm{pz})_{3}\right]^{2+}$ Secondary Building Unit. Inorganica Chim. Acta 2017, 455, 618-626. https://doi.org/10.1016/j.ica.2016.05.009.

(167) Di Nicola, C.; Forlin, E.; Garau, F.; Lanza, A.; Natile, M. M.; Nestola, F.; Pandolfo, L.; Pettinari, C. Coordination Polymers Based on Trinuclear and Mononuclear Copper-Pyrazolate Building Moieties Connected by Fumarate or 2-Methylfumarate lons. J. Organomet. Chem. 2012, 714, 7480. https://doi.org/10.1016/j.jorganchem.2012.03.026.

(168) Asha, K. S.; Bhattacharjee, R.; Mandal, S. Complete Transmetalation in a Metal-Organic Framework by Metal Ion Metathesis in a Single Crystal for Selective Sensing of Phosphate lons in Aqueous Media. Angew. Chem. Int. Ed. 2016, 55 (38), 11528-11532.

https://doi.org/10.1002/anie.201606185.

(169) Lefebvre, J.; Chartrand, D.; Leznoff, D. B. Synthesis, Structure and Magnetic Properties of 2-D and 3-D [Cation] $\left\{\mathrm{M}\left[\mathrm{Au}(\mathrm{CN})_{2}\right]_{3}\right\}(\mathrm{M}=\mathrm{Ni}, \mathrm{Co})$ Coordination Polymers. Polyhedron 2007, 26 (9-11), 2189-2199. https://doi.org/10.1016/j.poly.2006.10.045.

(170) Feuchter, H.; Ortiz, G.; Rousselin, Y.; Bessmertnykh-Lemeune, A.; Brandès, S. Cadmium Metal-Organic Frameworks Based on Ditopic Triazamacrocyclic Linkers: Unusual Structural Features and Selective $\mathrm{CO}_{2}$ Capture. Cryst. Growth Des. 2017, 17 (7), 3665-3676. https://doi.org/10.1021/acs.cgd.7b00217.

(171) Kamiyama, A.; Kajiwara, T.; Ito, T. Cage-Type Hexacopper(II) Complex Formed by Chloride Template. Chem. Lett. 2002, 31 (10), 980-981. https://doi.org/10.1246/cl.2002.980.

(172) Zhou, Q.-J.; Liu, Y.-Z.; Wang, R.-L.; Fu, J.-W.; Xu, J.-Y.; Lou, J.-S. Synthesis, Crystal Structure and Magnetic Properties of a Trinuclear $\mathrm{Cu}(\mathrm{II})$-Pyrazolate Complex Containing $\mu_{3}-\mathrm{OH}$. J. Coord. Chem. 2009, 62 (2), 311-318. https://doi.org/10.1080/00958970802238531.

(173) Sakai, K.; Yamada, Y.; Tsubomura, T.; Yabuki, M.; Yamaguchi, M. Synthesis, Crystal Structure, and Solution Properties of a Hexacopper(II) Complex with Bridging Hydroxides, Pyrazolates, and Nitrates. Inorg. Chem. 1996, 35 (2), 542-544. https://doi.org/10.1021/ic950181j. 
(174) Mathivathanan, L.; Rivera-Carrillo, M.; Raptis, R. G. Three New Multinuclear Motifs in $\mathrm{Cu}(\mathrm{II})$-Pyrazolate Chemistry. Inorganica Chim. Acta 2012, 391, 201-205. https://doi.org/10.1016/j.ica.2012.05.027.

(175) Mezei, G. Sulfate-Bridged Dimeric Trinuclear Copper(II)-Pyrazolate Complex with Three Different Terminal Ligands. Acta Crystallogr. E 2016, 72 (8), 1064-1067. https://doi.org/10.1107/S2056989016010719.

(176) Cañon-Mancisidor, W.; Gómez-García, C. J.; Espallargas, G. M.; Vega, A.; Spodine, E.; Venegas-Yazigi, D.; Coronado, E. Structural ReArrangement in Two Hexanuclear Cull Complexes: From a Spin Frustrated Trigonal Prism to a Strongly Coupled Antiferromagnetic Soluble Ring Complex with a Porous Tubular Structure. Chem. Sci. 2013, 5 (1), 324-332. https://doi.org/10.1039/C3SC52628C.

(177) Lider, E. V.; Peresypkina, E. V.; Smolentsev, A. I.; Elokhina, V. N.; Yaroshenko, T. I.; Virovets, A. V.; Ikorskii, V. N.; Lavrenova, L. G. Unusual Coordination of a Chloride lon to Six Copper lons: Synthesis and Crystal Structure of Copper(II) Complexes with 4-(4-Hydroxyphenyl)-1,2,4Triazole. Polyhedron 2007, 26 (8), 1612-1618. https://doi.org/10.1016/j.poly.2006.11.051.

(178) Li, H.-X.; Ren, Z.-G.; Liu, D.; Chen, Y.; Lang, J.-P.; Cheng, Z.-P.; Zhu, X.L.; Abrahams, B. F. Single-Crystal-to-Single-Crystal Structural Transformations of Two Sandwich-like Cu(II) Pyrazolate Complexes and Their Excellent Catalytic Performances in MMA Polymerization. Chem. Commun. 2010, 46 (44), 8430-8432. https://doi.org/10.1039/C0CC03027A.

(179) Angaridis, P. A.; Baran, P.; Boča, R.; Cervantes-Lee, F.; Haase, W.; Mezei, G.; Raptis, R. G.; Werner, R. Synthesis and Structural Characterization of Trinuclear Cull-Pyrazolato Complexes Containing $\mu_{3}-$ $\mathrm{OH}, \mu_{3}-\mathrm{O}$, and $\mu_{3}-\mathrm{Cl}$ Ligands. Magnetic Susceptibility Study of $[\mathrm{PPN}]_{2}\left[\left(\mu_{3}-\right.\right.$ O) $\mathrm{Cu}_{3}\left(\mu-\mathrm{pz}_{3} \mathrm{Cl}_{3}\right.$. Inorg. Chem. 2002, 41 (8), 2219-2228. https://doi.org/10.1021/ic010670l.

(180) Hulsbergen, F. B.; Hoedt, R. W. M. ten; Verschoor, G. C.; Reedijk, J.; Spek, A. L. Synthesis, Magnetic Properties, and X-Ray Structure of Catena- $\mu_{3}$-Nitrato-O,O',O"-[ $\mu_{3}$-Hydroxo-1-Nitrato-1,2;1,3;2,3-Tris $(\mu-$ Pyrazolato-N,N')-2,3-Bis(Pyrazole-N²)Tricopper(II) Monohydrate]. An Unusual Chain of Trinuclear Copper Clusters. Dalton Trans. 1983, 0 (3), 539-545. https://doi.org/10.1039/DT9830000539. 
(181) Drożdżewski, P. M. Normal Coordinate Analysis of Copper Complexes with 1-(2-Pyridylazo)-2-Naphthol. Spectrochim. Acta A 1988, 44 (12), 1297-1307. https://doi.org/10.1016/0584-8539(88)80173-9.

(182) Ondrejovič, G.; Kotočová, A.; Koman, M.; Segl'a, P. Synthesis, Spectral and Electrochemical Study of Coordination Molecules Cu4OX6L4: 3Cyanopyridine Cu4OBrnCl(6-n)(3-CNpy)4 Complexes. Chem. Pap. 2010, 64 (3), 339-345. https://doi.org/10.2478/s11696-010-0016-8.

(183) Ondrejovič, G.; Kotočová, A. Spectral and Electrochemical Study of Coordination Molecules Cu4OX6L4: 3-Methylpyridine and 4Methylpyridine Cu4OBrnCl(6-n)L4 Complexes. Chem. Pap. 2006, 60 (1), 10-21. https://doi.org/10.2478/s11696-006-0003-2.

(184) Lever, A. B. P.; Ramaswamy, B. S. Isotopic Studies of the Metal-Ligand Bond. Part II. The Far Infrared Spectra of Some Binuclear and Polymeric Copper Carboxylate Derivatives; Variable Temperature and Isotopic Studies of the Copper-Ligand Vibrations. Can. J. Chem. 1973, 51 (4), 514-519. https://doi.org/10.1139/v73-078.

(185) Bowmaker, G. A.; Hanna, J. V.; Hart, R. D.; Healy, P. C.; White, A. H. Structural and Spectroscopic Studies on the Dimeric Complexes of Tris(2Methylphenyl)Phosphine With Copper(I) Halides. Aust. J. Chem. 1994, 47 (1), 25-45. https://doi.org/10.1071/ch9940025.

(186) Cozar, O.; David, L.; Chiş, V.; Damian, G.; Todică, M.; Agut, C. IR and ESR Studies on Some Dimeric Copper(II) Complexes. J. Mol. Struct. 2001, 563-564, 371-375. https://doi.org/10.1016/S0022-2860(01)004963.

(187) Ondrejovič, G.; Kotočová, A. Spectral and Electrochemical Study of Coordination Molecules Cu4OX6L4: 3-Pyridylmethanol and 4Pyridylmethanol Cu4OBrnCl(6-n)(Pm)4 Complexes. Chem. Pap. 2006, 60 (3), 198-206. https://doi.org/10.2478/s11696-006-0036-6.

(188) Deng, Y.; Chang, C. J.; Nocera, D. G. Direct Observation of the "PacMan" Effect from Dibenzofuran-Bridged Cofacial Bisporphyrins. J. Am. Chem. Soc. 2000, 122 (2), 410-411. https://doi.org/10.1021/ja992955r.

(189) Chang, C. J.; Deng, Y.; Shi, C.; Chang, C. K.; Anson, F. C.; Nocera, D. G. Electrocatalytic Four-Electron Reduction of Oxygen to Water by a Highly Flexible Cofacial Cobalt Bisporphyrin. Chem. Commun. 2000, 0 (15), 1355-1356. https://doi.org/10.1039/B001620l. 
(190) Olguín, J.; Brooker, S. Synthesis of 3- and 5-Formyl-4-Phenyl-1HPyrazoles: Promising Head Units for the Generation of Asymmetric Imine Ligands and Mixed Metal Polynuclear Complexes. New J. Chem. 2011, 35 (6), 1242-1253. https://doi.org/10.1039/C0NJ00774A.

(191) Ehlert, M. K.; Rettig, S. J.; Storr, A.; Thompson, R. C.; Trotter, J. Metal Pyrazolate Polymers. Part 2. Synthesis, Structure, and Magnetic Properties of $\left[\mathrm{Cu}(4-\mathrm{Xpz})_{2}\right]_{\times}$Polymers (Where $\mathrm{X}=\mathrm{Cl}, \mathrm{Br}, \mathrm{Me}, \mathrm{H} ; \mathrm{Pz}=$ Pyrazolate). Can. J. Chem. 1991, 69 (3), 432-439.

https://doi.org/10.1139/v91-065.

(192) Baboul, A. G.; Curtiss, L. A.; Redfern, P. C.; Raghavachari, K. Gaussian-3 Theory Using Density Functional Geometries and Zero-Point Energies. J. Chem. Phys. 1999, 110 (16), 7650-7657.

https://doi.org/10.1063/1.478676.

(193) Check, C. E.; Faust, T. O.; Bailey, J. M.; Wright, B. J.; Gilbert, T. M.; Sunderlin, L. S. Addition of Polarization and Diffuse Functions to the LANL2DZ Basis Set for P-Block Elements. J. Phys. Chem. A 2001, 105 (34), 8111-8116. https://doi.org/10.1021/jp011945I.

(194) Neese, F. The ORCA Program System. Wiley Interdiscip. Rev. Comput. Mol. Sci. 2012, 2 (1), 73-78. https://doi.org/10.1002/wcms.81.

(195) Becke, A. D. Density-Functional Exchange-Energy Approximation with Correct Asymptotic Behavior. Phys. Rev. A 1988, 38 (6), 3098-3100. https://doi.org/10.1103/PhysRevA.38.3098.

(196) Lee, C.; Yang, W.; Parr, R. G. Development of the Colle-Salvetti Correlation-Energy Formula into a Functional of the Electron Density. Phys. Rev. B 1988, 37 (2), 785-789. https://doi.org/10.1103/PhysRevB.37.785.

(197) Stephens, P. J.; Devlin, F. J.; Chabalowski, C. F.; Frisch, M. J. Ab Initio Calculation of Vibrational Absorption and Circular Dichroism Spectra Using Density Functional Force Fields. J. Phys. Chem. 1994, 98 (45), 11623-11627. https://doi.org/10.1021/j100096a001.

(198) Ruiz, E.; Rodríguez-Fortea, A.; Cano, J.; Alvarez, S.; Alemany, P. About the Calculation of Exchange Coupling Constants in Polynuclear Transition Metal Complexes. J. Comput. Chem. 2003, 24 (8), 982-989. https://doi.org/10.1002/jcc.10257. 
(199) Ruiz, E.; Cano, J.; Alvarez, S.; Alemany, P. Broken Symmetry Approach to Calculation of Exchange Coupling Constants for Homobinuclear and Heterobinuclear Transition Metal Complexes. J. Comput. Chem. 1999, 20 (13), 1391-1400. https://doi.org/10.1002/(SICl)1096987X(199910)20:13<1391::AID-JCC6>3.0.CO;2-J.

(200) Weigend, F.; Ahlrichs, R. Balanced Basis Sets of Split Valence, Triple Zeta Valence and Quadruple Zeta Valence Quality for H to Rn: Design and Assessment of Accuracy. Phys. Chem. Chem. Phys. 2005, 7 (18), 3297-3305. https://doi.org/10.1039/B508541A.

(201) Weigend, F. Accurate Coulomb-Fitting Basis Sets for $\mathrm{H}$ to Rn. Phys. Chem. Chem. Phys. 2006, 8 (9), 1057-1065. https://doi.org/10.1039/B515623H.

(202) Neese, F.; Wennmohs, F.; Hansen, A.; Becker, U. Efficient, Approximate and Parallel Hartree-Fock and Hybrid DFT Calculations. A 'Chain-ofSpheres' Algorithm for the Hartree-Fock Exchange. Chem. Phys. 2009, 356 (1), 98-109. https://doi.org/10.1016/j.chemphys.2008.10.036.

(203) Izsák, R.; Neese, F. An Overlap Fitted Chain of Spheres Exchange Method. J. Chem. Phys. 2011, 135 (14), 144105.

https://doi.org/10.1063/1.3646921.

(204) Momma, K.; Izumi, F. VESTA 3 for Three-Dimensional Visualization of Crystal, Volumetric and Morphology Data. J. Appl. Crystallogr. 2011, 44 (6), 1272-1276. https://doi.org/10.1107/S0021889811038970.

(205) Whyman, R.; Hatfield, W. E. Low-Frequency Infrared Spectral Studies on Copper(II) Halide Complexes with Substituted Pyridine N-Oxides. Inorg. Chem. 1967, 6 (10), 1859-1862. https://doi.org/10.1021/ic50056a021.

(206) Brierley, M.; Geary, W. J.; Goldstein, M. Transition-Metal Complexes of the 1,2-Dipyridylethylene Isomers. Part IV. Far-Infrared Spectra (450-80 $\mathrm{cm}^{-1}$ ) of Cobalt(II), Nickel(II), and Copper(II) Halide Derivatives. J. Chem. Soc. A 1969, O (0), 2923-2927. https://doi.org/10.1039/J19690002923.

(207) Lever, A. B. P.; Mantovani, E. Far-Infrared and Electronic Spectra of Some Bis(Ethylenediamine) and Related Complexes of Copper(II) and the Relevance of These Data to Tetragonal Distortion and Bond Strengths. Inorg. Chem. 1971, 10 (4), 817-826. https://doi.org/10.1021/ic50098a031. 
(208) Gusev, A.; Nemec, I.; Herchel, R.; Shul'gin, V.; Ryush, I.; Kiskin, M.;

Efimov, N.; Ugolkova, E.; Minin, V.; Lyssenko, K.; et al. Copper(II) SelfAssembled Clusters of Bis((Pyridin-2-YI)-1,2,4-Triazol-3-YI)Alkanes. Unusual Rearrangement of Ligands under Reaction Conditions. Dalton Trans. 2019, 48 (9), 3052-3060. https://doi.org/10.1039/C8DT04816A.

(209) Liu, J.-L.; Bao, X.; Herchel, R.; Leng, J.-D.; Lin, Z.-J.; Tong, M.-L. Structurally Perfect $\mathrm{Ni}_{3}\left(\mu_{1}, 3-\mathrm{N}_{3}\right)_{3}$ Triangles for a Magnetic Model. Aust. J. Chem. 2010, 63 (7), 1111-1115. https://doi.org/10.1071/CH10117.

(210) Sameera, W. M. C.; Piñero, D. M.; Herchel, R.; Sanakis, Y.; McGrady, J. E.; Raptis, R. G.; Zueva, E. M. A Combined Experimental and Computational Study of the Magnetic Superexchange within a Triangular ( $\left.\mu_{3}-\mathrm{O}\right)-$ Pyrazolato-Fe $\mathrm{III}_{3}$ Complex. Eur. J. Inorg. Chem. 2012, 2012 (21), 3500-3506. https://doi.org/10.1002/ejic.201200206.

(211) Boča, R.; Herchel, R. Antisymmetric Exchange in Polynuclear Metal Complexes. Coord. Chem. Rev. 2010, 254 (23), 2973-3025. https://doi.org/10.1016/j.ccr.2010.06.012.

(212) Moriya, T. Anisotropic Superexchange Interaction and Weak Ferromagnetism. Phys. Rev. 1960, 120 (1), 91-98. https://doi.org/10.1103/PhysRev.120.91. 
DAVID IAN JAMES KREIGER

$\begin{array}{ll} & \text { Born, Harrisburg, Pennsylvania } \\ 2012 & \begin{array}{l}\text { B.S., Chemistry } \\ \text { Juniata College } \\ \text { Huntingdon, Pennsylvania }\end{array} \\ 2016 & \begin{array}{l}\text { M.S., Chemistry, } \\ \text { Florida International University } \\ \text { Miami, Florida }\end{array} \\ 2016 & \begin{array}{l}\text { Doctoral Candidate, } \\ \text { Florida International University } \\ \text { Miami, Florida }\end{array}\end{array}$

\section{SELECTED PUBLICATIONS AND PRESENTATIONS}

Kreiger, D. I., Mathivathanan, L., Herchel, R., and Raptis, R. G., (2012) Magnetic and Structural Properties of Open-Caged Hexanuclear Copper Pyrazolato Complexes. Poster presented at FAME.

Kreiger, D. I., Mathivathanan, L., Herchel, R., and Raptis, R. G., (2019) Synthesis, structure and magnetic studies of novel open-cage hexanuclear copper pyrazolato complexes. Paper presented at National ACS, Orlando.

Kreiger, D. I., Mathivathanan, L., and Raptis, R. G., Coordination polymers based on pyrazole-4-carboxaldehyde-containing $\mathrm{Cu}_{3} \mathrm{~N}_{6}$ metallacycles as building units. CrystEngComm 2019, 21, 3047-3055. DOI: 10.1039/c9ce00421a. 